Nevada

Environmental

Restoration

Project

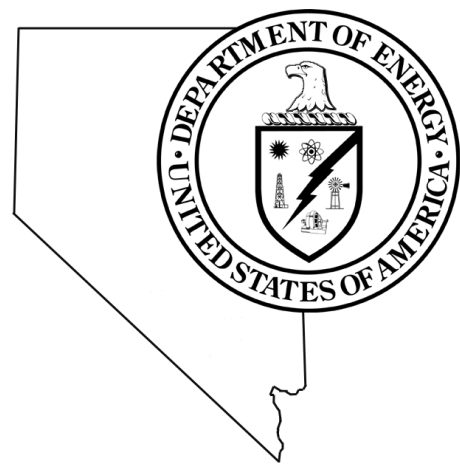

\title{
Site Characterization Work Plan for the Gnome-Coach Site, New Mexico
}

Controlled Copy No.:

Revision No.: 0

February 2001

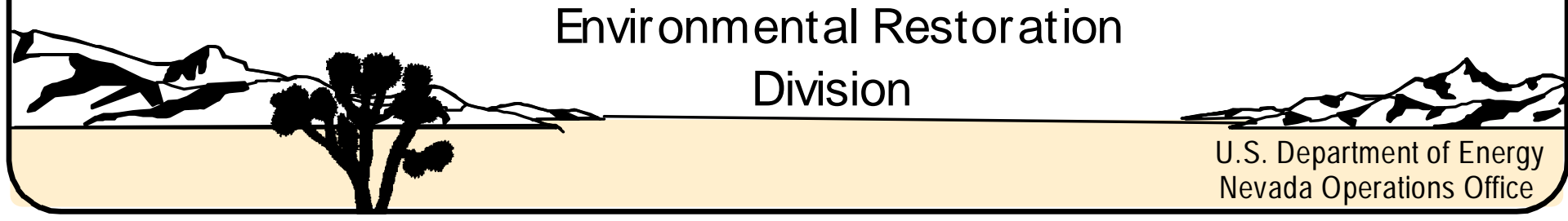


Available for public sale, in paper, from:

U.S. Department of Commerce

National Technology Information Service

5285 Port Royal Road

Springfield, VA 22161

Phone: 800.553 .6847

Fax: 703.605.6900

Email: orders@ntis.fedworld.gov

Online ordering: http//www.ntis.gov/ordering.htm

Available electronically at $\underline{h t t p: / / w w w . d o e . g o v / b r i d g e}$

Available for a processing fee to U.S. Department of Energy and its contractors, in paper, from:

\section{U.S. Department of Energy}

Office of Scientific and Technical Information

P.O. Box 62

Oak Ridge, TN 37831-0062

Phone: 865.576.8401

Fax: 865.576.5728

Email: reports@adonis.osti.gov

Reference herein to any specific commercial product, process, or service by trade name, trademark, manufacturer, or otherwise, does not necessarily constitute or imply its endorsement, recommendation, or favoring by the United States Government or any agency thereof or its contractors or subcontractors. 


\section{SITE CHARACTERIZATION WORK PLAN FOR THE GNOME-COACH SITE, NEW MEXICO}

DOE Nevada Operations Office

Las Vegas, Nevada

Controlled Copy No.:

Revision No.: 0

February 2001 


\section{SITE CHARACTERIZATION WORK PLAN FOR THE GNOME-COACH SITE, NEW MEXICO}

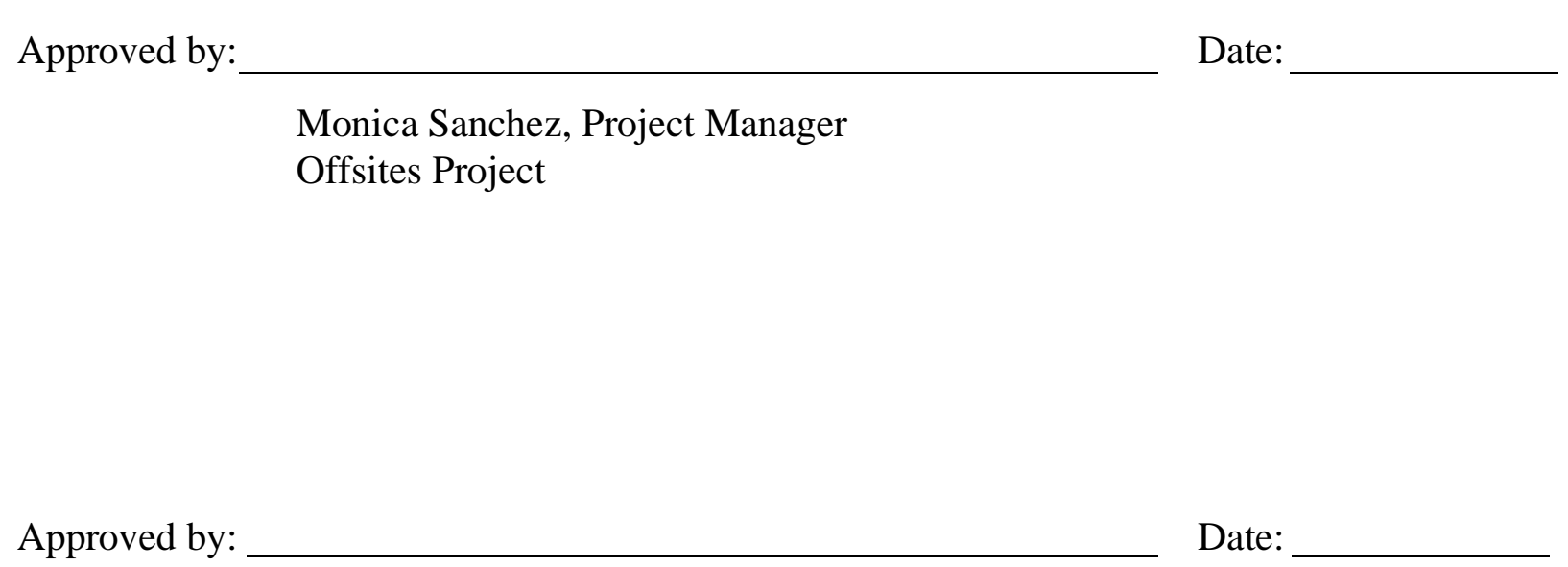

Runore C. Wycoff, Division Director

Environmental Restoration Division 


\section{Table of Contents}

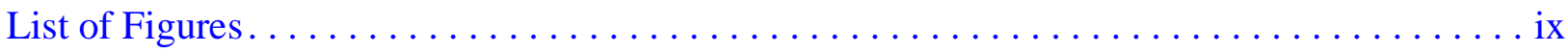

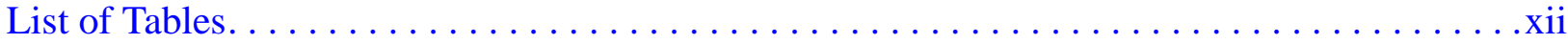

List of Acronyms and Abbreviations $\ldots \ldots \ldots \ldots \ldots \ldots \ldots \ldots \ldots \ldots \ldots \ldots \ldots \ldots \ldots \ldots$

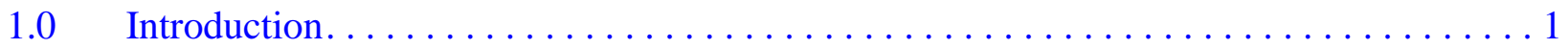

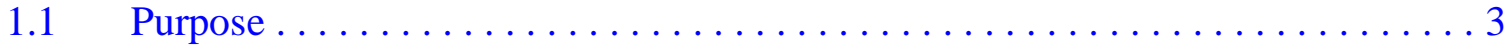

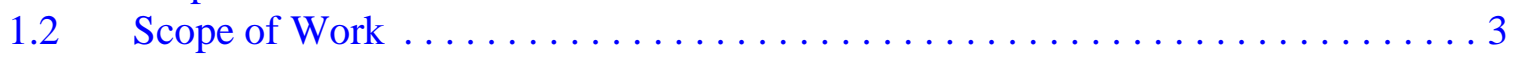

1.3 Investigation Work Plan Contents $\ldots \ldots \ldots \ldots \ldots \ldots \ldots \ldots \ldots \ldots \ldots \ldots \ldots \ldots \ldots \ldots \ldots \ldots$

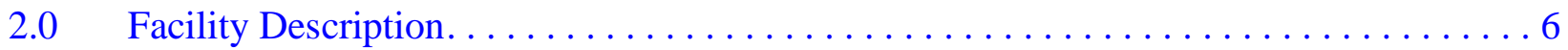

$2.1 \quad$ Physical Setting. . . . . . . . . . . . . . . . . . . . 6

2.1.1 Land Status . . . . . . . . . . . . . . . . . . . 6

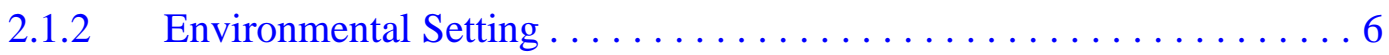

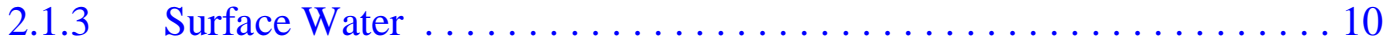

2.2 Operational History. . . . . . . . . . . . . . . . . . . 10

2.2.1 Trailer Park and Control Point. . . . . . . . . . . . . . . 13

$2.2 .2 \quad$ Fallout Plume. . . . . . . . . . . . . . . . . . . . . 13

2.2.3 Gnome-Coach Shaft Area . . . . . . . . . . . . . . . . 15

2.2.4 Gnome Surface Ground Zero. . . . . . . . . . . . . . . . . . . . 16

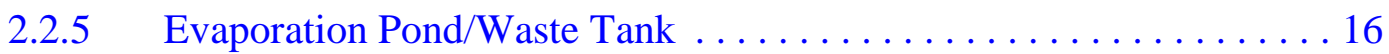

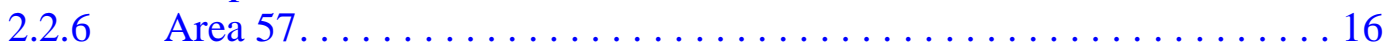

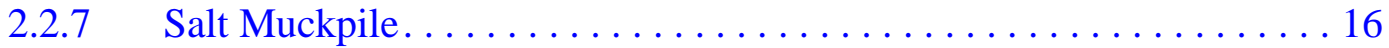

$2.2 .8 \quad$ Storage Areas. . . . . . . . . . . . . . . . . . . . . . . 17

2.2.9 Decontamination Pad........................ 18

2.2.10 Laundry/Lab Facilities. . . . . . . . . . . . . . . . . . . . . 18

2.2.11 Contaminated Waste Dump. . . . . . . . . . . . . . . . . . . 19

2.2 .12 Salvage Yard . . . . . . . . . . . . . . . . . . . . . . 19

2.2.13 Drill Hole Pads. . . . . . . . . . . . . . . . . . . . . . . . 20

2.2.13.1 LRL-7 and LRL-8 Drill Pads . . . . . . . . . . . 21

2.2.13.2 Drill Pad for Monitoring Wells USGS-4 and USGS-8 . . . 21

$2.3 \quad$ Site Restoration Activities . . . . . . . . . . . . . . . . . . . . 22

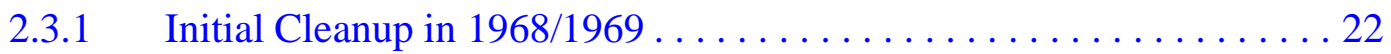

2.3.2 1972 Area Reconnaissance . . . . . . . . . . . . . . . . . . 23

2.3.3 Second Cleanup in 1977 to $1979 \ldots \ldots \ldots \ldots \ldots \ldots \ldots \ldots \ldots \ldots$

2.4 Current Conditions at the Gnome-Coach Site .................. 25 


\section{Table of Contents (Continued)}

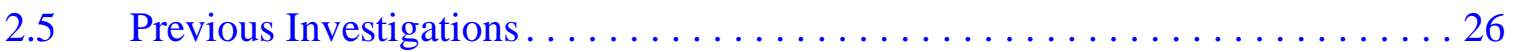

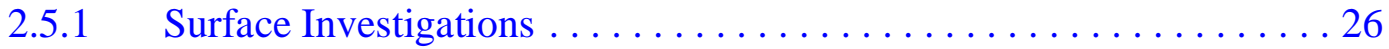

2.5.2 Radionuclide Background Investigations $\ldots \ldots \ldots \ldots \ldots \ldots \ldots$

2.5.2.1 Radionuclide Concentrations in Soil at the Gnome-Coach Site ...................... 29

2.5.2.2 Radionuclide Concentrations in Soil at the WIPP . . . . . 29

2.5.2.3 Radionuclide Concentrations in Soil in the Vicinity of WIPP .................... 30

2.5.2.4 Radionuclide Concentrations in Soil at Distant

2.5.2.5 Summary of the Background Radionuclide Concentrations in Soil for the Gnome-Coach Site . . . . . . . . . . . . . . 33

2.5.3 Subsurface Investigations $\ldots \ldots \ldots \ldots \ldots \ldots \ldots \ldots \ldots \ldots \ldots \ldots \ldots \ldots \ldots \ldots$

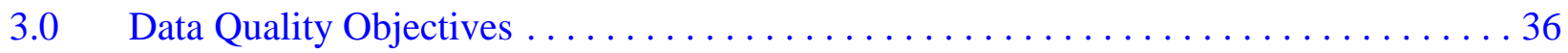

$3.1 \quad$ Surface Conceptual Site Model . . . . . . . . . . . . . . . . . . 36

3.1.1 Contaminants of Potential Concern for the Surface Investigation . . . . 39

$3.2 \quad$ Subsurface Conceptual Site Model. ......................... 43

3.2.1 Subsurface COPCs............................. 45

$4.0 \quad$ Surface and Shallow Subsurface Work Plan $\ldots \ldots \ldots \ldots \ldots \ldots \ldots \ldots \ldots \ldots \ldots \ldots \ldots \ldots$

$4.1 \quad$ Demarcate Operational Areas.............................. 50

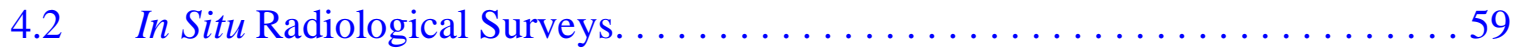

4.2.1 Technical Methodology ........................6 60

4.2.1.1 Driveover Radiological Survey $\ldots \ldots \ldots \ldots \ldots \ldots 60$

4.2.1.2 Downhole In Situ Radiological Survey ............ 61

4.2.2 Driveover Radiological Survey Design and Assumptions . . . . . . . . 61

4.2.3 Establishing Background Values for Radiological Surveys . . . . . . 63

$4.3 \quad$ Vegetation Sampling. . . . . . . . . . . . . . . . . . . . . . . . 64

4.4 Geophysical Investigation. ............................... 65

4.4.1 Geophysical Survey Areas.......................... 65

4.4.1.1 Technical Methodology $\ldots \ldots \ldots \ldots \ldots \ldots 66 . \ldots 66$

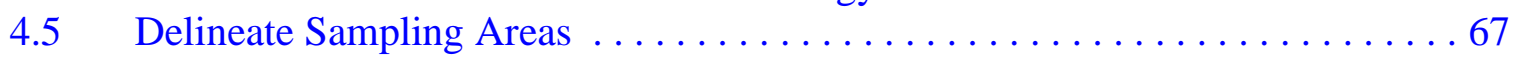

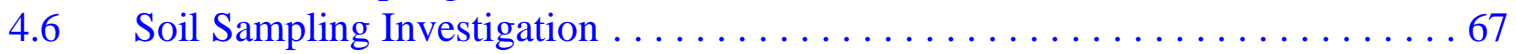

4.6.1 Representative Inorganic Background Sample Collection . . . . . . . . 67

4.6.2 Soil Sampling Techniques . . . . . . . . . . . . . . . . . 70

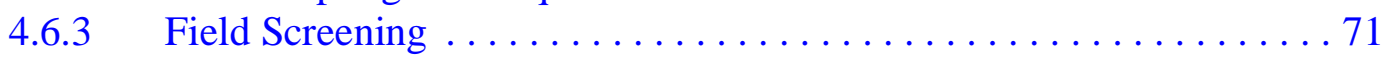

4.6.4 Sampling Criteria.......................... 72

4.6.5 Boring Locations for Shallow Subsurface Characterization . . . . . . . 73

4.6.5.1 Boring Locations at Mud Pits . ................ 74

4.6.5.2 Boring Locations at AOCs with Chemical COPCs ..... 76 


\section{Table of Contents (Continued)}
4.6.5.3 Boring Locations at AOCs with Radiological COPCs . . . 76

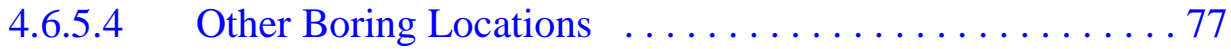
4.6.6 Quality Control Samples . . . . . . . . . . . . . . . . . . 77

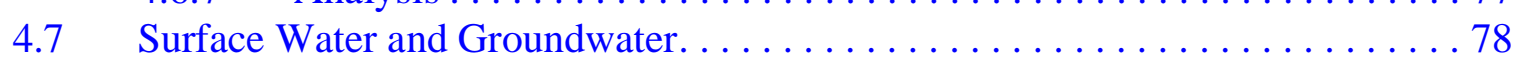

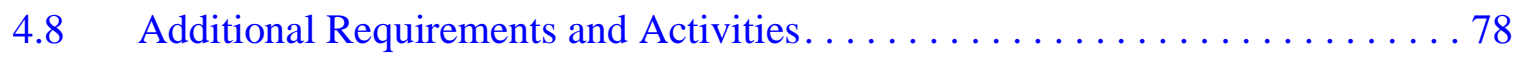
$4.8 .1 \quad$ Health and Safety. . . . . . . . . . . . . . . . . . . 78
4.8.2 Environmental Compliance and Waste Management . . . . . . . . . . 79
4.8.3 NEPA Requirements . . . . . . . . . . . . . . . . . . . 79

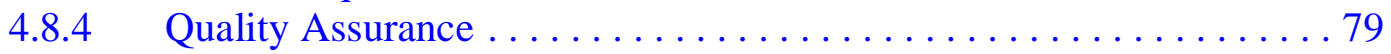

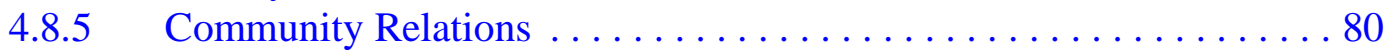

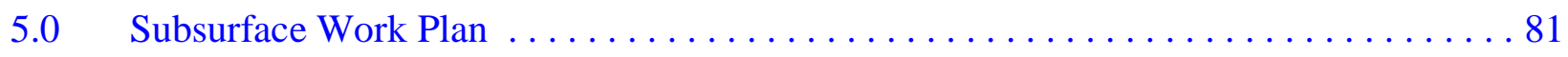

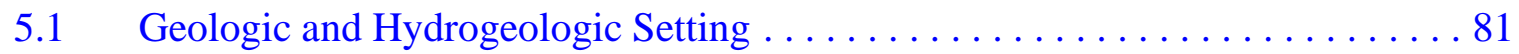

5.2 Description of the Gnome Test and Its Effects. . . . . . . . . . . . . 84

5.2.1 Hypothetical Release by Salt Creep. . . . . . . . . . . . . . . . . . . . 89

5.3 Release and Transport from the Tracer Test. . . . . . . . . . . . . . 90

5.4 Data Quality Objectives of Subsurface Investigation. . . . . . . . . . . . 92

5.5 Evaluation of Existing Subsurface Data . . . . . . . . . . . . . . 93

5.6 Identification of Proper Numerical Model . . . . . . . . . . . . . . 93

5.7 Investigation/Modeling Process . . . . . . . . . . . . . . . 95

5.7.1 Investigation Strategy for the Underground Nuclear Test. . . . . . . . 95

5.7.2 Investigation Strategy for the Tracer Test . . . . . . . . . . . . 96

$5.8 \quad$ Evaluation of Results . . . . . . . . . . . . . . . . . . . 99

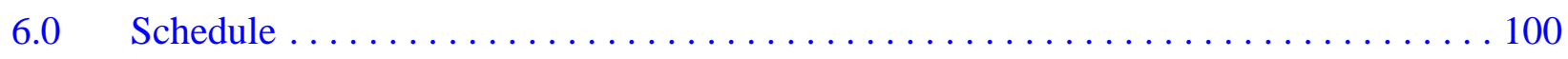

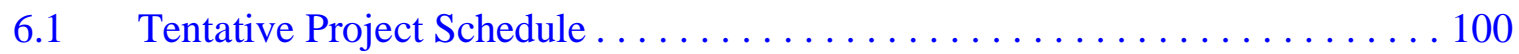

$7.0 \quad$ References..................................... 103

\section{Appendix A - Historical Radiological Survey Review for the Gnome-Coach Site}

A.1.0 Summary of Radiological Monitoring and Sampling for Gnome-Coach

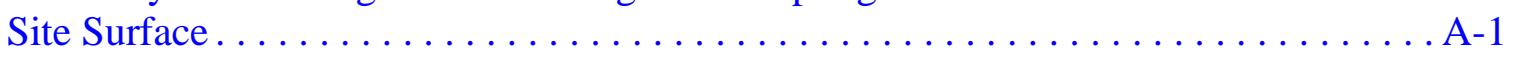

A.1.1 Historical Radiological Monitoring . . . . . . . . . . . . . . A-1

A.1.2 Summary of Areas of Concern . . . . . . . . . . . . . . . . . . A-2

A.2.0 Monitoring and Surveys During Detonation and Post Shot Drilling . . . . . . . . . . A-9

A.2.1 Aerial Radiation Surveys (December 9 and 10, 1961) . . . . . . . . . A-9

A.2.2 Ground Radiation Surveys . . . . . . . . . . . . . . . . . A-10

A.2.3 Decontamination and Standby Status . . . . . . . . . . . . A-10 


\section{Table of Contents (Continued)}

A.3.0 Monitoring and Surveys for Decommissioning Activities (1968 through 1979) . . . . A-12

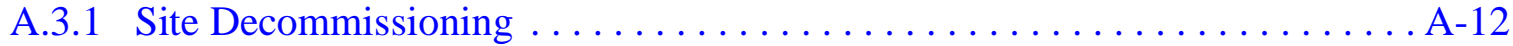

A.3.1.1 Initial Decommissioning Effort, 1968 - $1969 \ldots \ldots \ldots \ldots \ldots \ldots$. . . . . 12

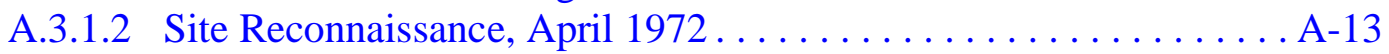

A.3.1.3 Second Decommissioning Effort, 1977-1979 . . . . . . . . . . . . A-14

A.3.2 Aerial Radiation Surveys (May 1972 and September 1979) . . . . . . . . . . A A-16

A.3.3 Ground Radiation Surveys (1968-1969, 1972, and 1977-1979). . . . . . . . A A-17

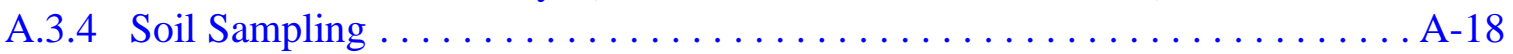

A.3.5 Vegetation Sampling. . . . . . . . . . . . . . . . . . 25

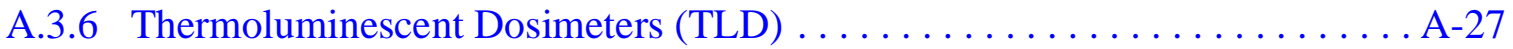

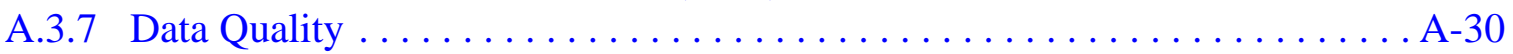

A.4.0 Monitoring and Surveys for Post 1977-1979 Decommissioning (1980-2000). . . . . A-53

A.4.1 Environmental Protection Agency . . . . . . . . . . . . . . . A-53

A.4.2 Environmental Evaluation Group . . . . . . . . . . . . . . . . A-54

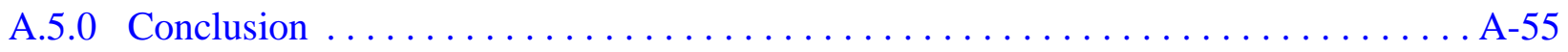

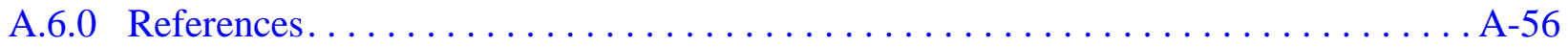

\section{Appendix B - New Mexico Quality Assurance Project Plan}

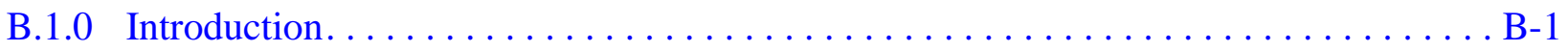

B.2.0 Criteria $1-$ Quality Program . . . . . . . . . . . . . . . . .

B.2.1 Quality Management Policy . . . . . . . . . . . . . . . . . . . B-4

B.2.2 Project Organization . . . . . . . . . . . . . . . . . . . . . .

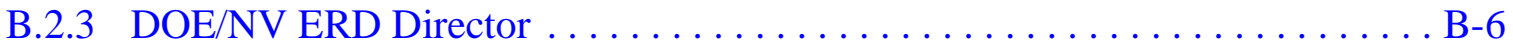

B.2.3.1 NV ERP Project Manager . . . . . . . . . . . . . . . . B-6

B.2.3.1.1 NV ERP Task Manager . . . . . . . . . . . . B-7

B.2.3.1.2 NV ERP Quality Assurance Coordinator .......... B-7

B.2.3.2 New Mexico Sites Project Participants . . . . . . . . . . . . . . . B-7

B.2.3.3 Analytical Laboratories . . . . . . . . . . . . . . . . . B-8

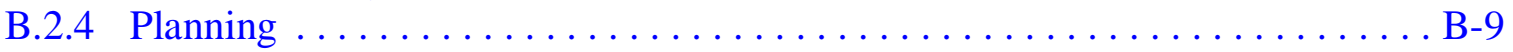

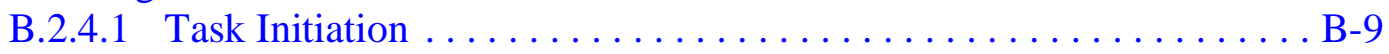

B.2.4.2 Data Quality Objectives.......................... B-9

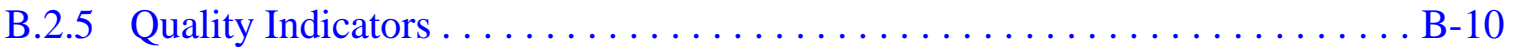

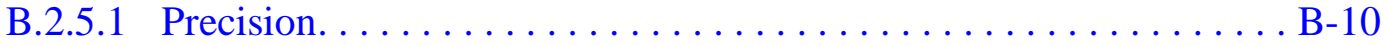




\section{Table of Contents (Continued)}

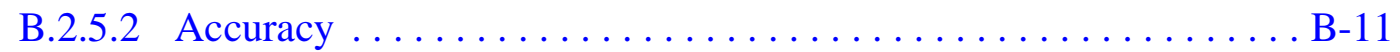

B.2.5.3 Representativeness.......................... . . . . . . . .

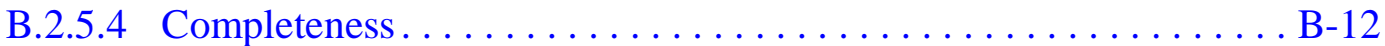

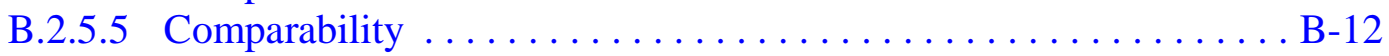

B.2.6 Reports to Management . . . . . . . . . . . . . . . . . . . B-12

B.2.7 Readiness Reviews . . . . . . . . . . . . . . . . . . . . . . B-13

B.3.0 Criteria 2 - Personnel Training and Qualifications . . . . . . . . . . . . . . . . . B-14

B.3.1 Project Personnel . . . . . . . . . . . . . . . . . . . . . . . . . . .

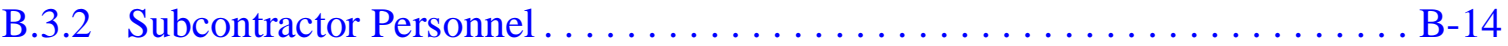

B.4.0 Criteria 3 - Quality Improvement $\ldots \ldots \ldots \ldots \ldots \ldots \ldots \ldots \ldots \ldots \ldots \ldots$

B.4.1 Internal Quality Control Checks . . . . . . . . . . . . . . . . . B-15

B.4.1.1 Field Quality Control . . . . . . . . . . . . . . . . . . . B-16

B.4.1.1.1 Equipment Rinsate Blank Samples . . . . . . . . . . . . B-16

B.4.1.1.2 Field Blank Samples . . . . . . . . . . . . . B-17

B.4.1.1.3 Trip Blank Samples .................. B-17

B.4.1.1.4 Duplicate Samples ................... B-18

B.4.1.1.5 Source Blanks ....................... B-18

B.4.1.2 Analytical Laboratory Quality Control . . . . . . . . . . . . . . . B-18

B.4.1.2.1 Laboratory Control Samples ... . . . . . . . . . . . B-19

B.4.1.2.2 Method Blank Samples . . . . . . . . . . . . . . . . B-19

B.4.1.2.3 Surrogate-Spike Samples . . . . . . . . . . . . . . . B-19

B.4.1.2.4 Matrix-Spike/Matrix-Spike Duplicate Samples . . . . . . B-20

B.4.1.2.5 Laboratory Duplicate Samples . . . . . . . . . . . . B-20

B.4.1.3 On-Site Radiological Laboratory Quality Control. . . . . . . . . . . . . B-21

B.4.1.3.1 Instrument Control Samples . . . . . . . . . . . . B-21

B.4.1.3.2 Blank Samples ... . . . . . . . . . . . . . . . B-21

B.4.1.3.3 Duplicate Samples ................... B-21

B.4.2 Data Precision, Accuracy, and Completeness . . . . . . . . . . . . B-21

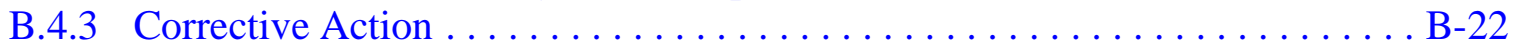

B.4.3.1 Nonconformance . . . . . . . . . . . . . . . . . . . B-22

B.4.3.2 Cause Analysis. . . . . . . . . . . . . . . . . . . . . . B-23

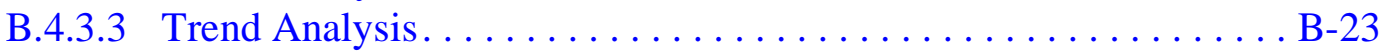

B.4.3.4 Lessons Learned ... . . . . . . . . . . . . . . . . . . . . . . . B-23

B.5.0 Criteria 4 - Documents and Records. . . . . . . . . . . . . . . . . . . . . . . B-24

B.5.1 Documents and Records . . . . . . . . . . . . . . . . . 


\section{Table of Contents (Continued)}

B.5.1.1 Document Review and Control . . . . . . . . . . . . . . B-24

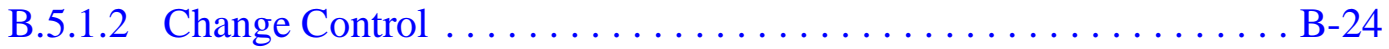

B.5.1.3 Records Maintenance.......................... .

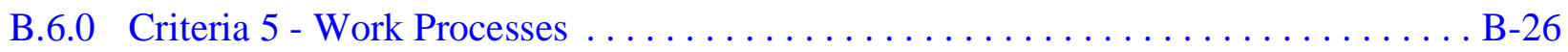

B.6.1 Evaluation and Use of Existing and New Data. . . . . . . . . . . . B-26

B.6.2 Computer Hardware and Software . . . . . . . . . . . . . . . . . B-26

B.6.2.1 Computer Systems . . . . . . . . . . . . . . . . . B-27

B.6.2.2 Software Design/Development . . . . . . . . . . . . B-27

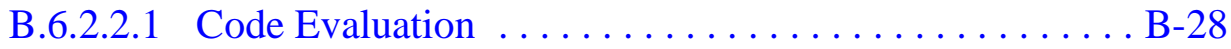

B.6.2.2.2 Code Verification/Validation .............. B-28

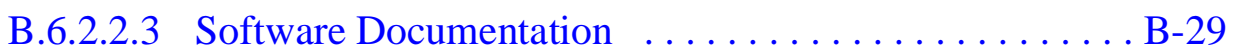

B.6.2.3 Peer Review of Software and Code Applications . . . . . . . . . . . B-29

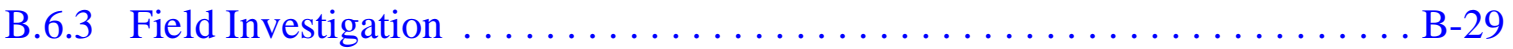

B.6.3.1 Sample Custody . . . . . . . . . . . . . . . . . . . . B-30

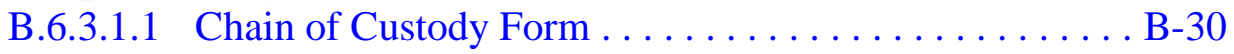

B.6.3.1.2 Custody Seals . . . . . . . . . . . . . . B-30

B.6.3.1.3 Sample Labels and Identification .............. B-31

B.6.3.1.4 Sample Handling, Preservation, Packaging, and Shipping ................ B-31

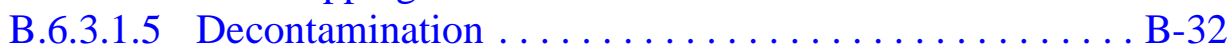

B.6.3.1.6 Investigation-Derived Waste $\ldots \ldots \ldots \ldots \ldots \ldots \ldots$ B-32

B.6.3.1.7 Field Documentation . . . . . . . . . . . . B-32

B.6.3.1.8 Photographic Documentation ............... B-32

B.6.3.2 Identification and Control of Items $\ldots \ldots \ldots \ldots \ldots \ldots \ldots$ B-33

B.6.3.3 Calibration and Preventive Maintenance................ B-33

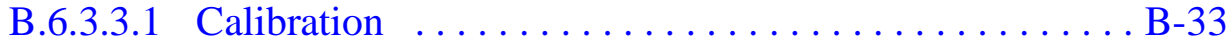

B.6.3.3.2 Preventive Maintenance .................. B-34

B.6.3.4 Laboratory Operation. . . . . . . . . . . . . . . . B-34

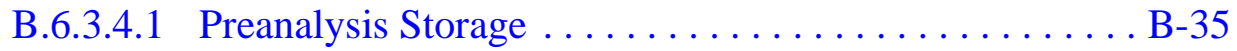

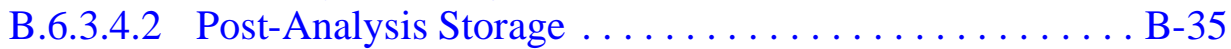

B.6.4 Analytical Data Usability . . . . . . . . . . . . . . . . . . . . B-35

B.6.4.1 Data Management . . . . . . . . . . . . . . . . . B-36

B.6.4.2 Evaluation and Use of Data . . . . . . . . . . . . . B-36

B.6.4.3 Data Reduction, Verification, and Validation . . . . . . . . . . . . B-37

B.6.4.3.1 Data Completeness Review . . . . . . . . . . . B-37

B.6.4.3.2 Data Review and Summary . . . . . . . . . . B-37

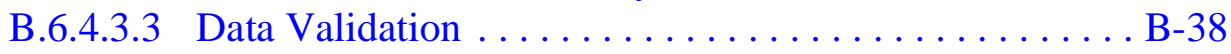

B.6.4.4 Laboratory Data Reporting . . . . . . . . . . . . . . B-39

B.6.4.4.1 Data Reporting . . . . . . . . . . . . . . B-40 


\section{Table of Contents (Continued)}

B.7.0 Criteria 6 - Design. . . . . . . . . . . . . . . . . . . . . . . B-41

B.8.0 Criteria 7 - Procurement . . . . . . . . . . . . . . . . . . . . . . B-42

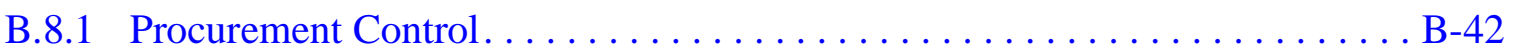

B.8.1.1 Procurement Documents . . . . . . . . . . . . . . . B-42

B.8.1.2 Measurement and Testing Equipment ................ B-43

B.8.1.3 Verification of Quality Conformance ................. B-43

B.9.0 Criteria 8 - Inspection and Acceptance Testing . . . . . . . . . . . . B-44

B.10.0 Criteria 9 - Management Assessment . . . . . . . . . . . . . . . . B-45

B.11.0 Criteria 10 - Independent Assessments . . . . . . . . . . . . . . . . B-46

B.12.0 References . . . . . . . . . . . . . . . . . . . . . . . . .

B.13.0 Glossary . . . . . . . . . . . . . . . . . . . . . . . . . . . .

\section{Appendix C - Radiological Screening Evaluation for the Gnome-Coach Site}

C.1.0 Introduction. . . . . . . . . . .

C.2.0 Identification of Radionuclides of Potential Concern. . . . . . . . . . . . . . C-2

C.2.1 Summary of Impacted Areas . . . . . . . . . . . . . . . . . C-2

C.2.2 Analytical Data Used for Dose/Risk Calculations . . . . . . . . . . . . C-7

C.3.0 Human Health Dose Assessment . . . . . . . . . . . . . . . . . . . . . C-10

C.3.1 Exposure Assessment . . . . . . . . . . . . . . . . . . . . -10

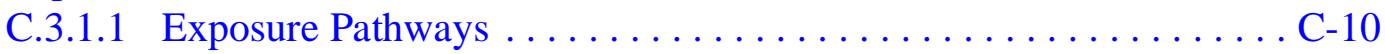

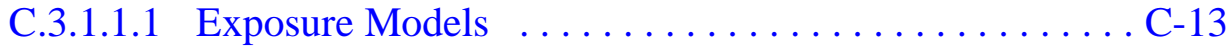

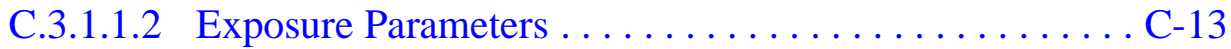

C.3.2 Dose/Risk-Screening Evaluation . . . . . . . . . . . . . . . C-18

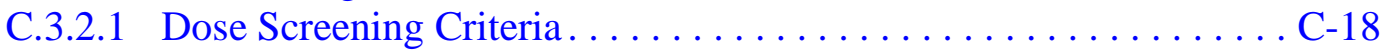

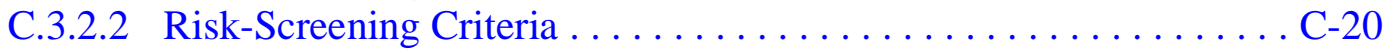

C.3.2.3 Results of the Human Health Dose/Risk-Screening Evaluation . . . . C-21

C.4.0 References.................................. C-23

\section{Appendix D - Vegetation Sampling and Analysis Plan}

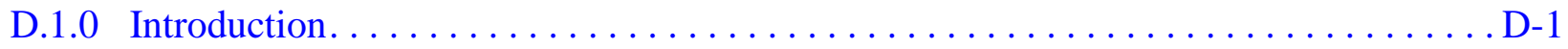




\section{Table of Contents (Continued)}

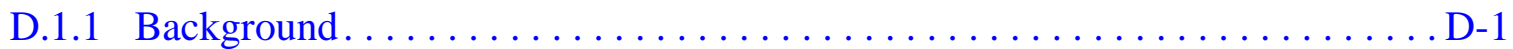

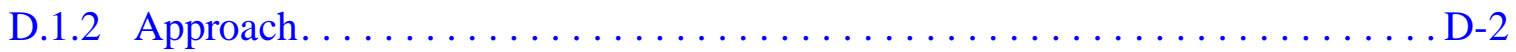

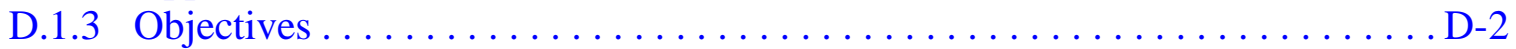

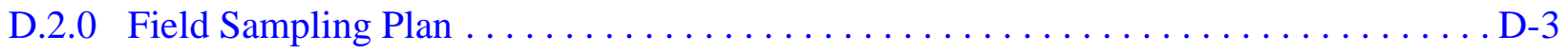

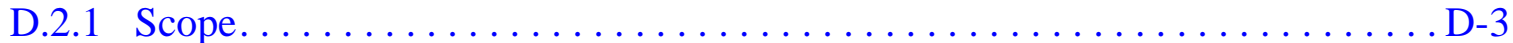

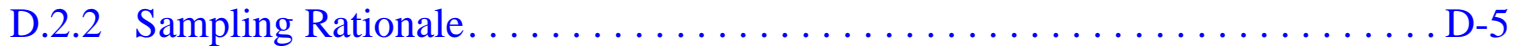

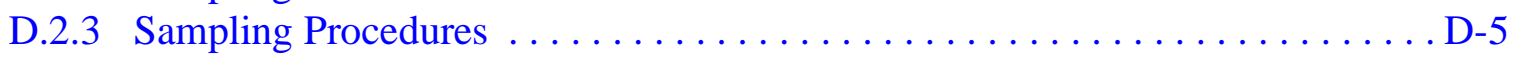

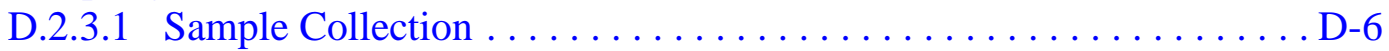

D.2.3.2 Sample Handling and Site Documentation . . . . . . . . . . . . D-6

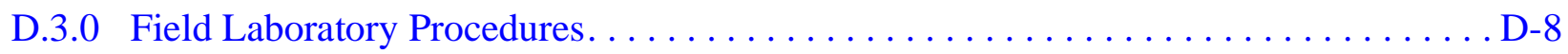

D.3.1 Sample Processing . . . . . . . . . . . . . . . . . . . . . . . .

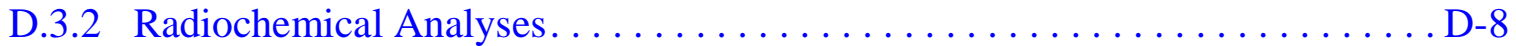

D.4.0 Data Analysis . . . . . . . . . . . . . . . . . . . . . . . . . . . D-10

D.5.0 References................................... 


\section{List of Figures}

1-1 Location of the Project Gnome-Coach Area $\ldots \ldots \ldots \ldots \ldots \ldots \ldots \ldots$

2-1 Project Gnome-Coach Area: Township/Range Boundaries and Land Withdrawal Boundaries, Eddy County, New Mexico............ 7

2-2 Topographic Map of Gnome-Coach and Surrounding Area $\ldots \ldots \ldots \ldots \ldots 9$

2-3 Gnome Shaft and Drift Plan . . . . . . . . . . . . . . . . . . . . . . 11

2-4 Historical Site Layout and Facility Locations at the

Gnome-Coach Area, New Mexico.............................. 14

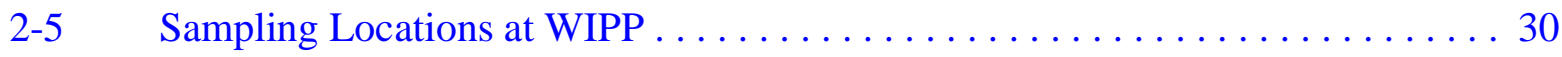

$2-6 \quad$ Sampling Locations in the Vicinity of the WIPP ............... 32

3-1 Conceptual Site Model ............................. 37

$4-1 \quad$ DQO Decision Flow Diagram $\ldots \ldots \ldots \ldots \ldots \ldots \ldots \ldots \ldots \ldots \ldots \ldots \ldots \ldots \ldots \ldots \ldots$

4-2 Oblique Photo of Gnome-Coach Site, $1961 \ldots \ldots \ldots \ldots \ldots \ldots \ldots \ldots . \ldots . \ldots . \ldots 4$

4-3 Aerial Photo of the Gnome-Coach Site, 1979 . . . . . . . . . . . . . . . . . . . 55

4-4 Example of Boring Locations.......................... 75

5-1 Location of the Gnome Site Within the Northern Delaware Basin ........ . . 81

5-2 North-South Stratigraphic Cross-Section Through the Delaware Basin and Northern Shelf ..................................... 83

5-3 Potentiometric Surface in the Vicinity of Gnome $\ldots \ldots \ldots \ldots \ldots \ldots$. . . . 84

5-4 Locations of Wells in the Vicinity of Gnome With Transmissivity Data . . . . 85

5-5 Drill Hole and Private Well Locations in the Vicinity of the Gnome-Coach Site . . . . . . . . . . . . . . . . 86

5-6 Cross-Section Through the Gnome Explosion Cavity . . . . . . . . . . . . 87

5-7 Cross-Section From Land Surface Down to Gnome Activity, Showing the Shaft, Drift, and Inferred Zone of Fracturing ........... 88

5-8 Schematic Representation of the Hypothetical Release Scenario from the Gnome Underground Workings ...................... 91

5-9 Data Decision Analysis Process............................ 98 


\section{List of Figures (Continued)}

Number

Title

Page

6-1 Gnome-Coach Project Proposed Schedule for Surface Investigation . . . . . . 101

6-2 Gnome-Coach Project Proposed Schedule for Subsurface Investigation. . . . . . 102

A.1-1 Historical Site Layout and Facility Locations at the

Project Gnome-Coach Area, New Mexico...................... A-3

A.3-1 Terrestrial Exposure Rate Levels: Man-Made Isopleths . . . . . . . . . . . A-32

A.3-2 CWD Cs-137 Soil Concentrations ....................... A-33

A.3-3 Gnome-Coach CWD Area Surface Sampling Locations ............. A-34

A.3-4 Gnome-Coach Salvage Yard Area Surface Sampling Locations.......... . A-35

A.3-5 Gnome-Coach Warehouse Area Surface Sampling Locations. . . . . . . . . . A-36

A.3-6 Gnome-Coach Evaporation Pond/Tank Surface Sampling Locations ...... . . A-37

A.3-7 Gnome-Coach SGZ Area Surface Sampling Locations . . . . . . . . . . . . A-38

A.3-8 Gnome-Coach Decontamination Pad Surface Sampling Locations....... . . A-39

A.3-9 Gnome-Coach Old Laundry/Lab Area Surface Sampling Locations. . . . . . . A A-40

A.3-10 Gnome-Coach New Laundry/Lab Area Surface Sampling Locations . . . . . . . A-41

A.3-11 Gnome-Coach Salt Muckpile Area Surface Sampling Locations . . . . . . . . A A-42

A.3-12 Gnome-Coach Shaft Area Surface Sampling Locations .............. A-43

A.3-13 Gnome-Coach Venting Fallout Track Surface Sampling Locations ... . . . . . A-44

A.3-14 Gnome-Coach Equipment Storage Area Surface Sampling Locations .... . . A A-45

A.3-15 Gnome-Coach Area 57 (NFCS) Surface Sampling Locations . . . . . . . . . . A A-46

A.3-16 Gnome-Coach Road Area Surface Sampling Locations . . . . . . . . . . . . . A-47

A.3-17 Gnome-Coach USGS-4 and -8 Area Surface Sampling Locations ......... A-48

A.3-18 Gnome-Coach General Crusher Plant Area Surface Sampling Locations . . . . . A-49

A.3-19 Gnome-Coach LRL-7 Drill Pad Area Surface Sampling Locations ........ A A-50

A.3-20 Gnome-Coach LRL-8 Drill Pad Area Surface Sampling Locations ....... . A-51

A.3-21 Vegetation Sampling Locations $(1973) \ldots \ldots \ldots \ldots \ldots \ldots \ldots \ldots \ldots \ldots \ldots \ldots \ldots \ldots$ 


\section{List of Figures (Continued)}

Number

B.1-1 Hierarchy of Documents. . . . . . . . . .

B.2-1 DOE/NV ERD Organizational Chart ..................... B-5

D.2-1 Tentative Vegetation Sampling Areas and Plots at the Gnome-Coach Site..... D-4

Plate 1 Gnome-Coach Historical Soil Sample Locations (Phase I and/or Phase II/III) 


\section{List of Tables}

Number

2-1 Historical Activities and Previous Investigations................ 27

2-2 Sample Results from Distant Locations within New Mexico.............. 33

2-3 Summary Table for Background Radionuclide Levels................... 34

3-1 Summary of Data Quality Objectives for the Surface ............... 40

3-2 Summary of Data Quality Objectives for the Gnome-Coach Subsurface ....... 46

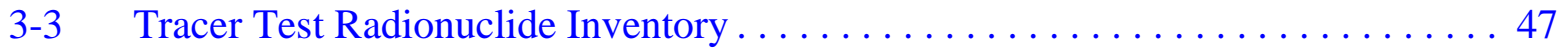

3-4 Long-Lived Radionuclides Produced by the Gnome Nuclear Test . . . . . . . . 48

4-1 List of Areas of Concern, Size of Area, and Potential COPCs for the Gnome-Coach Site, Eddy County, New Mexico ................ 56

A.3-1 Number of Sample Results for Each Area of Concern ${ }^{\mathrm{a}} \ldots \ldots \ldots \ldots \ldots \ldots$. . . . A-20

A.3-2 Gnome-Coach Phase I, II, and III - Soil Sampling Results (1977-1979) . . . . . A A-23

A.3-3 Gnome-Coach Phase I, II, and III - Surface ${ }^{a}$ Soil Analysis Results Statistics . . A A-24

A.3-4 Gnome-Coach Phase I, II, and III Shallow Subsurface Soil Analysis Results... A-25

A.3-5 Gnome-Coach Select Sample Locations for Cs-137, Sr-90, and Pu-239 Comparison ............................... A-26

A.3-6 First Historical Vegetation Sampling Results. . . . . . . . . . . . . . . A-27

A.3-7 Second Historical Vegetation Sampling Results $\ldots \ldots \ldots \ldots \ldots \ldots \ldots$ A-28

A.3-8 TLD Monitoring Results......................... A-29

C.2-1 Gnome-Coach Phase I, II and III Surface Soil Analysis Results . . . . . . . . C-8

C.2-2 Gnome-Coach Phase I, II, and III Shallow Subsurface Soil Analysis Results. . . C-9

C.3-1 Potentially Complete Human Exposure Pathways at Gnome-Coach Site . . . . . C-12

C.3-2 RESRAD Parameters for the Gnome-Coach Site................... C-14

D.3-1 Nominal Detection Limits for Vegetation Samples .................. D-9 


\section{List of Acronyms and Abbreviations}

AEC

Am-241

ALARA

AOC

ARMS

ATV

bgs

BLM

CERMC

CERCLA

CFR

$\mathrm{Ci}$

CLP

COPC

CSM

Cs-137

$\mathrm{CV}$

CWD

D\&D

DD

DOE

DOE/NV

DQO

EEG

EM

EPA

ERD
U.S. Atomic Energy Commission

Americium-241

As-low-as-reasonably-achievable

Area of concern

Aerial Radiation Measuring System

All-terrain vehicle

Below ground surface

U.S. Department of the Interior, Bureau of Land Management

Carlsbad Environmental Monitoring \& Research Center

Comprehensive Environmental Response Compensation and Liability Act

Code of Federal Regulations

Curie(s)

Contract Laboratory Program

Contaminants of potential concern

Conceptual site model

Cesium-137

Coefficient of Variation

Contaminated Waste Dump

Decontamination and decommissioning

Downhole disposal

U.S. Department of Energy

U.S. Department of Energy, Nevada Operations Office

Data Quality Objective(s)

Environmental Evaluation Group

Electromagnetic

U.S. Environmental Protection Agency

Environmental Restoration Division 


\section{List of Acronyms and Abbreviations (Continued)}

\begin{tabular}{|c|c|}
\hline ERP & Environmental Restoration Program \\
\hline $\mathrm{ft}$ & Foot (feet) \\
\hline $\mathrm{ft}^{2}$ & Square foot (feet) \\
\hline $\mathrm{ft}^{3}$ & Cubic foot (feet) \\
\hline GC & Gas chromatography \\
\hline GC/MS & Gas chromatography/mass spectrometry \\
\hline GPR & Ground penetrating radar \\
\hline GPS & Global Positioning System \\
\hline $\mathrm{H} \& \mathrm{~S}$ & Health and Safety \\
\hline ha & Hectare \\
\hline HASP & Health and Safety Plan \\
\hline HPLC & High performance liquid chromatography \\
\hline $\mathrm{I}-131$ & Iodine-131 \\
\hline ICRP & International Commission on Radiological Protection \\
\hline IDW & Investigation-derived waste \\
\hline ILCR & Incremental lifetime cancer risk \\
\hline in. & $\operatorname{Inch}(\mathrm{es})$ \\
\hline ITLV & IT Corporation, Las Vegas \\
\hline LAPS & Large area plastic scintillation \\
\hline lbs & Pound(s) \\
\hline LCS & Laboratory control sample \\
\hline LLW & Low-level waste \\
\hline LQC & Laboratory quality control \\
\hline LTHMP & Long-Term Hydrologic Monitoring Program \\
\hline MDA & Minimum detectable activity \\
\hline MDC & Minimum detectable concentration \\
\hline $\mathrm{mg} / \mathrm{cm}^{2}$ & Milligram(s) per square centimeter \\
\hline
\end{tabular}




\section{List of Acronyms and Abbreviations (Continued)}

\begin{tabular}{|c|c|}
\hline $\mathrm{mg} / \mathrm{L}$ & Milligram(s) per liter \\
\hline $\mathrm{mR} / \mathrm{hr}$ & MilliRoentgen per hour \\
\hline $\mathrm{mrad} / \mathrm{hr}$ & Millirad per hour \\
\hline mrem & Millirem \\
\hline $\mathrm{mrem} / \mathrm{yr}$ & Millirem per year \\
\hline MRI & Magnetic resonance image \\
\hline MS & Matrix spike \\
\hline MSD & Matrix spike duplicate \\
\hline M\&TE & Measurement and testing equipment \\
\hline $\mathrm{NCP}$ & National Contingency Plan \\
\hline NCR & Nonconformance report \\
\hline NEPA & National Environmental Policy Act \\
\hline NIST & National Institute of Standards and Technology \\
\hline NRC & U.S. Nuclear Regulatory Commission \\
\hline NTS & Nevada Test Site \\
\hline NV ERP & $\begin{array}{l}\text { U.S. Department of Energy, Nevada Operations Office, Environmental } \\
\text { Restoration Project }\end{array}$ \\
\hline PAL & Preliminary action levels \\
\hline $\mathrm{pCi}$ & Picocurie(s) \\
\hline $\mathrm{pCi} / \mathrm{g}$ & Picocurie(s) per gram \\
\hline $\mathrm{pCi} / \mathrm{mL}$ & Picocurie(s) per milliliter \\
\hline $\mathrm{pCi} / \mathrm{L}$ & Picocurie(s) per liter \\
\hline PID & Photoionization detector \\
\hline ppm & Part(s) per million \\
\hline PTRW & Particle tracking random-walk \\
\hline $\mathrm{Pu}-239$ & Plutonium-239 \\
\hline $\mathrm{Pu}-240$ & Plutonium-240 \\
\hline PVC & Polyvinyl chloride \\
\hline
\end{tabular}




\section{List of Acronyms and Abbreviations (Continued)}

\begin{tabular}{|c|c|}
\hline QA & Quality assurance \\
\hline QAC & Quality Assurance Coordinator \\
\hline QAPP & Quality assurance project plan \\
\hline QC & Quality control \\
\hline RCRA & Resource Conservation and Recovery Act \\
\hline RPD & Relative percent difference \\
\hline RESRAD & Residual Radiation \\
\hline RME & Reasonable maximum exposure \\
\hline $\mathrm{SD}$ & Standard deviation \\
\hline Sr-90 & Strontium-90 \\
\hline SGZ & Surface ground zero \\
\hline SSHASP & Site-specific health and safety plan \\
\hline SVOC & Semivolatile organic compounds \\
\hline TLD & Thermoluminescent dosimeter \\
\hline $\mathrm{TPH}$ & Total petroleum hydrocarbons \\
\hline UCL & Upper confidence level \\
\hline USGS & U.S. Geological Survey \\
\hline UST & Underground storage tank \\
\hline VOA & Volatile organic analysis \\
\hline VOC & Volatile organic compounds \\
\hline WIPP & Waste Isolation Pilot Plant \\
\hline$y^{3}$ & Cubic yard(s) \\
\hline${ }^{\circ} \mathrm{C}$ & Degree(s) Celsius \\
\hline${ }^{o} \mathrm{~F}$ & Degree(s) Fahrenheit \\
\hline$\mu \mathrm{Ci} / \mathrm{g}$ & Microcurie(s) per gram \\
\hline
\end{tabular}




\subsection{Introduction}

The scope of this work plan is to document the environmental sample collection objectives and the proposed technical site investigation strategies that will be utilized during the Gnome-Coach Site characterization.

Gnome was the first nuclear experiment conducted under the Plowshare Program under the direction of the U.S. Atomic Energy Commission (AEC), predecessor to the U.S. Department of Energy (DOE). The Plowshare Program focused on developing nuclear devices exclusively for peaceful purposes. Gnome, a 3-kiloton nuclear explosive, was detonated on December 10, 1961, at a depth of 1,184 feet (ft) below ground surface (bgs) in a thick, bedded salt deposit within the Salado Formation approximately 25 miles east of Carlsbad, New Mexico, in Eddy County (Figure 1-1). Immediately following the detonation, close-in stemming failed and cavity gases vented from the emplacement shaft into the atmosphere. The gases were carried downwind in a northwest direction from the site (AEC, 1962). Coach, an experiment to be located near Gnome also within the Salado Formation, was initially scheduled for 1963. Construction and rehabilitation were completed for Coach, but the test was canceled and never executed. Additionally, a hydrologic tracer test performed by the U.S. Geological Survey (USGS) in 1963 left residual radioactive tracers (i.e., tritium, cesium-137 [Cs-137], strontium-90 [Sr-90], and iodine-131 [I-131]) in the Culebra Dolomite at and between the tracer test wells, USGS-4 and -8 .

Major site restoration activities were conducted in 1968-1969 and 1977-1979. The restoration activities included: well plugging and abandonment, decontamination, disposal of equipment, soil, and salt muck into the Gnome cavity, shaft, and drift complex, and soil sampling and analysis. No soil or soil moisture samples collected during the final phase of the 1977-1979 restoration effort exceeded established radiological release criteria (DOE/NV, 1981).

Although restoration activities were performed for surface and shallow subsurface $(<20 \mathrm{ft})$ radiological contamination, radiologically elevated locations have been identified on the surface during recent survey and sampling events by the U.S. Environmental Protection Agency (EPA) (1994c) and the Environmental Evaluation Group (EEG) (1995). The surveying and sampling involved in these two recent efforts is too limited to adequately assess the surface conditions using 


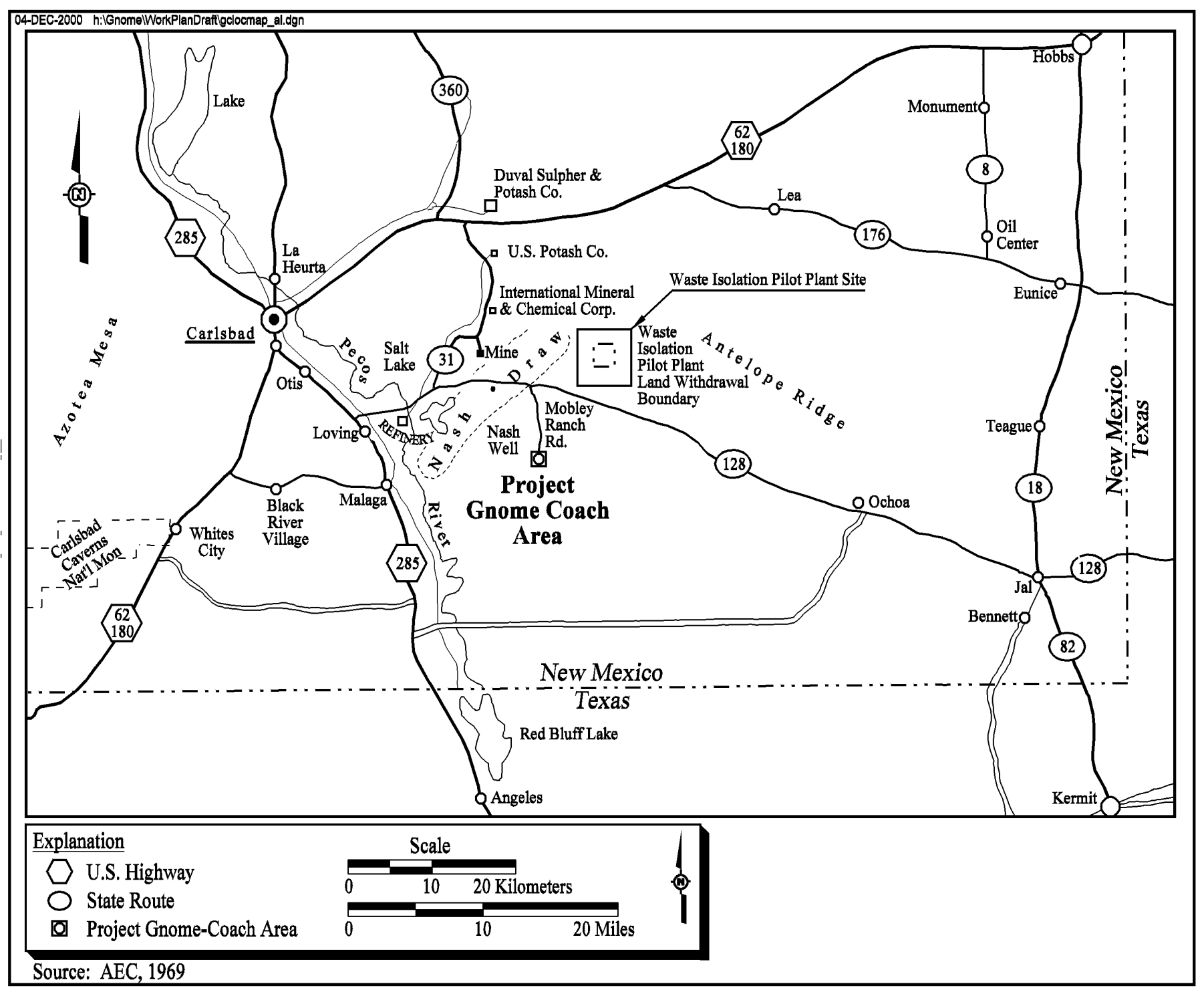

Figure 1-1 Location of the Project Gnome-Coach Area 
current standards. Reviews of historical radiological data also identified data gaps for shallow subsurface soils at several operational areas. Additionally, the historical restoration efforts have not adequately defined the potential for and extent of chemical contamination for the surface and shallow subsurface. The deep subsurface hazards (i.e., test cavity) have not been evaluated for potential migration outside of the current site subsurface intrusion restrictions.

\subsection{Purpose}

The purpose of this environmental investigation of the Gnome-Coach Site is to collect data of sufficient quantity and quality to establish current site conditions and to use the data to identify and evaluate if further action is required to protect human health and the environment and achieve permanent closure of the site. This investigation utilized available data and documented historical knowledge to the extent possible. Existing subsurface site information will be evaluated and migration of contaminants from the test cavity and tracer test area will be modeled to establish contaminant fate and transport. The subsurface modeling and risk evaluation will result in the potential refinement of the existing compliance boundary that defines the area where subsurface intrusion restrictions are applied.

\subsection{Scope of Work}

The details of the scope of work are discussed in two sections: the "Surface and Shallow Subsurface Work Plan" (Section 4.0), and the "Subsurface Modeling Work Plan" (Section 5.0). Historical and/or new data collected will be of sufficient quantity and quality to be used in addressing the Data Quality Objectives (DQOs). The following sequential DQOs need to be met to complete the scope of work for the surface and shallow subsurface site characterization investigations and the subsurface modeling effort:

- Determine the nature and extent of potential contamination at the surface.

- Support a risk-based decision on the need to perform corrective actions for the surface.

- Support a corrective action alternative analysis for the surface, if required.

- Determine the potential migration of the contamination in the Gnome cavity, shaft, and drifts to the Culebra aquifer. 
Gnome-Coach SC Work Plan

Section: 1.0

Revision: 0

Date: $02 / 14 / 2001$

Page 4 of 110

- Determine the potential of contaminant migration from the tracer test to the Culebra aquifer.

- Determine if existing subsurface intrusion restrictions need to be adjusted to ensure they are protective of human health and the environment.

The scope of work to be conducted at the Gnome-Coach Site for the surface and shallow subsurface includes in situ radiological surveys, a geophysical investigation, and soil and vegetation sample collection. The scope of work for the deep subsurface and groundwater will include an evaluation of existing well data, groundwater analyses, and previous modeling efforts to determine the threat posed by the underground workings (i.e., cavity, shaft, and drifts) and tracer test experiment. This data will be used to evaluate if existing subsurface intrusion restrictions need to be adjusted to be protective of human health and the environment.

The first portion of the investigation consisted of researching historical documents, photos, and engineering diagrams and drawings. The objective of this research was to identify suspect areas and to correlate these locations with their actual locations at the Gnome-Coach Site. Subsequent steps for the surface/shallow subsurface investigation will be to conduct both a geophysical survey and an in situ radiological survey of the Gnome-Coach areas of concern (AOC), which may include: drill pads associated with numerous well locations, the contaminated waste dump, salvage yard, old and new laundry/lab, warehouse area, equipment storage area, waste tank/evaporation pond, decontamination pad, surface ground zero, and the shaft area. The results of the geophysical investigation and radiological survey, coupled with historical data, will be used to identify and/or further delineate potential areas of contamination within each of these AOCs.

As determined by the radiological survey, geophysical investigation, historical data, and the radiological screening evaluation, additional data will be collected at each AOC where data gaps have been identified to adequately characterize the AOC. Background conditions will be established by utilizing existing data for the Gnome-Coach Site and surrounding area, as well as collecting soil samples at nonimpacted areas near the site to fill data gaps. Vegetation samples will be collected and analyzed to support a risk assessment.

The subsurface at the Gnome-Coach Site has two contaminant sources that are fundamentally different in terms of both their stratigraphic location and release mechanism. For this reason, the strategy to address each is different and they are discussed separately in Section 5.0. In general, the 
subsurface strategy will focus on locating and evaluating all existing data for boreholes, geology, and hydrology; use previous modeling data; collect additional data, if necessary; and determine if the existing subsurface intrusion restrictions and compliance boundary need to be adjusted with consideration of uncertainty.

\subsection{Investigation Work Plan Contents}

This document provides a detailed description of past and present site conditions, a description of the DQO process results, and a description of the methods and procedures to be used for investigation activities. This work plan has been organized as follows:

- Section 1.0 - Introduction

- Section 2.0 - Facility Description

- Section 3.0 - Data Quality Objectives

- Section 4.0 - Surface and Shallow Subsurface Work Plan

- Section 5.0 - Subsurface Work Plan

- Section 6.0 - Schedule

- $\quad$ Section 7.0 - References

Previous radiological monitoring and sampling results are described in Appendix A, a Quality Assurance Project Plan (QAPP) is provided in Appendix B, a Radiological Screening Evaluation is provided in Appendix C, and Appendix D contains the Vegetation Sampling and Analysis Plan. 


\subsection{Facility Description}

\subsection{Physical Setting}

This section describes the location of the Gnome-Coach Site, land status, and environmental setting which includes topography, vegetation, climate, and surface water.

\subsubsection{Land Status}

The Gnome-Coach Site is located approximately 25 miles southeast of Carlsbad, Eddy County, New Mexico. The Gnome-Coach Site was withdrawn from U.S. Department of Interior, Bureau of Land Management (BLM) by Public Land Order 2526 issued on October 26, 1961, and is still assigned to the DOE. The land withdrawal encompasses 640 acres in Section 34, Township 23 South, Range 30 East (Gnome-Coach Facility Area), and approximately 40 acres in the NW1/4 of the NW1/4 of Section 10 in Township 23 South, Range 30 East (Gnome Control Point Area), New Mexico, Principle Meridian (Areas A and B on Figure 2-1) (AEC, 1962). Section 34 includes nearly all of the surface AOCs as well as the Gnome-Coach underground workings (e.g., ground zero, the main shaft, and the entire drift complex) (DOE/NV, 1978). Several drill pads associated with Project Gnome exist outside of the land withdrawal boundaries. The principal land use in the area of the Gnome-Coach Site is open-range (e.g., livestock grazing). No areas within the Gnome-Coach Site constitute prime agricultural land (LTSP, 1972). In addition to the land withdrawal, Rights-of-Way for access roads, power lines, seismic cables, sites for radio relay towers and test wells were acquired by Land Use Agreements (AEC, 1962). Although land withdrawal is still assigned to DOE, in June 1969, these Land Use Agreements were released (AEC, 1969).

Currently there are restrictions on subsurface intrusion (i.e., drilling, excavation) from the surface to 1,500 ft total vertical depth within the entire Section 34, Township 23 South, Range 30 East (DOE/NV, 1978).

\subsubsection{Environmental Setting}

The Gnome-Coach Site is situated within the Delaware Basin on the Mescalero pediment of the Pecos River. The approximate elevation of the Gnome-Coach Site is 3,406 ft above mean sea level. Karst 


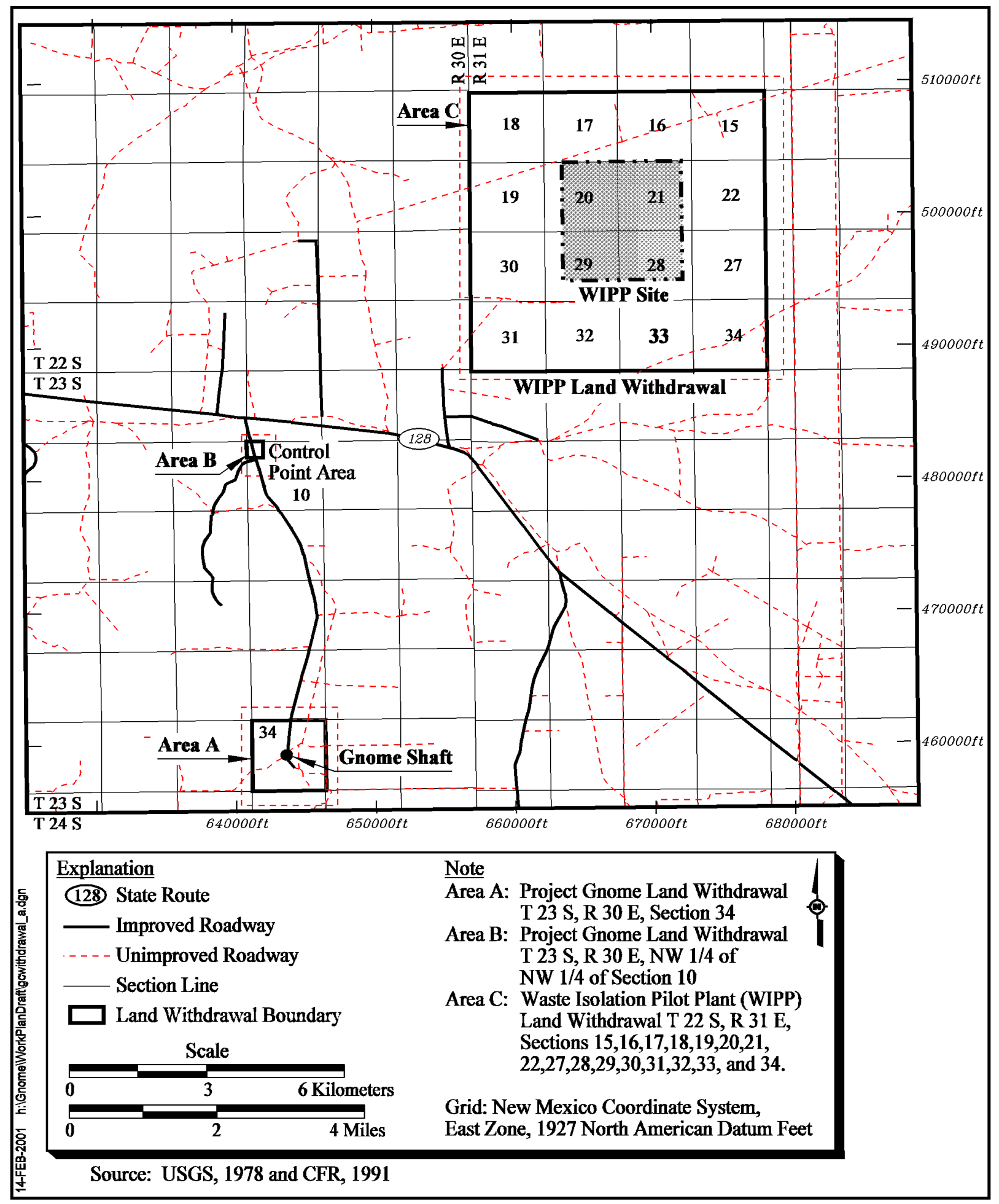

Figure 2-1

Project Gnome-Coach Area: Township/Range Boundaries and Land Withdrawal Boundaries, Eddy County, New Mexico 
topography is common in the surrounding area with immature drainage courses characterizing the land surface and generally leading to local depressions. Caliche, windblown sand, alluvium, and playa lake deposits of Quaternary age comprise most of the surficial geology immediately surrounding the Gnome-Coach Site. Topographic relief of the project area is characterized by gently rolling plains, stabilized dunes, and deflation basins (DOE/NV, 1993b). The land surface slopes northeastward less than one-half degree. Sand dunes up to $20 \mathrm{ft}$ high with a maximum length of $300 \mathrm{ft}$ and a width of $50 \mathrm{ft}$ are present at or near the site. Figure 2-2 is a topographic map of the area surrounding the Gnome-Coach Site. A detailed discussion of the geology and hydrology, as they relate to the subsurface investigation, is presented in Section 5.0.

Kermit Series soils in association with Berino Series soils produce the Kermit-Berino fine sands, which is the only soil map unit within and immediately surrounding the Gnome-Coach Site boundary (USDA, 1971). Kermit-Berino fine sands consist of noncalcareous, yellowish-red sandy soils to a depth of about $5 \mathrm{ft}$. The Berino Series at depth consists of sandy clay loam with clay loam (soft caliche) typically forming at the base of soil layers. The loose, sandy soils are easily eroded by wind and water. Caliche is known to form calcareous zones in soil and near-surface deposits. It ranges in composition from dense to thinly-banded and contains sand grains and rock fragments. Where it has long been exposed at the surface, it is commonly very hard and resistant; however, where it has remained covered, it may be soft and friable. The color is primarily white to gray, but may be stained brown or red. In much of the Gnome-Coach area, caliche forms a cap over older formations of several ages in the topographically high and less eroded parts of the land surface and is also present within the eolian sand deposits. The caliche crops out where sand cover has been removed. Drill holes within the Gnome-Coach area have encountered a layer of friable caliche from about 7 to $10 \mathrm{ft}$ bgs. Beds of caliche as thick as $3 \mathrm{ft}$ have been encountered above $15 \mathrm{ft}$ bgs (Cooper, 1962a).

Climate in the Gnome-Coach area is semiarid with a mean annual precipitation of 12.3 inches (in.). Long-term monitoring shows a range of less than 3 in. to over 30 in. of precipitation annually. The rainy season, May through October, accounts for about 70 percent of the annual precipitation. Typical temperature fluctuations occur in the area, ranging from -24 degrees Fahrenheit $\left({ }^{\circ} \mathrm{F}\right)$ in January to $107^{\circ} \mathrm{F}$ in July and August. Extreme diurnal temperature fluctuations are common, often exceeding $40^{\circ} \mathrm{F}$ (DRI, 1988). Winds are generally out of the southeast and average around 8 miles/hour. 


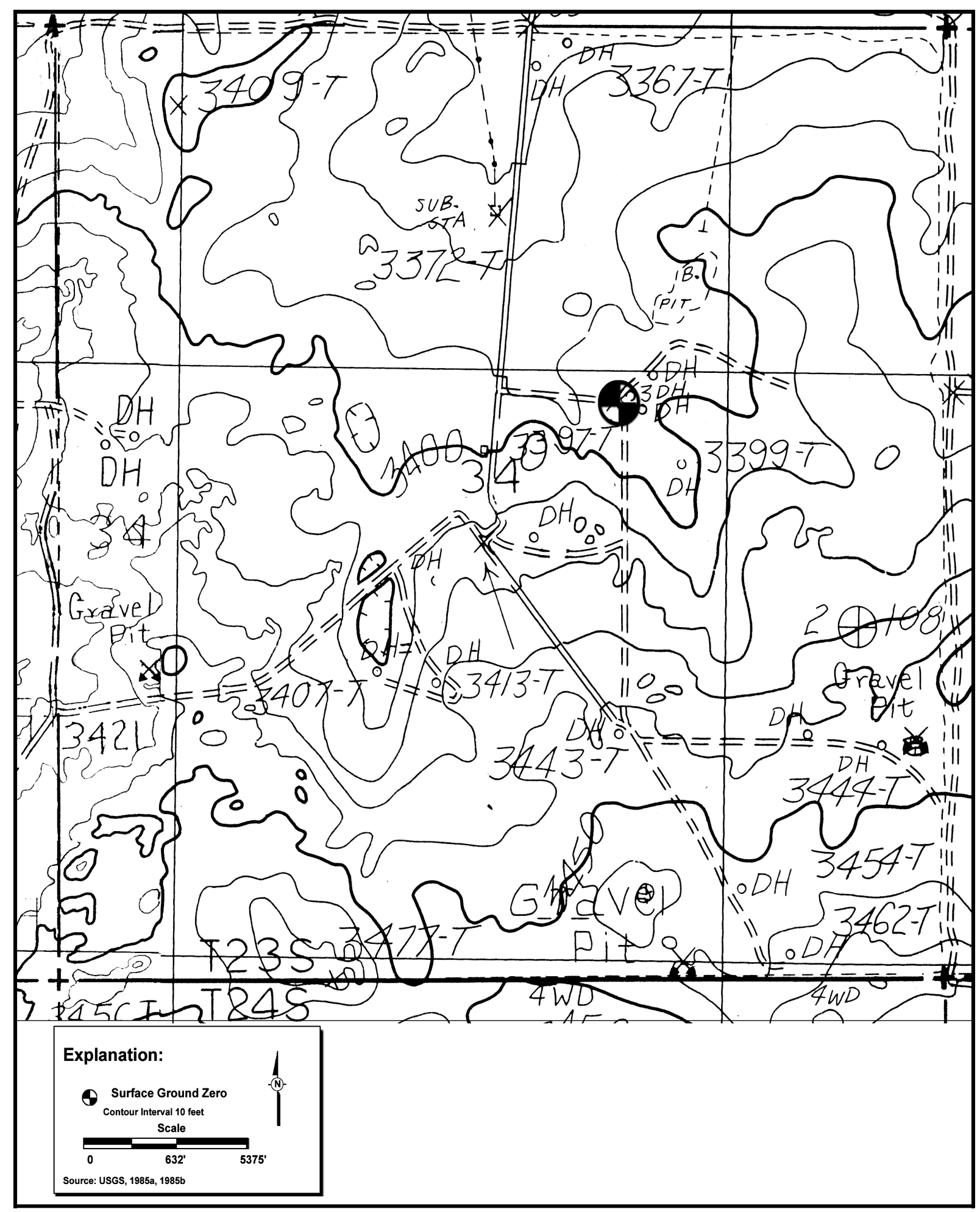

Figure 2-2 
Vegetation at the Gnome-Coach Site is sparse, mostly hardy range grasses with mesquite, yucca, and shinnery oak on the hilltops and in depressions.

\subsubsection{Surface Water}

There is no surface water at the Gnome-Coach Site. The Pecos River, a perennial stream, is located approximately 11 miles west of the project area. To the east of the Pecos River valley is the Nash Draw, located approximately 7 miles west of the Gnome-Coach Site. The Nash Draw contains many karst features including a large surface depression known as the Laguan Grande de la Sal.

Surveys were conducted in 1993 for wetlands and floodplain determination. The survey used aerial photographs, USGS topographic maps (7.5-Minute Los Medranos and Remuda Basin Quadrangles), and field surveys. The survey showed no wetland sites or floodplain areas in the Gnome-Coach Site (DOE/NV, 1993b).

\subsection{Operational History}

Gnome was the first nuclear detonation conducted under the AEC's (predecessor to the DOE) Plowshare Program and the first detonation conducted within the continental United States outside the Nevada Test Site (NTS). The Plowshare Program was established by the AEC to provide research and development directed toward peaceful uses of nuclear explosives. The objectives of the Gnome test were specifically designed to explore the possibility of converting the energy of a nuclear explosion to electric power, investigate the production and recovery of radioactive isotopes, collect data on the characteristics of nuclear detonations within a salt medium, to obtain neutron cross-section measurements over a wide energy range, and to obtain information useful in the design of future Plowshare tests (AEC, 1969).

Gnome consisted of detonating a 3-kiloton yield nuclear device on December 10, 1961 (AEC, 1962). The device was placed in a thickly bedded salt deposit $1,184 \mathrm{ft}$ bgs surface via a 10-ft diameter, vertical shaft with a lateral drift approximately 8 by $10 \mathrm{ft}$, extending to the northeast about 1,116 ft, and terminating in a buttonhook configuration (Figure 2-3) (AEC, 1969).

Immediately following detonation, close-in stemming failed and cavity gases vented into the emplacement drift and shaft, allowing the low pressure release of steam and gaseous fission products 


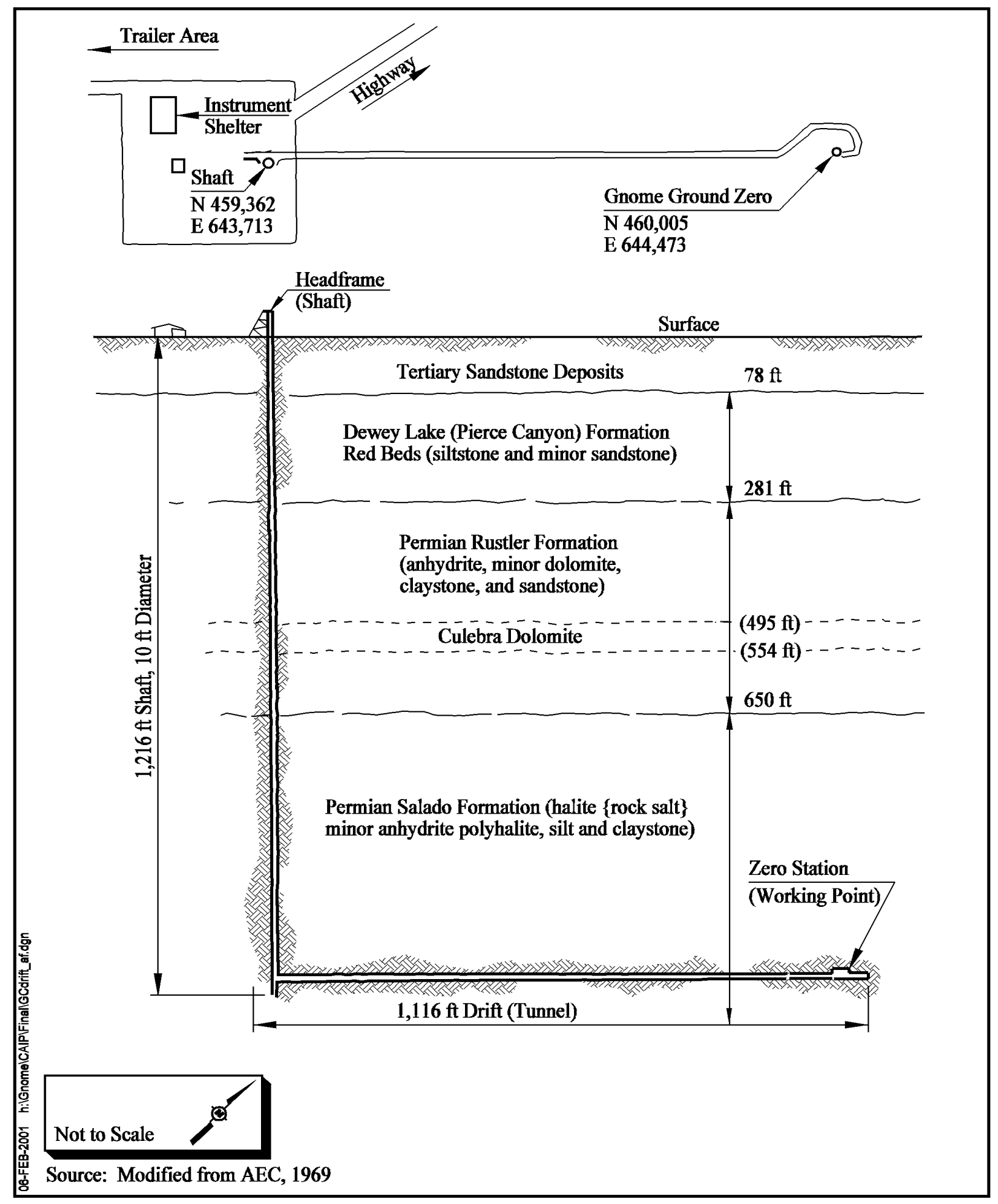

Figure 2-3

Gnome Shaft and Drift Plan 
onto the surface. For more than 24 hours, the steam and short-lived radioactive gases vented from the shaft, and were carried in a northwest direction from the site. Aerial monitoring results indicated that these short-lived radionuclides were deposited on the ground for approximately 10 miles.

Posttest drill-back activities began on December 11, 1961, and continued through September 1963. Surface activities consisted of drilling sample recovery holes (e.g., SR-2A and SR-3A), which were completed into the test cavity at approximately the 1,079-ft depth. Subsurface activities included excavation of exploratory drifts and crosscut alcoves, drilling holes into the original tunnel from the alcoves, and excavating crawl holes into the tunnel. Drill-back activities connected the shaft to the cavity, allowing it to be entered. It was calculated that the explosion melted 7,054,673 pounds of rock salt, forming a 960,452-cubic feet cavity (Rawson, et al., 1965). All subsurface exploration from the shaft to the test cavity was completed by June 1962. Both the surface and subsurface activities brought contaminated material to the surface, mostly in the form of salt muck.

Construction activities commenced in June 1962 through July 1963 for Project Coach. These activities included: rehabilitation of the Gnome shaft and extending its depth to $1,284 \mathrm{ft}$; constructing a lateral drift southeastward to the Coach ground zero room; and drilling four holes from the ground surface to the Coach drift. Project Coach was cancelled in late 1963.

In 1963, a hydrologic tracer experiment within the Culebra Dolomite member of the Rustler Formation was conducted at the Gnome-Coach Site. The experiment involved injecting water spiked with tritium, I-131, Sr-90, and Cs-137 into the Culebra Dolomite. Well USGS-8 was used to inject the isotopes into the aquifer system, while samples were taken from Well USGS-4 to determine breakthrough curves for the different isotopes (Beetem and Angelo, 1964). This experiment resulted in contamination of both wells and direct contact of radionuclides with the Culebra aquifer groundwater. Section 5.0 of this work plan discusses the tracer test in more detail.

After being on caretaker status for approximately five years, the U.S. Department of Energy, Nevada Operations Office (DOE/NV) was given orders to begin site decommissioning. Subsequently, the Gnome-Coach Site has undergone two major decontamination/cleanup efforts and one area reconnaissance. The initial decontamination effort was conducted in 1968 and 1969. The area reconnaissance occurred in 1972. The second decontamination effort was a three-phase operation 
conducted between the years of 1977 and 1979. These decontamination and decommissioning (D\&D) efforts are further discussed in Section 2.3.1, Section 2.3.2, Section 2.3.3, and Appendix A.

Appendix A, "Radiological Summary for the Gnome-Coach Site," describes the on-site radiological monitoring activities and results for the surface; summarizes the surface and shallow subsurface radiological sampling conducted during cleanup efforts; and assesses the results and adequacy of this sampling and monitoring.

The following sections briefly describe historical aspects (i.e., former operations, cleanup activities) of each AOC. Figure 2-4 depicts the former operational layout and areas of concern within the Gnome-Coach Site.

\subsubsection{Trailer Park and Control Point}

Historical information indicates that the structures and activities within the Trailer Park and Control Point area were used mainly for instrument and administrative purposes and did not involve handling hazardous or radioactive material. Subsequently, these areas have been eliminated from additional characterization (AEC, 1962; LRL, 1961).

\subsubsection{Fallout Plume}

During the execution of Gnome in 1961, steam and short-lived radioactive gases vented through the shaft and low level fallout occurred in a northwest direction. Although the potential for surface radiological contamination outside the land withdrawal boundary of Section 34 may exist, recent surveys and soil sampling have found remaining contamination extends only a short distance (less than $600 \mathrm{ft}$ ) from the shaft. The 1977-1979 aerial radiological surveys (DOE/NV, 1981), 1994 soil sample results (EPA, 1994c), and an EEG survey (EEG, 1995) all show the highest concentration of residual gamma contamination at a small area about $490 \mathrm{ft}$ northwest of the shaft. Small particles from demolishing the shaft collar during cleanup may also contribute to isolated contaminated locations. The fallout track area has not required any type of cleanup effort due to concentrations of contamination below previously established release criteria. 


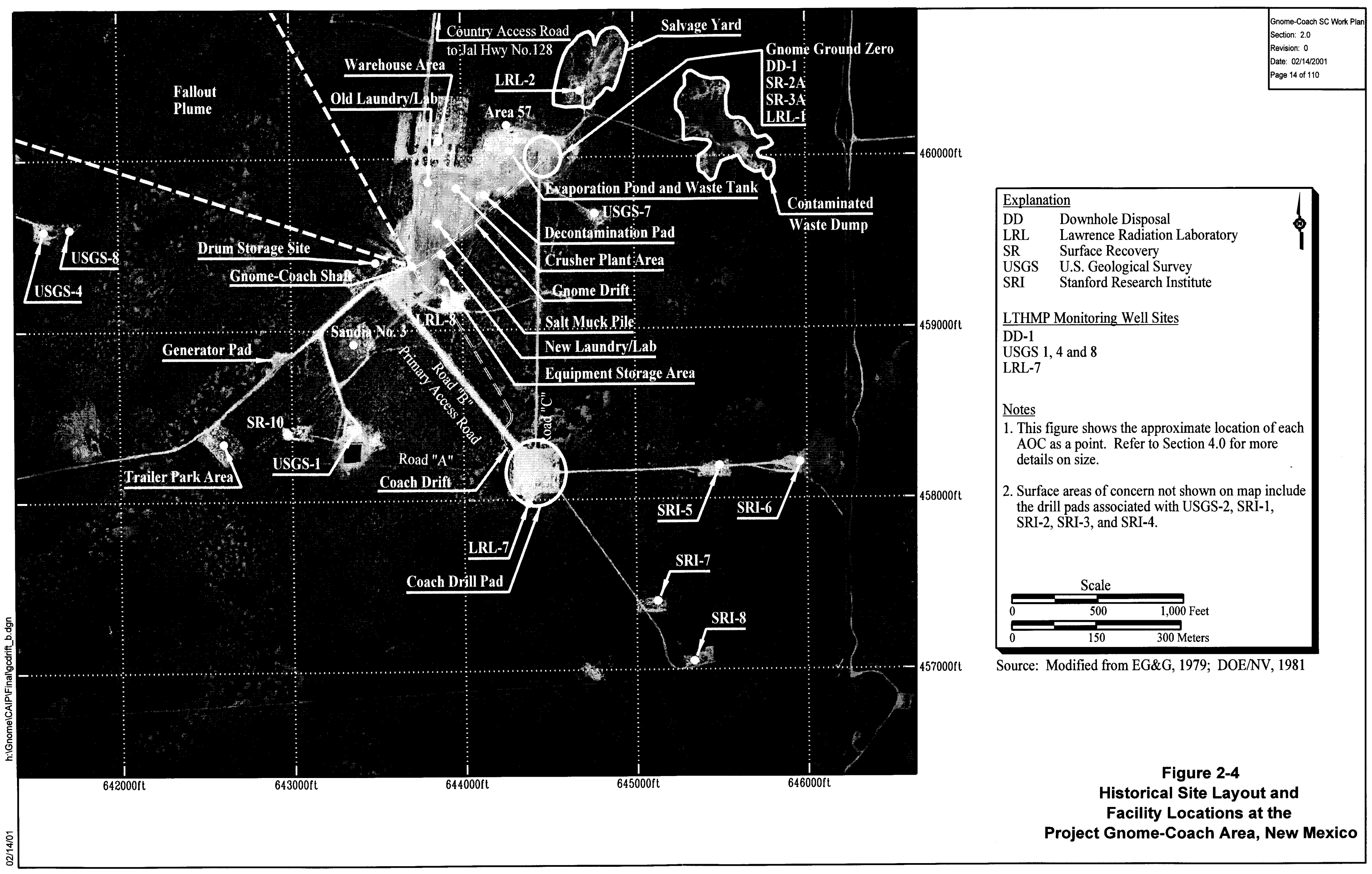




\subsubsection{Gnome-Coach Shaft Area}

The shaft provided access to both the Gnome and Coach drifts which led to the respective ground zero rooms. The shaft is circular in plan, had a finished diameter of $10 \mathrm{ft}$, and was constructed to a depth of 1,216 ft below ground surface. The shaft was lined with reinforced concrete from the surface to a depth of $722 \mathrm{ft}$ bgs into the Salado Formation (USGS, 1962). The elevation of the shaft collar was 3,408.7 ft above sea level. The caliche-stabilized pad was approximately 250 by $300 \mathrm{ft}$ and held all the housing necessary to operate the mine shaft and hoist, as well as instrument trailers and a parking area. The ground area surrounding the shaft was used for posttest drilling and recovery operations for Project Gnome and construction for Project Coach. Radiological contamination of soil and equipment resulted from both the venting episode immediately following the Gnome test and posttest operations. Historical documentation indicates a vehicle maintenance and machine shop was operated within the shaft area. According to historical documents, a concrete-lined grease pit was located behind a machine shop near the shaft (Holmes and Narver, 1963). It is unknown if this grease pit was actually used and, if so, if any contents remain.

During the 1968-1969 cleanup effort, radiologically contaminated material was disposed down the shaft and into the Gnome and Coach drifts. After all known contaminated material had been deposited in the shaft, the remainder of the shaft was backfilled with uncontaminated soil to within $5 \mathrm{ft}$ of the surface. The remaining concrete shaft collar was subsequently demolished using explosives prior to sealing with a 5-ft thick, permanent concrete plug (Tappan and Lorenz, 1969). The explosives demolition deposited small contaminated concrete and soil particles on the surface, which were reportedly excavated and disposed of in the shaft prior to sealing. Historical documentation indicate that 6,605 gallons of "clean" water was added to the shaft to settle the disposed muck and that the shaft was filled above the Culebra aquifer with the low-level radioactive materials and muck.

No subsurface restoration work has been undertaken for the shaft or drifts. A 27-ft diameter circular concrete pad currently resides on the surface above the shaft's five-foot concrete plug. Additional AOCs near the shaft, which are briefly described below, include the fallout plume and areas previously occupied by the salt muckpile, the equipment storage yard, and a drum storage area. 


\subsubsection{Gnome Surface Ground Zero}

The Project Gnome surface ground zero area, located about 1,000 ft northeast of the main shaft was the site of reentry drilling activities into the test cavity as well as operations involving the posttest power measurement program. Contamination related to the power measurement program is discussed in Section 2.2.5. Radiological contamination of the surface ground zero (SGZ) area occurred as a result of drill-back operations into the test cavity and the slurry disposal operations of contaminated materials during both the 1968-1969 and 1977-1979 cleanup efforts. The site currently measures approximately 200 by $200 \mathrm{ft}$ and encompasses the ground surface area associated with several reentry wells (e.g., DD-1, SR-2A, and SR-3A). Well DD-1 is open and currently sampled as part of the Long-Term Hydrologic Monitoring Program (LTHMP). Drilling mud pits may be located near ground zero from various pretest wells drilled nearby.

\subsubsection{Evaporation Pond/Waste Tank}

The evaporation pond and liquid waste tank were utilized as part of the power measurement program. Contaminated water and sludge generated during the power program operation was pumped from both the waste tank and evaporation pond into the Gnome cavity during the 1968-1969 cleanup. The evaporation pond was excavated to a depth of $12 \mathrm{ft}$ during the initial cleanup (1968-1969) to remove contaminated soil underneath the pond liner, which was also deposited into the shaft. None of the operational area structures remain.

\subsubsection{Area 57}

Area 57 was an area identified during the second cleanup as having surface radiological contamination from known contaminated areas nearby. The area was subjected to sampling and radiological cleanup during the 1977-1979 restoration effort. Area 57 is also referred to as NFCS; the acronym has not been identified.

\subsubsection{Salt Muckpile}

The salt muckpile, originally located about $100 \mathrm{ft}$ north-northeast of the shaft, consisted of salt muck and rock waste from the mining operations during construction of the main shaft and the Gnome and Coach drifts. The overall dimensions of the muckpile reached 450 by $350 \mathrm{ft}$ and $21 \mathrm{ft}$ thick. Portions 
of the salt muckpile had become radiologically contaminated during the posttest drill-back activities. Approximately 27,000-30,000 cubic yards of salt and salt-polluted soil left in place after the 1969 cleanup were later removed in the 1977-1979 cleanup effort and disposed into the Gnome cavity. Excess uncontaminated salt that could not fit into the cavity was buried in a trench located in the old laundry/lab area (see Section 2.2.10).

\subsubsection{Storage Areas}

The drum storage area was identified during a review of historical documents. Aerial photographs and an engineering drawing revealed a site located across the road from the shaft that apparently was used for storage of drums and possibly electrical cable (LLNL, 1961; Holmes \& Narver, 1963). Approximately 20 to 25 drums are visible in various photographs. Nothing was found in the historical literature that identified this site or discussed the use or contents of these drums. Based on process knowledge of historic DOE/AEC operations, these drums probably contained petroleum products (e.g., oil, grease).

The generator pad was identified during a review of historical documents. Engineering drawings indicate a generator shelter, generator(s), and aboveground fuel tank(s) existed on this pad for the duration of Gnome-Coach Site activities (Holmes \& Narver, 1961; 1963). It is unclear from the historical records how many tanks and generators were located on the pad at any one time because of continuous changes to engineering drawings. Historical records do not indicate the size of the fuel $\operatorname{tank}(\mathrm{s})$ and if there were any fuel spills/releases on the pad.

The equipment storage area, located east-southeast of the shaft, was identified as an area used for holding tunneling equipment and possibly used as a sandblasting area for radiologically contaminated drill pipe (DOE/NV, 1978).

The warehouse area, located north of the old laundry/lab area, was used for storage of miscellaneous tools and equipment within the building and the outside storage yard. During the 1968-1969 cleanup, radiologically contaminated tools, equipment, and concrete pieces were removed from the building; additionally, a dump truck, mine cars, a hoist muck bucket, a hoist man cage, and soil were removed from the storage yard and disposed of in the shaft. A burial pit/trench with scrap metal was 
uncovered during the 1977-1979 cleanup; however, these materials were not radiologically contaminated.

\subsubsection{Decontamination Pad}

A decontamination pad was used for the decontamination of equipment and facilities associated with Gnome-Coach Site during posttest activities (DOE/NV, 1978). Decontamination techniques included high-pressure detergent washing, vacuuming, and the use of solvents (AEC, 1962).

\subsubsection{Laundry/Lab Facilities}

The old laundry/lab facility was used to decontaminate personnel anticontamination clothing and used as on-site analytical laboratory during the drill-back activities (DOE/NV, 1978; AEC, 1962). Sections of the area were also radiologically contaminated by material spilled from trucks which hauled contaminated waste during the 1968-1969 cleanup. Based on knowledge of laundry and laboratory processes at the time of Project Gnome, relatively small amounts of solvents may have been used at this facility. In addition to cleanup activities at this facility during the 1977-1979 restoration effort, a trench was excavated in the same area as the old laundry/lab facility for the burial of uncontaminated salt that was leftover after disposal operations. The trench measured approximately $380 \times 95 \times 12 \mathrm{ft}$, covering the entire areal extent of the old laundry/lab facility. A 4-ft thick salt layer was deposited in this trench, then saturated with water to compact the salt and minimize the bulking factor. A thin (4-in.) layer of crushed concrete was then deposited on the salt, followed by the placement of a layer of vinyl. The trench was then backfilled with approximately $6 \mathrm{ft}$ of clean soil and the area recontoured. It is reasonable to assume that any remaining contaminated soil was removed during the excavation due to the areal coverage and depth of this trench.

The new laundry/lab facility was built to provide a more centralized location for laundry and radiochemical laboratory activities. The principal radiological contamination of this facility was found in the subsurface at the sump area (DOE/NV, 1978). During the 1977-1979 cleanup, one trench was dug across the new laundry/lab sump area to determine the area encompassed by the sump (DOE/NV, 1978); however, the historical reports do not specify how much, if any, contaminated soil was removed. Documentation was not located to verify the purpose of the sump; however, based on 
process knowledge of laundry and laboratory processes, effluent most likely drained from the facility to the sump.

\subsubsection{Contaminated Waste Dump}

The area known historically as the contaminated waste dump (CWD) was originally used as a caliche borrow pit during construction of the Gnome Site. Documentation indicates that the CWD was later used for the burial of contaminated soil and debris (e.g., metal, wood, salt muck) from post-Gnome activities through the Project Coach abandonment. The CWD was a rectangular area originally measuring 500 by $300 \mathrm{ft}$. During the 1968-1969 cleanup, the CWD site was trenched using a backhoe to determine the exact location of unknown quantities of radioactive materials. Four separate disposal pits were uncovered within the CWD site during this trenching operation. Metal and large debris were sifted from the soil and salt muck at the site and segregated to facilitate disposal operations. All contaminated material, including soil and salt muck measuring greater than the established release criteria, was removed and disposed of into the Gnome shaft and Coach drift (Tappan and Lorenz, 1969). After it was determined that all contaminated materials had been removed from the CWD site, the excavated trenches were back-filled and mounded with uncontaminated soil.

During the 1977-1979 cleanup, the CWD site again underwent decontamination. The effort consisted of the site being scraped to a depth of approximately 6 in. and/or trenched to locate contamination at depth. The contaminated soil was then transported and deposited on the salt muckpile for eventual disposal into the cavity by means of a water injection system through Well DD-1 (DOE/NV, 1981). All excavations were backfilled and the area recontoured.

\subsubsection{Salvage Yard}

The salvage yard may have initially been used as a caliche borrow pit, but was later used to store salvaged material during Gnome-Coach Site operations. Radiologically contaminated fiberglass was located and removed during a reconnaissance of this area in 1972. The area underwent two separate metal detection survey and trenching activities during the first phase of the 1977-1979 decontamination cleanup. Numerous pieces of metal and crushed metal drums were located at various depths within the salvage yard. Documentation indicates that no radiation levels above 
background were detected on these items (DOE/NV, 1978). One area, identified as a burn pit, was uncovered within the salvage yard as having elevated radiological readings (DOE/NV, 1978). The material in the burn pit was subsequently excavated and disposed during the 1977-1979 cleanup. A potential mud pit associated with the LRL-2 drill pad may be located in this area.

\subsubsection{Drill Hole Pads}

Various drill pads surrounding the site and within Section 34 are still easily identified on the ground surface with the aid of aerial photographs due to the lighter colored caliche used to stabilize the pad. All of the pads were constructed for holes (e.g., instrument holes) that supported either the Gnome or Coach experiment. Historically, none of the pads were subjected to previous cleanup efforts unless directly involved with known radiologically contaminated areas such as reentry holes or disposal operational areas. Selected drill pad locations, described in Section 4.0, will be subjected to a geophysical investigation to determine if a mud pit exists and, if so, will be sampled for chemical constituents associated with mud pits.

A recent, more rigorous review of historical documentation has identified at least three suspected mud pits at the Gnome-Coach Site; however, exact locations in relation to the drill holes are not available. One pit was described in a geologic report where "a circular crack 30 to $40 \mathrm{ft}$ in diameter and ranging in width from a hairline to one-quarter inch that was observed after the Gnome test, about 25 feet south of USGS-1 well. This crack appears to have formed over the perimeter of the filled-in mud pit used when the well was drilled" (USGS, 1962). A second pit was identified in a photo titled Figure 30, "Drilling LRL hole No. 1," from the Project Manager's Report (AEC, 1962). An excavated pit adjacent to the drill rig can be detected in this photo figure. It is assumed this pit was used as a mud pit for drilling operations. Based on photo interpretation, the depth of the mud pit appears to be $5 \mathrm{ft}$ at a minimum. The third pit was identified in a historic newspaper photo about Project Gnome in the Carlsbad Current Argus (8-27-1958). The photo depicts a suspected mud pit adjacent to AEC hole No. 1.

A complication to identifying the suspected mud pit at the USGS-1 well is a water storage pit built south of the well and used for clean water storage during the 1979 slurry operation. The dimensions of the water pit were approximately $75 \times 100 \times 6 \mathrm{ft}$ (capacity of 45,000 cubic feet), which essentially covers the areal extent of the disturbed area in the assumed location of the mud pit. The water storage 
pit was lined with 20-mil polyvinyl chloride (PVC), which was reportedly left in place (DOE/NV, 1979). This information is consistent with current conditions at the site where large pieces of plastic were observed at and near the surface.

\subsubsection{LRL-7 and LRL-8 Drill Pads}

The LRL-7 hole was originally drilled as a cable hole into the Coach drift for the Project Coach experiment (DOE/NV, 1979). The well was subsequently used to slurry contaminated salt/soil into the Gnome cavity during the 1969 cleanup (DOE/NV, 1979). Hole LRL-7 was reopened during the 1977-1979 cleanup effort to support the slurry operations into the Gnome cavity. The support consisted of linking the Gnome cavity wells (SR-2A and DD-1) to LRL-7 with a water line and pump, which allowed contaminated water to recirculate between the two areas during the slurrying process (DOE/NV, 1979 and 1981). The well was left open at the completion of cleanup efforts as part of the LTHMP.

Hole LRL-8, drilled for Project Coach and located about $300 \mathrm{ft}$ southeast of the main shaft, was used for downhole disposal of contaminated slurried salt/soil during both cleanup efforts. An engineering drawing (Fenix \& Scisson, 1969) shows LRL-8 extending into the Coach drift where contaminated soil is depicted within the drift. The historical literature states that LRL-8 was open during the 1977-1979 cleanup, but no details were found to show if the hole was redrilled or left open during 1969 effort. Analytical results from the 1979 sampling programs under the heading "Study 32" have been identified as the area surrounding the LRL- 8 hole based on location coordinates. Hole LRL- 8 was reported as being plugged and abandoned during the 1977-1979 cleanup operations (DOE/NV, 1979).

\subsubsection{Drill Pad for Monitoring Wells USGS-4 and USGS-8}

In 1963, the USGS conducted a hydrologic tracer test in which Cs-137, tritium, I-131 and Sr-90 were injected into the Culebra aquifer at Well USGS-8 and pumped to Well USGS-4. This fluid purged from Well USGS-4 was reinjected in USGS-8. The soil surrounding the wells may have become contaminated from minor fluid spills during the reinjection phase of the tracer test. A potential for a mud pit at this drill pad has been identified based on historical documents. Both of these wells are sampled annually by EPA as part of the LTHMP. 


\subsection{Site Restoration Activities}

The Gnome-Coach Site underwent two major decontamination cleanup efforts and one area reconnaissance. These are described briefly in the following subsections. Appendix A summarizes and discusses the radiological survey and analytical results of these cleanup efforts.

\subsubsection{Initial Cleanup in 1968/1969}

The initial site cleanup and restoration activities were conducted between 1968 and 1969. The cleanup was undertaken following guidelines that specified removal of all contaminated material above 0.1 milliRoentgen per hour $(\mathrm{mR} / \mathrm{hr})$ beta plus gamma as measured by a 30-milligram per square centimeter $\left(\mathrm{mg} / \mathrm{cm}^{2}\right)$ Geiger Mueller portable survey instrument (Tappan and Lorenz, 1969). Cleanup activities were conducted at numerous locations within Gnome operational areas and included:

- Dismantling the metal liquid waste tank near ground zero after removing radioactive sludge from the bottom. The tank was then disposed of down the shaft. The sludge was placed in twenty-four 55-gallon drums and placed down the shaft.

- Pumping the liquid from the evaporation pond near ground zero into the Gnome cavity and disposing of the pit liner, which consisted of tar and asphalt covered plastic, down the shaft. The perimeter sludge was bulldozed and dumped into the shaft when monitoring revealed radioactive contamination.

- Excavating the contaminated waste dump to determine extent of buried radioactive material, then segregating the metal and other large items from soil and salt to facilitate disposal operations. The contaminated materials were either dumped into the shaft or slurried and placed in drill holes leading to the drift and cavity. All excavated areas were backfilled, recontoured, and monitored for radioactive contamination.

- Characterizing the salt muckpile. The muckpile consisted of approximately 27,000 cubic yard $\left(\mathrm{yd}^{3}\right)$ of salt, soil, and muck with thin lenses of radiological contamination at various depths. The salt muckpile was left in place.

- Disposal of all other contaminated salt/soil (approximately 4,800 $\mathrm{yd}^{3}$ ) and contaminated metal and scrap materials on the site by lowering into and releasing in the shaft.

- Decontaminating all radiologically contaminated, salvageable equipment before transporting it off site as well as removal of all uncontaminated project-related surface buildings, facilities and equipment. Perform general housekeeping type activities across entire site. 
- Plugging all AEC wells and drill holes and the capping and padlocking of all USGS wells retained for groundwater monitoring (i.e., USGS-1, USGS-4, USGS-8).

\subsubsection{Area Reconnaissance}

In 1972, a site reconnaissance and survey was conducted with the express purpose of verifying reported observations that the muckpile was eroding away and its exact condition was not known. A site inspection was conducted in April 1972 to primarily sample the surface of the eroding muckpile; however, during this visit, additional areas were surveyed and found to have radiologically elevated readings from $5 \mathrm{millirad}$ per hour ( $\mathrm{mrad} / \mathrm{hr}$ ) up to $45 \mathrm{mrad} / \mathrm{hr}$ on fiberglass at the salvage yard (REECo, 1973). Additionally, small quantities of unexploded dynamite and blasting caps were found to have weathered to the surface of the muckpile, and were subsequently collected and disposed of by burning on site.

It was concluded from this 1972 reconnaissance that a more extensive survey with additional sampling was necessary to reevaluate the Gnome-Coach Site (REECo, 1973). During a period between 1973 to 1977, additional surveys were made to reassess public safety and environmental conditions on and near the Gnome Area (DRI, 1988). These additional surveys led to the initiation of work on the second D\&D effort of the Project Gnome Site in July of 1977.

\subsubsection{Second Cleanup in 1977 to 1979}

Between the years of 1977 to 1979 , the second cleanup effort was undertaken following guidelines that specified decontamination to levels below $2 \times 10^{-5}$ microcuries per gram $(\mu \mathrm{Ci} / \mathrm{g})(20$ picocuries per gram $[\mathrm{pCi} / \mathrm{g}]$ ) for beta-gamma emitters in soil averaged over 0.25 hectare (ha) and 30,000 picocuries per milliliter ( $\mathrm{pCi} / \mathrm{mL}$ ) of tritium in soil moisture (DOE/NV, 1981). Appendix A provides additional detail of the activities completed during this cleanup effort and an evaluation of the radiological data that will be used as a guide for characterization efforts during this investigation.

The cleanup effort was conducted in a three-phase approach, with the following general objectives:

- August 1977 to September 1978

- Phase I - Conducted aerial and ground radiological surveys, established radiological decontamination criteria, and developed an operational plan for D\&D activities based upon the results of the surveys. 
- $\quad$ March 1979 to September 1979

- Phase II - Cleaned out existing wells and made other preparations for the D\&D work.

- Phase III - Executed the operational plan for the cleanup and disposal of contaminated materials in accordance with the approved decontamination criteria.

The Phase I radiological survey results indicated Cs-137 is the primary beta-gamma emitter. The decontamination criteria were applied as if all gamma contamination was Cs-137 (DOE/NV, 1981). The only other beta-emitting contamination is tritium. The cleanup and restoration activities completed in 1979 included:

- Preparing the site for disposal of contaminated salt and soil into the Gnome cavity and the drift complex. This included rehabilitation and installation of a pump at Well USGS 1 for an operational water supply and the excavation of a water storage reservoir; clean out and opening of the Gnome reentry holes SR-2A and LRL-7; establishment of a decontamination holding area and a clean holding area; fabrication and installation of a tritium effluent filter system at LRL-7; installation of a crushing plant with slurry and mud tanks on the north side of the salt muckpile; and drilling a new hole, DD-1, into the cavity for the downhole disposal system operation (DOE/NV, 1981).

- Scraping and excavating contaminated soil and salt in operational areas identified by the Phase I surveys, and depositing at the salt muckpile for eventual disposal into the cavity and drifts through the reopened holes SR-2A, LRL-7, and DD-1 until capacity was reached.

- Removal of all excess nonradiological scrap metal and material located on the site by packaging into drums and wooden boxes and transporting to the NTS for disposal.

- Burial of approximately $6,000 \mathrm{yd}^{3}$ of clean salt from the salt muckpile in a trench located on site near the old laundry/lab area. The clean salt was covered with a thin layer of crushed concrete and vinyl, and the trench filled with $6 \mathrm{ft}$ of clean soil.

- Removal of miscellaneous concrete pads located throughout the site and recontouring all surface areas disturbed during the contaminated soil and salt removal operations (when necessary, fill was taken from clean areas on the Gnome Site).

- Plugging all reentry holes (i.e., SR-2A, SR-3A, LRL-8) except LRL-7, USGS-1, and DD-1 which were prepared to remain open as monitoring wells for the LTHMP.

- Conducting extensive survey and sampling activities after cleanup operations were completed to verify that soil was below the established radiological release criteria.

- Demobilization of all equipment and facilities associated with D\&D activities. 
Over the duration of the downhole disposal operations, the Gnome cavity was filled to capacity. It was estimated that approximately $35,750 \mathrm{yd}^{3}$ of contaminated soil and salt had been slurried into the Gnome cavity for disposal. At the end of the operations, contaminated soil, salt, and debris still remained. It was decided that this excess contaminated material would be packaged and shipped to the NTS for disposal as low-level radioactive waste (LLW). A total of 242 drums $(73,972 \mathrm{lbs})$ and 14 boxes $(50,200 \mathrm{lbs})$ were transported to the NTS. The total radiological content of this material was $2.67 \times 10^{2}$ curies $(\mathrm{Ci})$ (based on Cs-137).

The following structures remained at the site at the completion of the 1977-1979 Gnome-Coach Site decommissioning and restoration activities:

- Open monitoring wells DD-1, LRL-7, USGS-1, USGS-4, and USGS-8 as part of the LTHMP.

- A concrete and bronze historical monument with two bronze plates and inscribed wording on historical and restrictive information.

- The shaft concrete cover, the warehouse pad, and two concrete pads located south of shaft cover.

- Caliche-stabilized drill pads and roads that were not recontoured to original grade.

There was no restoration effort on any of the subsurface facilities (i.e., cavity, drifts, or tracer test wells). Limited access to subsurface facilities are through four of the five on-site monitoring wells sampled in the LTHMP, namely LRL-7, DD-1, USGS-4, and USGS-8. All four wells are radiologically contaminated. The fifth well, USGS-1, is not radiologically contaminated and is currently used as a livestock water supply well for local ranchers.

\subsection{Current Conditions at the Gnome-Coach Site}

A site visit was conducted in June 1993 and again in June 2000 by project personnel. The only notable change between the visits was the lack of hydrocarbon staining at Well USGS-1 and the growth of vegetation. All of the structures listed in the above section remain on site, with the addition of two water storage tanks and a watering trough associated with ranching activities at the site and an electric power line terminus and meter at Well USGS-1. Miscellaneous debris mostly in the form of cables, wood stakes, and small metal pieces remain in many areas but generally do not pose any hazard. The general locations of former operational areas could be identified by comparing historical 
photographs with the area and recognizing changes in vegetation and soil properties. Boundaries of known backfilled excavations (i.e., CWD) and any existing mud pits are indistinguishable on the surface because of recontouring after the 1979 cleanup effort. Some salt muck still remains near the shaft area and is easily distinguished by the lack of vegetation. General locations of drill holes that were plugged and abandoned below ground surface can usually be identified by the presence of a small area of crushed concrete on the surface of the caliche-stabilized drill pad associated with the hole. These pads are in relatively good condition with minimal vegetation growth compared to unstabilized or undisturbed areas.

Upon inspection of the drill hole known as SRI-10, which is enclosed by a barbed-wire fence, it appears the hole may not have been plugged and abandoned as stated in historical documents. The well head is above ground, capped, and enclosed in a square metal vault.

\subsection{Previous Investigations}

This section presents and briefly describes previous investigations of the surface soils, surface background radiological conditions both at and surrounding the site, and subsurface and groundwater studies.

\subsubsection{Surface Investigations}

An account of historical activities and previous investigations of the Gnome-Coach Site are listed on Table 2-1. After site restoration activities were completed in 1979, two other limited radiological surveys were conducted at the Gnome-Coach Site (see Appendix A for details). In 1988, a Comprehensive Environmental Response Compensation and Liability Act (CERCLA) evaluation of the Gnome-Coach Site determined the site to be of low risk (DRI, 1988). The site did not score high enough to be registered on the National Priority List. In 1993, in support of the National Environmental Policy Act (NEPA) process, DOE conducted a floodplains and wetlands survey, sensitive species survey, and a Class III cultural resources survey to determine potentially sensitive areas in advance of conducting intrusive investigative work. The potential for adverse impacts resulting from the proposed investigation at the Gnome-Coach Site to sensitive species, wetlands, or cultural resources is low (DOE/NV, 1993a, b, d). 
Table 2-1

Historical Activities and Previous Investigations

\begin{tabular}{|c|c|}
\hline Date & Description of Activity \\
\hline 1958 to 1961 & Project Gnome pretest activities were conducted (AEC, 1962). \\
\hline December 10, 1961 & Gnome test (AEC, 1962). \\
\hline $\begin{array}{l}\text { December } 1961 \text { to } \\
\text { June } 1962\end{array}$ & $\begin{array}{l}\text { Posttest drill-back activities (drilling sample recovery holes into the cavity, excavation of drifts and crosscut } \\
\text { alcoves, connecting shaft to cavity) were conducted. Activities brought contaminated material (salt muck) } \\
\text { to the surface (AEC, 1969). }\end{array}$ \\
\hline June 1962 to July 1963 & $\begin{array}{l}\text { Construction for Project Coach commenced; included rehabilitation of shaft, construction of drift to Coach } \\
\text { ground zero room, drilling of four holes (AEC, 1969). }\end{array}$ \\
\hline 1963 & USGS conducted tracer test in wells USGS-4 and -8 (Beetem and Angelo, 1964). \\
\hline September 1963 & Project Coach canceled and Gnome-Coach Site placed on "Caretaker Status" (AEC, 1969). \\
\hline April 1964 & Gnome-Coach Site placed on a "Minimal Standby Status" under a caretaker (AEC, 1969). \\
\hline November 1967 & Authorization given to proceed with deactivation and site disposal at Gnome-Coach (AEC, 1969). \\
\hline 1968-1969 & $\begin{array}{l}\text { Initial site cleanup conducted and included: decommissioning, plug/abandon wells, and restoration } \\
\text { activities (Tappan and Lorenz, 1969). Drilling exclusion boundary is set for all of Section 34, T23S, R30E, } \\
\text { to depth of 1,500 ft. All holes plugged except USGS-1, USGS-4, and USGS-8 (AEC, 1969). }\end{array}$ \\
\hline 1972 to 1977 & $\begin{array}{l}\text { Site reconnaissance of Gnome-Coach Site indicated contaminated debris had been exposed through } \\
\text { weathering (REECo, 1973). From } 1973 \text { to 1977, surveys were conducted to reassess public safety and } \\
\text { environmental conditions on and near the site. }\end{array}$ \\
\hline 1977 & DOE/NV initiated work on a plan for the second cleanup of the Gnome-Coach Site. \\
\hline 1977-1978 & Phase I of site decommissioning was conducted (DOE/NV, 1978). \\
\hline 1979 & $\begin{array}{l}\text { Phase II and III of site decommissioning conducted; included drilling new Well DD-1 into cavity, reentering } \\
\text { LRL-7, LRL-8, and SR-2A for downhole disposal of contaminated materials (DOE/NV, 1981). }\end{array}$ \\
\hline 1980 to Present & EPA conducts annual Long-Term Hydrological Monitoring Program (DOE/NV, 1982; EPA, 1999a). \\
\hline April 1988 & $\begin{array}{l}\text { A CERCLA preliminary assessment was conducted to determine CERCLA hazard ranking. The Hazard } \\
\text { Ranking System score was not high enough for the site to be registered on the National Priority List } \\
\text { (DRI, 1988). }\end{array}$ \\
\hline June 1993 & $\begin{array}{l}\text { DOE conducted a Class III Cultural resources survey, a floodplains and wetlands survey, and a sensitive } \\
\text { species survey (DOE/NV, 1993a, b, d). }\end{array}$ \\
\hline 1992 to 1995 & $\begin{array}{l}\text { The EPA and EEG conducted independent survey/sampling projects at Gnome-Coach and detected } \\
\text { elevated areas of radioactivity above background at isolated locations within the site. }\end{array}$ \\
\hline May 1998 & Preliminary Risk Assessment submitted to the State of New Mexico by the DOE (SNL, 1998). \\
\hline
\end{tabular}




\subsubsection{Radionuclide Background Investigations}

A site radiological background area is defined as an area that has similar physical, chemical, radiological, and biological characteristics as the site area being investigated, but has not been contaminated by site activities. A background area is a nonimpacted area from which representative background measurements are performed for comparison with measurements performed in impacted survey units at the site being investigated.

The following radionuclide contaminants have been detected or are likely to be present in the surface soil at the Gnome-Coach Site: Cs-137, Sr-90, tritium, Americium-241 (Am-241), and plutonium-239 and -240 (Pu-239/240).

Cesium-137 and Sr-90 are present in undisturbed background surface soil as a result of global fallout from nuclear weapon tests. Tritium is present in undisturbed background surface soil because it is created naturally by cosmic ray interactions in the atmosphere, is released as a vapor from nuclear power plants, and as a result of the global fallout from nuclear weapon tests. However, it is rarely detected in soil moisture because the tritium concentration is too low. Plutonium-239/240 and Am-241 are present in undisturbed background surface soil as a result of the global fallout from nuclear weapon tests.

The concentrations of these nuclides in soil at the Gnome-Coach Site, at the nearby Waste Isolation Pilot Plant (WIPP), in the vicinity of the WIPP site, and at distant offsite background locations are described below. Background levels will be established based on the data reported in the following publications:

- U.S. Department of Energy, Nevada Operations Office. 1981. Gnome Site Decontamination and Decommissioning Project, Radiation Decontamination Clearance Report, March 28, 1979 - September 23, 1979, DOE/NV/00410-59. Las Vegas, NV.

- U.S. Department of Energy. 2000. Waste Isolation Pilot Plant 1999 Site Environmental Report. DOE/WIPP 00-2225, September 2000. Carlsbad, NM.

- Carlsbad Environmental Monitoring \& Research Center. 2000. 1999 Report Carlsbad Environmental Monitoring and Research Center, February 1, 2000. Carlsbad, NM.

- McArthur, R., and F. Miller. 1989. Offsite Radiation Exposure Review Project Phase II Soils Program. Las Vegas, NV: Desert Research Institute. 


\subsubsection{Radionuclide Concentrations in Soil at the Gnome-Coach Site}

A soil sampling program was conducted between 1977 and 1979 during the decommissioning of the site. Surface soil samples were taken from six nonoperational areas located along the perimeter of the Gnome-Coach Site. The samples were collected to a depth of two inches, with all samples analyzed for Cs-137 and a limited number analyzed for tritium (DOE/NV, 1981).

The Cs-137 concentrations in the background areas at the Gnome-Coach Site ranged from 0.16 to $1.6 \mathrm{pCi} / \mathrm{g}$, with a mean value of $0.623 \mathrm{pCi} / \mathrm{g}$. The tritium concentration in soil moisture samples taken from the background areas of the Gnome-Coach Site has a bimodal distribution, ranged from $37 \mathrm{pCi} / \mathrm{mL}$ to $2,060 \mathrm{pCi} / \mathrm{mL}$, with a mean value of $1,061 \mathrm{pCi} / \mathrm{mL}$. This is about 10,000 to 600,000 times greater than that found in undisturbed background locations. These tritium concentrations are well above naturally occurring levels and may be attributed to both the venting cloud following detonation, and also the systematic release of tritium-contaminated gas from the test cavity during drill-back operations and disposal operations. Historical records indicate that gas was released from reentry holes SR-2A and SR-3A for several weeks during drill-back operations in 1961-1962; additionally, gas was again released during the disposal operation in 1979 through SR-2A and DD-1. These gas releases would account for the presence of higher levels of tritium in areas other than the fallout plume area.

\subsubsection{Radionuclide Concentrations in Soil at the WIPP}

The DOE and its subcontractors perform radiological environmental monitoring at the WIPP site in Carlsbad, NM. As a part of this environmental monitoring program, soil samples are collected on an annual basis at the six locations shown in Figure 2-5 (DOE, 2000). In 1999, samples were collected from each location in three incremental vertical profiles: $0-0.8$ in., 0.8-2.0 in., and 2.0-4.0 in.

Gamma spectroscopy, Sr-90, Pu-239/240, and Am-241 analyses were performed. The results of the top two soil sample intervals ( $0-0.8 \mathrm{in}$. and 0.8-2.0 in.) were averaged to obtain comparable results to those collected at the Gnome-Coach Site, namely 0.0-2.0 in. surface soil samples.

The Cs-137 concentrations on site at WIPP ranged from 0.026 to $0.315 \mathrm{pCi} / \mathrm{g}$, with a mean value of $0.106 \mathrm{pCi} / \mathrm{g}$. The $\mathrm{Sr}-90$ concentrations on site at WIPP ranged from 0.16 to $0.365 \mathrm{pCi} / \mathrm{g}$, with a mean 


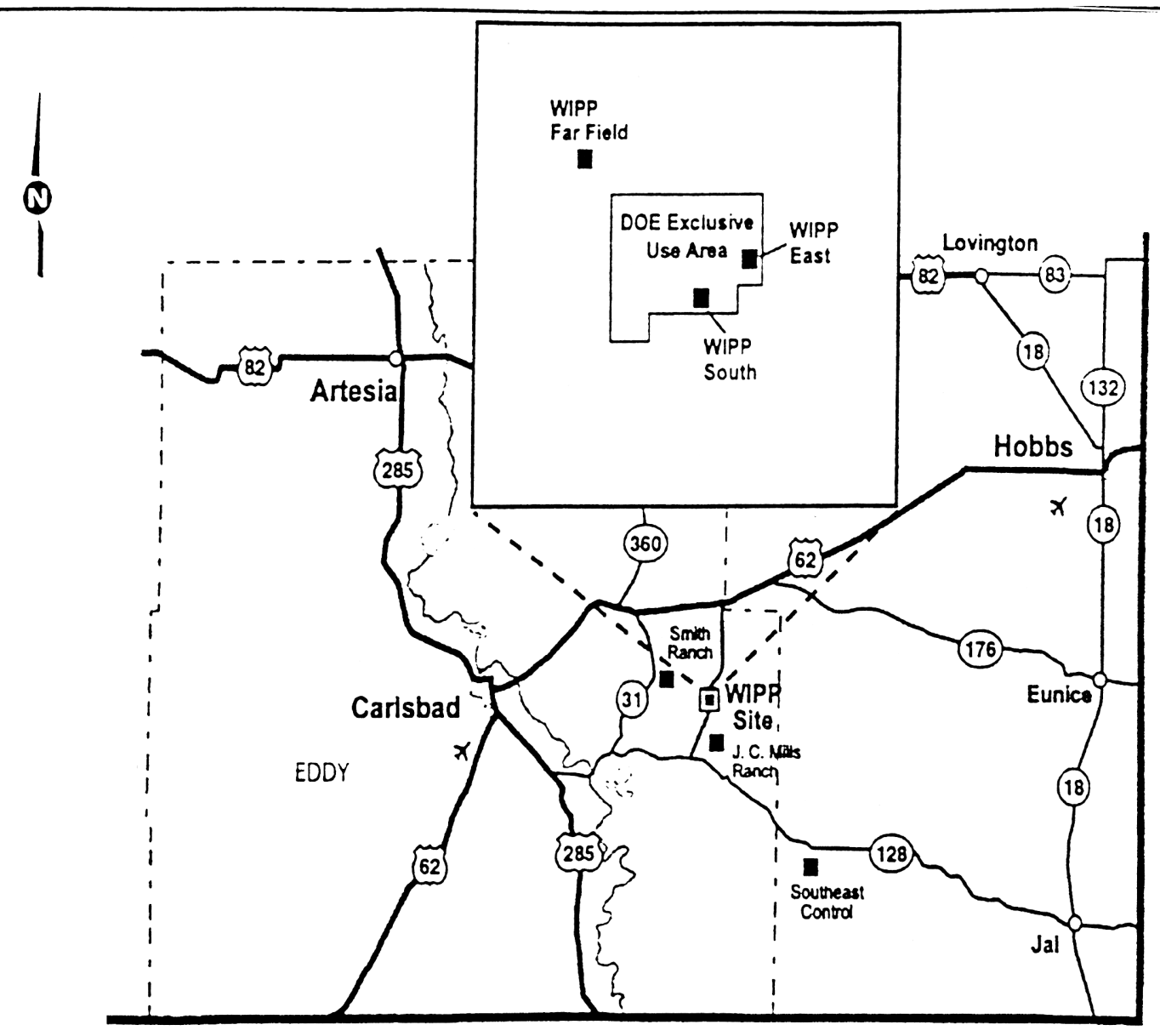

V Vopetation'Soll Sampling Shes(6)

Source: DOE, 2000

Figure 2-5

Sampling Locations at WIPP

value of $0.283 \mathrm{pCi} / \mathrm{g}$. The $\mathrm{Pu}-239 / 240$ concentrations on site at WIPP ranged from 0.002 to $0.038 \mathrm{pCi} / \mathrm{g}$. The only detectable Am-241 concentrations were 0.01 and $0.007 \mathrm{pCi} / \mathrm{g}$.

\subsubsection{Radionuclide Concentrations in Soil in the Vicinity of WIPP}

The scientific staff at the Carlsbad Environmental Monitoring \& Research Center (CEMRC), a division of the Waste Management Education and Research Consortium in the College of Engineering at New Mexico State University, developed and implemented an environmental 
monitoring program in the vicinity of the WIPP. Results from this program are accessible to the public and are utilized here in evaluating background values.

In 1998, soil samples were collected by CEMRC staff at two distinct sampling sites (CEMRC, 2000). The first site is referred to as Near Field which includes the set of sampling locations within the WIPP site boundary. The second site is referred to as Cactus Flats which includes the set of sampling locations on a parcel of land located approximately ten miles southeast of the WIPP facility (Figure 2-6). At these two sampling sites, a grid was established with sixteen soil sampling locations. Three randomly selected sampling spots were located within a $165-\mathrm{ft}$ radius of the sixteen gridded sampling locations resulting in a total of 48 samples at each site. At each sampling spot, soil was collected to a depth of approximately $1 \mathrm{in}$. The samples were then sent to the CEMRC for gamma spectroscopy and isotopic plutonium analysis.

The CERMC purports that the radionuclide concentration in samples taken from Cactus Flats and Near Field at WIPP imply that significant levels of variability in the radionuclide concentration in soil at background levels can occur in areas having relatively similar soil texture and the same climatology (CERMC, 2000). The Cs-137 concentrations in the Near Field ranged from 0.008 to $0.16 \mathrm{pCi} / \mathrm{g}$, with a mean value of $0.084 \mathrm{pCi} / \mathrm{g}$; in Cactus Flats, Cs-137 ranged from 0.019 to $0.405 \mathrm{pCi} / \mathrm{g}$, with a mean value of $0.17 \mathrm{pCi} / \mathrm{g}$. The $\mathrm{Pu}-239 / 240$ concentrations in the Near Field ranged from 0.0004 to $0.005 \mathrm{pCi} / \mathrm{g}$, with a mean value of $0.003 \mathrm{pCi} / \mathrm{g}$; in Cactus Flats, $\mathrm{Pu}-239 / 240$ ranged from 0.0007 to $0.014 \mathrm{pCi} / \mathrm{g}$, with a mean value of $0.006 \mathrm{pCi} / \mathrm{g}$. The Am-241 concentrations in the Near Field ranged from 0.0004 to $0.004 \mathrm{pCi} / \mathrm{g}$, with a mean value of $0.001 \mathrm{pCi} / \mathrm{g}$; in Cactus Flats, Am-241 ranged from 0.0006 to $0.0007 \mathrm{pCi} / \mathrm{g}$, with a mean value of $0.002 \mathrm{pCi} / \mathrm{g}$.

\subsubsection{Radionuclide Concentrations in Soil at Distant Locations within New Mexico}

In 1982-1987, the DOE collected 1,800 soil samples at more than 100 communities in the western United States as a part of the DOE Off-Site Radiation Exposure Review Project (ORERP). The ORERP was designed to estimate the dose from fallout from the nuclear tests conducted at the NTS. As part of the ORERP project, 248 surface soil samples were taken from 62 undisturbed background locations in New Mexico. Table 2-2 lists the locations where the surface soil samples were taken from in New Mexico and the Cs-137 concentration in the soil samples. 


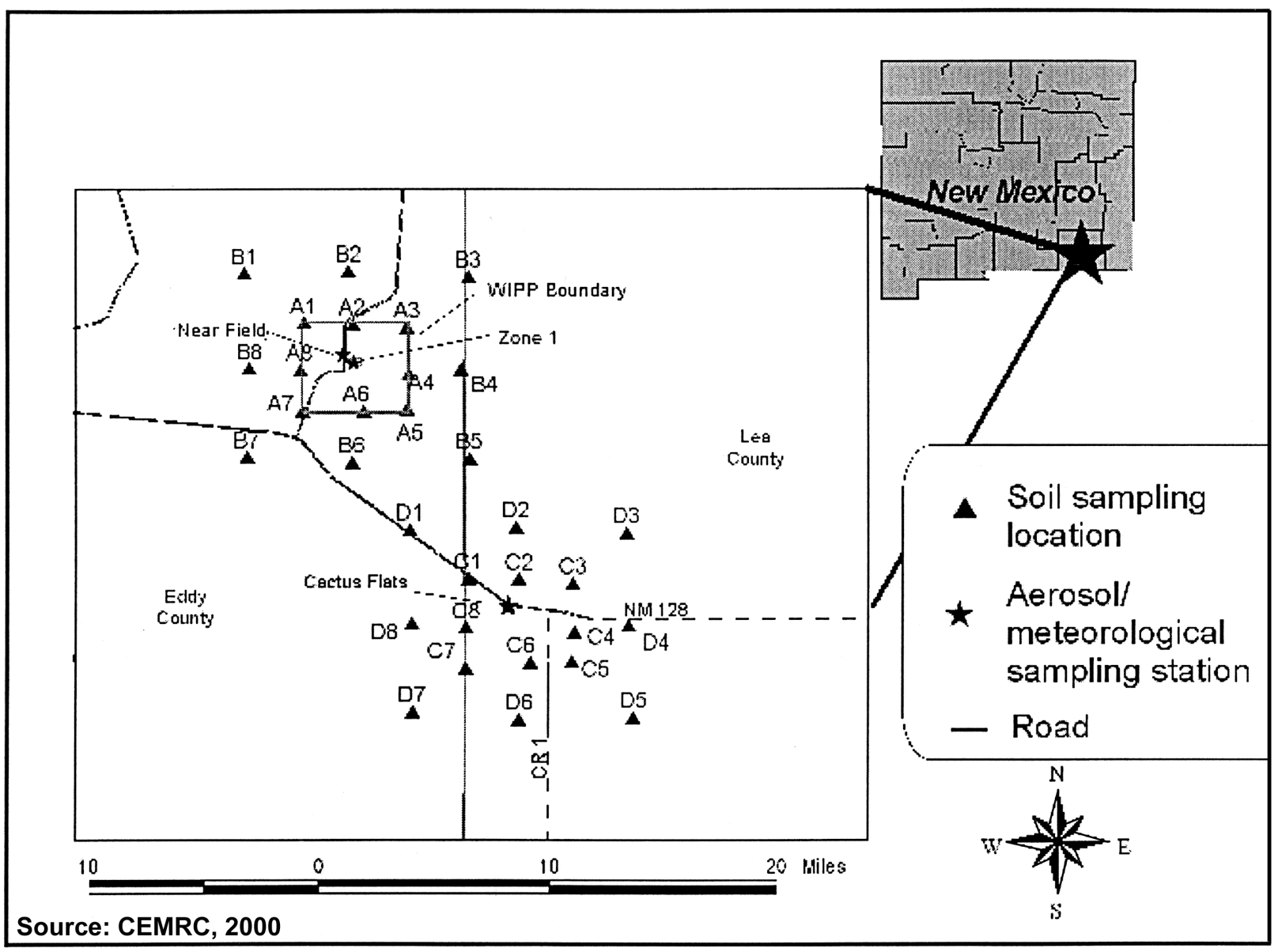

Figure 2-6

Sampling Locations in the Vicinity of the WIPP

A Wilcoxon Rank Sum test was performed to determine if the Cs-137 concentration in the Gnome-Coach background soil samples is equal to or greater than the Cs-137 concentration in the ORERP soil samples taken from undisturbed background locations in New Mexico. The Wilcoxon Rank Sum test demonstrate that the Cs-137 concentration in the Gnome-Coach soil samples is equal to the Cs-137 concentration in the ORERP soil samples (Adams, 2001). 
Table 2-2

Sample Results from Distant Locations within New Mexico

\begin{tabular}{|c|c|c|}
\hline Location & $\begin{array}{l}\text { Cs-137 Concentration } \\
(\mathrm{pCi} / \mathrm{g})\end{array}$ & $\begin{array}{l}\text { Pu-239/240 Concentration } \\
(\mathrm{pCi} / \mathrm{g})\end{array}$ \\
\hline Albuquerque & $0.175-1.277^{\mathrm{a}}$ & $0.0034-0.1899^{a}$ \\
\hline Belen & 0.427 & 0.008946 \\
\hline Carlsbad & 0.404 & - \\
\hline Chama & 1.243 & .01682 \\
\hline Cimarron & 0.453 & 0.009032 \\
\hline Cortez & 0.401 & 0.01818 \\
\hline Estancia & 0.355 & - \\
\hline Farmington & $0.341-0.802^{\mathrm{a}}$ & $0.007473-0.0105^{\mathrm{a}}$ \\
\hline Gallop & 1.095 & .01566 \\
\hline Las Cruces & 0.252 & 0.0047 \\
\hline Moriarty & 1.326 & .01204 \\
\hline Portales & 0.394 & 0.008432 \\
\hline Raton & 1.875 & 0.01685 \\
\hline Roswell & 0.526 & 0.0047 \\
\hline Santa Fe & $0.465-0.843^{\mathrm{a}}$ & $0.007589-0.009302^{\mathrm{a}}$ \\
\hline Silver City & 0.391 & 0.0086 \\
\hline Socorro & $0.295-0.355^{\mathrm{a}}$ & 0.0082 \\
\hline Tocumcari & 0.394 & 0.008432 \\
\hline Geometric Mean & 0.52 & 0.01539 \\
\hline
\end{tabular}

${ }^{a}$ The listed values represent the range of the maximum concentrations in the surface soil samples taken in the community.

\subsubsection{Summary of the Background Radionuclide Concentrations in Soil for the Gnome-Coach Site}

A review of historical information on radionuclide concentrations in soil at background locations has been performed to establish baseline levels for measurements made during site characterization. It has been shown that Cs-137 concentrations in soil at the boundary of the Gnome-Coach Site are consistent with global fallout levels seen at other background locations within New Mexico. These 
values will be compared with the results from on-site background measurements that will be performed during the field investigation and also referred to when specifying the needed analytical sensitivities for the associated radiochemical measurements. Table 2-3 summarizes the range of background radionuclide concentrations that exist at and around the Gnome-Coach Site. This summary encompasses measurements made at the following background locations: Gnome-Coach Site, WIPP on site, WIPP vicinity (Near Field and Cactus Flats), and distant locations within New Mexico.

Table 2-3

Summary Table for Background Radionuclide Levels

\begin{tabular}{||c|c|c|c|c|c||}
\hline Sampling Event & $\begin{array}{c}\text { Cs-137 } \\
\text { Concentration } \\
(\mathbf{p C i} / \mathbf{g})\end{array}$ & $\begin{array}{c}\text { Sr-90 } \\
\text { Concentration } \\
(\mathbf{p C i} / \mathbf{g})\end{array}$ & $\begin{array}{c}\text { Pu-239/240 } \\
\text { Concentration } \\
(\mathbf{p C i} / \mathbf{g})\end{array}$ & $\begin{array}{c}\text { Am-241 } \\
\text { Concentration } \\
(\mathbf{p C i} / \mathbf{g})\end{array}$ & $\begin{array}{c}\text { Tritium } \\
\text { Concentration } \\
(\mathbf{p C i} / \mathbf{m L})\end{array}$ \\
\hline $\begin{array}{c}\text { Gnome-Coach } \\
\text { Site }\end{array}$ & $0.16-1.61$ & --- & -- & $37-2,060$ \\
\hline WIPP On Site & $0.053-0.315$ & $0.16-0.365$ & $0.002-0.038$ & $0.001-0.007$ & --- \\
\hline $\begin{array}{c}\text { WIPP Vicinity } \\
\text { Near Field }\end{array}$ & $0.008-0.16$ & --- & $0.0004-0.005$ & $0.0004-0.004$ & - \\
\hline $\begin{array}{c}\text { WIPP Vicinity } \\
\text { Cactus Flats }\end{array}$ & $0.019-0.405$ & --- & $0.0007-0.014$ & $0.0006-0.007$ & - \\
\hline $\begin{array}{c}\text { Distant } \\
\text { Locations }\end{array}$ & $0.175-1.277$ & --- & $0.0034-0.1889$ & -- & - \\
\hline
\end{tabular}

"-" Denotes no data collected

Tritium soil moisture concentrations at the boundary of the site are much higher than typical background concentrations and can be attributed to historical Gnome-Coach Site activities. The DOE Order 5400.5, Radiation Protection of the Public and Environment, states that guidelines for residual radioactive material in soil are derived from the basic dose limit by means of environmental pathway analysis using specific property data where available. Adapting guideline concentrations without consideration of background is conservative and will result in over estimating any additional dose to future land users and does not require tritium analysis of any background samples as part of this site characterization. 


\subsubsection{Subsurface Investigations}

Geologic and hydrologic data were collected in the vicinity of Gnome-Coach in support of the original Plowshare test. This included regional geologic studies (Cooper, 1960; Jones, 1960) and surface geologic studies (Vine, 1960), regional groundwater studies (Hale and Clebsch, 1959), and investigations into the chemical, physical, and seismic properties of salt (Robertson et al., 1958; Byerly et al., 1960). Site-specific investigations include detailed borehole reports (Cooper, 1961; Moore, 1958) and local groundwater investigations (Cooper, 1962a and b). Much of this work was later compiled into two comprehensive reports on the Gnome-Coach area geology (Gard, 1968) and hydrology (Cooper and Glanzman, 1971). Detailed studies of the geology (in the shaft and drifts) and hydrology at Gnome-Coach, and effects from the test are given by the U.S. Geological Survey (1962). Additional testing effects are described by Nathans (1965), Rawson (1963), Rawson et al., (1965), and Gard (1963).

The subsequent hydrologic tracer test is described in a series of technical letters (Beetem and Angelo, 1964; Bittinger and Beetem, 1964; Cooper, 1963), with the results published by Grove and Beetem (1971). An initial analysis of the subsurface hazard represented by the site is given by Gardner and Sigalove (1970). More recently, Desert Research Institute assessed radionuclide transport from the site (Earman et al., 1996), and performed two evaluations of transport related to the tracer test (Pohlmann and Andricevic, 1994; Pohll and Pohlmann, 1996). Through much of this time, the site has been monitored under the LTHMP (DOE/NV, 1982), with results reported annually by the EPA (e.g., EPA, 1992; EPA, 1999a). 


\subsection{Data Quality Objectives}

The DQO process is a strategic planning approach based on the scientific method that is used to prepare for a site characterization data collection activity (EPA, 1994b). Data Quality Objectives were used for the Gnome-Coach Site Characterization Work Plan to develop an effective scientific and resource-efficient data collection design.

The DQOs for the investigation of the Gnome-Coach Site are designed to ensure that data of sufficient quantity and quality are collected to establish the current site conditions. These data will be used to identify and evaluate if further action is required to achieve long-term closure of the site that is protective of human health and the environment.

The field investigation will be conducted to allow for either the modification or termination of characterization activities, when it is determined that sufficient data exists to support or refute the conceptual model. If, during the planned field investigation, the conceptual model is proven to be incorrect (i.e., the extent of contamination if greater than predicted), a contingency would be implemented to adjust the scope of the field investigation. For example, this contingency may include the modification of the radiological surveys to include areas outside the original study limits to fully identify the extent of contamination.

\subsection{Surface Conceptual Site Model}

A site-specific conceptual site model (CSM) for the Gnome-Coach Site is provided in Figure 3-1. This model is based on the assumption that land use will continue as open-range with ranchers and trespassers as the receptors. The CSM illustrates the relationships between the identified potential sources of contamination, the mechanism(s) for release and migration away from the potential source, the potential pathway(s) the contamination would follow once released, the exposure routes that potential contamination would travel to affect receptors, and the receptors that would be impacted by the potential contamination. 
Page 37 of 110

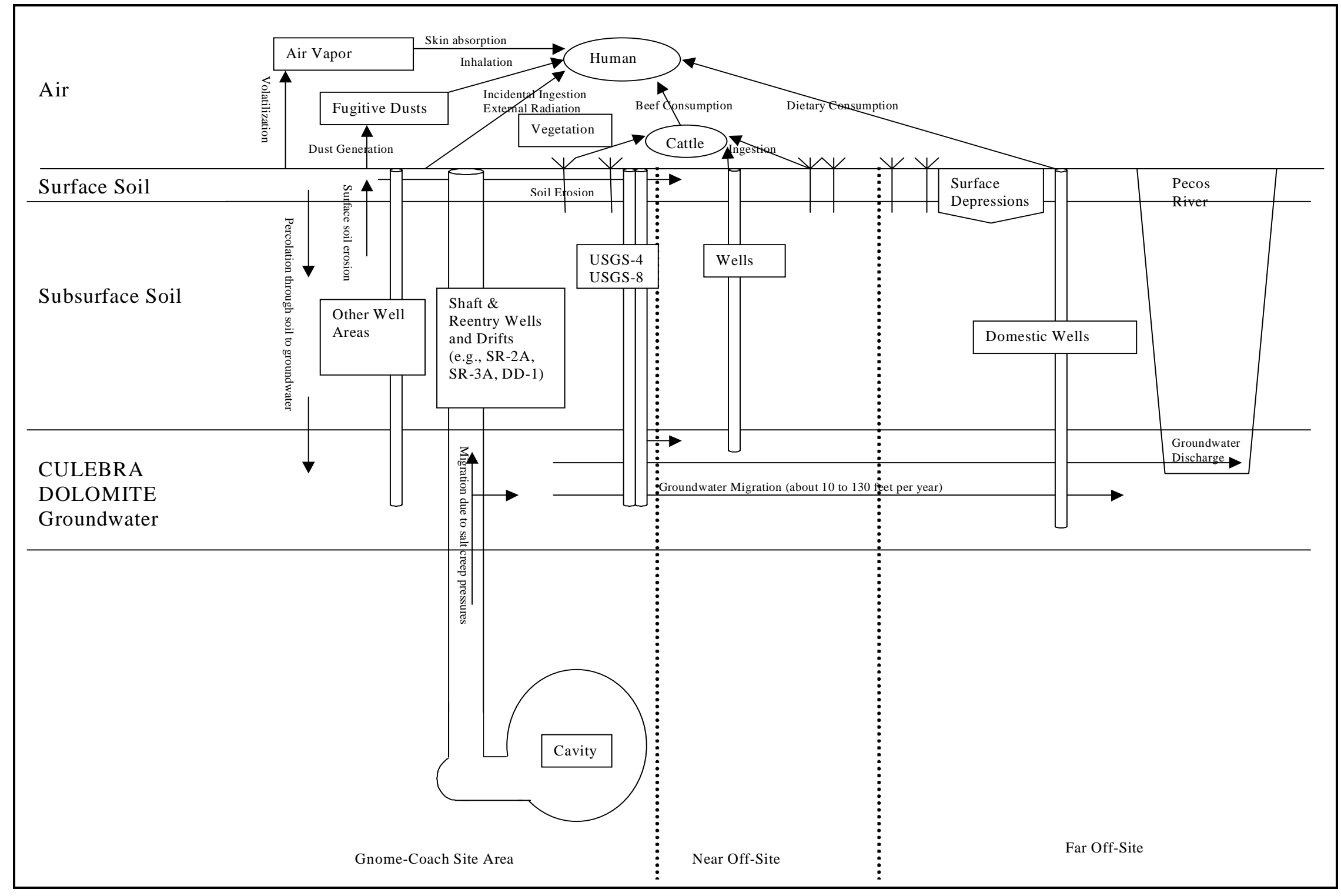

Figure 3-1

Conceptual Site Model 
Historical and potential sources of contamination in the surface or shallow subsurface include the operations associated with the following:

- Contaminated waste dump

- Salvage yard and storage areas

- Laundry/laboratory areas

- Posttest drilling operations at wells, drill pads, and potential mud pits

- Decontamination areas

- Former operational areas where there may have been releases and/or spills (e.g., fallout plume)

As required by the DQO process, a conceptual site model presumes that potential migration of contamination from these potential sources into the surface and shallow subsurface may occur at the site. The release mechanisms that would facilitate migration include the following:

- Percolation of precipitation through impacted soil and transport of potential contamination into shallow subsurface soil

- Contaminated soil transport via erosion, dispersion, and storm water runoff into surrounding surface soil

- Volatilization of volatile organic compounds (VOCs), semivolatile organic compounds (SVOCs), or tritium into the atmosphere

- Surface contaminants entering the atmosphere as fugitive dusts

- Uptake of contaminants by plants from surface and shallow subsurface soils

Potential exposure routes to humans or ecological receptors from contaminants in the surface or shallow subsurface include ingestion, inhalation, dermal contact, or external gamma radiation. Pathways include the following (with route specified):

- Contaminant uptake by plants or animals (ingestion)

- Contaminants in surface soil (ingestion, dermal, external exposure)

- Contaminants in fugitive dust (inhalation)

- Contaminant uptakes by humans through beef (ingestion)

These identified potential sources and release mechanisms for potential contaminant migration formulate the basis for the design of the characterization work plan. The data collected by this characterization program will be utilized to determine the extent of contamination and impact to 
potential receptors (human health and the environment) through the preparation of a dose/risk assessment. The dose/risk assessment, if required, will be conducted using the open-range land use scenario (with rancher and trespasser). A corrective action alternative analysis will be completed should the dose/risk assessment indicate there is an unacceptable risk to identified potential receptors. The DQO process for the surface is summarized in Table 3-1.

\subsubsection{Contaminants of Potential Concern for the Surface Investigation}

To determine if contamination exists, results of laboratory analysis for chemical contaminants of potential concern (COPCs) in soil will be compared to preliminary action levels (PALs). For the purposes of this investigation, the PALs will be the industrial risk-based preliminary remediation goals (PRGs) provided in the EPA Region IX Risk-Based Concentration Table (EPA, 1999b). Laboratory results above PALs indicate the presence of COPCs at levels that may require a risk assessment to determine if corrective actions are required. Results of laboratory analysis for radiological COPCs in soil will be compared to site-specific, dose-based screening levels. Comparisons of inorganic constituents will also be made to representative background conditions established through statistical analysis of sample results. If representative inorganic site characterization values from AOCs are shown through statistical analysis to be not significantly different from representative background values, then a risk assessment may not be warranted. If representative inorganic background values exceed the EPA Region IX PRGs, risk due solely to background values may be estimated independently for comparison to the risk posed by the actual detected or representative COPC concentrations; however, regulatory guidance state that the risk due solely to background constituent concentrations should not trigger corrective action (NMED, 2000a).

As specified in the New Mexico Environment Department, Hazardous Waste Bureau Position Paper, “Use of Total Petroleum Hydrocarbon (TPH) Test Results for Site Characterization," in the absence of other contaminants above risk-based cleanup levels, results for TPH may be used to guide potential cleanup (NMED, 2000b).

The NM QAPP (Appendix B), "Laboratory Chemical, Toxicity Characteristic Leaching Procedure, and Radiochemistry Analytical Requirements for New Mexico Sites," table covers both Method 5035 and Method 8260B for VOC analysis. Due to the remoteness of the site, planned work schedules, and required hold times for Method 5035, it is likely that if Method 5035 were used, a significant portion 
Table 3-1

\section{Summary of Data Quality Objectives for the Surface}

\begin{tabular}{|c|c|c|c|c|c|}
\hline $\begin{array}{c}\text { Step } 1 \\
\text { State the Problem }\end{array}$ & $\begin{array}{l}\text { Potential surface contamination at the } \\
\text { extent of potential contamination is ur }\end{array}$ & $\begin{array}{l}\text { nome-Coach Site may pose a threat to } \\
\text { own. Therefore, it is unknown if poten }\end{array}$ & $\begin{array}{l}\text { uman health and the environment } \\
\text { al contamination at the site poses }\end{array}$ & $\begin{array}{l}\text { The location of potential } \\
\text { hreat to human health a }\end{array}$ & $\begin{array}{l}\text { urces and the nature and } \\
\text { or the environment. }\end{array}$ \\
\hline $\begin{array}{c}\text { Step } 2 \\
\text { Identify the Decision }\end{array}$ & $\begin{array}{c}\text { Step } 3 \\
\text { Identify the Inputs to the } \\
\text { Decision }\end{array}$ & $\begin{array}{c}\text { Step } 4 \\
\text { Define the Study Boundaries }\end{array}$ & $\begin{array}{c}\text { Step } 5 \\
\text { Develop a Decision Rule }\end{array}$ & $\begin{array}{c}\text { Step } 6 \\
\text { Specify Limits on } \\
\text { Decision Errors }\end{array}$ & $\begin{array}{c}\text { Step } 7 \\
\text { Optimize the Design } \\
\text { for Obtaining Data }\end{array}$ \\
\hline $\begin{array}{l}\text { Determine the radiological and } \\
\text { chemical COPCs. }\end{array}$ & $\begin{array}{l}\text { Historical data and documentation, } \\
\text { process knowledge from } \\
\text { underground nuclear tests. COPCs: } \\
\text { VOCs, SVOCs, Metals, TPH, } \\
\text { radionuclides (specifically } \\
\text { cesium-137) }\end{array}$ & \multirow{7}{*}{$\begin{array}{l}\text { Areas of Concern (AOC) } \\
\text { Area surrounding Gnome-Coach } \\
\text { main shaft and Gnome ground zero, } \\
\text { salvage yard, CWD, Coach ground } \\
\text { zero, (LRL-7) area, USGS-1 area, } \\
\text { Trailer park, Control point, Wells } \\
\text { USGS-4 and } 8 \text { area, Fallout plume } \\
\text { area } \\
\text { Within AOCs: old and new laundry } \\
\text { sites, potential mud pits, } \\
\text { decontamination pad, operational } \\
\text { areas, storage areas, potential spill } \\
\text { areas, salt muck pile, evaporation } \\
\text { pond/liquid waste tank, gas station } \\
\text { Migration from AOC: surface and } \\
\text { shallow subsurface soils, surface } \\
\text { depressions, surface water } \\
\text { Collect background samples and } \\
\text { measurements. }\end{array}$} & \multirow{7}{*}{$\begin{array}{l}\text { Area-specific: } \\
\text { If no COPCs are detected, then } \\
\text { no action is required. } \\
\text { If COPCs are detected, then a } \\
\text { RA will be conducted. } \\
\text { If RA determines unacceptable } \\
\text { levels, then a corrective action } \\
\text { evaluation will be conducted. }\end{array}$} & \multirow{7}{*}{$\begin{array}{l}\text { Decision errors are } \\
\text { based on risk } \\
\text { assessment. } \\
\text { If data is insufficient to } \\
\text { make a decision, then } \\
\text { additional data will be } \\
\text { collected. }\end{array}$} & \multirow{7}{*}{$\begin{array}{l}\text { Develop work plan and } \\
\text { technical approach. }\end{array}$} \\
\hline Determine the PALs for COPCs. & $\begin{array}{l}\text { State and Federal Regulations, } \\
\text { technological limits, site-specific } \\
\text { dose-based levels }\end{array}$ & & & & \\
\hline $\begin{array}{l}\text { Determine the location of the } \\
\text { sources of potential } \\
\text { contamination. }\end{array}$ & $\begin{array}{l}\text { Historical data and documentation, } \\
\text { geophysical techniques }\end{array}$ & & & & \\
\hline $\begin{array}{l}\text { Determine if COPC } \\
\text { concentrations are above PALs. }\end{array}$ & $\begin{array}{l}\text { Results of field-screening and/or } \\
\text { laboratory data, statistical analysis, } \\
\text { background conditions }\end{array}$ & & & & \\
\hline $\begin{array}{l}\text { Determine the nature and extent } \\
\text { of potential contamination in } \\
\text { surface and shallow subsurface } \\
\text { soils. }\end{array}$ & $\begin{array}{l}\text { Results of field-screening and/or } \\
\text { laboratory data, soil properties, } \\
\text { mobility of COPCs }\end{array}$ & & & & \\
\hline $\begin{array}{l}\text { Determine if COPC } \\
\text { concentrations are within } \\
\text { acceptable dose/risk levels. }\end{array}$ & $\begin{array}{l}\text { Risk requirements, future land use } \\
\text { scenarios, dose/risk levels }\end{array}$ & & & & \\
\hline $\begin{array}{l}\text { Determine if a corrective action } \\
\text { is necessary. }\end{array}$ & $\begin{array}{l}\text { Results of dose/risk assessment } \\
\text { (RA) }\end{array}$ & & & & \\
\hline
\end{tabular}


of data would be qualified as estimated. Because estimated data is not usable for risk assessment purposes (DOE, 2000), Method 8260B will be used for this investigation.

All laboratory data for chemical COPCs will be evaluated for data quality according to "Contract Laboratory Program National Functional Guidelines for Inorganic Data Review (EPA, 1994b),” or “Contract Laboratory Program National Functional Guidelines for Organic Data Review (EPA, 1999c)," as appropriate. In addition, five percent of this data will be subjected to independent verification using the same guidelines. All laboratory data for radiochemistry analysis will be evaluated according to internal procedures.

The COPCs to be considered were determined based on an evaluation of site-specific historical documentation, previous sampling efforts performed at the Gnome-Coach Site, and process knowledge from other underground nuclear test areas.

A review of historical documentation identified solvents as the only potentially hazardous constituent used during decontamination and cleaning operations at the old and new laundry/lab and decontamination pad (AEC, 1962b). These areas will be investigated for chemical COPCs; however, because these areas also had radiological contamination and were subject to radiological cleanup efforts, it is assumed that most chemical constituents present were excavated and disposed of along with the radiological contaminants. Based on process knowledge of similar nuclear test areas, it is assumed the volume of solvents potentially released would have been small. In addition to radiological cleanup, the areal coverage and depth of the trench excavated for the burial of uncontaminated salt at the old laundry/lab facility would have removed any residual chemical contamination (see Section 2.2.10).

A gas station was reportedly used on site (AEC, 1962b) but reviews of additional historical records were unsuccessful at identifying the location of this facility; subsequently, it cannot be investigated. However, two additional areas (i.e., generator pad and drum storage area) have been identified as potentially requiring soil sampling for chemical constituents. Hydrocarbon-stained soil had been previously identified at the USGS-1 pad; although this staining was no longer evident during a year 2000 site visit, the area will be investigated. 
Standard drilling methods in practice during the time of Project Gnome-Coach suggest that mud pits would have been used for disposition of soil cuttings and drilling fluids; however, reviews of historical records and photographic documentation for pre- and posttest drilling operations have provided very limited information on the use and locations of mud pits at the Gnome-Coach Site. Historical photographs of the site show no conclusive evidence of mud pit construction; although, two historical photos show areas resembling mud pits adjacent to a drill rig, and for the purposes of this investigation, will be assumed mud pits. A review of historical records indicate that drilling fluids such as "mud gels," muds, and brackish or brine water were used at some holes. These same reviews also indicate that the cable-tool method was a common drilling technique for a majority of the wells constructed for the project (Cooper, 1962b and USGS, 1962). Normally, cable-tool methods do not utilize drilling mud. Existing documentation indicates all drilling/circulation fluids used during the cleanup drilling operations of 1977-1979 were contained in tanks rather than using mud pits. All fluids were then disposed of either downhole into the cavity or were contained and then transported to the NTS as low-level radioactive waste (DOE/NV, 1981). Fluid containment during these cleanup operations reduced the potential for radiological contamination of the surface. However, this does not preclude any drilling practices during the mine-back operations of 1962 or the cleanup effort of 1968-1969.

Due to the uncertainty regarding the existence of mud pits, geophysical investigations of the Gnome-Coach Site will be performed prior to characterization to identify disturbed ground in areas where mud pits would be potentially located. If geophysical data indicate anomalous areas indicative of mud pits, then those areas will be investigated under the assumption that the anomalies represent mud pits and may contain potentially hazardous and/or radioactive contamination. Investigation of mud pits will not be pursued if the geophysical data is negative.

The analytical results from previous sampling programs are used in this investigation to further refine the surface and shallow subsurface investigation strategy. A summary of the sampling activities, radioanalytical results, and survey results from previous sampling programs for the surface are presented in Appendix A. The radiological summary identifies AOCs that require additional soil data collection. Section 4.0 provides more detail on the strategies for this data collection. The radiological summary confirmed that the radiological COPCs are aged fission products, primarily Cs-137 and tritium. Detections of Am-241 and Pu-239/240 have been identified at isolated locations 
(EEG, 1995); therefore, a limited investigation will be conducted to establish the presence/absence of these nuclides and, if present, confirm these detections do not represent significant contamination. None of these historical sampling efforts included analysis for chemical constituents.

Furthermore, sample results from the 1977-1979 cleanup program were also used to define parameters for a preliminary human health radiological screening evaluation of the Gnome-Coach Site (Appendix C). The radiological screening evaluation confirmed that Cs-137 is the primary contributor to the calculated dose through external gamma exposure. Tritium has a minimal contribution to the total dose. The radiological screening evaluation also helped to further refine the surface and shallow subsurface investigation strategy by identifying AOCs that require additional soil data collection to confirm concentrations of Cs-137 are consistent with historical data. The screening evaluation was able to establish that radiologically contaminated shallow subsurface soils do not significantly contribute external dose due to soil attenuation.

The following list of COPCs for the surface and shallow subsurface was determined based on an evaluation of site-specific historical documentation regarding drilling methods and site operations, previous sampling efforts performed at the Gnome-Coach Site, and process knowledge from other underground nuclear test areas (additional COPCs may be analyzed for waste characterization purposes):

- $\quad \mathrm{TPH}$ (diesel- and gasoline-range)

- VOCs

- SVOCs

- Total Resource Conservation and Recover Act (RCRA) Metals

- Radionuclides/Fission products (primarily Cs-137)

\subsection{Subsurface Conceptual Site Model}

Nearly all of the contamination at the Gnome-Coach Site is associated with the underground nuclear test cavity. The Gnome and Coach drifts, shaft, and reentry holes are radiologically contaminated because of their communication with the Gnome test cavity and the downhole disposal of radiologically contaminated materials (which were originally mined or drilled out of the cavity) during the decontamination and cleanup efforts undertaken in 1968-1969 and again in 1977-1979. A tracer test performed by the USGS in 1963 left residual radioactive tracers (i.e., tritium, I-131, Sr-90, and Cs-137) in the Culebra Dolomite at and between the tracer test wells, USGS-4 and USGS-8. 
Sources of contamination in the subsurface include:

- Gnome test cavity, shaft, and drifts

- Wells (both open and abandoned) into the cavity and drifts, including the current monitoring wells DD-1 and LRL-7

- The tracer test subsurface area, including wells USGS-4, USGS-8, and the Culebra Dolomite between these wells

- Groundwater in the Culebra Dolomite downgradient from the cavity and tracer test areas

A site-specific CSM for the Gnome-Coach Site is provided in Figure 3-1. The two distinct subsurface contaminant sources are the Gnome underground workings and the tracer test in the Culebra Dolomite. The radioactive gases released to the land surface during the venting at the time of the Gnome test are considered a potential surface contaminant due to their present location, rather than a subsurface source. The possible pathways for potential migration from these sources include:

- Leakage of contaminated brine upward from the cavity through failed borehole or shaft seals

- Migration by groundwater flow through the Culebra Dolomite

During the construction of the Gnome shaft, the rocks were inspected by the USGS and water was not detected in any formation other than the Culebra Dolomite (Gardner and Sigalove, 1970). As a result, the Culebra is the only aquifer through which contaminate transport could occur. No release mechanism is known for the contaminants in the cavity, drifts, and shaft without assuming some type of system failure (e.g., well plug, shaft liner). A release mechanism is not required for the tracer test contaminants, as they were left in direct contact with groundwater.

The conceptual model for transport must include a hypothetical system failure to cause any release. The unsaturated, impermeable nature of bedded salt deposits results in the lack of a realistic release mechanism for the contaminants in the Gnome cavity, drifts, and shaft. The limited historical documentation on borehole and shaft sealing, and record of slurried subsurface disposal activities, creates the possibility of a release mechanism of salt creep in the cavity and drifts driving contaminated water upward to the Culebra Dolomite. This requires an unlikely scenario of a failed borehole or shaft seal, sufficient fluid to dissolve and transport contaminants, and the precise timing of a pressure build-up above hydraulic head in the Culebra aquifer prior to salt creep sealing the very 
pathway by which migration could occur. This scenario is described in more detail in Section 5.0. The conceptual model for transport of contamination once in the Culebra would be identical to that for the tracer test, involving groundwater flow through a fractured aquifer with diffusion into matrix blocks, sorption processes, and radioactive decay. Section 5.0 provides a more detailed description of this process.

Potential exposure would be through direct exposure to contaminated groundwater (i.e., dermal and ingestion routes, although the marginal water quality in the Culebra will require additional evaluation of the direct ingestion route), through uptake by plants or animals from contaminated water wells (i.e., ingestion route), and through contaminant migration to surface water and uptake of the surface water (i.e., ingestion and dermal routes).

These identified potential sources and release mechanisms for potential contaminant migration will formulate the basis for the design of the characterization work plan. Currently, there is no technology to remediate underground nuclear test cavities; therefore, the approach is to use existing data and analyses of sufficient quantity and quality to evaluate if current subsurface intrusion restrictions and monitoring need to be adjusted to be protective of human health and the environment. Although pump-and-treat technologies exist for remediation of contaminated groundwater such as the residual from the tracer test, they are not always cost-effective relative to natural remediation processes. Therefore, the approach identified in this plan is to evaluate flow and transport of the tracer constituents to determine the appropriate strategy for protection of human health and the environment. The DQO process for the subsurface is summarized in Table 3-2.

\subsubsection{Subsurface COPCs}

The COPCs for the tracer test are the radionuclides injected into the Culebra Dolomite at Well USGS-8 and pumped from Well USGS-4 (with subsequent reinjection in USGS-8) (Beetem and Angelo, 1964). The initial total inventory of radionuclides injected in the 1963 test and the calculated present day activity level for each radionuclide is given in Table 3-3.

The COPCs for the underground nuclear test come from four primary sources: radioisotopes placed in or near the device as part of an isotope production study, radioisotopes produced by neutron activation, radionuclides produced by fission of plutonium-239, and any nuclear fuel from the device 
Table 3-2

\section{Summary of Data Quality Objectives for the Gnome-Coach Subsurface}

\begin{tabular}{|c|c|c|c|c|c|}
\hline $\begin{array}{c}\text { Step } 1 \\
\text { State the Problem }\end{array}$ & $\begin{array}{l}\text { Radiological contamination in the suk } \\
\text { possible leakage into the overlying } C \\
\text { and extent of these contaminants mi } \\
\text { human health and/or the environmen }\end{array}$ & $\begin{array}{l}\text { face workings of the test cavity, shaft } \\
\text { bra aquifer. Radiological contaminati } \\
\text { ing in the Culebra is uncertain; theref }\end{array}$ & $\begin{array}{l}\text { d drift complex poses a potentia } \\
\text { rom the tracer test experiment re } \\
\text { it is uncertain if contamination }\end{array}$ & $\begin{array}{l}\text { reat to human health an } \\
\text { ins within the Culebra D } \\
\text { e Culebra aquifer poses }\end{array}$ & $\begin{array}{l}\text { the environment through } \\
\text { mite aquifer. The nature } \\
\text { resent or future threat to }\end{array}$ \\
\hline $\begin{array}{c}\text { Step } 2 \\
\text { Identify the Decision }\end{array}$ & $\begin{array}{c}\text { Step } 3 \\
\text { Identify the Inputs to the } \\
\text { Decision }\end{array}$ & $\begin{array}{c}\text { Step } 4 \\
\text { Define the Study Boundaries }\end{array}$ & $\begin{array}{c}\text { Step } 5 \\
\text { Develop a Decision Rule }\end{array}$ & $\begin{array}{c}\text { Step } 6 \\
\text { Specify Limits on } \\
\text { Decision Errors }\end{array}$ & $\begin{array}{l}\text { Step } 7 \\
\text { Optimize the Design } \\
\text { for Obtaining Data }\end{array}$ \\
\hline $\begin{array}{l}\text { Determine the radiological and } \\
\text { chemical COPCs. }\end{array}$ & $\begin{array}{l}\text { Historical data, process knowledge, } \\
\text { past modeling results, known } \\
\text { radiological decay processes }\end{array}$ & \multirow{8}{*}{$\begin{array}{l}\text { Modeling boundary to be based on } \\
\text { scoping calculations. }\end{array}$} & \multirow{8}{*}{$\begin{array}{l}\text { If calculations predict possible } \\
\text { contaminant transport beyond } \\
\text { existing restrictions, either } \\
\text { reduce uncertainty with } \\
\text { additional data collection, or } \\
\text { extend institutional controls. }\end{array}$} & \multirow{8}{*}{$\begin{array}{l}\text { Decision errors are } \\
\text { based on model. } \\
\text { If data is insufficient to } \\
\text { make a decision, then } \\
\text { additional data will be } \\
\text { collected. }\end{array}$} & \multirow{8}{*}{$\begin{array}{l}\text { Develop work plan and } \\
\text { technical approach. }\end{array}$} \\
\hline Determine the PALs for COPCs. & $\begin{array}{l}\text { State and Federal Regulations, } \\
\text { site-specific dose-based levels }\end{array}$ & & & & \\
\hline $\begin{array}{l}\text { Determine the migration } \\
\text { potential to the Culebra aquifer } \\
\text { from the Gnome cavity, drifts, } \\
\text { and shaft. }\end{array}$ & $\begin{array}{l}\text { Historical data, process knowledge, } \\
\text { existing calculations, past modeling } \\
\text { results }\end{array}$ & & & & \\
\hline $\begin{array}{l}\text { Determine potential of COPC } \\
\text { migration in the Culebra aquifer } \\
\text { due to the tracer test. }\end{array}$ & $\begin{array}{l}\text { Historical data, knowledge of } \\
\text { subsurface geology and hydrology, } \\
\text { mobility of COPCs, past and } \\
\text { proposed modeling }\end{array}$ & & & & \\
\hline $\begin{array}{l}\text { Determine if the potential } \\
\text { reduction in uncertainty } \\
\text { regarding groundwater } \\
\text { contamination justifies the } \\
\text { commitment of resources to } \\
\text { collect new subsurface data. }\end{array}$ & $\begin{array}{l}\text { Data Decision Analysis, past and } \\
\text { proposed modeling, cost estimating }\end{array}$ & & & & \\
\hline $\begin{array}{l}\text { Determine if a human health } \\
\text { dose assessment is warranted. }\end{array}$ & $\begin{array}{l}\text { Modeling results, COPC } \\
\text { concentration guidelines }\end{array}$ & & & & \\
\hline $\begin{array}{l}\text { Determine if existing subsurface } \\
\text { intrusion restrictions are } \\
\text { adequate for site closure. }\end{array}$ & $\begin{array}{l}\text { Modeling results, possible dose } \\
\text { assessment, and future land use } \\
\text { scenarios }\end{array}$ & & & & \\
\hline $\begin{array}{l}\text { Determine if a long-term } \\
\text { monitoring program is } \\
\text { technically warranted. }\end{array}$ & $\begin{array}{l}\text { Modeling results, subsurface } \\
\text { intrusion restrictions, possible } \\
\text { monitoring well installation if } \\
\text { technically warranted }\end{array}$ & & & & \\
\hline
\end{tabular}


Table 3-3

Tracer Test Radionuclide Inventory

\begin{tabular}{||c||c|c|c||}
\hline Nuclide & $\begin{array}{c}\text { Half Life } \\
\text { (years) }\end{array}$ & $\begin{array}{c}\text { Initial Injected Activity in } \\
\text { Year 1963 (pCi) }\end{array}$ & $\begin{array}{c}\text { Injected Activity Decayed to } \\
\text { Year 2000 (pCi)* }\end{array}$ \\
\hline \hline Tritium & 12.32 & $1.85 \times 10^{13}$ & $2.31 \times 10^{12}$ \\
\hline Cs-137 & 30.07 & $1.0 \times 10^{13}$ & $4.26 \times 10^{12}$ \\
\hline I-131 & $2.20 \times 10^{-2}$ & $4.0 \times 10^{12}$ & Zero \\
\hline Sr-90 & 28.78 & $1.0 \times 10^{13}$ & $4.10 \times 10^{12}$ \\
\hline
\end{tabular}

${ }^{*}$ Assumes no migration or diffusion from source area

that was not consumed by the test. An unclassified estimate of neutron activation products and fission products that resulted from the Gnome test was calculated by Gardner and Sigalove (1970) and is included in Table 3-4. Some information about the Gnome test remains classified and though the isotopes added for the production study are also classified, it is known that the most significant isotope was tritium; therefore, tritium is the primary isotope of concern for the subsurface.

Nonradioactive materials were added to the test for shielding and support. These included several tons each of iron, lead, polyethylene, and wood, as well as smaller quantities of aluminum and brass. These materials reacted with the surrounding rock as a result of the nuclear explosion and formed a wide variety of iron-rich minerals, such as magnetite, olivine, galena, and lead hydrochloride (Nathans, 1965). The investigation will evaluate if other chemical constituents from the surface were introduced during disposal operations (e.g., solvents, diesel fuel), although if present, their volumes are assumed to be very small relative to the radioactive constituents.

The nonradioactive test materials are not considered primary COPCs in the subsurface investigation due to their lower mobility when compared to some of the radionuclides, primarily tritium. Since tritium is at least as mobile (if not greatly more so) than any of the possible chemical constituents, it is a good first indicator for migration of both radionuclide and chemical constituents from the Gnome underground workings. Initial collocation of radioactive and nonradioactive constituents is assured by the placement within the cavity and shaft and lack of effective permeability in the surrounding salt. Although the disposal operations were unstructured, the majority of disposal involved reintroducing mined salt back into the cavity and drifts, with the COPCs being radionuclides. Additionally, the medium of migration is groundwater, and all groundwater in the underground workings can be reasonably expected to be contaminated with tritium. 
Table 3-4

Long-Lived Radionuclides Produced by the Gnome Nuclear Test (Page 1 of 2)

\begin{tabular}{|c|c|c|c|c|}
\hline Nuclide & Source & $\begin{array}{l}\text { Half-life } \\
\qquad(y r)^{*}\end{array}$ & Initial Activity (pCi) & $\begin{array}{l}\text { Activity in } 2000 \\
\text { (pCi) }\end{array}$ \\
\hline Tritium & $a, p, t$ & $1.23 \times 10^{1}$ & $7.10 \times 10^{14}$ & $7.91 \times 10^{13}$ \\
\hline Carbon-14 & a & $5.72 \times 10^{3}$ & $4.90 \times 10^{7}$ & $4.88 \times 10^{7}$ \\
\hline Sodium-22 & a & $2.61 \times 10^{0}$ & $1.70 \times 10^{9}$ & $5.27 \times 10^{4}$ \\
\hline Chlorine-36 & $\mathrm{a}$ & $3.01 \times 10^{5}$ & $5.60 \times 10^{11}$ & $5.60 \times 10^{11}$ \\
\hline Argon-39 & $\mathrm{a}$ & $2.69 \times 10^{2}$ & $9.10 \times 10^{11}$ & $8.23 \times 10^{11}$ \\
\hline Potassium-40 & $\mathrm{a}$ & $1.27 \times 10^{9}$ & $3.85 \times 10^{5}$ & $3.85 \times 10^{5}$ \\
\hline Calcium-41 & a & $1.03 \times 10^{5}$ & $8.40 \times 10^{8}$ & $8.40 \times 10^{8}$ \\
\hline Calcium-45 & $\mathrm{a}$ & $4.46 \times 10^{-1}$ & $1.29 \times 10^{13}$ & $6.13 \times 10^{-14}$ \\
\hline Manganese-54 & a & $8.55 \times 10^{-1}$ & $5.95 \times 10^{7}$ & $1.10 \times 10^{-6}$ \\
\hline Iron-55 & a & $2.73 \times 10^{0}$ & $1.72 \times 10^{10}$ & $8.61 \times 10^{5}$ \\
\hline Cobalt-57 & a & $7.45 \times 10^{-1}$ & $7.00 \times 10^{6}$ & $1.22 \times 10^{9}$ \\
\hline Cobalt-60 & a & $5.27 \times 10^{0}$ & $2.03 \times 10^{8}$ & $1.20 \times 10^{5}$ \\
\hline Nickel-63 & $\mathrm{a}$ & $1.00 \times 10^{2}$ & $5.60 \times 10^{7}$ & $4.27 \times 10^{7}$ \\
\hline Zinc-65 & $\mathrm{a}$ & $6.68 \times 10^{-1}$ & $3.01 \times 10^{9}$ & $8.01 \times 10^{-9}$ \\
\hline Krypton-85 & $a, f$ & $1.08 \times 10^{1}$ & $4.50 \times 10^{13}$ & $3.65 \times 10^{12}$ \\
\hline Rubidium-87 & $f$ & $4.88 \times 10^{10}$ & $7.35 \times 10^{4}$ & $7.35 \times 10^{4}$ \\
\hline Strontium-90 & $f, t$ & $2.88 \times 10^{1}$ & $2.40 \times 10^{14}$ & $9.38 \times 10^{13}$ \\
\hline Niobium-94 & $f$ & $2.00 \times 10^{4}$ & $7.00 \times 10^{6}$ & $6.99 \times 10^{6}$ \\
\hline Technetium-98 & $f$ & $4.20 \times 10^{6}$ & $1.61 \times 10^{4}$ & $1.61 \times 10^{4}$ \\
\hline Technetium-99 & $f$ & $2.13 \times 10^{5}$ & $8.75 \times 10^{10}$ & $8.75 \times 10^{10}$ \\
\hline Ruthenium-106 & $f$ & $1.02 \times 10^{0}$ & $1.40 \times 10^{16}$ & $4.33 \times 10^{4}$ \\
\hline Rhodium-102 & $f$ & $2.90 \times 10^{0}$ & $1.01 \times 10^{9}$ & $9.04 \times 10^{4}$ \\
\hline Palladium-107 & a & $6.50 \times 10^{6}$ & $1.28 \times 10^{6}$ & $1.28 \times 10^{6}$ \\
\hline Silver-110m & $a, f$ & $6.84 \times 10^{-1}$ & $6.90 \times 10^{12}$ & $4.73 \times 10^{-5}$ \\
\hline Cadmium-113m & $f$ & $1.41 \times 10^{1}$ & $1.19 \times 10^{10}$ & $1.75 \times 10^{9}$ \\
\hline Indium-115 & $f$ & $4.40 \times 10^{14}$ & $3.39 \times 10^{-1}$ & $3.39 \times 10^{-1}$ \\
\hline Antimony-125 & $f$ & $2.76 \times 10^{0}$ & $1.36 \times 10^{14}$ & $7.53 \times 10^{9}$ \\
\hline
\end{tabular}


Table 3-4

Long-Lived Radionuclides Produced by the Gnome Nuclear Test (Page 2 of 2)

\begin{tabular}{|c|c|c|c|c|}
\hline Nuclide & Source & $\begin{array}{c}\text { Half-life } \\
(\mathbf{y r})^{*}\end{array}$ & Initial Activity (pCi) & $\begin{array}{c}\text { Activity in 2000 } \\
\text { (pCi) }\end{array}$ \\
\hline \hline lodine-129 & $\mathrm{f}$ & $1.57 \times 10^{7}$ & $5.60 \times 10^{8}$ & $5.60 \times 10^{8}$ \\
\hline Cesium-134 & $\mathrm{a}, \mathrm{f}$ & $2.07 \times 10^{0}$ & $1.16 \times 10^{12}$ & $2.39 \times 10^{6}$ \\
\hline Cesium-135 & $\mathrm{a}$ & $2.30 \times 10^{6}$ & $7.82 \times 10^{-2}$ & $7.82 \times 10^{-2}$ \\
\hline Cesium-137 & $\mathrm{f}, \mathrm{t}$ & $3.00 \times 10^{1}$ & $7.00 \times 10^{14}$ & $2.85 \times 10^{14}$ \\
\hline Lanthanum-138 & $\mathrm{a}$ & $1.05 \times 10^{11}$ & $8.87 \times 10^{3}$ & $8.87 \times 10^{3}$ \\
\hline Neodymium-144 & $\mathrm{f}$ & $2.38 \times 10^{15}$ & $1.92 \times 10^{0}$ & $1.92 \times 10^{0}$ \\
\hline Promethium-147 & $\mathrm{f}$ & $2.62 \times 10^{0}$ & $2.24 \times 10^{15}$ & $7.50 \times 10^{10}$ \\
\hline Samarium-147 & $\mathrm{f}$ & $1.06 \times 10^{11}$ & $5.25 \times 10^{4}$ & $5.25 \times 10^{4}$ \\
\hline Samarium-151 & $\mathrm{a}, \mathrm{f}$ & $9.00 \times 10^{1}$ & $3.10 \times 10^{13}$ & $2.30 \times 10^{13}$ \\
\hline Europium-152 & $\mathrm{a}$ & $1.35 \times 10^{1}$ & $3.90 \times 10^{13}$ & $5.30 \times 10^{12}$ \\
\hline Europium-154 & $\mathrm{a}, \mathrm{f}$ & $8.59 \times 10^{0}$ & $9.94 \times 10^{12}$ & $4.28 \times 10^{11}$ \\
\hline Europium-155 & $\mathrm{f}$ & $4.75 \times 10^{0}$ & $4.20 \times 10^{14}$ & $1.42 \times 10^{12}$ \\
\hline Gadolinium-153 & $\mathrm{a}$ & $6.62 \times 10^{-1}$ & $8.98 \times 10^{8}$ & $1.66 \times 10^{-9}$ \\
\hline Terbium-158 & $\mathrm{a}$ & $1.80 \times 10^{2}$ & $6.76 \times 10^{7}$ & $5.82 \times 10^{7}$ \\
\hline
\end{tabular}

Source: Gardner and Sigalove, 1970, for initial activities.

*Half lives from chart of the Nuclides, 15th Edition (Knolls Atomic Power Laboratory, 1996)

$\mathrm{a}=$ Activation: Nuclide produced by neutron activation in salt.

$\mathrm{t}=$ Tracer test: Nuclide also used in the tracer test, although that mass is not included in this table (see Table 3-2).

$\mathrm{f}=$ Fission: Nuclide produced by neutron-induced fission of Pu-239.

$\mathrm{p}=$ Production study: Nuclide added to zero room as part of isotope production study. 


\subsection{Surface and Shallow Subsurface Work Plan}

This section of the Gnome-Coach Work Plan contains the scope of work and technical approach for the investigation of surface (0-1 ft) and shallow subsurface (1-20 ft) soils at the Gnome-Coach Site. Data will be collected during the field investigation to confirm or refute the conceptual site model for Gnome-Coach. Figure 4-1 is a DQO Decision Flow Chart that summarizes the site characterization scope of work and technical approach. The following sections define the technical approach as outlined in Figure 4-1 and details the activities to be completed for the field investigation. The investigation activities to be completed at the Gnome-Coach Site are presented in the general order they will be performed.

The technical approach for this site will be a multiphase investigation consisting of radiological surveys, geophysical surveys, and soil and vegetation sample collection. The results of the initial survey activities will be reviewed and used as the baseline for subsequent survey and/or sampling activities. Although this represents a phased approach to the completion of the site characterization process, the intention is that all characterization activities will be completed in a single field effort, minimizing number of mobilizations of personnel and equipment. Unexpected site conditions may require modifications to the conceptual site model, DQOs, and/or field investigation activities.

\subsection{Demarcate Operational Areas}

Historical aerial and oblique photographs, along with site drawings, will be compared with physical locations at the Gnome-Coach Site to demarcate the operational areas. Figure 4-2 is an oblique historical photograph showing the primary operational areas in 1961 before the Gnome test. For comparison, Figure 4-3 is an aerial photograph taken in 1979, near the completion of the decontamination activities. Refer to Figure 2-4 for the locations of each AOC overlain on this same aerial photo.

Prior to beginning the in situ radiological surveys and geophysical investigation, the estimated extent of each AOC (e.g., CWD, salvage yard, area between shaft and ground zero, and monitoring well locations) will be located and staked at the corners, then gridded as appropriate. Table 4-1 lists each AOC to be investigated, its approximate size, and suspected COPCs. The table also indicates what 


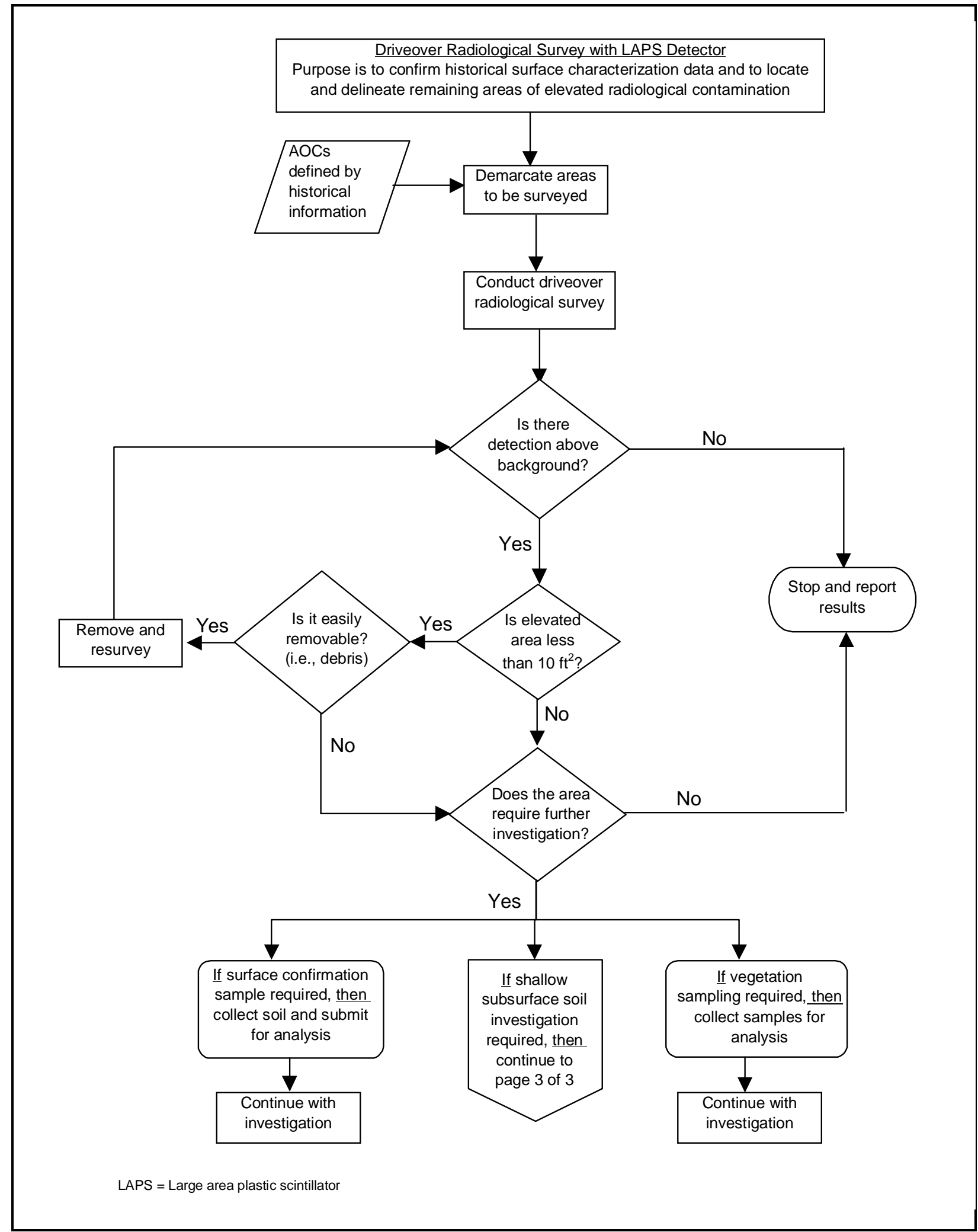

Figure 4-1 


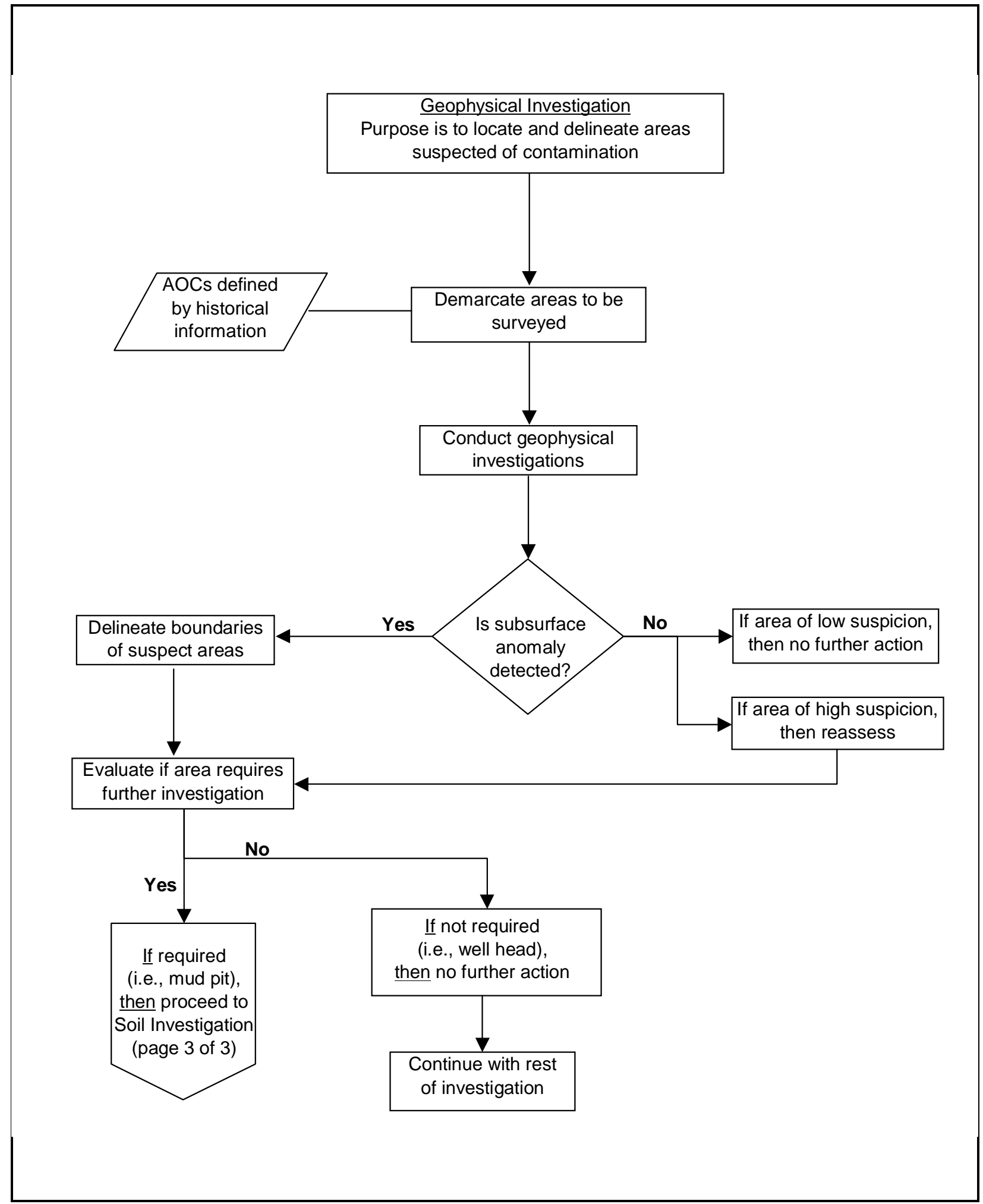

Figure 4-1

Decision Flow Diagram

(Page 2 of 3) 


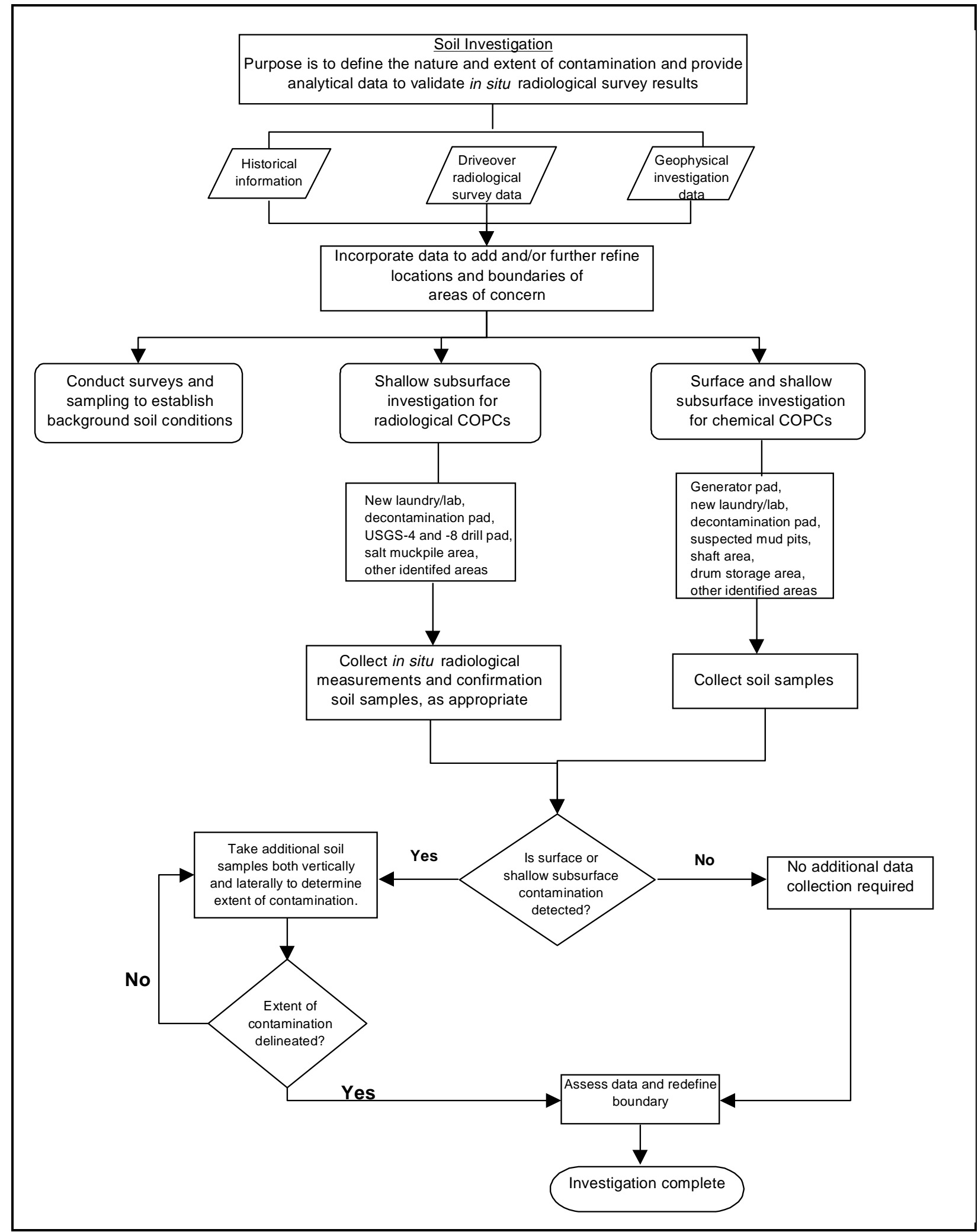

Figure 4-1

Decision Flow Diagram

(Page 3 of 3) 


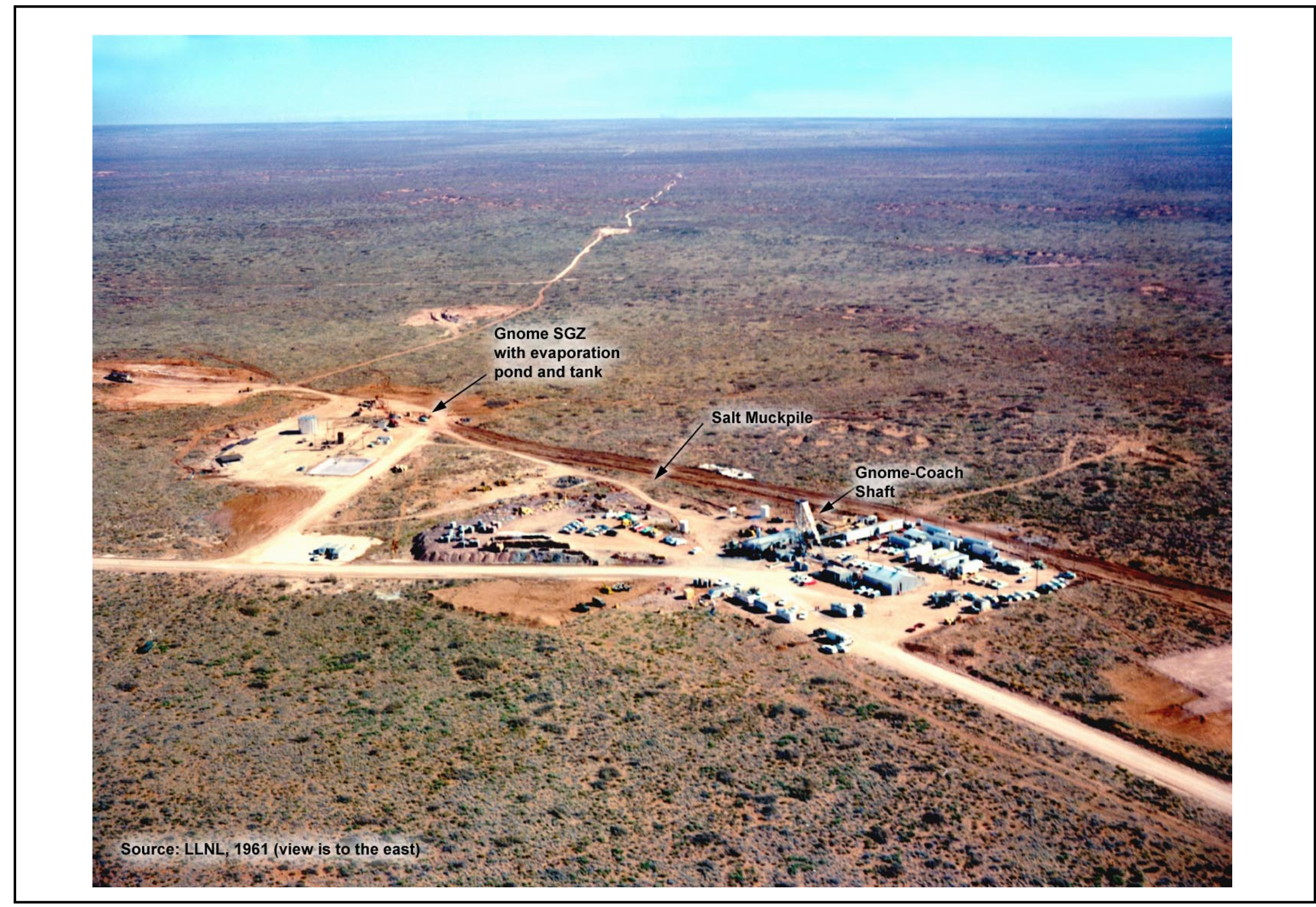

Figure 4-2

Oblique Photo of Gnome-Coach Site, 1961 


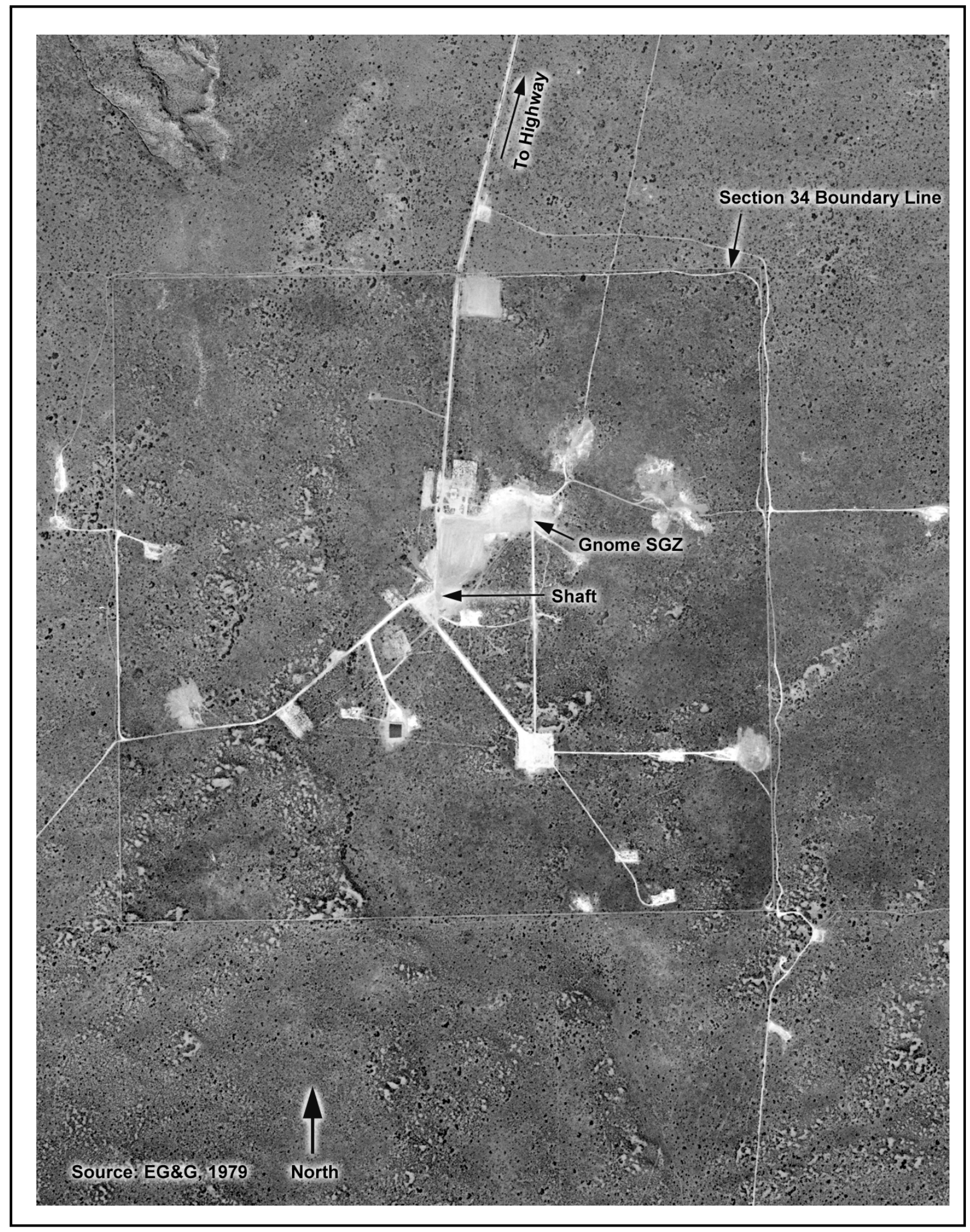

Figure 4-3 
Table 4-1

List of Areas of Concern, Size of Area, and Potential COPCs for the Gnome-Coach Site, Eddy County, New Mexico (Page 1 of 3)

\begin{tabular}{|c|c|c|c|c|c|}
\hline \multirow[b]{2}{*}{ Area of Concern } & \multirow[b]{2}{*}{$\begin{array}{l}\text { Approximate } \\
\text { Size in Square } \\
\text { Feet }\end{array}$} & \multirow[b]{2}{*}{ COPCs } & \multicolumn{3}{|c|}{ Initial Investigation Technique } \\
\hline & & & Drilling $^{a}$ & $\begin{array}{c}\text { Geophysical } \\
\text { Survey }\end{array}$ & $\begin{array}{c}\text { Driveover } \\
\text { Radiological } \\
\text { Survey }\end{array}$ \\
\hline \multicolumn{6}{|c|}{ Sites with Chemical and Radiological cOPCs } \\
\hline New laundry/lab & 5,600 & $\begin{array}{c}\text { Solvents }(\mathrm{VOCS}, \text { SVOCs, Total Metals) and residual } \\
\text { radioactive contamination (Cs-137) }\end{array}$ & $\checkmark$ & & $\checkmark$ \\
\hline Decontamination pad & 10,000 & $\begin{array}{c}\text { Solvents (VOCs, SVOCs, Total Metals) and residual } \\
\text { radioactive contamination (Cs-137) }\end{array}$ & $\checkmark$ & & $\mathcal{V}$ \\
\hline Drum storage area & 10,000 & $\begin{array}{l}\text { Unknown contents of drums (VOCs, SVOCs, Total Metals) and } \\
\text { potential residual radioactive contamination from fallout plume } \\
\qquad(\text { Cs-137) }\end{array}$ & $\checkmark$ & & $\mathcal{V}$ \\
\hline $\begin{array}{l}\text { Wells USGS-4 and } \\
\text { USGS-8 }\end{array}$ & 20,000 & $\begin{array}{l}\text { Mud pit (TPH, VOCs, SVOCs, Total Metals) and residual } \\
\text { radioactive contamination (Cs-137, tritium, and Sr-90) }\end{array}$ & $\mathcal{V}$ & & $\checkmark$ \\
\hline LRL-1 drill pad ${ }^{b}$ & 53,000 & $\begin{array}{l}\text { Mud pit (TPH, VOCs, SVOCs, Total Metals) and residual } \\
\text { radioactive contamination (Cs-137) }\end{array}$ & $\mathcal{V}$ & & $\mathcal{V}$ \\
\hline $\begin{array}{l}\text { Gnome-Coach Shaft } \\
\quad \text { (surface area) }\end{array}$ & 57,200 & $\begin{array}{l}\text { Vehicle/equipment maintenance chemicals (TPH, VOCs, } \\
\text { SVOCs, Total Metals) and residual radioactive contamination } \\
\text { (Cs-137) }\end{array}$ & $\checkmark$ & $\checkmark$ & $\boldsymbol{V}$ \\
\hline Coach/LRL-7 drill pad ${ }^{\mathrm{c}}$ & 90,000 & $\begin{array}{c}\text { Residual radioactive contamination (Cs-137) and potential } \\
\text { mud pit (TPH, VOCs, SVOCs, Total Metals) }\end{array}$ & & $\checkmark$ & $\checkmark$ \\
\hline LRL-8 drill pad & 14,300 & $\begin{array}{c}\text { Residual radioactive contamination (Cs-137) and potential } \\
\text { mud pit (TPH, VOCs, SVOCs, Total Metals) }\end{array}$ & & $\checkmark$ & $\checkmark$ \\
\hline LRL-2 drill pad & 22,750 & $\begin{array}{c}\text { Residual radioactive contamination (Cs-137) and potential } \\
\text { mud pit (TPH, VOCs, SVOCs, Total Metals) }\end{array}$ & & $\checkmark$ & $\checkmark$ \\
\hline \multicolumn{6}{|c|}{ Sites with Radiological COPCs only } \\
\hline $\begin{array}{l}\text { Gnome Ground Zero } \\
\text { (surface area) }\end{array}$ & 40,000 & Residual radioactive contamination (Cs-137) & & $\checkmark$ & $\checkmark$ \\
\hline $\begin{array}{l}\text { Evaporation pond/waste } \\
\text { tank }\end{array}$ & 10,000 & Residual radioactive contamination (Cs-137) & & $\checkmark$ & $\checkmark$ \\
\hline Area 57 & 1,200 & Residual radioactive contamination (Cs-137) & & & $\checkmark$ \\
\hline Warehouse area & 60,000 & Residual radioactive contamination (Cs-137) & & $V$ & $V$ \\
\hline
\end{tabular}


Table 4-1

List of Areas of Concern, Size of Area, and Potential COPCs for the Gnome-Coach Site, Eddy County, New Mexico (Page 2 of 3)

\begin{tabular}{|c|c|c|c|c|c|}
\hline \multirow[b]{2}{*}{ Area of Concern } & \multirow[b]{2}{*}{$\begin{array}{c}\text { Approximate } \\
\text { Size in Square } \\
\text { Feet }\end{array}$} & \multirow[b]{2}{*}{ COPCs } & \multicolumn{3}{|c|}{ Initial Investigation Technique } \\
\hline & & & Drilling $^{a}$ & $\begin{array}{c}\text { Geophysical } \\
\text { Survey }\end{array}$ & $\begin{array}{c}\text { Driveover } \\
\text { Radiological } \\
\text { Survey }\end{array}$ \\
\hline Equipment storage area & 10,000 & Residual radioactive contamination (Cs-137) & & & $\checkmark$ \\
\hline Old laundry/lab & 20,000 & Residual radioactive contamination (Cs-137) & & $\checkmark$ & $\checkmark$ \\
\hline Crusher Plant & 75,000 & Residual radioactive contamination (Cs-137) & & & $\checkmark$ \\
\hline Salt muckpile & 140,000 & Residual radioactive contamination (Cs-137) & $\checkmark$ & & $\checkmark$ \\
\hline Contaminated waste dump & 150,000 & Residual radioactive contamination (Cs-137) & & $\mathcal{V}$ & $\mathcal{V}$ \\
\hline Salvage yard & 60,000 & Residual radioactive contamination (Cs-137) & & $V$ & $\checkmark$ \\
\hline $\begin{array}{l}\text { Road between CWD and } \\
\text { salvage yard }\end{array}$ & 7,000 & Residual radioactive contamination (Cs-137) & & & $\checkmark$ \\
\hline Fallout plume & 880,000 & Residual radioactive contamination (Cs-137) & & & $V$ \\
\hline \multicolumn{6}{|c|}{ Sites with Chemical cOPCs Only } \\
\hline Generator pad & 20,000 & Fuel spills (TPH, VOCs, SVOCs, Total Metals) & 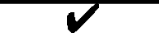 & $V$ & \\
\hline USGS-1 & 131,250 & $\begin{array}{l}\text { Mud pit, generator fuel spills (TPH, VOCs, SVOCs, Total } \\
\text { Metals) }\end{array}$ & $\checkmark$ & & \\
\hline USGS-2 & unknown & Potential mud pit (TPH, VOCs, SVOCs, Total Metals) & & $\checkmark$ & \\
\hline USGS-5 & unknown & Potential mud pit (TPH, VOCs, SVOCs, Total Metals) & & $\checkmark$ & \\
\hline USGS-7 & 75,000 & Mud pit (TPH, VOCs, SVOCs, Total Metals) & $\checkmark$ & & \\
\hline Sandia No. 1 & unknown & Potential mud pit (TPH, VOCs, SVOCs, Total Metals) & & $\mathcal{V}$ & \\
\hline Sandia No. 3 & 75,000 & Potential mud pit (TPH, VOCs, SVOCs, Total Metals) & & $V$ & \\
\hline SRI No. 1 & unknown & Potential mud pit (TPH, VOCs, SVOCs, Total Metals) & & $\checkmark$ & \\
\hline SRI No. 2 & unknown & Potential mud pit (TPH, VOCs, SVOCs, Total Metals) & & $\mathcal{V}$ & \\
\hline SRI No. 3 & unknown & Potential mud pit (TPH, VOCs, SVOCs, Total Metals) & & $\checkmark$ & \\
\hline
\end{tabular}


Table 4-1

List of Areas of Concern, Size of Area, and Potential COPCs for the Gnome-Coach Site, Eddy County, New Mexico (Page 3 of 3)

\begin{tabular}{|c|c|c|c|c|c|}
\hline \multirow[b]{2}{*}{ Area of Concern } & \multirow[b]{2}{*}{$\begin{array}{c}\text { Approximate } \\
\text { Size in Square } \\
\text { Feet }\end{array}$} & \multirow[b]{2}{*}{ cOPCs } & \multicolumn{3}{|c|}{ Initial Investigation Technique } \\
\hline & & & Drilling $^{a}$ & $\begin{array}{c}\text { Geophysical } \\
\text { Survey }\end{array}$ & $\begin{array}{c}\text { Driveover } \\
\text { Radiological } \\
\text { Survey }\end{array}$ \\
\hline SRI No. 4 & unknown & Potential mud pit (TPH, VOCs, SVOCs, Total Metals) & & $\checkmark$ & \\
\hline SRI No. 5 & 37,500 & Potential mud pit (TPH, VOCs, SVOCs, Total Metals) & & $\checkmark$ & \\
\hline SRI No. 6 & 37,500 & Potential mud pit (TPH, VOCs, SVOCs, Total Metals) & & $\checkmark$ & \\
\hline SRI No. 7 & 37,500 & Potential mud pit (TPH, VOCs, SVOCs, Total Metals) & & $\checkmark$ & \\
\hline SRI No. 8 & 37,500 & Potential mud pit (TPH, VOCs, SVOCs, Total Metals) & & $\checkmark$ & \\
\hline SRI No. 9 & unknown & Potential mud pit (TPH, VOCs, SVOCs, Total Metals) & & $\checkmark$ & \\
\hline SRI No. 10 & 60,000 & Potential mud pit (TPH, VOCs, SVOCs, Total Metals) & & $\checkmark$ & \\
\hline
\end{tabular}

${ }^{a}$ Drilling to be used for chemical COPC soil sampling and/or downhole in situ radiological measurements

bLRL-1 drill pad may include holes USGS-6, SR-1, SR-2, SR-2A, SR-3, SR-3A due to proximity of one another

${ }^{\circ}$ Coach pad includes drill holes LRL-7, LRL-6, and LRL-4

SRI = Stanford Research Institute 
type of initial investigations will be conducted at each AOC as part of the characterization. Other types of investigations for each AOC will be dependent upon the results of these initial investigations. The AOCs are divided in sections by the type of potential contamination suspected based on historical information and past analytical data.

\subsection{In Situ Radiological Surveys}

The collection of in situ radiological data to characterize residual radiological contamination in surface and shallow subsurface soils are proven technologies used by the DOE at other DOE and Department of Defense facilities. Two different radiological survey technologies will be utilized during this investigation. The first is a driveover radiological survey which will utilize a large-area plastic scintillation (LAPS) detector to measure gamma counts for surface soil. The second will consist of a downhole gamma detector to collect in situ gamma measurements for shallow subsurface soil. The objectives in collecting the in situ radiological data are to:

- Provide confirmation of historical characterization data regarding the distribution and concentration of residual radiological contamination in the surface soils of previously cleaned areas.

- Identify "hot spots" or areas of elevated radiological contamination remaining in surface soils.

- Gather additional shallow subsurface data to fill identified data gaps (i.e., new laundry/lab, decontamination pad).

The radiological surveys will proceed once each AOC is demarcated. Survey location coordinates will be determined using a global positioning system (GPS). If geophysical surveys are to be conducted in radiological AOCs that require shrub/vegetation clearing, both the initial driveover radiological survey and vegetation sampling (if required) will be completed prior to commencement of the geophysical surveys.

The AOCs to be included in the initial driveover survey of the surface are summarized in Table 4-1 and include all the AOCs known or suspected to be radiologically impacted. In addition to the driveover survey, four AOCs have been identified as requiring additional shallow subsurface characterization due to data gaps identified in the historical data review (Appendix A) and the radiological screening evaluation (Appendix C). A downhole gamma detector will be used to collect 
in situ radiological measurements within soil borings to provide vertical characterization data. These AOCs include:

- Decontamination pad

- New laundry/lab

- USGS-4 and 8 drill pad

- Limited areas of the former salt muckpile

\subsubsection{Technical Methodology}

The two radiological survey technologies to be utilized during this investigation are described in the following sections.

\subsubsection{Driveover Radiological Survey}

The driveover radiological survey will provide confirmation of historical characterization data regarding the distribution and concentration of residual radiological contamination in the surface soils of previously cleaned areas, aid in verifying AOC boundaries, and identify areas of elevated radiological measurements (i.e., hot spots) which may require further characterization or removal. This survey will be conducted at designated areas by mounting a LAPS detector to the bumper of an all-terrain vehicle (ATV) or 4-wheel drive vehicle. The maximum attainable coverage, up to 100 percent if possible, of an AOC will be surveyed, as site conditions permit. A ratemeter will provide digital data in units of counts per second and transmit this data continuously to a field computer. A GPS will provide measurement of positional data. At the conclusion of a survey, the collected radiological data will be used with the positional data and processed to generate a graphical representation of the measured radioactivity.

Calibration of the LAPS detector will be for Cs-137. The driveover survey shall be performed in a manner that detects at least $10 \mathrm{pCi} / \mathrm{g}$ of Cs-137 concentration equivalent in surface soils. Reporting of radiological driveover survey findings shall be in units of $\mathrm{pCi} / \mathrm{g}$ and counts per second. Walkover surveys may be performed on portions of the site inaccessible by the driveover survey. 


\subsubsection{Downhole In Situ Radiological Survey}

The downhole in situ radiological survey will be used to measure gamma counts within soil borings. These in situ measurements will aid in determining the vertical extent of radiological contamination in areas that require further shallow subsurface characterization. During the completion of a boring, a small gamma detector will be lowered into the hole and readings will be collected at approximately 1-ft intervals. Readings will be collected until two consecutive measurements are recorded that are within the range of background to a minimum depth of $4 \mathrm{ft}$. This minimum depth assumes that any contamination remaining after soil removal activities during the 1977-1979 remediation will be encountered. The depth of the first consecutive measurement recorded within the background range will be considered the maximum depth of contamination at that location. If bedrock or refusal (caliche) is encountered before two consecutive background measurements are made, additional measurements will not be obtainable. To confirm in situ measurements, a limited number of random soil samples will be collected from boring depths and submitted to the on-site laboratory for gamma spectrometry analysis.

\subsubsection{Driveover Radiological Survey Design and Assumptions}

This work assumes that the combined total of approximately 1,857,500 square feet $\left(\mathrm{ft}^{2}\right)$ or approximately 42 acres, excluding the fallout plume, will be included in the initial driveover radiological investigation. As a conservative estimate, the fallout plume is assumed to encompass the entire NW 1/4 of Section 34 (160 acres). The ATV or 4-wheel drive vehicle, with the mounted LAPS detector, will systematically traverse each designated AOC. The distance between traverses (or detector passes) is dependant upon the detector height and the required density of the survey. The detector height determines the detector field of view. For example, with the detector approximately $2 \mathrm{ft}$ above the ground surface, the field of view is an oval $7 \mathrm{ft}$ long by $4 \mathrm{ft}$ wide.

All AOCs identified for the radiological investigation, as shown in Table 4-1, will be first surveyed with the LAPS detector. For most AOCs, the driveover survey grid will extend to the edges of disturbed ground associated with each AOC and then extend approximately $30 \mathrm{ft}$ outside the boundary into relatively undisturbed land. The actual areas to be investigated will be determined in the field by project personnel prior to initiating the surveys. All areas investigated may be expanded if radiation measurements continue to indicate elevated results above background. In the case of the 
fallout plume, the initial driveover survey will originate at the shaft and may extend to the edges of the NW 1/4 of Section 34; however, if during the completion of the survey, no radioactivity is measured for a distance of $80 \mathrm{ft}$ from the last indication of radioactive material, the survey will be terminated in that direction even though the predetermined distance may not have been reached.

Following the decision flow on Figure 4-1 (page 1 of 3), all radiological anomalies identified by the driveover survey will be evaluated to determine if further investigation is required. Portable hand-held instruments may be used to verify and/or refine the locations of elevated measurements. Surveyed areas with elevated radiation measurements will be identified and marked on a site map. Anomalies with elevated radiation measurements over 10 times the surrounding measured activity and less than $10 \mathrm{ft}^{2}$ in size will be considered a "hot spot" (as derived from DOE Order 5400.5 [DOE/NV, 1993c]) and a marker (e.g., pin flag) will be placed at the approximate location. The "hot spot" will be further evaluated with a hand-held radiation detector to determine if it can be easily removed (i.e., debris) or if the area requires further investigation. To determine if an area requires further investigation (i.e., additional soil data collection), several decision factors may be considered; some examples of the decisions (if/then statements) to be applied are:

- If a "hot spot" is not removable debris, then collect a biased surface confirmation sample to validate the survey results.

- If survey data for areas larger than $10 \mathrm{ft}^{2}$ are consistent with historical characterization data, then no further investigation is required.

- If the location or survey data for areas larger than $10 \mathrm{ft}^{2}$ are inconsistent with historical characterization data and site operational knowledge, then collect additional soil data as appropriate.

Inconsistency with historical data may include such factors as unexpectedly high levels of radioactive contamination or more widespread contamination. The various data collection activities may consist of additional surface surveys (e.g., using portable instruments), removal of hot spots, downhole in situ measurements, or collection of confirmation soil samples for analysis. Additional inputs into the decision to investigate an area further are not limited to those decisions listed above. Other field data such as geophysics and field observations will be evaluated by the Site Supervisor in selecting the most appropriate data collection method. Figure 4-1 (page 3 of 3) shows the decision flow for the 
shallow subsurface soil investigation. Section 4.6 provides details for the in situ radiological soil investigation and soil sampling.

\subsubsection{Establishing Background Values for Radiological Surveys}

Background values will be established for both the driveover and in situ radiological surveys.

\section{Background Values for Driveover Survey}

The ability to determine whether or not the residual radioactivity at a site exceeds the desired reporting criteria depends on the Minimum Detectable Concentration (MDC) of the measurement. The MDC is the minimum activity concentration on a surface or within a material volume that an instrument is expected to detect with a 95 percent confidence.

The MDC concept is derived from statistical hypothesis testing in which a decision is made on the presence of activity. The null hypothesis is generally stated as "no net activity in the sample" (i.e., observed counts are not greater than background), while the alternative hypothesis states that the observed counts are greater than background (i.e., activity is present in the sample).

The background distribution for the medium to be evaluated can be defined as the observed counts from a sample, which is identical to the sample of interest, except that the residual radioactivity is absent. In the context of this activity, the medium is nonradiologically impacted soil.

The assessment of Cs-137 concentration in soil requires a determination of area background for establishing whether a reading exceeds a desired reporting criteria. The backgrounds to be used for this survey will take advantage of the capability of the LAPS to measure the entire area under study. When the entire area is measured, background can be established from uncontaminated areas within the area being surveyed. A statistical evaluation is used to separate any contaminated areas from uncontaminated areas.

The background areas for these activities will be established by statistical evaluation of all data collected. The determined background value is established using the mean and the standard deviation of the entire data set. The data outside of three standard deviations (SD) of the mean is considered elevated and should be investigated further. If more than 5 percent of the total data is over three SD 
of the mean, then the elevated data is excluded from the calculation of background and a new mean and SD is calculated.

\section{Background Values for In Situ Radiological Survey}

Soil background for downhole in situ measurements will be established at undisturbed locations. A "downhole" count rate and gamma spectra for soils relative to the areas being investigated will be established as a range of background values prior to actual data collection. The downhole background values will be used for comparison to actual gamma count rates within the AOC.

\subsection{Vegetation Sampling}

A review of historical documents containing vegetation analyses revealed a lack of Cs-137 data for important range species in all areas of the Gnome-Coach Site (Smith and Giles, 1973;

DOE/NV, 1978; DOE, 2000). As a result, a limited vegetation sampling effort will be conducted as part of the field investigation. The objectives of collecting and analyzing vegetation are:

(1) characterize radionuclides (specifically Cs-137) in important range species of the area and

(2) provide crucial information for estimation of radionuclide ingestion by range cattle as constituents of any pathway analysis that may be conducted.

Vegetation species important to grazing cattle will be the primary vegetation selected for analysis (e.g., black gramma and dropseed grasses). Several factors (e.g., weather conditions, grazing pressure, and terrain disturbance) may influence the availability sufficient biomass of selected range grasses for radionuclide analyses; thus, creating a need to potentially collect additional species or change sample locations. A minimum of three areas have been tentatively identified for sampling and include one area each in the downwind and upwind direction of the venting plume, and one control area. Alternate locations for sample collection may be selected upon the results of the driveover radiological survey so that samples may be collected in radiologically elevated areas. Analyses for other radionuclides may be added if, during the course of soil characterization, radiological data suggest COPCs of significance, other than Cs-137, are present at the site. Final location and size of the sample area as well as the type of range species to be sampled will be determined by field conditions and documented in project files. Refer to the Vegetation Sampling and Analysis Plan in Appendix D for details concerning sample data collection and analysis. 


\subsection{Geophysical Investigation}

The last decommissioning and restoration effort for the Gnome-Coach Site occurred in 1979, when most affected land areas subjected to restoration were reshaped to as near the original contours as was practical (DOE/NV, 1981). The only project-related land features not reshaped or recontoured were the dirt roads and stabilized drill pads. The objective of the geophysical investigation is to more accurately locate and delineate known areas of potential contamination, locate other suspect areas, detect residual buried debris, and map any potential mud pits and subsurface structures identified by geophysics. Locating and delineating the boundaries of suspect areas will help guide soil characterization efforts. Figure 4-1 (page 2 of 3) shows the decision flow for the geophysical investigation.

\subsubsection{Geophysical Survey Areas}

The geophysical investigation will proceed once each known AOC and suspected location is demarcated. Geophysical surveys may be conducted concurrently with the initial driveover radiological survey in areas where brush clearing will not interfere with potential vegetation sampling. A GPS will provide measurement of positional data. The following sections describe the areas to be investigated and the technical methodology.

The geophysical surveys will be conducted to accomplish the following target area-specific objectives:

- Investigate all drill pads and suspect areas to identify potential backfilled drilling mud pits, and, if identified, map their dimensions.

- Delineate the CWD boundaries and identify any remaining buried metallic debris.

- Delineate the salvage yard boundaries and identify any remaining buried metallic debris.

- Locate and delineate boundaries of the buried, uncontaminated salt trench at the old laundry/lab area.

- Investigate the general area near and between shaft and Gnome ground zero to detect a concrete-lined grease pit near shaft, any unknown burial sites, unknown underground storage tanks (USTs) or septic tanks.

- Verify there are no USTs at the generator pad. 
- Verify all buried debris was excavated from the warehouse area.

- Map out identified buried water, phone, or cable lines.

For the purposes of this work plan, it is assumed approximately 3,575,000 $\mathrm{ft}^{2}$ (approximately 82 acres) will be included in the geophysical investigation. The actual areas to be investigated will be determined in the field by project personnel prior to initiating the surveys. The areas investigated may be expanded depending on results of the geophysical survey. The areas to be investigated are shown in Figure 2-4. Table 4-1 provides a more detailed list of the AOCs that will be included in the geophysical investigation. The general areas are listed here:

- $\quad$ SGZ Area (to include the evaporation pond)

- Main Shaft Area

- Waste Disposal Areas (which include the salvage yard and CWD)

- Coach Drill Pad

- New and Old Laundry/Lab

- Miscellaneous Drill Pad Areas

- Generator Pad Area

\subsubsection{Technical Methodology}

The surface geophysical investigation will be conducted in accordance with contractor procedures covering the following:

- Surface Magnetic Surveys

- Surface Frequency-Domain Electromagnetic (EM) Surveys

- Surface Time-Domain Electromagnetic Surveys

- Electrical Resistivity Surveys

- Ground Penetrating Radar (GPR) Surveys

- Global Positioning System Surveys

- Geophysical Data Management

The most appropriate geophysical method(s) will be used at each designated AOC. The methods will be determined in the field based on site conditions with one or more methods being employed to meet the objectives for each AOC. Emphasis will be placed on EM, magnetics, resistivity, and perhaps GPR survey data for identifying any drilling mud pits and backfilled trenches, and determining their thickness and dimensions. Former burial pits, such as the CWD, with the potential of remaining buried metallic objects/debris will be identified using EM, magnetics, and/or GPR. Areas with the 
potential for buried structures such as storage tanks will be surveyed with EM, magnetics, and/or GPR to identify anomalies.

\subsection{Delineate Sampling Areas}

The results of the geophysical and radiological investigations, along with the conclusions of the historical radiological review in Appendix A and the radiological screening evaluation in Appendix C, will be used to more accurately define the boundaries of each suspect area and determine areas requiring additional investigation. Historical, geophysical, and radiological data will be compared to make a determination as to what any geophysical and/or radiological anomaly represents (e.g., a known or unknown mud pit, trenches) and a unique name will be assigned. The initially staked areas from the radiological and geophysical investigations will be adjusted, any new sampling areas will be staked, and a field investigative map will be developed showing areas to be sampled.

\subsection{Soil Sampling Investigation}

Soil sampling will be conducted for the purpose of site characterization, validation of radiological survey results, quality control (QC), and waste characterization. Figure 4-1 (page 3 of 3) shows the decision flow of the soil investigation. The sampling investigation may include soil sampling in areas with data gaps identified in the historical characterization (both chemical and radiological), and locations where in situ radiological measurements require analytical confirmation.

Soil sampling will be conducted primarily by using drilling or direct-push technologies. Excavation techniques may also be employed where drilling is deemed inappropriate. Shallow groundwater is not present, therefore not expected, in the Gnome-Coach area and is not included in the sampling investigation.

\subsubsection{Representative Inorganic Background Sample Collection}

Samples will be collected from uneffected areas near the Gnome-Coach Site to establish baseline levels for inorganic COPCs (i.e., radionuclides and metals). 


\section{Radionuclides}

Background soil samples will be collected as part of this field investigation to reduce the uncertainty of naturally occurring radionuclides in surface and shallow subsurface soil to a 95 percent confidence limit. The number of additional samples to be collected is based on a statistical analysis of the 1977-1979 Cs-137 background sample results. The statistical method used was in accordance with the Multi-Agency Radiation Survey and Site Investigation Manual for site characterization (NRC, 2000).

Additional background soil samples will be collected at the surface and shallow subsurface at the Gnome-Coach Site. The 1977-1979 D\&D background analysis focused only on radiological parameters, and primarily surface soil samples were collected. It is proposed during this investigation that both surface and shallow subsurface background soil samples be collected from four boring clusters at two of the 1977-1979 background locations. A total of eight borings will be advanced with soil samples collected at the surface (0-6 in.), at $2 \mathrm{ft}$, and at $4 \mathrm{ft}$ in each boring. The boring locations and depth interval sampled will be determined based on field conditions encountered. Sampling will be performed using approved sampling procedures and methods, and radiological analysis will include Cs-137, Sr-90, and Pu-239/240.

Background surface and shallow subsurface soil sample results will be combined with the 1977-1979 background sampling results to determine with a 95 percent confidence the upper limit of radionuclides detected in soil at the Gnome-Coach Site. The radiological background results will be used to identify naturally occurring radionuclides and radionuclides associated with worldwide fallout.

\section{Inorganic Chemicals}

Background inorganic chemical concentrations for total RCRA metals will be established for the Gnome-Coach Site. Systematic random sampling will be conducted in a designated area to collect background samples for off-site laboratory analysis. The results will be used in comparing characterization samples and supporting risk assessments, if required.

Statistical methods will be employed in order to form a basis for determining the appropriate number of samples to establish background concentrations for the following RCRA metals: mercury, silver, 
selenium, chromium, lead, arsenic, cadmium, and barium. Equation 8 of Chapter 9 of SW-846 (EPA, 1996) gives the number of samples required to determine the mean value of a given parameter to within a specified percent error, $\mathrm{e}_{\mathrm{r}}$, with a confidence limit of 90 percent, using an analytical method with a specified coefficient of variation $(\mathrm{CV})$, as:

$$
\mathrm{n}=\left(\mathrm{t}_{0.90, \mathrm{n}-1} *\left[\mathrm{CV} / \mathrm{e}_{\mathrm{r}}\right]\right)^{2}
$$

where " $\mathrm{t}$ " is the one-tailed 90 percent Student's "t" value for the appropriate number of degrees of freedom $(\mathrm{n}-1)$.

The $\mathrm{CV}$ in the above equation refers to the variability of the specific parameter in the medium being sampled. Its value cannot be determined until sufficient samples from the site have been analyzed. Since previous sampling information regarding metal concentrations and variability in the soil at or surrounding the Gnome-Coach Site have not been located, some assumptions must be made:

- The variability of the analytical method may be used as a first approximation of the variability of the distribution of natural metal concentrations in the soil. This is a reasonable assumption because the composition of soils in the Gnome-Coach area are somewhat uniform. As determined from the individual SW-846 procedures 6010 and 7470, typically the average CVs for metals is 21.3 percent and for mercury is 69.5 percent, respectively.

For the Gnome-Coach Site, a CV of 40 percent will be assumed. This figure represents a compromise between the high $\mathrm{CV}$ of the mercury and the lower $\mathrm{CV}$ of the metals. It is an acceptable starting point for the purposes of Equation 8 .

A relative error of 10 to 20 percent from the true mean at a confidence limit of 90 percent is considered acceptable for planned removal and remedial response studies (EPA, 1989). A relative error of 15 percent will be specified for this site. Substituting the appropriate values for " $\mathrm{t}$ " (Taylor, 1990), CV (40 percent) and $\mathrm{e}_{\mathrm{r}}(15$ percent) into this equation and iterating the equation several times gives $n=22$. Although only 22 samples are required, 24 samples will be collected to keep consistency between the borings (i.e., 6 boreholes with 4 sample levels each).

The background samples will be collected in an area that is undisturbed, unaffected by site operations, and upwind of the historic venting plume. The random sample locations will be computer generated in these background areas. 
The 24 samples will be taken from 6 soil borings drilled to a depth of $12 \mathrm{ft} \mathrm{bgs,} \mathrm{with} \mathrm{sample}$ collection at 4-ft intervals starting with the surface. If refusal is hit at a shallower depth, then additional borings will be drilled to collect the required number of samples. The depth of $12 \mathrm{ft}$ was based on the assumption that chemical contamination would not extend beyond this depth based on process knowledge and operational history. If contamination should be detected at deeper intervals, additional background samples will be collected for those depths at the same approximate locations as previously collected.

\subsubsection{Soil Sampling Techniques}

For areas requiring only surface soil collection (i.e., 0-6 in.), the soil may be collected with a hand auger, trowel, or scoop instead of using an excavation or boring method.

For shallow subsurface soil data collection, coring methods such as direct-push, rotosonic, or other appropriate drilling techniques will be primarily used for the investigative drilling and soil characterization. The direct-push penetrates the soil with minimal disturbance using a decontaminated 4-ft core barrel. Acetate, cellulose, or PVC liner sleeves can be used to contain the cores at each boring. If a direct-push method is chosen, and in the event that an additional volume of soil is needed for analysis, additional cores will be obtained from around the original boring at a radius of not greater than $1 \mathrm{ft}$. The rotosonic method also penetrates soil with minimal disturbance using a decontaminated 10 -ft core barrel. The resulting soil cores can be extruded into plastic bags in convenient handling lengths (approximately $5 \mathrm{ft}$ ). This drilling method may be employed if the direct-push method experiences consistent refusal at a depth shallower than expected vertical contamination (i.e., $<10 \mathrm{ft}$ ).

Excavation techniques may be used to locate shallow subsurface anomalies identified by the geophysical investigation (e.g., septic tanks or landfills) or in areas where drilling is deemed inappropriate. Excavation techniques will be appropriate for the anticipated depth and volume of the excavation (e.g., hand tools or heavy equipment). If soil sampling is required, soil may be collected either directly from the bottom of the excavation or from the material removed (i.e., from a backhoe bucket). 
All equipment that may come in contact with soil samples shall be decontaminated prior to each sampling event to minimize potential cross-contamination between sample locations. All samples collected for laboratory analysis will be fresh media rather than material used for field screening. Records will be kept of the soil description, field-screening measurements, and other relevant data. All required sampling information (i.e., date, time, sample interval) will be documented in accordance with the New Mexico QAPP (Appendix B) and applicable contractor-approved procedures.

\subsubsection{Field Screening}

Field screening will be conducted on soil samples at intervals appropriate for the method of investigation (e.g., 4-ft intervals for direct-push or 5-ft intervals for rotosonic), depth of investigation, and for the feature being investigated. For example, TPH field screening would not be used where TPH is not a COPC nor would field screening be conducted every $4 \mathrm{ft}$ if contamination is obvious due to staining and/or odor. When field screening is being used to guide the investigation and select sampling locations, it will be continued until two consecutive, nondetect, field-screening samples are obtained.

Soil samples will be visually inspected and screened for either VOCs using a photoionization detector (PID) (or similar) and/or radiation using portable alpha and beta/gamma detectors. Soil may be also be field screened for TPH using an appropriate field-screening method (e.g., Hanby or other test kit). The results of field screening will be recorded on the appropriate forms. Visual indications of contamination, elevated VOC readings, elevated radiation readings, and/or elevated TPH screening will be used to select samples for laboratory analysis. The following field-screening results will be used to indicate contamination is present for chemical COPCs:

- VOC head-space readings of twice background (established daily) or 20 parts per million (ppm), whichever is higher

- $\quad$ TPH results of 100 ppm or greater

Radiation field-screening levels for the portable instruments measuring alpha and beta/gamma are defined as the mean background activities level (measured from 20 background locations prior to the start of field activities) plus two times the standard deviation of the mean background activity level. 
This field-screening level will be utilized for soil collection activities and should not be confused with the downhole in situ gamma-screening levels used for the shallow subsurface radiological characterization or the background levels established for the driveover radiological survey.

If contamination is detected by any of the above methods, the horizontal and vertical extent of the contamination will be defined by continuing soil borings and/or excavations until two consecutive nondetects are recorded and/or by completing step-out borings or excavations.

\subsubsection{Sampling Criteria}

Discretionary sampling points, in addition to those discussed below, may be selected for laboratory analysis based on examination. Selection criteria for discretionary samples include:

- Moist or discolored zones

- Significant changes in soil grain size or debris in sample

- Changes in field-screening detection (e.g., odor)

Geotechnical samples may be collected for evaluation of soil parameters to facilitate future corrective action strategies.

\section{Chemical COPCs}

When sampling for chemical constituents, soil samples will be collected at intervals appropriate for the method being used (i.e., $4 \mathrm{ft}$ for direct-push or $5 \mathrm{ft}$ for rotosonic) from the surface to shallow subsurface $(<20 \mathrm{ft})$ to determine the nature and extent of possible contamination, and if contaminant migration is occurring. A minimum of two samples will be selected from each boring for off-site laboratory analysis if field-screening levels are exceeded. One sample will be from the highest field-screening interval and the second sample will be from the deepest vertical, nondetect interval. If field screening and observation does not indicate contamination in a boring drilled in a suspected area, then a sample will be collected from an interval based on the assumed depth of which contamination would have been expected based on process knowledge and historical operations.

If field screening does not detect any contamination in a step-out boring, a sample from the equivalent depth interval (same depth as the contaminated boring) will be submitted for confirmation of the nondetect field-screening readings. 


\section{Radiological COPCs}

Soil sample collection for Cs-137 (gamma spectrometry) will be limited to random confirmation sampling to validate driveover and/or downhole in situ measurements. Soil collection and analysis will be primarily at surface areas or depth intervals where elevated radiological readings are measured to validate survey data. During the downhole in situ survey, if more than one depth interval shows elevated measurements, then a confirmation sample will be collected from the depth interval with the highest radiological measurement. Another confirmation sample may be submitted for analysis at the deepest nondetect interval. Confirmation samples will be submitted to an on-site laboratory for gamma spectrometry analysis. Sr-90 and tritium analysis will be conducted on limited soil samples at the USGS-4 and -8 drill pad area because of a different source term for contamination (i.e., tracer test isotopes); these analyses will be submitted to an off-site laboratory. To confirm that $\mathrm{Pu}-239 / 240$ is not a COPC at the site, confirmation soil samples will be collected at areas near the shaft with elevated radiation measurements and analyzed by gamma spectrometry to measure the Am-241 (a daughter product) activity. If Am-241 is detected, then the sample will be sent to an off-site laboratory for isotopic plutonium analysis.

\subsubsection{Boring Locations for Shallow Subsurface Characterization}

Known and anticipated boring locations have been identified and are shown in Table 4-1 and described in the following sections. Other boring locations will be established when the results from the geophysical and radiological investigation are available. Each soil boring will be named and described in a soil boring log. In the field, decisions will be made to allow for changes to boring and/or sampling locations or to take fewer or more samples, depending on encountered field conditions. For example, if apparent contamination is more widespread than originally anticipated, it may be decided to drill additional borings and collect additional characterization data. If bedrock or refusal (caliche) is encountered at a very shallow depth, a subsurface soil sample may not be possible at that sampling location. If drilling and/or sampling at a recommended location presents an undue health and safety risk to field personnel, the location will be changed. Excavation techniques may also be employed for sample collection and/or investigation of anomalies where more appropriate or if drilling is not feasible. Changes, and the rationale behind each change, will be documented. 


\subsubsection{Boring Locations at Mud Pits}

Mud pits possibly containing hazardous and/or radioactive contamination have been tentatively identified at the following areas: wells USGS-1, USGS-4, USGS-8, USGS-7, and LRL-1 near surface ground zero. Geophysics will not be conducted at these areas since it is assumed mud pits exist and their locations are fairly certain. Instead, soil borings will be drilled for the purpose of identifying the existence of a mud pit and, if detected, determine the dimensions, and collect soil samples.

The investigation of potential mud pits at other well locations, where the presence or orientation of a mud pit relative to the drill hole was not identified in historical documentation, is contingent upon the results of the geophysical investigation to be performed prior to soil investigations (e.g., well AEC No. 1 near shaft). If geophysical data indicate anomalous areas indicative of mud pits, then those areas will be investigated under the assumption that the anomalies may contain potentially hazardous and/or radioactive contamination. Investigations for mud pits at these well locations will not be pursued if the geophysical data does not indicate their presence.

If a mud pit is identified, samples will be collected to characterize the materials present and define vertical and lateral extent of potential contamination. Additionally, soil borings will aid in determining pit dimensions through visual inspection of the subsurface material. To facilitate the objective of finding the mud pit and performing characterization, the area of each suspected mud pit will be initially divided into grids equal to half the length of the short axis and half the length of the long axis of the estimated mud pit with soil borings located at grid nodes. For example, if a suspected mud pit is approximately $100 \mathrm{ft}$ (short axis) by $200 \mathrm{ft}$ (long axis), then initial soil borings will be located at grid nodes every $50 \mathrm{ft}$ on short axis and $100 \mathrm{ft}$ on long axis. See Figure 4-4 (Illustration A) for example boring locations. Additional boring locations, if required to further define lateral and vertical extent of contamination or mud pit dimensions, will be determined by a combination of grid node distance, visual inspection for mud pit materials, and field-screening results.

If contamination is detected within a mud pit by visual and/or field screening, then additional step-out borings will be conducted outside the boundary of the mud pit to define the horizontal and vertical extent of contamination. If the initial step-out boring detects contamination, then an additional step-out boring will be conducted until the lateral extent of contamination is detected. If the lateral 


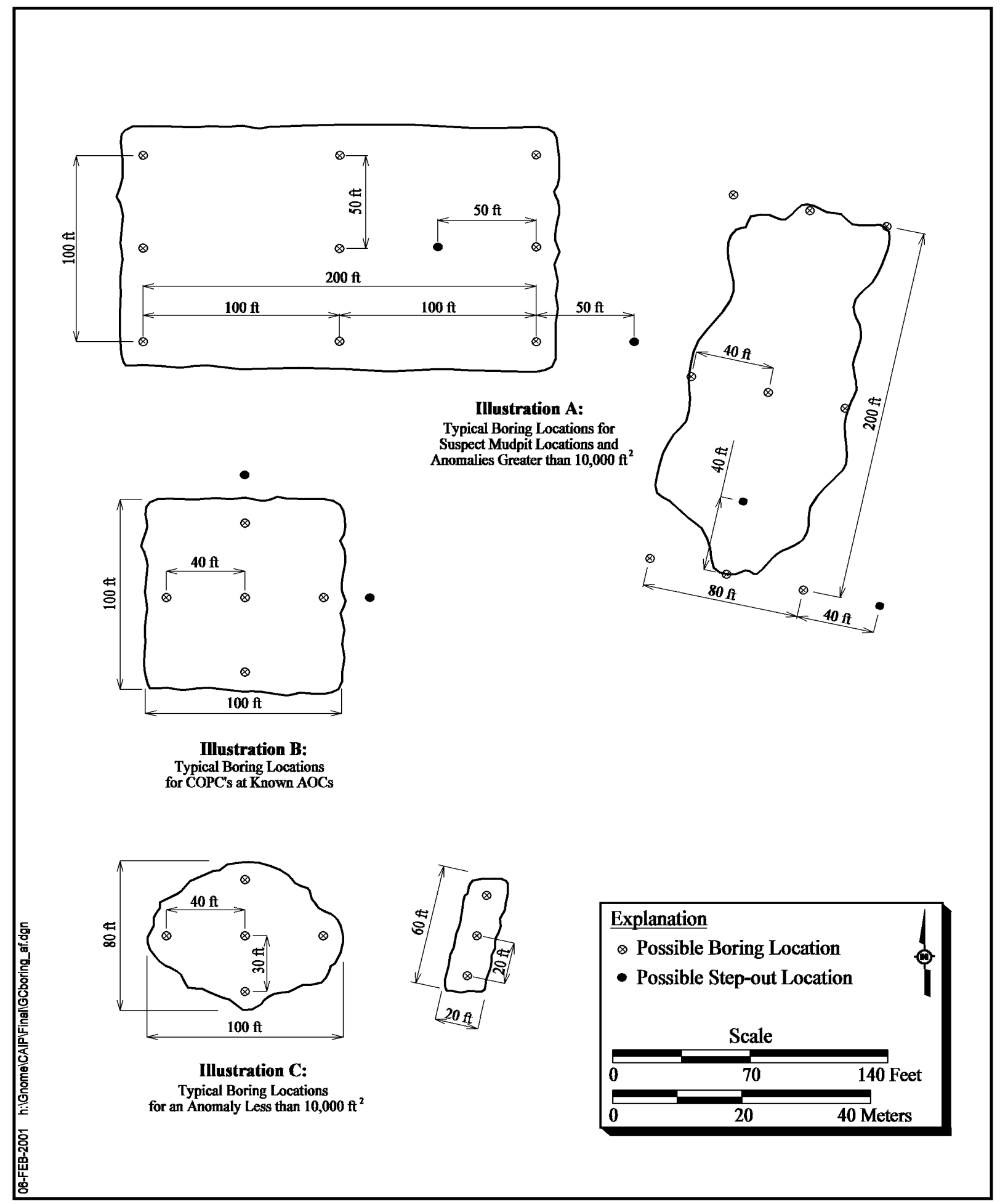

Figure 4-4

Example of Boring Locations 
extent of contamination trends out of the boundaries of the AOC while conducting the step-out borings, an evaluation will be conducted to determine if the AOC extends further than originally anticipated or if a secondary area of contamination has been encountered. Once the trend has been evaluated, along with possible causes, then additional borings will be conducted to define the lateral and vertical extent of contamination.

\subsubsection{Boring Locations at AOCs with Chemical COPCs}

The following areas were identified as potentially contaminated with chemical COPCs and require soil characterization: generator pad, drum storage area, decontamination pad area, the new laundry/lab area, grease pit near shaft (if identified by geophysics), and USGS-1 stained concrete pad. These listed AOCs, with the exception of USGS-1 concrete pad, will have one soil boring drilled at the estimated center of each area, and four others drilled at a distance of approximately $40 \mathrm{ft}$ from the center location. If contamination is detected within an AOC, additional step-out borings will be conducted to completely define the vertical and lateral extent. See Figure 4-4 (Illustration B) for example boring locations. Because the USGS-1 staining was confined to within four feet of the concrete pad, the first boring will be drilled in the most visually stained area as shown in historical photos and step-out borings will be drilled at a distance of approximately $3 \mathrm{ft}$ if contamination is detected. See Table 4-1 for approximate dimensions of the other AOCs.

\subsubsection{Boring Locations at AOCs with Radiological COPCs}

Based on the evaluation of the historical characterization data provided in Appendix A, the following areas were identified as requiring further shallow subsurface characterization for radiological COPCs: decontamination pad area, the new laundry/lab area, salt muckpile, and USGS-4 and -8 drill pad. These listed AOCs will have one soil boring drilled at the estimated center of each area, and four others drilled at a distance of approximately $40 \mathrm{ft}$ from the center location. If contamination is detected near the boundary of an AOC, additional step-out borings will be conducted to completely define the vertical and lateral extent. See Figure 4-4 (Illustration B) for example boring locations. See Table 4-1 for approximate dimensions of these AOCs. 


\subsubsection{Other Boring Locations}

Soil borings may be drilled at other suspect locations as determined by the driveover radiological survey results, geophysical survey results, radiological screening evaluation, and historical data evaluation. If the suspect area or anomaly measures less than $10,000 \mathrm{ft}^{2}$, then one boring will be drilled at the estimated center. The number of additional borings required and the distance from the center boring may be varied in the field depending on the dimension and configuration of the denoted anomaly (see Figure 4-4, Illustration C). If contamination is detected, additional step-out borings will be conducted to completely define the horizontal and vertical extent. If the area is larger than $10,000 \mathrm{ft}^{2}$, then the area will be sampled in the same manner as the mud pits. The anomaly will be initially divided into grids equal to half the length of the short axis and half the length of the long axis of the estimated area with soil borings located at grid nodes. For example, if a suspect location is approximately $100 \mathrm{ft}$ (short axis) by $200 \mathrm{ft}$ (long axis), then soil borings will be located at grid nodes every $50 \mathrm{ft}$ on short axis and $100 \mathrm{ft}$ on long axis.

\subsubsection{Quality Control Samples}

Quality control samples at the Gnome-Coach Site will be collected, labeled, handled, and shipped to the laboratory in accordance with the New Mexico QAPP located in Appendix B of this document and the DOE contractor procedures.

\subsubsection{Analysis}

Samples will be field screened with either a portable alpha and beta/gamma detector and/or a PID (or equivalent) at the time they are extracted. The COPCs identified at an AOC based on site operational knowledge will determine which field screening is appropriate. For example, field screening with a PID is not appropriate and will not be conducted on samples collected in the fallout track area where all COPCs are radiological. Field screening and visual observations will determine which samples will be submitted for analysis.

Potential COPCs at the Gnome-Coach Site, as mentioned in Section 3.1.1, are related primarily to radiological constituents associated with venting and posttest drill-back operations. The primary radiological COPC is Cs-137 but may also include tritium, $\mathrm{Sr}-90$, and $\mathrm{Pu}-239 / 240$. The potential chemical COPCs at limited areas may include TPH (e.g., diesel, waste oil fraction, and gasoline); 
SVOCs; VOCs; and total and leachable metals, specifically chromium. Laboratory chemical and radiochemistry analytical requirements that will be used for the site characterization at Gnome-Coach are shown in Attachment 2 of Appendix B.

\subsection{Surface Water and Groundwater}

There are no surface waters within the vicinity of the Gnome-Coach Site that will require investigation. All geologic records for the Gnome-Coach Site indicate there is no shallow groundwater table in the vicinity; therefore, no shallow groundwater investigation is planned. Groundwater is located within the Culebra Dolomite at a depth of approximately $500 \mathrm{ft}$ bgs (Cooper, 1962a).

\subsection{Additional Requirements and Activities}

The requirements and activities described in this section apply to both the surface and subsurface investigations.

\subsubsection{Health and Safety}

All site preparations and work activities will be conducted in a manner that is protective of the safety and health of site workers, the public, and the environment. Site workers are encouraged to utilize the best available methods to perform job functions in supporting field activities. Standard work practices and procedures are designed to comply with all relevant and applicable federal, state, and local regulatory agencies.

Operations conducted at the Gnome-Coach Site will be conducted in accordance with the primary Real Estate and Operations Permit (REOP) holder's fully developed health and safety program. This program places the emphasis for the health, safety, and environmental protection on the company management team and the associates doing the work. The "safety first" philosophy is passed down from the management to the associates as the best method of doing business. The health and safety program and philosophy fully supports the DOE Integrated Safety Management System (ISMS), and is maintained through a system of inspections, audits, and reviews of field activities as they occur. 
A site-specific health and safety plan (SSHASP) will be developed defining the scope of work to be conducted at Gasbuggy Site to identify the particular features, hazards, communication methods, responsibilities, and protective measures to be employed on site. Controls will be developed and implemented to minimize or eliminate identified hazards. The provisions of this plan are mandatory for all personnel assigned to the field project. Visitors are also required to abide by these procedures. The SSHASP is a living document and may be amended as necessary to deal with new hazards and changing conditions. Changes to the document may be verbal or written after obtaining the approval of the signatories to the original SSHASP. In addition, these changes may only be implemented after being discussed with the affected personnel on site.

\subsubsection{Environmental Compliance and Waste Management}

Contractor personnel will comply with applicable environmental compliance and waste management regulations and requirements in the conduct of site activities. A designated contractor shall be responsible for the on-site management and ultimate disposal of all waste generated as a result of the Gnome-Coach Site characterization investigations. Personnel must comply with waste management and environmental compliance policies and procedures established for the Gnome-Coach Site.

\subsubsection{NEPA Requirements}

In accordance with the DOE/NV NEPA compliance program, a NEPA checklist shall be completed prior to commencement of site investigation activities at Gnome-Coach. This checklist compels $\mathrm{DOE} / \mathrm{NV}$ to evaluate this proposed project against a list of several potential environmental impacts which include, but are not limited to: air quality, chemical use, waste generation, noise levels, and land use. Completion of the checklist results in a determination of the appropriate level of NEPA documentation by the DOE/NV NEPA Compliance Officer for this project.

\subsubsection{Quality Assurance}

All investigation activities will be completed in accordance with standardized operating procedures and quality practices established in the site-specific New Mexico Quality Assurance Project Plan. This plan, located in Appendix B, describes the measures that will be taken to ensure the quality of field sample collection, storage, transport, analytical activities and modeling associated with environmental data collection for the Gnome-Coach Site investigation. 


\subsubsection{Community Relations}

As part of the Gnome-Coach Site investigation, DOE/NV will interface with the State of New Mexico to establish the scope for this activity. 


\subsection{Subsurface Work Plan}

\subsection{Geologic and Hydrogeologic Setting}

The Gnome Site is located in the northern part of the Delaware Basin, a 10,155-square mile structural basin containing over $16,400 \mathrm{ft}$ of limestone, shale, and evaporites that accumulated in a slowly sinking shallow sea. The basin is well defined by the surrounding Capitan Limestone, a late Permian-age reef deposit (Figure 5-1). The basin is tilted to the east so that formations outcropping along the western edge occur at increasing depths below land surface to the east. The Delaware Basin has great economic value, primarily from oil and gas deposits, but also from mining of evaporites (potash) and waste disposal activities. As a result, the geology and structure of the basin are well known.

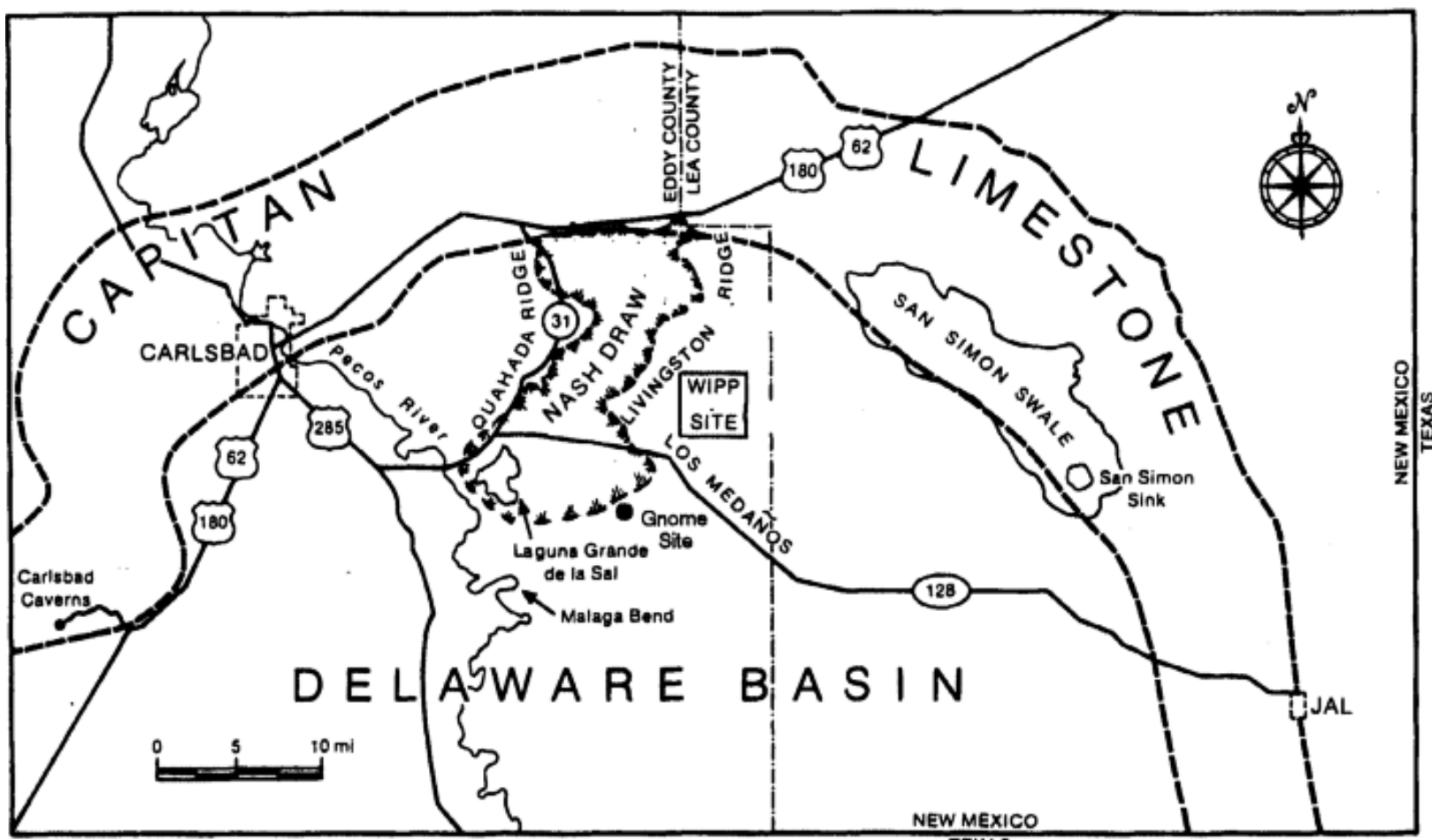

Source: Chapman, 1986

Figure 5-1

Location of the Gnome Site Within the Northern Delaware Basin 
The Gnome test was conducted in the bedded salt of the Salado Formation. Immediately below the Salado is a thick sequence of evaporites (anhydrite and halite) of the Castile Formation (Figure 5-2), which in turn overlies the Bell Canyon Formation and others, representing sedimentary deposition in deeper seas. These deeper formations, though targets of oil and gas exploration are not relevant to contaminant transport concerns at Gnome. The Salado itself is approximately 1,640 ft thick at the site. Over 75 percent of the formation is halite, with the remainder comprised of potassium minerals (USGS, 1962). The Gnome test occurred about $525 \mathrm{ft}$ below the top of the Salado, at a depth of $1,180 \mathrm{ft}$ bgs.

The contact between the Salado Formation and overlying Rustler is marked by a "Leached Member" of interlayered gypsum and sandstone residual from halite dissolution. The Rustler Formation is comprised principally of anhydrite/gypsum and siltstone and sandstone. Two carbonate members of the Rustler, the Magenta and Culebra Dolomites, are the only significant water-bearing units in the formation. The Magenta is unsaturated in the Gnome area so that the Culebra is the only aquifer at the site. The overlying Dewey Lake (Pierce Canyon) Redbeds and Gatuna Formations are also unsaturated in the area.

The Culebra is a fractured, grayish-white dolomite. It is approximately $30 \mathrm{ft}$ thick at Gnome, $500 \mathrm{ft}$ below ground surface, and $670 \mathrm{ft}$ above the Gnome test point (Cooper and Glanzman, 1971). The Culebra is saturated and confined in the area. The potentiometric surface is about $75 \mathrm{ft}$ above the top of the dolomite. The recharge area for the Culebra is not well defined, with the regional flow pattern suggesting a primary recharge area to the north and east (Cooper, 1962b). Groundwater flows in a westward or southwestward direction from the site (Figure 5-3) (Cooper, 1962a; Cooper and Glanzman, 1971). The Pecos River, particularly in the area of springs at Malaga Bend, is believed to be the primary discharge areas. Pohlmann and Andricevic (1994) note that the transmissivity in the Culebra increases from east to west in the Gnome area (Figure 5-4) due to increased fracturing as the result of greater dissolution of underlying halite, and increased thickness of the Culebra, to the west.

Due to the dissolution of evaporites, the water quality in the Culebra dolomite is marginal and used principally for livestock. Cooper and Glanzman (1971) identified four supply wells completed in the Culebra that were in use in the late 1950s and early 1960s. The water from these wells ranged in total dissolved solids content from 3,260 to 6,960 milligrams per liter (mg/L), with sulfate concentrations 


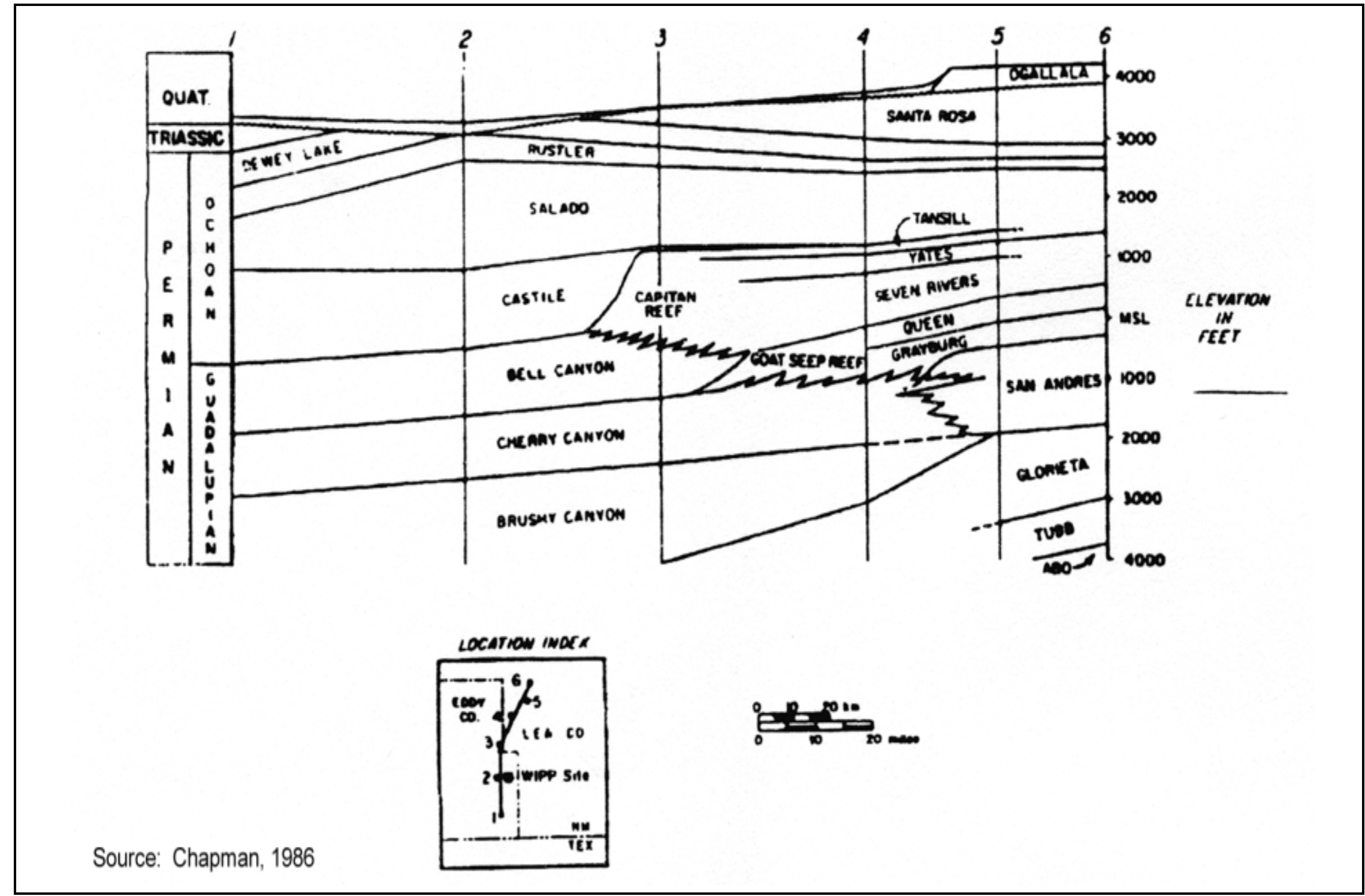

Figure 5-2

North-South Stratigraphic Cross-Section Through the Delaware Basin and Northern Shelf 


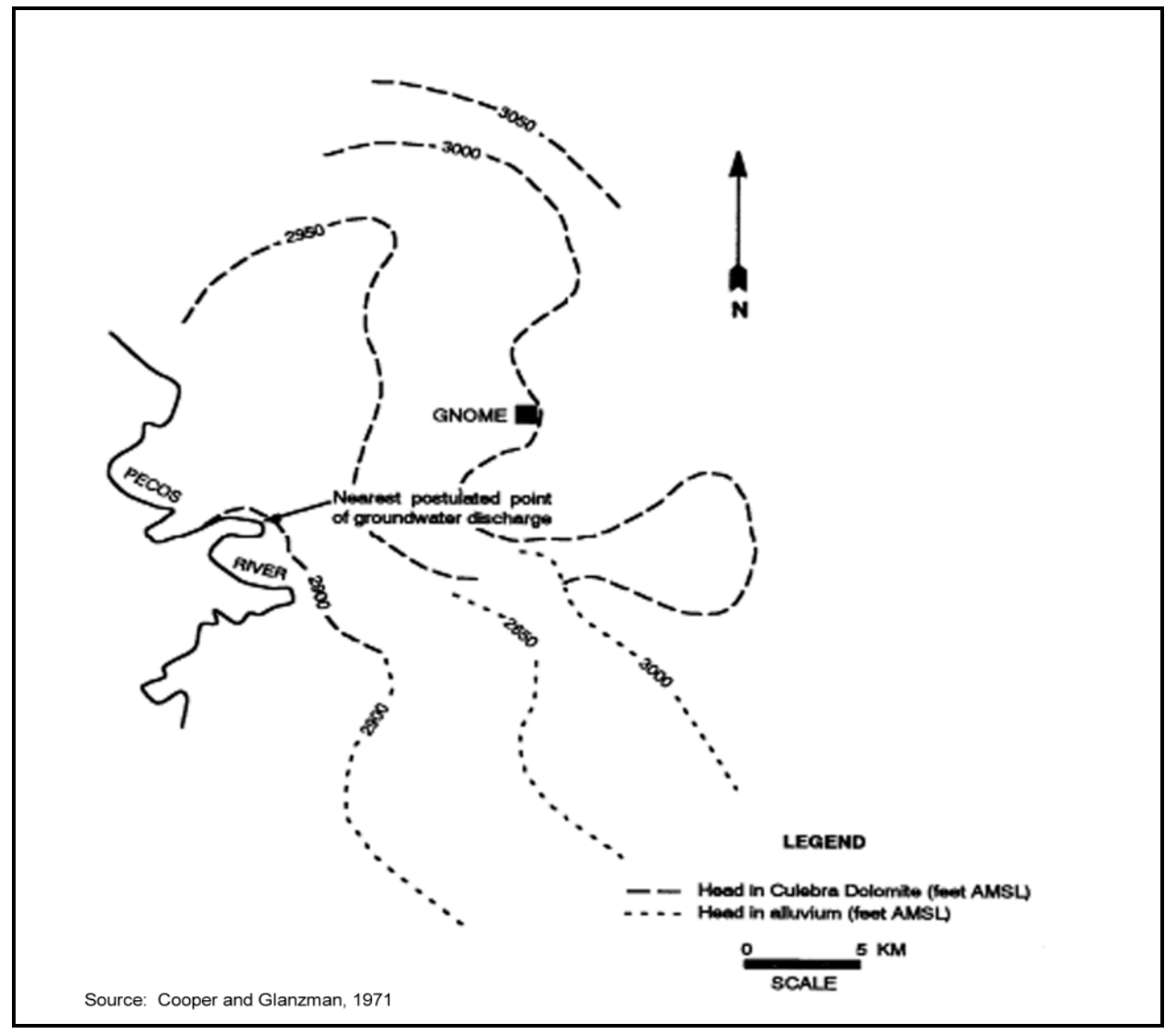

Figure 5-3

Potentiometric Surface in the Vicinity of Gnome

over 2,000 mg/L. For comparison, New Mexico groundwater standards for domestic use is less than 1,000 mg/L total dissolved solids, with sulfate concentrations less than $600 \mathrm{mg} / \mathrm{L}$ (NMAC, 1996).

Figure 5-5 shows the wells and holes drilled in support of Project Gnome and Project Coach and a number of other wells located near the Gnome-Coach Site which are principally used for livestock. Not all these wells are located within the Culebra dolomite; however, they may still contribute useful hydrologic data for this characterization and are shown for completeness.

\subsection{Description of the Gnome Test and Its Effects}

At the time of the Gnome detonation, intense temperatures and pressures were generated at ground zero. Rock immediately around the device was vaporized into a plasma, creating a cavity approximately $70 \mathrm{ft}$ in radius, with melting of nearby rock (Figure 5-6). As the gases cooled and condensed, there was partial collapse into the cavity, quenching the melted rock. 


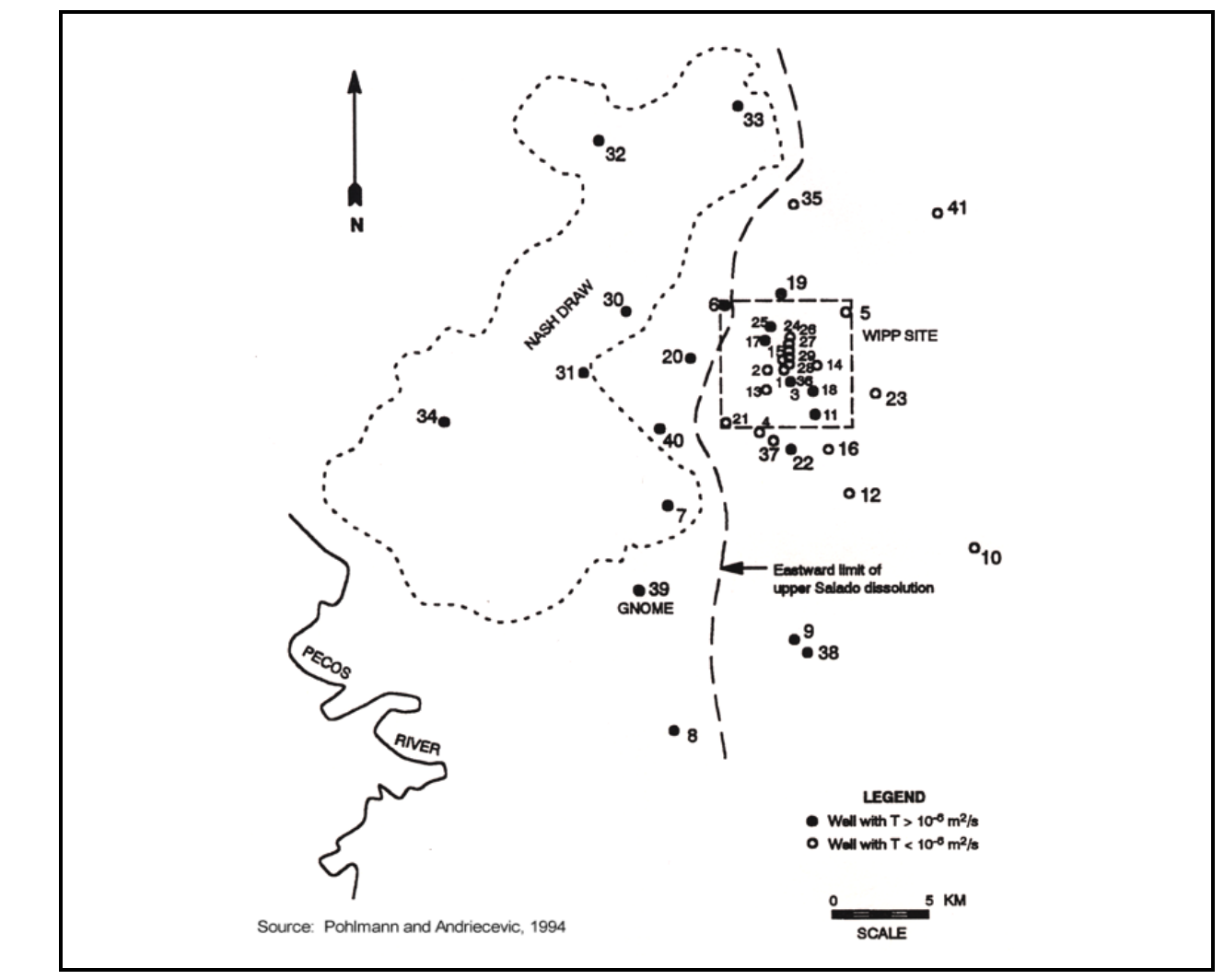

Figure 5-4

\section{Locations of Wells in the Vicinity of Gnome With Transmissivity Data}

A compressional shock wave created by a nuclear test typically travels several thousand feet before decaying to an elastic wave. This wave travels to land surface, causing a rise in surface elevation. Surface spall can occur where the surface layers split away under the influence of tensile reflections from the surface and there is subsequent slap-down when the layers fall. This can result in fracturing of the near surface rock, confined to the upper tens to several hundreds of feet below land surface and unconnected to fractures from the cavity.

At Gnome specifically, major effects due to the test were confined to a radial distance of approximately $140 \mathrm{ft}$ from the detonation point, with some curving vertical faults with slight horizontal movement observed as far as $230 \mathrm{ft}$ (Gard, 1963). A separate reference (Rawson et al., 1965) cites a zone of increased permeability to extend at least $150 \mathrm{ft}$ laterally and $345 \mathrm{ft}$ above the point of the explosion, based on loss of circulation of drilling fluid during posttest drilling (Figure 5-7). 


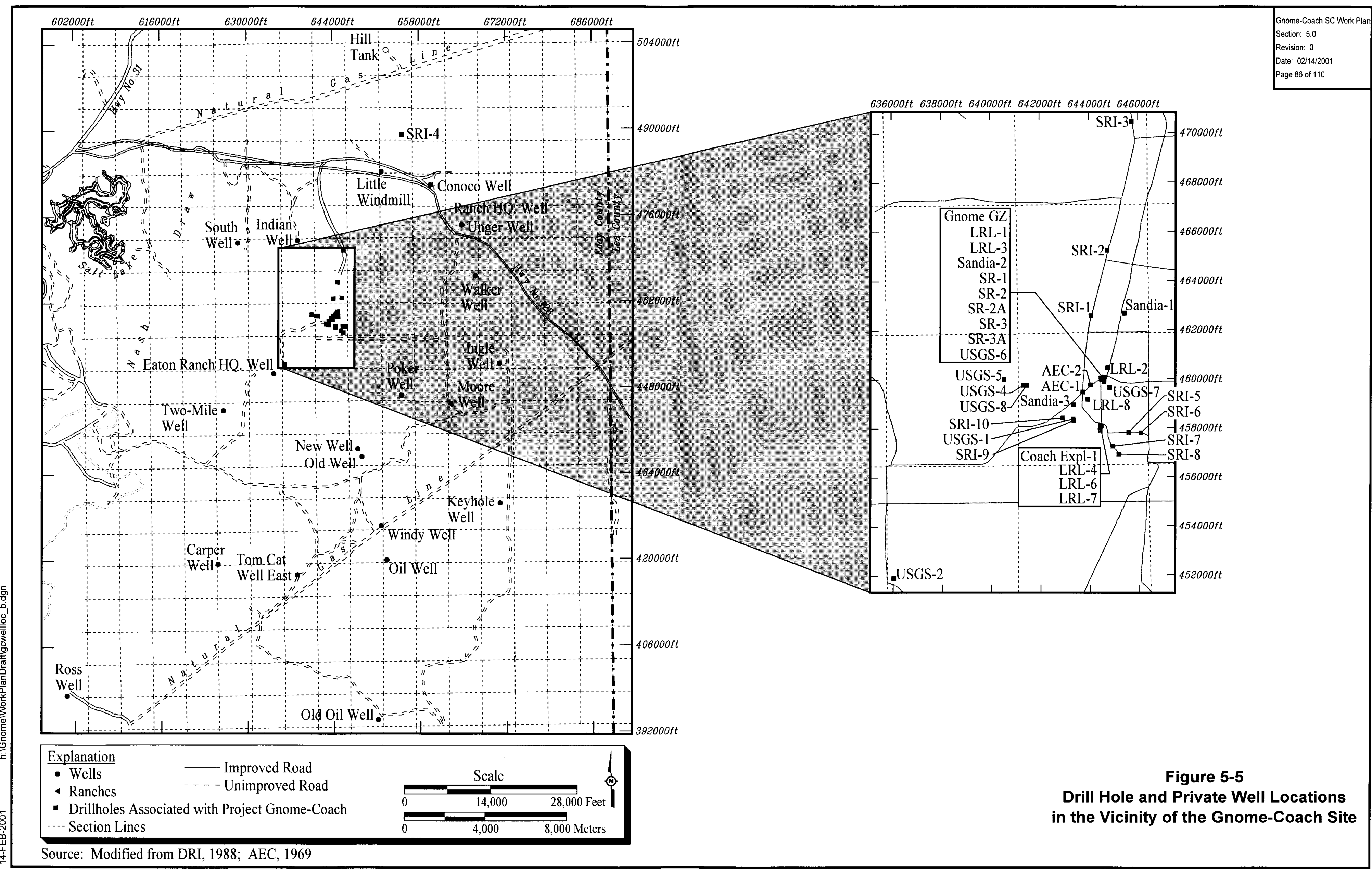




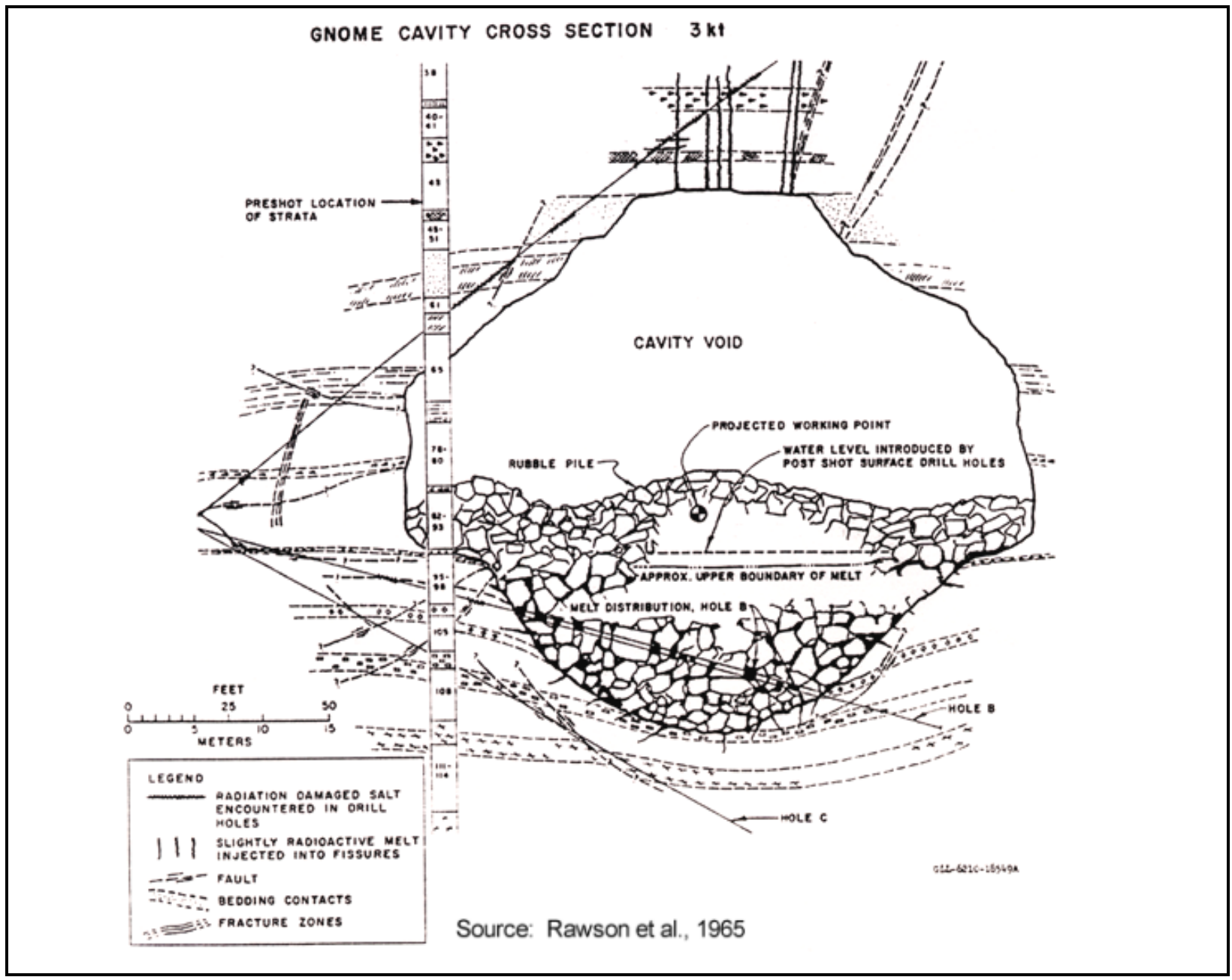

Figure 5-6 Cross-Section Through the Gnome Explosion Cavity

About 2,400 tons of melt were created and mixed with 13,000 tons of rock. Most of the melt is found in the bottom of the cavity, and most of the radioactivity generated by the test is contained in the melt. Drilling above the cavity found melt injection and radiation-damaged salt (an indicator of leakage of radioactive gases) no farther than $125 \mathrm{ft}$ above and $75 \mathrm{ft}$ below the working point. Along the equator of the cavity, but not associated with the venting, radiation-damaged salt was found to $217 \mathrm{ft}$ from the working point, with melt injected in radial cracks to a distance of $131 \mathrm{ft}$ from the working point (Rawson, 1963). Along the vent path, small amounts of melt were found injected up to $200 \mathrm{ft}$ away from the cavity along zones of weakness in clays, and up to the concrete block stemming in the open drift (950 ft from ground zero), though some of this melt is not radioactive. Melt found in radial cracks beyond the cavity generally did not contain much radioactivity, inferred to be the result of 


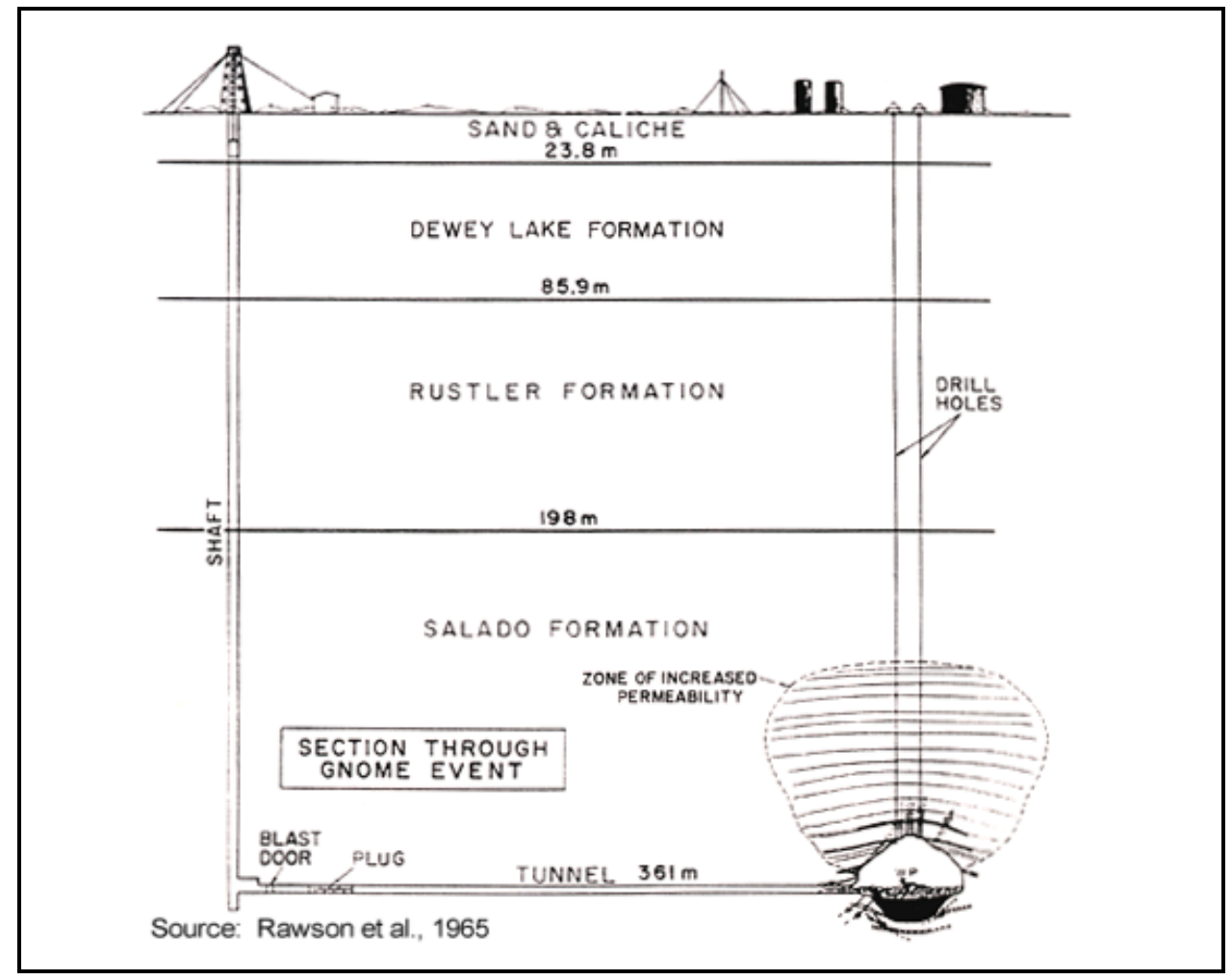

Figure 5-7

\section{Cross-Section From Land Surface Down to Gnome Activity, Showing the Shaft, Drift, and Inferred Zone of Fracturing}

injection prior to mixing of molten rock and test products in the cavity (Rawson et al., 1965).

Nathans (1965) concluded that the lower quarter of the cavity contains almost all of the radioactivity.

Underground nuclear tests are designed to prevent venting to the atmosphere; however, in the case of Gnome, the design failed. Less than a minute after the detonation, very high, short-lived, radioactivity levels were observed at the blast door in the tunnel. Three minutes later, high levels were detected at the bottom of the shaft, and after seven minutes, smoke and steam began to escape the shaft at the surface. The release continued for more than a day (AEC, 1962). During the initial release, melt and gases were able to penetrate from the cavity into the closed, but apparently permeable, line-of-site portion of the emplacement drift. This zone was structurally weak due to an open neutron pipe leading from the drift to the working point, several weak clay seams along the drift, and the relative geometry of the drifts and cavity. Rawson et al. (1965) infer that a rarefaction wave, generated by the compressional wave reflecting at the ground surface, momentarily put the cavity region under tension, causing parting of the clay seams and injection of melt through them to the open 
drift beyond. Once this happened, dynamic venting followed, with melt, rock, neutron pipe, vent line and drift material all blown down the drift to pile up at the cement plug. Melt was encountered as far as the concrete block stemming. This stemming held the pressure, as designed, but was not gas tight, reducing the dynamic venting to a gas leak. The next barrier was a blast door, where one of two rupture disks was broken, and the blowout continued up the shaft, through a filter, and out into the open. Particulate radioactivity and violent venting were contained underground, while steam and gaseous fission products escaped.

Physical examination of the shaft and underground workings found relatively minor damage as a result of the test (Randolph and Higgins, 1962). In particular, the cement lining surrounding the shaft down to the level of the Salado salt displayed only minor cracks at $75,90,160$, and 480 feet. The crack at 480 feet (20 feet above the Culebra), and a few lower cement joints, exhibited water seepage into the shaft. Given the integrity of the cement liner, the higher hydraulic head in the formations beyond the liner in the shaft, and the gaseous nature of the release, the venting cannot be considered a contaminant source for the Culebra aquifer.

\subsubsection{Hypothetical Release by Salt Creep}

The extremely low permeability and plastic deformation qualities of salt have led to its use for long-term disposal of radioactive waste (such as at the WIPP). The shaft leading to the underground workings was lined with concrete until it reached the Salado Formation halite (the shaft below that level and the drifts were unlined), and grouting was conducted by injection of cement materials through holes drilled into the Culebra (Gardner and Sigalove, 1970). Cooper (1962a) presents water levels in Well USGS-1 through the time period when grout was injected behind the shaft's concrete liner at the depth of the Culebra, recording a period of leakage into the shaft of about 5 gallons per minute, followed by "slight seepage" after final grouting. Boreholes drilled into the underground workings were similarly cased until at least the Salado Formation, and with the exception of several left open for monitoring purposes, were sealed and/or plugged and abandoned in accordance with the New Mexico State regulations regarding borehole abandonment (AEC, 1973). Given these physical constraints, the release mechanism for contaminants in the underground workings is a hypothetical one of salt creep pressurizing fluid present as the porosity of the underground workings decreases, driving contaminated water upward to contact the Culebra through a failed shaft or borehole seal. 
This mechanism requires an improbable scenario of a failed borehole seal, sufficient fluid to dissolve and transport contaminants, and the delicate timing of a pressure build-up above hydraulic head in the Culebra aquifer prior to the salt creep sealing the pathway. This sequence of events is described in Figure 5-8. Again, this scenario is considered improbable, as evidenced by the results of an investigation in 1968 of the amount of water collecting in the underground workings after site activities ended. It concluded that the leakage rate from the Culebra down the shaft must have slowed considerably from the operational estimate of 210 gallons/week in 1963, suggesting that the shaft seal remained competent (Gardner and Sigalove, 1970). Long-term hydrologic monitoring, though limited to Well USGS-1 for groundwater near the shaft, has detected no indication of contaminant migration from the cavity and shaft.

\subsection{Release and Transport from the Tracer Test}

No release mechanism is needed for contaminants remaining from the USGS tracer test, as the tritium, Sr-90 and Cs-137 remained within the Culebra Dolomite at the conclusion of the test. The conceptual model for flow and transport assumes that fracture flow dominates in the dolomite. Fracture flow will likely be numerically simulated as an equivalent porous medium, taking into account the hydraulic characteristics and effective porosity of the fracture system. Contaminant transport will include significant retardation and degradation processes: diffusion of dissolved constituents into the relatively porous matrix blocks, sorption of the reactive tracers ( $\mathrm{Sr}$ and $\mathrm{Cs}$ ) onto mineral surfaces, and radioactive decay.

Flow will be simulated based on a hydraulic gradient directed toward Malaga Bend on the Pecos River, consistent with regional head data. Discharge to the river will be evaluated, as well as concentrations crossing the DOE land withdrawal boundary. Potential exposure would be through direct exposure to contaminated groundwater (dermal and possibly ingestion routes, taking into account the poor water quality), through uptake by plants or animals from contaminated water wells (ingestion route), and through contaminant migration to surface water and uptake of the surface water (ingestion and dermal routes). 


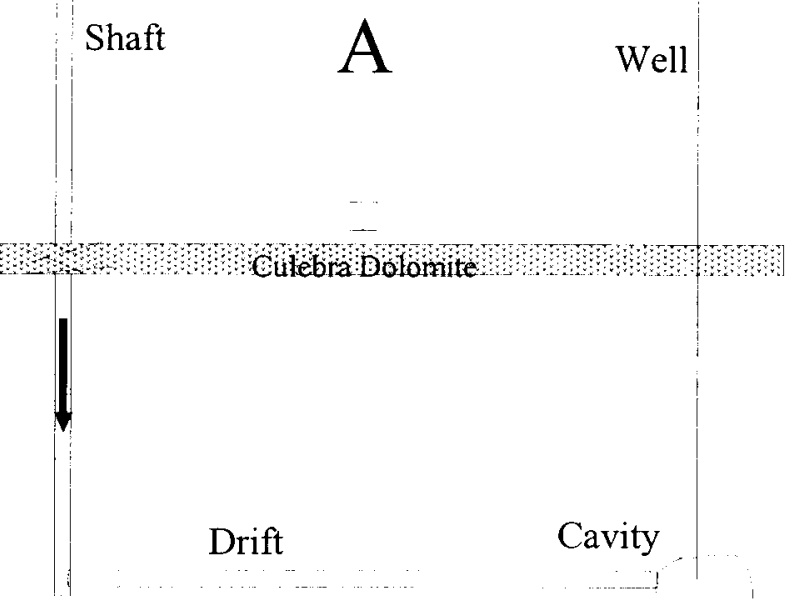

A. The hydraulic condition after the Gnome test, but prior to

disposal operations. The hydraulic head in the Culebra Dolomite is slightly higher than the elevation of the formation itself. The cavity, drift, shaft and post-test holes are at atmospheric pressure.

Examination of the shaft indicates minor water seepage into the shaft through a minor crack at a depth of $480 \mathrm{ft}$ ( $20 \mathrm{ft}$ above the Culebra) and through cement joints below that level, confirming the higher

head in the water bearing formations above the Salado.
Water Level

Cracks/Fractures

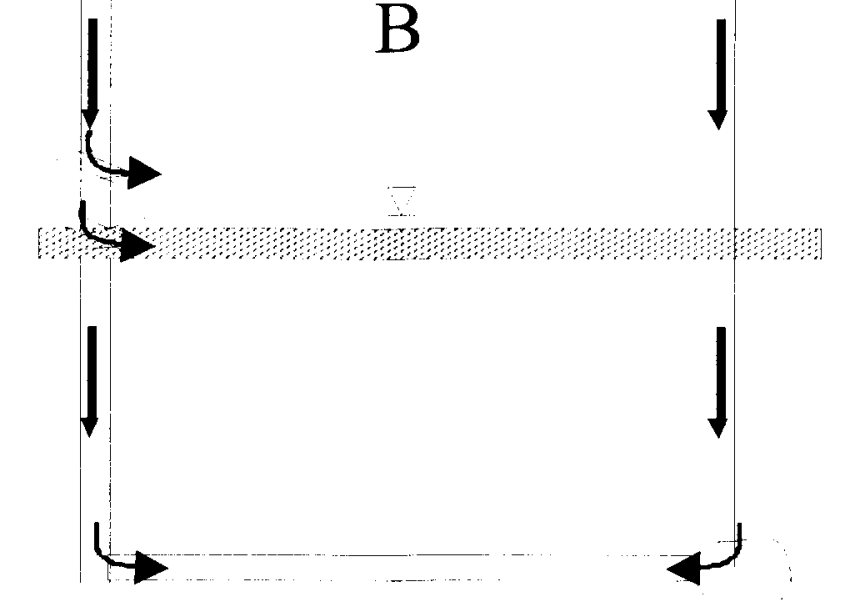

B. Disposal operations involved the injection of large amounts of fluid and slurried solids in a recirculating pattern. Records suggest that head may have been temporarily raised in the shaft and injection wells to near land surface. The majority of flow would be down the open conduits of the shaft and injection wells, but some flow out into the Culebra may have occurred through the minor crack in the cement shaft lining mentioned above (leakage out through the injection wells is less likely as they were cased and cemented through the Culebra)

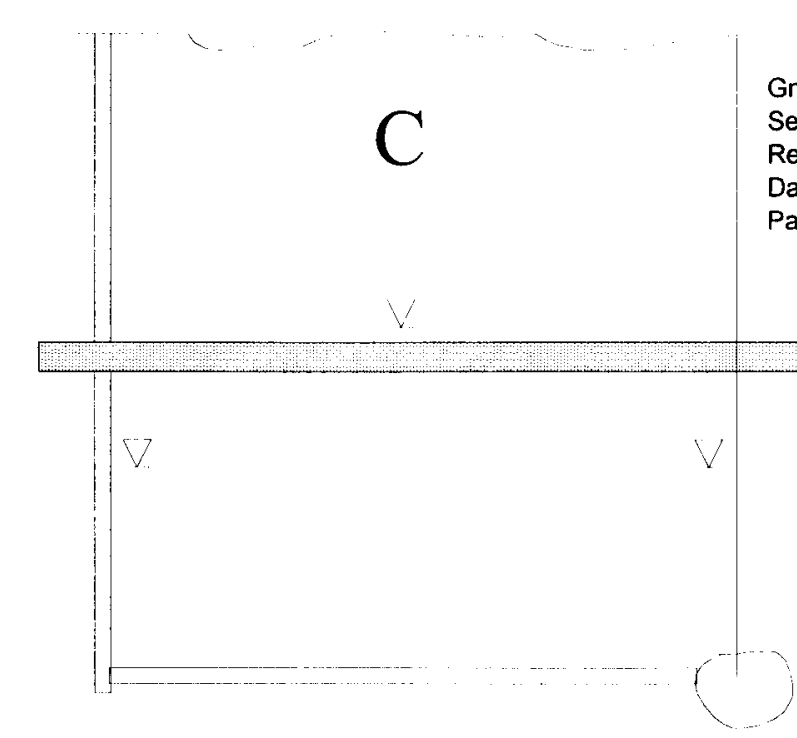

C. As disposal operations ceased and fluid filled available space in the underground workings, the hydraulic head in the cavity dropped below that of the Culebra. This is evidenced by EPA water level measurements for Well LRL-7 being at an elevation lower than that of USGS-4. Under these conditions, as for the predisposal condition, if there is any hydraulic communication, it is seepage from the Culebra down into the underground workings.

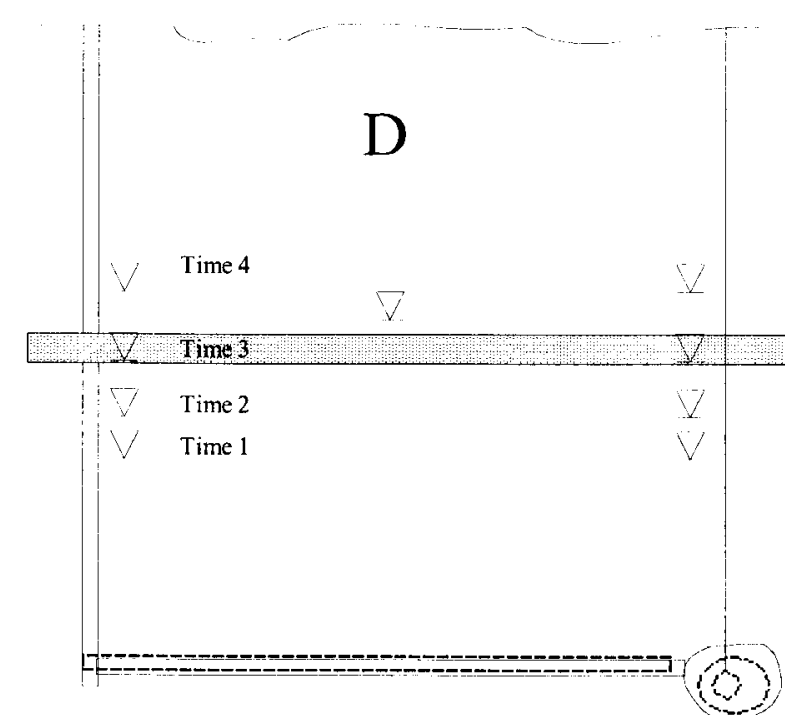

D. Under the lithostatic pressure conditions, open, mined underground spaces in the salt will begin to plastically deform and close. Based on data from the WIPP site (Munson et al., 1989), Earman et al. (1996) estimated that closure of the Gnome cavity in its original state to the point where water would be squeezed from the cavity would require 25 to 51 years, but the actual time would likely be less due to filling of the cavity during disposal operations. The creep closure will increase the hydraulic head in the cavity and drift, perhaps accelerated by seepage from the Culebra in the shaft. If the head builds up higher than that in the Culebra, a hydraulic connection will be made between the

contaminated subsurface material and the Culebra and contaminant transport could occur into the aquifer. It should be noted tha unant con the little bulds up substantially above that in the Culebra, there would be driven by much slower diffusional gradients.

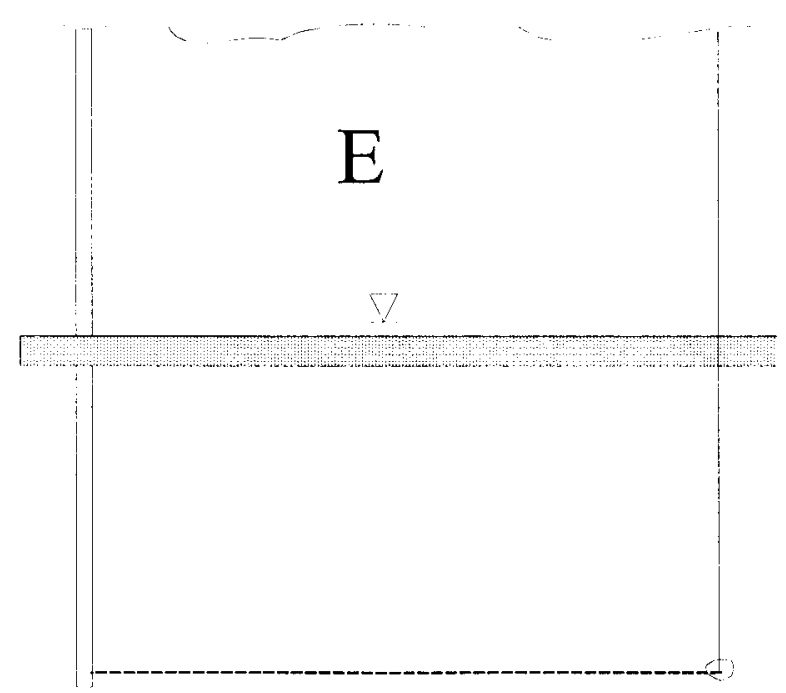

Eventually, salt creep closes the cavity and drift, sealing the migration pathway. This sealing will be hastened by the placement of large amounts of solid material into the openings for disposal. If a hydraulic connection was created between the cavity and the Culebra, the hydraulic head will eventually equilibrate. If the salt closure occurs prior to head rising above that in the Culebra, no hydraulic connection between the aquifer and cavity will be established and no contaminant migration path will exist.

Figure 5-8 


\subsection{Data Quality Objectives of Subsurface Investigation}

The objective of any subsurface modeling for Gnome is to determine if the radiological contamination in the subsurface workings of the test cavity, shaft and drift complex, or the contamination remaining in the Culebra aquifer from the tracer test, is migrating. This information will be used to identify an appropriate corrective action.

The specific objectives of the subsurface investigation are as follows:

- Determine the migration potential to the Culebra aquifer by the contamination in the Gnome cavity, drifts, and shaft.

- Determine the potential of COPC migration in the Culebra aquifer due to the tracer test.

- Determine if the potential reduction in uncertainty regarding groundwater contamination justifies the commitment of resources to collect new subsurface data.

- Determine the potential for contaminants to reach a receptor.

- Determine if existing subsurface intrusion restrictions are adequate for site closure.

- Determine if a long-term monitoring program is technically warranted.

Five decision points are identified for the subsurface investigation, with corresponding associated actions:

- If the Data Decision Analysis indicates significant uncertainty reduction is possible at a reasonable commitment of resources, then collect additional subsurface data.

- If the Data Decision Analysis indicates significant uncertainty reduction is not possible at a reasonable commitment of resources, then proceed with contaminant transport predictions using existing data.

- If the contaminant analysis (cavity) or transport predictions (tracer test), combined with existing subsurface intrusion restrictions, indicate a potential for contaminants to reach a receptor, then perform a human health dose assessment.

- If subsurface intrusion restrictions are considered inadequate to protect human health, based on the dose assessment, then adjust the existing subsurface intrusion restrictions.

- If the existing LTHMP is considered inadequate for long-term monitoring, then modify the program, if technically warranted. 


\subsection{Evaluation of Existing Subsurface Data}

The focus the cavity release investigation will be locating and compiling documentation regarding completion and stemming of boreholes into the underground workings, or on the specifics of shaft construction. A previous evaluation of a release scenario from the Gnome cavity (Earman et al., 1996) compiled readily available information pertaining to the underground test and failure scenario. This included the physical test configuration and radionuclide inventories (Rawson et al., 1965), and the record of underground disposal operations that were performed in conjunction with surface cleanup activities (DOE/NV, 1981). In addition, radionuclide concentration data and water levels have been recorded through the last several decades as part of the EPA LTHMP. These data will be carefully evaluated to see if they can add to the understanding of cavity closure processes.

There are strengths and weaknesses to the data existing to support flow and transport modeling through the Culebra Dolomite. The two primary strengths are the abundance of hydraulic conductivity data for the Culebra from studies conducted for the WIPP site (see Figure 5-4), and data on the effective porosity of the Culebra in the immediate Gnome area derived from the tracer test itself. These data represent a major strength for analysis at Gnome, providing data vital to understanding transport velocity. Another plus is the number of laboratory sorption experiments performed using the Culebra as a sorbate, both in support of the Gnome tracer test and, more recently, in support of WIPP. The tracer test will help in scaling these lab measurements to the field scale. The most significant data weakness is related to hydraulic heads. Although heads and gradients are known with reasonable confidence at and east of Gnome, there are no groundwater head measurements between the site and the Pecos River. Although this adds uncertainty, it should be noted that the river itself bounds the gradient range.

\subsection{Identification of Proper Numerical Model}

It is not planned a priori to perform numerical modeling in support of the investigation into a cavity system failure. Rather, the release analysis of Earman et al. (1996) will be combined with any additional data located to determine the threat posed to the Culebra aquifer from the Gnome test. If a modeling effort appears beneficial in the course of the investigation, it will likely focus on transport through the Culebra dolomite and/or optimization of monitoring in the Culebra. 
Several modeling studies have been performed regarding the fate of the Gnome tracer test. Two of these have used semianalytical approaches to solving the flow and transport equations (Pohlmann and Andricevic, 1994; Earman et al., 1996), and one used numerical methods (Pohll and Pohlmann, 1996). Any approach used needs to be able to simulate the processes important in the conceptual model of flow and transport. These processes and other necessary capabilities include:

- Heterogeneous spatial properties

- Steady-state and transient conditions

- Flexible boundary conditions

- Advection, dispersion, adsorption, matrix diffusion

- Radioactive decay, daughter products

- Minimal numerical dispersion

Additional considerations include the capability for multiple realizations, efficient data handling, preand postprocessors, and efficient numerical solvers.

The previous numerical codes used for Gnome include MODFLOW (McDonald and Harbaugh, 1988) and MT3D (Zheng, 1990). Though MODFLOW may be selected again, it is more likely that transport will be simulated using a particle-tracking approach. The particle-tracking, random-walk (PTRW) method has several important advantages over other numerical methods for solving contaminant migration problems, including ease of implementation, inherent conservation of mass, and lack of numerical errors (Tompson et al., 1988). In the PTRW method, the solute mass is divided evenly into a large number of hypothetical indivisible particles. The movement of the particles in the groundwater flow field is primarily a function of the groundwater velocity and, to a lesser degree, the microscopic dispersivity. By increasing the number of particles used in the simulation, the solution becomes more consistent and reliable, and predictions of solute concentrations at specific locations become more accurate.

A numerical model of flow and transport at Gnome will be used to quantify the uncertainty of transport predictions and evaluate the possible reduction in uncertainty that could be gained from a field data collection program. To characterize the uncertainty in model predictions, the probability distributions of each input random variable needs to be characterized and then analyzed to determine how these uncertainties propagate through the model itself. This is sometimes termed the prior probabilities and describes the likelihood of obtaining the true estimate of a parameter given existing 
data. The changes in uncertainty resulting from collection of additional data are determined by characterizing the posterior distributions. This describes the likelihood that a given data collection activity will obtain the true parameter estimate. The posterior distributions may be determined utilizing Bayes theorem (IT, 1998), which allows for the mean of the parameter to be significantly different after data collection, or may be simplified by assuming that the mean will be similar but the distribution around the mean reduced (Pohll et al., 1999). Evaluation of the sources of uncertainty and supporting data will determine which approach is used for Gnome. The method of Monte Carlo simulation will be used to calculate the output variances based on the prior and posterior distributions by sampling from the input distributions, performing model simulations hundreds of times, and characterizing the output distributions. Finally, the estimated uncertainty reductions will be evaluated relative to the estimated costs of the field activities.

\subsection{Investigation/Modeling Process}

The two contaminant sources in the subsurface are fundamentally different in terms of both their stratigraphic location and release mechanisms. For this reason, the process to address each is different and they are discussed separately below. Despite this, there are also similarities in terms of geographic location and aquifer of concern, so there will be strong coordination between the efforts.

\subsubsection{Investigation Strategy for the Underground Nuclear Test}

Currently, there is no technology to remediate underground nuclear cavities; therefore, the approach of the subsurface investigation for the Gnome-Coach underground workings is to use existing data and analyses to evaluate if existing subsurface intrusion restrictions and monitoring need to be adjusted to be protective of human health and the environment. The majority of contaminants are isolated within the Gnome cavity, located in the bedded salt of the Salado Formation. Lesser amounts of contamination are located in the drifts (also in the Salado salt), shaft, and disposal wells, as a result of disposal operations during surface clean-up. The shaft and wells penetrate all formations between the Salado and land surface, with grouted liners and casing through water-bearing formations.

Given that the release scenario is hypothetical and dependent upon a system failure, it is doubtful that modeling beyond what is presented by Earman et al. (1996) would add significantly to understanding the contaminant migration hazard. However, possibly important details regarding as-built specifics 
of boreholes and shafts, as well as monitoring data for system behavior, may either add confidence to existing predictions or justify additional analysis. Therefore, the strategy is to concentrate on collating all such pertinent data and identify any new data that can be obtained in a cost effective manner (such as confirming water levels in DD-1 and LRL-7, and the wellhead elevations), and determine the migration potential to groundwater in the Culebra Dolomite. From this, decisions can be made regarding the existing subsurface intrusion restriction boundary and long-term monitoring.

The steps anticipated for the cavity investigation are as follows:

1. Locate and evaluate all available completion and stemming data for boreholes and shafts intercepting the Gnome-Coach underground workings.

2. Evaluate existing data from wells into the Gnome cavity and drift (DD-1 and LRL-7) regarding contaminant concentration and water levels through time.

3. Collect additional data from existing wells, if necessary.

4. Use the information gathered in the previous steps, combined with the release analysis of Earman et al. (1996) to determine the threat posed to the Culebra aquifer from the Gnome test.

5. Use the release analysis to evaluate existing subsurface intrusion restrictions in regard to protection of human health and the environment.

6. Determine appropriate long-term monitoring, if technically warranted.

\subsubsection{Investigation Strategy for the Tracer Test}

Although the tracer test represents a much smaller contaminant mass relative to the nuclear test, it poses a much more direct problem because the radionuclides are in contact with groundwater in the Culebra Dolomite. Several modeling studies have been performed that evaluated the tracer test (Pohlmann and Andricevic, 1994; Pohll and Pohlmann, 1996; Earman et al., 1996). These models will provide the framework for evaluating the extent of contaminant migration in the Culebra aquifer.

The first step in determining the nature and extent of contaminant migration from the tracer test will be to use existing monitoring data from the EPA LTHMP and existing hydraulic data from Gnome-Coach and WIPP to build on the previous modeling efforts. The uncertainties will be evaluated and a Data Decision Analysis (Pohll et al., 1999) performed to weigh the potential reduction in uncertainty from additional data collection against the cost of such field efforts. The Culebra aquifer is highly spatially variable, a condition which tends to require the addition of large 
amounts of data to significantly affect uncertainty. The DOE will use the Data Decision Analysis, in consultation with the State of New Mexico, to determine whether additional characterization data are needed prior to evaluating existing subsurface intrusion restrictions and determining long-term monitoring. Important to this decision process will be the potential use of the Culebra aquifer, as the water quality is below New Mexico drinking water standards (NMAC, 1996).

The Data Decision Analysis process begins by quantifying the existing uncertainty and estimating the effectiveness of various field data collection efforts at reducing that uncertainty (Figure 5-9). Monte Carlo modeling techniques are used to obtain the model variance resulting from different values of input uncertainty (based on the parameters and field activities). The effectiveness of various data collection methods at reducing overall model uncertainty can then be weighed against the cost of the field activity.

The steps anticipated for the tracer test investigation are as follows:

1. Use the strengths of the previous modeling efforts to optimize a model for performing the Data Decision Analysis.

2. Incorporate any additional data derived since the previous modeling was completed in 1996 (e.g., new LTHMP and WIPP data).

3. Perform a Data Decision Analysis to provide a systematic method to measure the potential gains (through reduction in uncertainty) against the costs of acquiring new subsurface data.

4. If indicated by the analysis, collect additional data.

5. Calculate final contaminant transport predictions for the tracer test contaminants, incorporating new data if collected.

6. Use the transport predictions to evaluate current subsurface intrusion restrictions in regard to protection of human health and the environment.

7. Determine appropriate long-term monitoring, if technically warranted. 


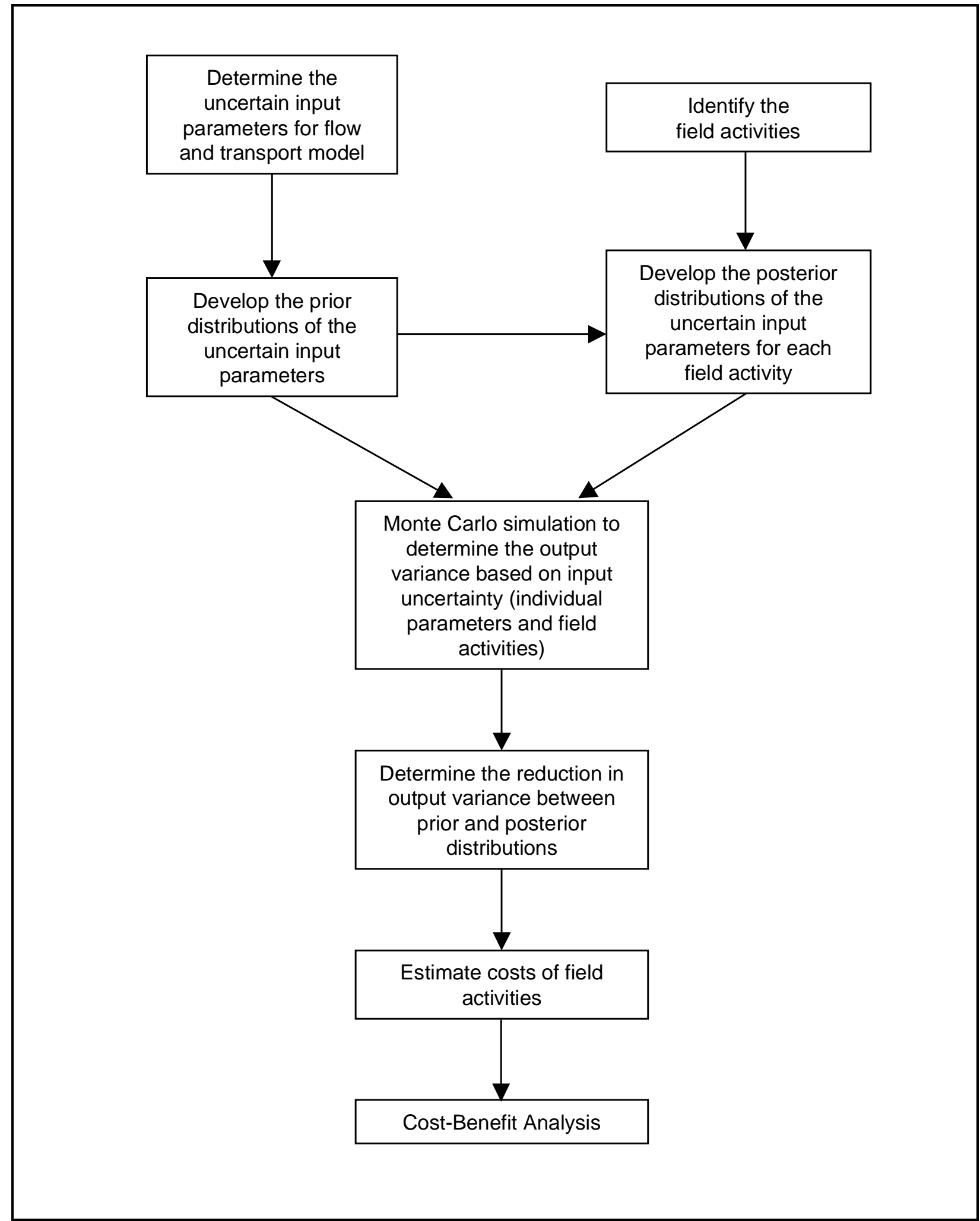

Figure 5-9

Data Decision Analysis Process 


\subsection{Evaluation of Results}

The results of the cavity investigation will be used to determine if the underground cavity and workings pose a threat to the groundwater quality in the Culebra Dolomite. The investigation of the tracer test will be used to determine the extent of radionuclide migration through the Culebra Dolomite. If either analysis indicates a potential to reach a receptor, a human health dose assessment will be performed. The existing subsurface intrusion restrictions will be evaluated, and possibly altered, depending on the results of the transport analyses and dose assessment (if performed). 


\subsection{Schedule}

\subsection{Tentative Project Schedule}

A tentative project schedule has been developed and is presented in Figure 6-1 and Figure 6-2. This schedule provides information regarding the start times and durations for the tasks to be completed as part of the Gnome-Coach Site investigation and modeling activities. This schedule also identifies dates for submission of progress reports and other reporting requirements for the Gnome-Coach project. 
Page 101 of 110

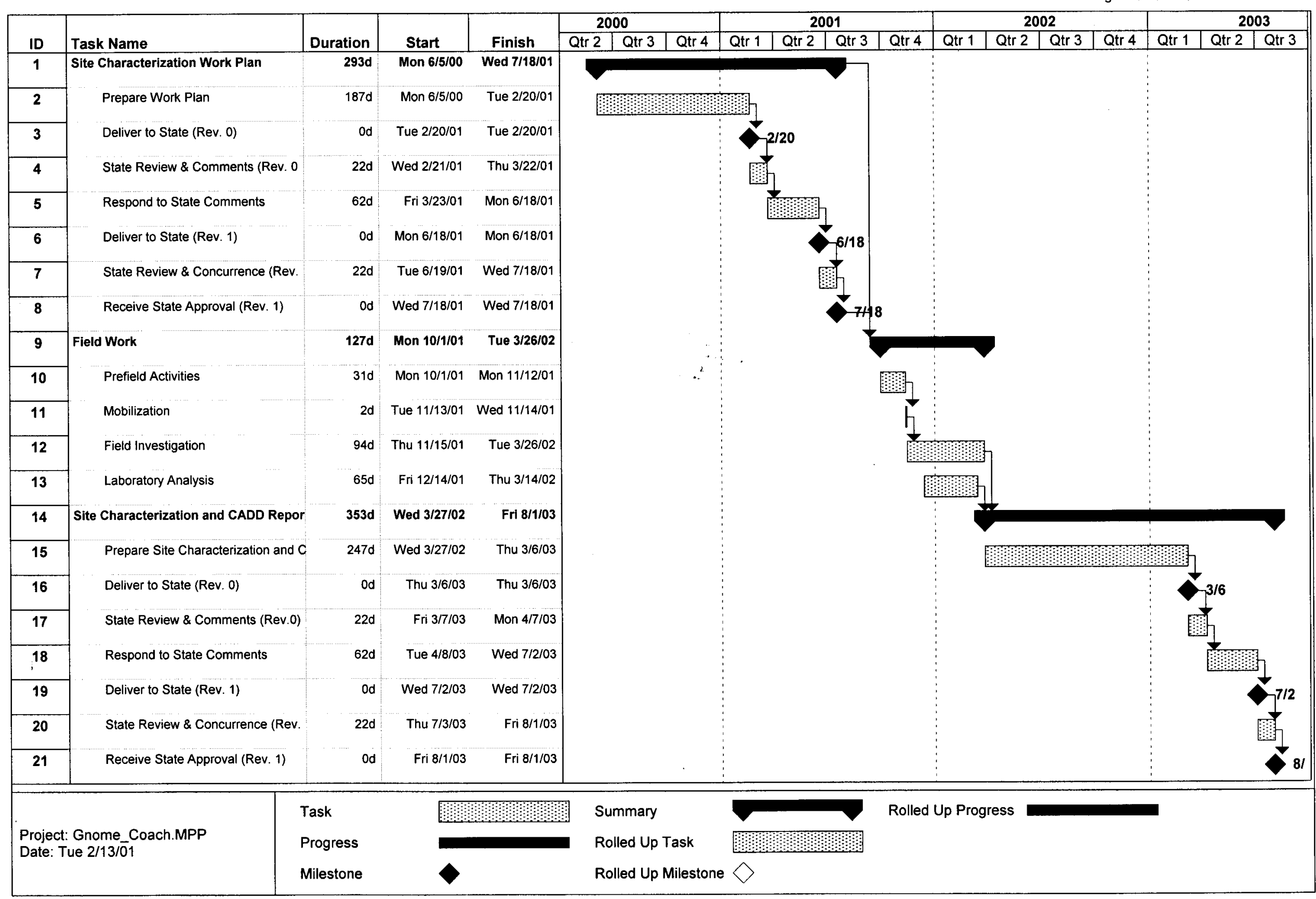


Page 102 of 110

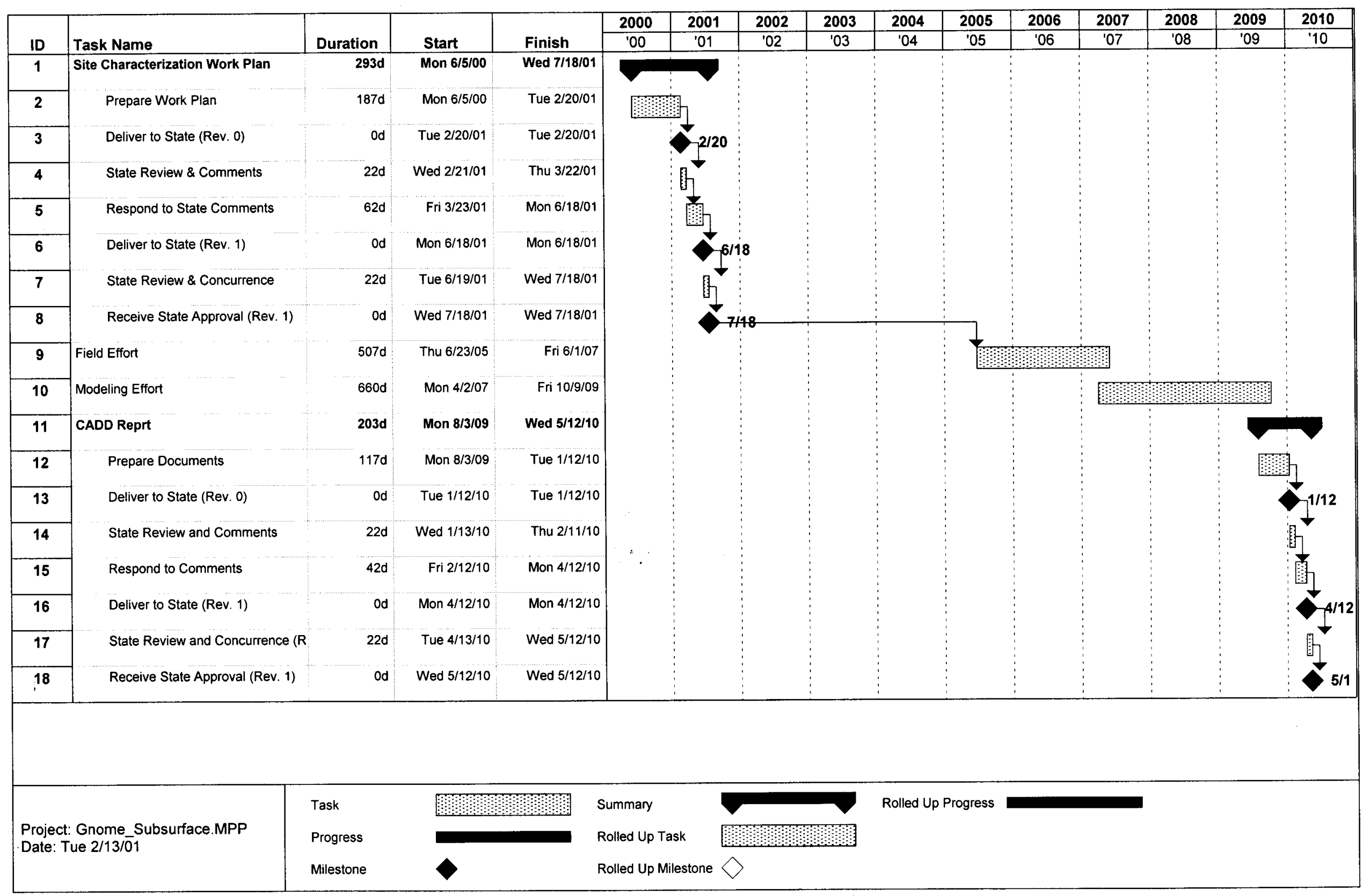

Figure 6-2

Gnome-Coach Project Proposed Schedule for Subsurface Investigation 


\subsection{References}

Adams, S.R. 2000. Concentration of Cesium-137 in Surface Soil Samples in New Mexico. ITLV interoffice memorandum, S.R. Adams to D.M. Arnold, November 30, 2000. Las Vegas, NV.

AEC, see U.S. Atomic Energy Commission.

Beetem, W.A., and C.G. Angelo. 1964. Tracer Study at Project Gnome Site, Near Carlsbad, New Mexico-Background Information, USGS Technical Letter, Carlsbad Hydrology-2. Denver, CO: U.S. Geological Survey.

Bittinger, M.L., and W.A. Beetem. 1964. Analysis of Arrival Times of Water for a Described Recharging and Discharging Well System, USGS Technical Letter, Carlsbad Hydrology-4. Denver, CO: U.S. Geological Survey.

Byerly, P.E., S.W. Stewart, and J.C. Roller. 1960. Seismic Measurements by the U.S. Geological Survey During the Pre-Gnome High-Explosive Tests Near Carlsbad, New Mexico-Final Report, USGS-OFR-TEI-761. Denver, CO: U.S. Geological Survey.

CERMC, see Carlsbad Environmental Monitoring \& Research Center.

CFR, see Code of Federal Regulations.

Carlsbad Environmental Monitoring \& Research Center. 2000. 1999 Report Carlsbad Environmental Monitoring \& Research Center, February 1. Carlsbad, NM.

Chapman, J.B. 1986. Stable Isotopes in Southeastern New Mexico Groundwater: Implications for Dating Recharge in the WIPP Area, State of New Mexico Report No. EEG-35. Santa Fe, NM: Environmental Improvement Division.

Code of Federal Regulations. 1991. Title 43, Public Land Order (PLO) 6826, "Department of Interior, Bureau of Land Management." Washington, DC.

Cooper, J.B. 1960. Geologic Section from Carlsbad Caverns National Park through the Project Gnome Site, Eddy and Lea Counties, New Mexico, USGS-OFR-TEI-767. Denver, CO: U.S. Geological Survey.

Cooper, J.B. 1961. Test Holes Drilled in Support of Ground-Water Investigations, Project Gnome, Eddy County, New Mexico-Basic Data Report, USGS-OFR-TEI-786. Denver, CO: U.S. Geological Survey.

Cooper, J.B. 1962a. Ground-Water Investigations of the Project Gnome Area, Eddy and Lea Counties, New Mexico, USGS-TEI-802. Denver, CO: U.S. Geological Survey. 
Cooper, J.B. 1962b. Hydrology and Geology of USGS Test Holes 4 and 5, Project Gnome, USGS Technical Letter, Gnome-7. Denver, CO: U.S. Geological Survey.

Cooper, J.B. 1963. Completion and Development of USGS Test Hole 8 and USGS Test Hole 4, Carlsbad Hydrologic Studies, Eddy County, New Mexico, USGS Technical Letter, Carlsbad Hydrology-1. Denver, CO: U.S. Geological Survey.

Cooper, J.B., and V.M. Glanzman. 1971. Geohydrology of Project Gnome Site, Eddy County, New Mexico, USGS-PP-712-A. Prepared in cooperation with the U.S. Atomic Energy Commission. Denver, CO: U.S. Geological Survey.

DOE/NV, see U.S. Department of Energy, Nevada Operations Office.

Desert Research Institute. 1988. CERCLA Preliminary Assessment of DOE's Nevada Operations Office Nuclear Weapons Testing Areas. Las Vegas, NV.

DRI, see Desert Research Institute.

Earman, S., J. Chapman, K. Pohlmann, and R. Andricevic. 1996. Assessment of Hydrologic Transport of Radionuclides From the Gnome Underground Nuclear Test Site, New Mexico, Publication No. 45143, DOE/NV/11508-11. Reno, NV: Desert Research Institute.

EEG, see Environmental Evaluation Group.

EG\&G, see EG\&G Energy Measurements.

EG\&G Energy Measurements. 1979. Photo Number 2988-228, 09 October. Nellis Air Force Base, NV: BN Remote Sensing Laboratory Photo Library.

EG\&G Energy Measurements. 1988. Photo Number 6014-08, 21 May. Nellis Air Force Base, NV: BN Remote Sensing Laboratory Photo Library.

Environmental Evaluation Group. 1995. Radionuclide Baseline in Soil Near Project Gnome and The Waste Isolation Pilot Plant, DOE/AL/58309-58, EEG 58. Prepared by J.W. Kenney, P.S. Downes, D.H. Gray, and S.C. Ballard. Carlsbad, NM.

EPA, see U.S. Environmental Protection Agency.

Fenix \& Scisson, Inc. 1969. Engineering Drawing, "Project Gnome-Coach Asbuilt Drawings," Number LV-171, August 28, 1969. Las Vegas, NV.

Gard, L.M., Jr. 1963. "Nuclear Explosions: Some Geologic Effects of the Gnome Shot." In Science, Vol. 139: 911-914. Washington, DC: American Association for the Advance of Science. 
Gard, L.M., Jr. 1968. Geologic Studies, Project Gnome, Eddy County, New Mexico, USGS-PP-589. Denver, CO: U.S. Geological Survey.

Gardner, M.C., and J.J. Sigalove. 1970. Evaluation of the Project Gnome/Coach Site, Carlsbad, New Mexico for Disposition, Including Identification of Restrictions, Part I, NVO-1229-106, Part I. Palo Alto, CA: Teledyne Isotopes.

Grove, D.B., and W.A. Beetem. 1971. "Porosity and Dispersion Constant Calculations for a Fractured Carbonate Aquifer Using the Two Well Tracer Method." In Water Resources Research, Vol.7 (1): 128-134. Washington, DC: American Geophysical Union.

Hale, W.E., and A. Clebsch, Jr. 1958. Preliminary Appraisal of Ground-Water Conditions in Southeastern Eddy County and Southwestern Lea County, New Mexico, USGS-OFR-TEM-1045. Denver, CO: U.S. Geological Survey.

Holmes \& Narver, Inc. 1961. Engineering Drawing Number F.D.129-3, “As Built, Project Gnome Scientific Cable Installation." Carlsbad, NM.

Holmes \& Narver, Inc. 1963. Engineering Drawing Plate 5, S34 R30 T23, “As Built, Project Gnome Site Plan." Carlsbad, NM.

IT Corporation. 1998. Value of Information Analysis for Corrective Action Unit Nos. 101 and 102: Central and Western Pahute Mesa, Nevada Test Site, Nevada, DOE/NV/13052-041.

Las Vegas, NV.

Jones, C.L. 1960. Thickness, Character, and Structure of Upper Permian Evaporites in Part of Eddy County, New Mexico, USGS-OFR-TEM-1033. Denver, CO: U.S. Geological Survey.

Knolls Atomic Power Laboratory. 1996. Chart of the Nuclides, 15th ed. San Jose, CA: General Electric Co.

Lawrence Livermore Laboratory. 1961. Photo No. GLC-6112-2592 is an aerial overview looking east of the Gnome-Coach Site in December of 1961 prior to the Gnome test. Livermore, CA: LLNL Laboratory Archives.

Lawrence Radiation National Laboratory. 1961. Engineering Drawing L6-13314, "Control Point Site Plan, Project Gnome, Carlsbad, NM,” 12 July. Livermore, CA.

LLNL, see Lawrence Livermore National Laboratory.

Long Term Surveillance Program, Gnome/Coach Site, Carlsbad, Eddy County, New Mexico, December, 1972. (Obtained from the Coordination and Information Center, Las Vegas, Nevada, Document Control Number 13635).

LRL, see Lawrence Radiation Laboratory. 
LTSP, see Long Term Surveillance Program.

McArthur, R.D., and F.L. Miller. 1989. Off-Site Radiation Exposure Review Project (ORERP), Phase II Soil Program, DOE/NV/10384-23. Las Vegas, NV: Desert Research Institute.

McDonald, M.G., and A.W. Harbaugh. 1988. A Modular Three-Dimensional Finite Difference Ground-water Flow Model, USGS, Techniques of Water-Resources Investigations, Book 6, Chapter A1. Denver, CO: U.S. Geological Survey.

Moore, G.W. 1958. Description of Core from AEC Drill Hole No. 1, Project Gnome, Eddy County, New Mexico, USGS-OFR-TEM-927. Denver, CO: U.S. Geological Survey.

NRC, see U.S. Nuclear Regulatory Commission.

NMED, see New Mexico Environment Department.

NMAC, see New Mexico Administrative Code.

Nathans, M.W. 1965. Project Gnome: Isotope Program - Final Report, PNE-102F. Livermore, CA: Lawrence Livermore National Laboratory.

New Mexico Administrative Code. 1996. Title 20 NMAC 6.2, "Ground and Surface Water Protection." Santa Fe, NM.

New Mexico Environment Department. 2000a. Application of Inorganic Background Values in the Risk Assessment Process, Position Paper, Section III.A.1.c, p.1. Santa Fe, NM: Hazardous Waste Bureau.

New Mexico Environment Department. 2000b. Use of Total Petroleum Hyrdrocarbon (TPH) Test Results for Site Characterization, Position Paper. Santa Fe, NM: Hazardous Waste Bureau.

Pohll, G., and K. Pohlmann. 1996. Evaluation of the Radionuclide Tracer Test Conducted at the Project Gnome Underground Nuclear Test Site, New Mexico, Publication No. 45141, DOE/NV/11508-08. Reno, NV: Desert Research Institute.

Pohll, G., J. Tracy, and F. Forsgren. 1999. Data Decision Analysis: Project Shoal, Publication No. 45166, DOE/NV/11508-42. Reno, NV: Desert Research Institute.

Pohlmann, K., and R. Andricevic. 1994. Scoping Calculations for Groundwater Transport of Tritium From the Gnome Site, New Mexico, Publication No. 45126, DOE/NV/10845-46. Reno, NV: Desert Research Institute.

Randolph, P., and G. Higgins (Lawrence Livermore Laboratory). 1962. Memorandum to Distribution, regarding various papers giving some early Gnome results, 29 January. Livermore, CA. 
Rawson, D.E. 1963. "Review and summary of some project Gnome results." In Transactions of the American Geophysical Union, Vol. 44(1): 129-135. Washington, DC: American Geophysical Union.

Rawson, D., C. Boardman, and N. Jaffe-Chazan. 1965. Project Gnome, Carlsbad, New Mexico, Final Report, The Environment Created by a Nuclear Explosion in Salt, PNE-107F. Prepared for U.S. Atomic Energy Commission. Livermore, CA: Lawrence Radiation Laboratory.

REECo, see Reynolds Electrical \& Engineering Co., Inc.

Reynolds Electrical \& Engineering Co., Inc. 1973. Carlsbad Reconnaissance 1972, Gnome Site. Las Vegas, NV.

Robertson, E.C., A.R. Robie, and K.G. Books. 1958. Physical Properties of Salt, Anhydrite, and Gypsum - A Preliminary Report, USGS-OFR-TEM-1048. Denver, CO: U.S. Geological Survey.

SNL, see Sandia National Laboratories.

Sandia National Laboratories. 1998. A Preliminary Human Health Risk Assessment of the Gnome Site, New Mexico. Prepared for the U.S. Department of Energy, Nevada Operations Office by S. Conrad, M. Goodrich, and T. Feeney. Albuquerque, NM.

Smith, D.D., and K.R. Giles. 1973. Report of Bioenvironmental Sampling at the Gnome Site, Carlsbad, New Mexico-October 1972, NERC-LV-539-25. Prepared for the U.S. Atomic Energy Commission. Las Vegas, NV: U.S. Environmental Protection Agency.

Tappan, J.T., and J.J. Lorenz. 1969. On-Site Radiological Safety Report, Carlsbad Site Roll-Up Program, NVO-410-2. Prepared for the U.S. Atomic Energy Commission. Mercury, NV: Reynolds Electrical \& Engineering Co., Inc.

Taylor, J.K. 1990. Statistical Techniques for Data Analysis. Chelsea, MI: Lewis Publishers, Inc.

Tompson, A.F.B., E.G. Vomvoris, and L.W. Gelhar. 1988. Numerical Simulation of Solute Transport in Randomly Heterogeneous Porous Media: Motivation, Model Development, and Application, Report No. 316. Cambridge, MA: Ralph M. Parsons Laboratory.

USDA, see U.S. Department of Agriculture.

U.S. Atomic Energy Commission. 1962. Project Manager's Report, Project Gnome, Plowshare Program, NVO-1. Washington, DC.

U.S. Atomic Energy Commission. 1969. Site Disposal Report, Carlsbad (Gnome/Coach) Nuclear Test Site, Eddy County, New Mexico, NVO-41. Prepared by Holmes \& Narver, Inc. Las Vegas, NV. 
U.S. Atomic Energy Commission. 1973. Gnome/Coach Site Disposal Options, NVO-131. Las Vegas, NV.

U.S. Department of Agriculture, Soil Conservation Service. 1971. Soil Survey of Eddy Area, New Mexico. Washington, DC: U.S. Government Printing Office.

U.S. Department of Energy. 2000. Waste Isolation Pilot Plant 1999 Site Environmental Report, DOE/WIPP 00-2225. Carlsbad, NM.

U.S. Department of Energy, Nevada Operations Office. 1978. Gnome Site Decontamination and Decommissioning - Phase I Radiological Survey and Operations Report, Carlsbad, New Mexico, NVO/0410-48, Vols. 1 and 2. Prepared by Reynolds Electrical \& Engineering Co., Inc. Las Vegas, NV.

U.S. Department of Energy, Nevada Operations Office. 1979. Project Gnome Decontamination and Decommissioning Plan, NVO-202. Las Vegas, NV.

U.S. Department of Energy, Nevada Operations Office. 1981. Gnome Site Decontamination and Decommissioning Project, Radiation Decontamination Clearance Report, March 28, 1979 September 23, 1979, DOE/NV/00410-59. Prepared by Reynolds Electrical \& Engineering Co., Inc. Las Vegas, NV.

U.S. Department of Energy, Nevada Operations Office. 1982. Long-Term Hydrologic Monitoring Program, Gnome Site, Eddy County, New Mexico, NVO-241. Las Vegas, NV.

U.S. Department of Energy, Nevada Operations Office. 1993a. A Class III Cultural Resources Survey of the U.S. Department of Energy Gnome Coach Test Site, Eddy County, New Mexico, DOE/NV/10972--56. Prepared by IT Corporation and Mariah Associates, Inc. Las Vegas, NV.

U.S. Department of Energy, Nevada Operations Office. 1993b. Floodplains and Wetlands Survey Results for the Gasbuggy and Gnome-Coach Sites, New Mexico, DOE/NV/10972-58. Prepared by IT Corporation. Las Vegas, NV.

U.S. Department of Energy, Nevada Operations Office. 1993c. Radiation Protection of the Public and the Environment, DOE Order 5400.5. Washington, DC: U.S. Government Printing Office.

U.S. Department of Energy, Nevada Operations Office. 1993d. Sensitive Species Survey Results for the Gasbuggy and Gnome-Coach Sites, New Mexico, DOE/NV/10972--54. Prepared by IT Corporation. Las Vegas, NV.

U.S. Environmental Protection Agency. 1989. Soil Sampling Quality Assurance User's Guide, Second Edition, EPA/600/8-89/046. Washington, DC. 
U.S. Environmental Protection Agency. 1992. Offsite Environmental Monitoring Report: Radiation Monitoring Around United States Nuclear Test Areas, Calendar Year 1991, EPA-600/R-93/141. Prepared for the U.S. Department of Energy. Las Vegas, NV.

U.S. Environmental Protection Agency. 1994a. Guidance for the Data Quality Objectives Process, EPA QA/G-4. Washington, DC: U.S. Government Printing Office.

U.S. Environmental Protection Agency. 1994b. USEPA Contract Laboratory Program National Functional Guidelines for Inorganic Data Review, EPA-540/R-94/013. Washington, DC.

U.S. Environmental Protection Agency. 1994c. Residual Soil Radioactivity at the Gnome Test Site, Eddy County, New Mexico, EPA 600/R-94/117. Prepared by S.H. Faller. Las Vegas, NV.

U.S. Environmental Protection Agency. 1996. Test Methods for Evaluating Solid Waste, Physical/Chemical Methods, SW-846, Third Edition, CDROM, PB97-501928GEI (CD ROM includes revisions to 1986, 1992, and 1994). Washington, DC.

U.S. Environmental Protection Agency. 1999a. Annual Water Sampling and Analysis, Calendar Year 1999, EPA-402-R-99-012. Prepared for the U.S. Department of Energy. Las Vegas, NV.

U.S. Environmental Protection Agency. 1999b. Memo from S.J. Smucker to PRG Table Mailing List regarding Region 9 Preliminary Remediation Goals (PRGs), 1 October. San Francisco, CA.

U.S. Environmental Protection Agency. 1999c. USEPA Contract Laboratory Program National Functional Guidelines for Organic Data Review, EPA-540/R-99/008. Washington, DC.

U.S. Geological Survey. 1962. Hydrologic and Geologic Studies, Project Gnome Final Report, PNE-130F. Prepared for the U.S. Atomic Energy Commission Plowshare Program. Las Vegas, NV.

U.S. Geological Survey. 1978. JAL West 100,000, New Mexico-Texas Digital Line Graph (DGL). This information was downloaded from the USGS File Transfer Protocol (FTP) on the Internet.

U.S. Geological Survey. 1985a. "Los Medanos Quadrangle, New Mexico-Eddy County, 7.5 Minute Series (Topograhic)." Denver, CO.

U.S. Geological Survey. 1985b. "Remuda Basin Quadrangle, New Mexico-Eddy County, 7.5 Minute Series (Topographic).” Denver, CO.

U.S. Nuclear Regulatory Commission. 2000. Multi-Agency Radiation Survey and Site Investigation Manual (MARSSIM), NUREG-1575/EPA 402-R-97-016. Prepared by the NRC, EPA, DOE, and DoD. Washington, DC: U.S. Government Printing Office.

Vine, J.D. 1960. Geologic Map of the Nash Draw Quadrangle, Eddy County, New Mexico. USGS-OFR-TEM-830. Denver, CO: U.S. Geological Survey. 
Zheng, C. 1990. MT3D: A Modular Three-Dimensional Transport Model for Simulation of Advection, Dispersion, and Chemical Reactions of Contaminants in Groundwater Systems. Prepared for the U.S. Environmental Protection Agency. Rockville, MD: S.S. Papadopulos \& Associates, Inc. 


\section{Appendix A}

\section{Historical Radiological Survey Review for the Gnome-Coach Site}




\section{A.1.0 Summary of Radiological Monitoring and Sampling for Gnome-Coach Site Surface}

A radiological review was performed for the Gnome-Coach Site using historical radiological data. The results of this review were used to identify the type and quantity of additional data required to effectively characterize the site. If required, the historical and new characterization data will then be used to evaluate remedial action alternatives and obtain site closure. The information presented in this appendix primarily includes results for the in situ radiological survey and soil sampling conducted to support the decommissioning and cleanup activities at the Gnome-Coach Site. A discussion of the groundwater data is included in Section 5.0 of the Work Plan; therefore, it is not included in this appendix.

\section{A.1.1 Historical Radiological Monitoring}

Several reports have been prepared that summarize the radiological surveys conducted before and during the Gnome detonation, and as part of the immediate postdetonation monitoring and cleanup. These surveys were conducted between December 1961 and January 1962. The principal reports that summarize this data include:

- Project Gnome - Final Report, On-Site Radiological Safety Report (AEC, 1962a). This report summarizes the results of the on-site radiological program conducted during detonation and postdetonation activities.

- Aeroradioactivity Survey and Geology of the Gnome (Carlsbad) Area, New Mexico and Texas (ARMS-1) (AEC, 1965). This report presents the results of pre- and postdetonation aerial radiation surveys.

- Radiological Survey of the Area Surrounding the Project Gnome Test Site Carlsbad, New Mexico (EG\&G, 1973). This report was prepared after the 1968-1969 cleanup of the site and presents the results of postdetonation aerial surveys and soil sampling.

Gnome-Coach Site deactivation started in 1968. Five additional on-site surface radiological sampling and survey programs were conducted after 1968. The sampling programs were conducted in conjunction with the site restoration efforts conducted in 1968-1969 and 1977-1979. The Carlsbad Site Roll-Up Program (Tappan and Lorenz, 1969) addresses the 1968-1969 cleanup. The cleanup in 1977-1979 is discussed in the Phase I Gnome Site D\&D Report (DOE/NV, 1978) and the Gnome Site 
D\&D Clearance Report (DOE/NV, 1981). A third sampling program was conducted during the 1972 site reconnaissance survey (Carlsbad Reconnaissance, 1972 [REECo, 1973]). The fourth Gnome-Coach sampling/survey program was conducted in 1992 by the EPA for a surface characterization study (EPA, 1994). A fifth soil sample/survey program was conducted in 1994-1995 by the EEG to obtain information on long-term trends in radionuclide transport in the area surrounding the WIPP (EEG, 1995).

The documents listed above were reviewed along with other historical documents to determine the current radiological status of the surface and shallow subsurface at the Gnome-Coach Site. For simplicity, shallow subsurface is defined as soil contamination associated with surface activities conducted at the site. Deep subsurface contamination is associated with test cavity, shaft, and drifts. The historical document review was conducted to identify areas where data gaps may exist, areas where no contamination was encountered and additional characterization data is not required, and areas where corrective actions have been completed and no additional characterization data is required. Results from the data evaluation were used to perform a radiological screening evaluation (Appendix C), which in turn was used to strategize and focus the site characterization activities presented in this work plan.

This appendix is organized as follows:

- Section A.1.0 - Introduction and Summary of Areas of Concern

- Section A.2.0 - Summary of surveys conducted between 1961 and 1962

- $\quad$ Section A.3.0 - Summary of surveys conducted between 1968 and 1979 (To maintain the fluency of Section 3.0 text, all figures are provided at the end.)

- Section A.4.0 - Summary of surveys conducted from 1979 to Present

- Section A.5.0 - Conclusions

- Section A.6.0 - References

\section{A.1.2 Summary of Areas of Concern}

The historical data review identified 18 AOCs that may be impacted by radiological contamination. A brief description of each AOC is provided below. A more detailed discussion of the AOCs is included Section 2.0 of the Work Plan. The locations of the AOCs are presented on Figure A.1-1. 


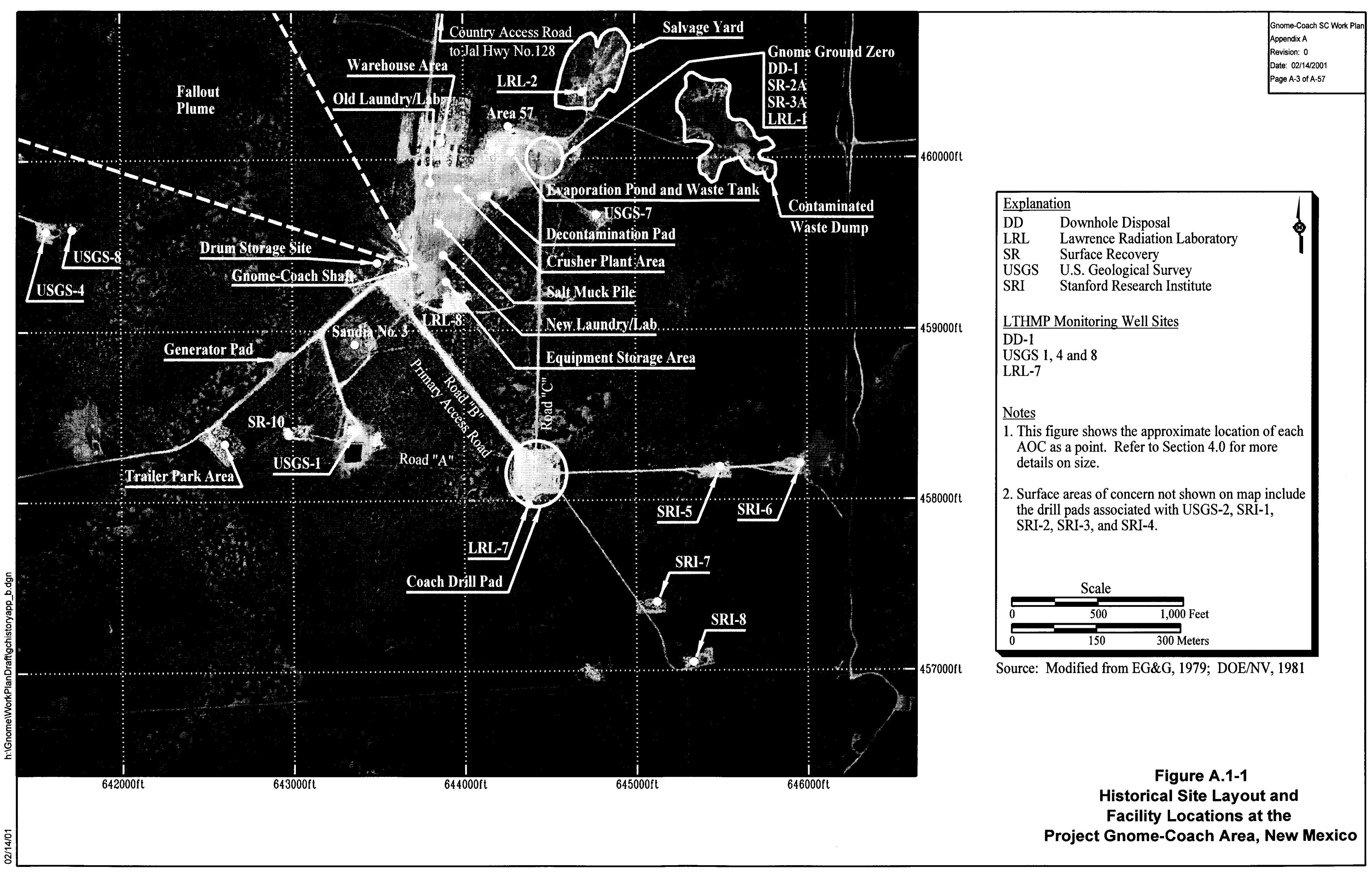




\section{Contaminated Waste Dump}

The CWD was used for the burial of radiologically contaminated soil and debris (e.g., metal, wood, salt muck, insulated wiring) generated from the Gnome mine-back operations. During the 1969 CWD cleanup, four burial pits were identified within the waste dump containing contaminated soil and debris measuring greater than $0.1 \mathrm{mR} / \mathrm{hr}$. This material was removed and disposed of in the Gnome shaft and Coach drift (Tappan and Lorenz, 1969). During the 1979 cleanup, additional contaminated soil and debris above the established 1979 cleanup levels was removed from the CWD and disposed of in the Gnome test cavity (DOE/NV, 1981).

\section{Salvage Yard}

The salvage yard was used to store material salvaged during Gnome-Coach Site operations and may potentially contain mud pits from well drilling. Metal scrap and debris were left in place after the 1968-1969 cleanup effort. Soil samples taken during the 1972 reconnaissance revealed gross gamma activity ranging from 4.5 to $46 \mathrm{pCi} / \mathrm{g}$. Scrap metal and burned debris were excavated and disposed of in the test cavity during the 1977-1979 cleanup effort. Only the burned debris had elevated radiological levels.

\section{Warehouse Area}

The warehouse was used to store hand tools and equipment, no other uses were identified.

Radiologically contaminated material and concrete were removed from the warehouse during the 1968-1969 cleanup (Tappan and Lorenz, 1969). Buried scrap metal was uncovered during the 1977-1979 cleanup and disposed of either in the Gnome cavity or shipped to the NTS.

\section{Waste Tank - Evaporation Pond}

The evaporation pond and liquid waste tank were utilized as part of the power measurement program at SGZ. During this program, contaminated liquid waste was generated and pumped from the cavity to the waste tank and evaporation pond. During the 1968-1969 cleanup (Tappan and Lorenz, 1969), all the liquid waste from the tank and pond was pumped into the Gnome Cavity. An additional $12 \mathrm{ft}$ of soil beneath the pond liner was found to be contaminated and was removed. This material was disposed of in the Gnome cavity. 


\section{Gnome Surface Ground Zero (SGZ), SR-3A, and DD-1 Monitoring Well}

This AOC includes an area measuring $200 \times 200 \mathrm{ft}$ and was used for postdetonation drilling operations of reentry wells SR-2A and SR-3A (DOE/NV, 1978). This area potentially contained mud pits from well drilling. Well DD-1 was also installed at this location in July of 1979 to provide access to the Gnome cavity for the disposal of the salt/soil slurry from decommissioning operations. Well DD-1 was not plugged after its use, but remained open for the LTHMP. Radiological contamination of the SGZ and Well DD-1 area occurred as a result of drill-back operations into the test cavity and the slurry disposal operations. Sample results from SGZ, Well SR-3A, and Well DD-1 were combined for this summary because of the overlap in geographic location.

\section{Decontamination Pad}

A decontamination pad was used for the decontamination of equipment and facilities associated with Gnome-Coach Site during posttest activities (DOE/NV, 1978). Decontamination techniques included high-pressure detergent washing, vacuuming, and the use of solvents (AEC, 1962b).

\section{Old Laundry/Laboratory}

Laundry decontamination and counting laboratory activities were performed at this facility during the drill-back activities. Sections of the area were contaminated by material spilled from trucks which hauled contaminated waste during the 1968-1969 cleanup. The area was subsequently cleaned up in 1979 (DOE/NV, 1978). At the end of 1977-1979 cleanup activities, about 6,000 cubic yards $\left(\mathrm{y}^{3}\right)$ of uncontaminated salt was buried in a $380 \times 95 \times 12 \mathrm{ft}$ trench in this area and covered with crushed concrete and $6 \mathrm{ft}$ of clean soil. The trench covers the entire areal extent of this facility.

\section{New Laundry/Laboratory}

This facility was built to provide a more centralized location for laundry and radiochemical laboratory activities. The principal radiological contamination of this facility was subsurface activity in the sump area (DOE/NV, 1978). During the 1977-1979 cleanup, one trench was dug across the New Laundry/Lab sump area to determine the area encompassed by the sump (DOE/NV, 1978). 


\section{Salt Muckpile}

Mine tailings from the construction of the Gnome drift and shaft were placed approximately $100 \mathrm{ft}$ north of the shaft. After the Gnome test, low-level radiologically contaminated salt from Gnome reentry operations was deposited on top of the pile, then clean salt from the Coach drift construction was placed over this (DOE/NV, 1978). The salt muckpile eventually encompassed an area of approximately $140,000 \mathrm{ft}^{2}$. The muckpile was left in place following the 1969 cleanup. However, all of the radiologically contaminated salt muck was later removed during the 1979 cleanup by injection into the Gnome cavity or disposal as solid waste at the NTS (DOE/NV, 1981).

\section{Gnome-Coach Shaft Surface Area}

The ground area surrounding the shaft was used for postdetonation drilling operations and Project Coach construction. Radiological contamination of soil and equipment resulted from the venting episode following the Gnome detonation, postdetonation drill-back operations, and disposal of contaminated materials during cleanup efforts. Radiologically contaminated material and equipment were disposed of down the shaft. At the completion of disposal operations into the shaft, the concrete shaft collar was demolished with explosives to a depth of $5 \mathrm{ft}$ bgs prior to setting a permanent concrete plug. The destruction of the collar deposited small contaminated concrete and soil particles on the surface; however, the material was excavated and disposed of in the shaft.

\section{Venting Fallout Track}

During the execution of Project Gnome in 1961, radioactive gas vented through the shaft and low level fallout occurred in a northwest direction. The 1977 and 1979 aerial radiological surveys (DOE/NV, 1981) and 1994 EPA soil sample results (EPA, 1994) show the highest concentration of residual gamma contamination at a small area about $490 \mathrm{ft}$ northwest of the shaft. The EEG surveys (EEG, 1995) confirmed residual contamination in the same approximate area. The surface radiological contamination associated with the venting episode only extends a short distance from the shaft. However, small particles from demolishing the shaft collar during cleanup may also contribute to isolated contaminated locations. 


\section{Equipment Storage Area}

This area was used as a holding area for tunneling equipment and may have been used as a sand-blasting area for radiologically contaminated drill pipe (DOE/NV, 1978). The results of the DOE final status survey indicate that surface radiological contamination does not exist at this AOC (DOE/NV, 1981).

\section{Area 57}

This site became of interest during 1977 Phase IA investigation when surface radiation levels above background were measured. Contamination in this area was supposedly due to runoff from one of the contaminated locations closely associated with this area (DOE/NV, 1978). It is important to note that Area 57 is referred to as NFCS (unknown acronym) in the 1979 Phase II/III sampling program.

\section{Road Between the Salvage Yard and the CWD}

A dirt road approximately $700 \mathrm{ft}$ long existed in front of the Salvage Yard and the CWD. The road between these two areas of concern was contaminated during the mine-back operations, when contaminated soil and debris was transported to and from the CWD and/or salvage yard from other areas of the site (DOE/NV, 1978).

\section{Crusher Plant}

A crushing and slurry facility (consisting of crushers, conveyor belts, and mixing tanks) was set up on north side of the salt muckpile during the 1979 final phase of cleanup. The crusher reduced solids (salt muck and soil) to a size which could be mixed with gel-water to form a slurry that was subsequently pumped from mixing tanks into a disposal well.

\section{LRL-7 Drill Pad Area}

The LRL-7 hole was originally drilled as a cable hole into the Coach drift for the Project Coach experiment (DOE/NV, 1979). The well was subsequently used to slurry contaminated salt/soil into the Gnome cavity during the 1969 cleanup (DOE/NV, 1979). Hole LRL-7 was redrilled and opened during the 1977-1979 cleanup effort. Reportedly, a screen system was installed over a return pit and cement cuttings were collected and later injected into the cavity with the salt muck (DOE/NV, 1979). 
Hole LRL-7 was then configured to support the slurry operations in 1979 by hooking up a recirculating system to the Gnome cavity with a water line between the hole, SR-2A and later DD-1 (DOE/NV, 1979 and 1981). The well was left open at the completion of cleanup efforts so that it could be used as part of the LTHMP. Sample results from the water line area have been included with the LRL-7 sample data.

\section{LRL-8 Drill Pad Area}

Hole LRL-8, located about $300 \mathrm{ft}$ southeast of the main shaft, was used for downhole disposal of contaminated slurried salt/soil during both cleanup efforts. Analytical results from the 1979 sampling programs under the heading "Study 32" have been identified as the area surrounding the LRL-8 hole based on location coordinates. Hole LRL-8 was reported as being plugged and abandoned during the 1977-1979 cleanup operations (DOE/NV, 1979).

\section{Monitoring Wells USGS-4 and USGS-8 Surface Area}

In 1963, the USGS conducted a hydrologic tracer test in which Cs-137, tritium, I-131 and Sr-90 were injected into the Culebra aquifer at Well USGS-8 and pumped to Well USGS-4. This fluid purged from Well USGS-4 was reinjected in USGS-8. The soil surrounding the wells may have become contaminated from minor fluid spills during the reinjection phase of the tracer test. Both of these wells are sampled annually by EPA as part of the LTHMP. 


\section{A.2.0 Monitoring and Surveys During Detonation and Post Shot Drilling (1961 - 1962)}

Several reports have been prepared that summarize the radiological surveys conducted before and during the Gnome detonation, and as part of the immediate postdetonation monitoring and cleanup. These surveys were conducted between December 1961 and January 1962. The data from these reports were reviewed and determined they are no longer applicable in describing the contamination that currently exits at the Gnome-Coach Site. However, these surveys are useful in presenting the level of radioactive contamination present before site cleanup was performed.

Aerial and ground surveys were conducted immediately after the detonation and after the venting episode from the shaft. Radioactive contamination was detected in the venting cloud and at the ground surface downwind of the shaft. However, within days after the detonation, the radioactivity had significantly decreased because most of the radiation measured was from isotopes with relatively short half-lifes. Subsequent radiation surveys and soil sampling indicate that the radioactive contamination measured in 1962 has decreased to levels similar to background at the Gnome-Coach Site.

\section{A.2.1 Aerial Radiation Surveys (December 9 and 10, 1961)}

A predetonation aerial radiological survey was conducted on December 9, 1961 (AEC, 1965), and a postdetonation aerial radiological survey was conducted on December 10, 1961 (AEC, 1962b). The purpose of these surveys was to measure radiation levels over the Gnome-Coach Site and surrounding areas before and after the nuclear detonation and observe any increase in radiation caused by the detonation. The December 9, 1961, aerial radiological survey results were within the range of natural background exposure rates.

An aerial and ground radiation survey using a helicopter-based platform performed cloud tracking on December 10, 1961, after the detonation. The maximum near-field exposure rates occurred 22 minutes after the detonation and were in excess of $2,000 \mathrm{mR} / \mathrm{hr}$ in the venting cloud. For comparison, $2,000 \mathrm{mR} / \mathrm{hr}$ is approximately the radiation flux for a whole-body magnetic resonance image (MRI) (NCRP, 1993). This data was not used for the radiological screening evaluation or site characterization because it does not represent what was measured at the ground surface or currently 
exists at the site. The data is being presented to demonstrate the amount of radioactive material that vented after the detonation.

\section{A.2.2 Ground Radiation Surveys}

Due to the unanticipated postdetonation venting, the initial ground radiation survey was reduced and the schedule delayed. The initial radiation survey was limited to the main access road with the largest measurement 1,300 ft north of SGZ area with an exposure rate of $35 \mathrm{mR} / \mathrm{hr}$. After several hours, survey teams were again dispatched to collect radiation readings at locations of interest. A postdetonation radiation exposure rate measured at ground level in the path of the plume (northwest) seven hours after detonation was $1,000 \mathrm{mR} / \mathrm{hr}$. The highest reported exposure rate was $5,000 \mathrm{mR} / \mathrm{hr}$ measured at $10 \mathrm{ft}$ east of the Vent House near the shaft (AEC, 1962a). The day of the detonation, an exclusion zone perimeter was established approximately $200 \mathrm{ft}$ from the shaft. One day following the detonation, exposure rates had decreased to a level that allowed workers to enter the exclusion zone. Historical records indicate personnel exposure rates for the workers averaged 2 to $5 \mathrm{mR} / \mathrm{hr}$ in the days following the detonation (AEC, 1962a). The data was not used for site characterization and is being presented only to demonstrate the amount of radioactivity that was present immediately after the detonation.

\section{A.2.3 Decontamination and Standby Status}

A major decontamination program was initiated after it was determined that there was no longer a significant human health or contamination problem. Decontamination techniques included the removal and burial of contaminated material, high-pressure water washing with added detergents, washing with solvents, and vacuuming. Logging and coring equipment were decontaminated to levels to allow off-site release to the contracting organization (AEC, 1962a). After the two reentry well drill rigs were released, the equipment and piping was disassembled, weatherproofed, and moved to an on-site storage area. The SGZ area was then relandscaped with road equipment and the spray pond was drained and covered (AEC, 1962b).

From 1963 to 1968, the Gnome-Coach Site was placed in a caretaker status. In February or March 1963, the AEC planned to conduct Project Coach and construction activities were initiated. 
However, Project Coach was cancelled in late 1963. The caretaker staff was reduced during 1965 and 1966 and approval to deactivate the site was given on May 27, 1968 (DRI, 1988). 


\section{A.3.0 Monitoring and Surveys for Decommissioning Activities (1968 through 1979)}

Major site restoration efforts were conducted in 1968-1969 and 1977-1979. An area reconnaissance was performed in 1972 between the two site restoration efforts. The initial restoration effort conducted in 1968 and 1969 occurred as part of site deactivation authorized in 1968. The purpose of a 1972 reconnaissance was to verify observations that the salt muckpile was eroding and to measure the radiological conditions that remained after the 1968-1969 cleanup effort. The 1977-1979 restoration activities included well plugging and abandonment; decontamination; disposal of equipment, soil, and salt muck into the Gnome cavity, shaft, and drift complex; soil sampling; and analysis.

Site deactivation and cleanup activities were performed to radiological standards, based on the existing Federal and State of New Mexico regulations and industry and DOE standards. Subsequent radiological surveys and sampling indicate that these standards were generally met. However, since these cleanup activities were completed, these standards have generally become more restrictive.

\section{A.3.1 Site Decommissioning}

The Gnome-Coach Site underwent an initial decontamination effort between 1968 and 1969, an area reconnaissance in 1972, and a second major decontamination cleanup effort between 1977 and 1979 (Tappan and Lorenz, 1969; DOE/NV, 1978; DOE/NV, 1981). These three efforts are briefly summarized below.

\section{A.3.1.1 Initial Decommissioning Effort, 1968 - 1969}

An account of the sampling activities, radiological analytical results, and cleanup conducted during the initial decommissioning effort is presented in On-site Radiological Safety Report, Carlsbad Site Roll-up Program, 1969 (Tappan and Lorenz, 1969). The 1968 and 1969 cleanup was undertaken following radiological release guidelines that specified removal of all contaminated material above $0.1 \mathrm{mR} / \mathrm{hr}$ beta plus gamma, as measured by a $30-\mathrm{mg} / \mathrm{cm}^{2}$ Geiger Mueller portable survey instrument. Cleanup activities were conducted site-wide, but focused primarily on the operational areas that included a liquid waste disposal tank, evaporation pond, miscellaneous storage sites and facilities, 
and the CWD site. Various decontamination methods were employed including the disposal of all radioactive materials (i.e., salt muck, liquid wastes, metal, wood, insulated wiring, dump trucks, mine cars, drill rig equipment, the Gnome shaft headframe, and the concrete collar) into the Gnome shaft and drift and the Coach drift (Tappan and Lorenz, 1969). The contaminated materials filled the Gnome shaft to within $7 \mathrm{ft}$ of the surface. The shaft was backfilled with uncontaminated gravel and soil to within $5 \mathrm{ft}$ of the surface and then sealed with a concrete plug and pad to form a permanent plug (Gardner and Sigalove, 1970). Cleanup activities at the salvage yard and the CWD consisted of the burial of low-level radioactive soil by excavating trenches, burying the contaminated material, and covering it with approximately $2 \mathrm{ft}$ of clean fill.

Exploration of the salt muckpile was undertaken during this initial cleanup effort and consisted of drilling, monitoring, and sampling the muckpile contents to determine the extent and degree of radiological contamination. The results from the sample analyses indicated elevated levels of radiological contamination within the muckpile. The AEC Nevada Operations Office considered the amount of overburden and decided that the limited radioactivity within the salt muckpile was "sufficiently low in radiological content" to present no significant environmental or health hazard (Tappan and Lorenz, 1969). No cleanup activities of the muckpile were conducted during the 1968-1969 cleanup.

During the 1968-1969 cleanup, all above ground materials and facilities were removed, and all drill holes were plugged, except those retained for long-term hydrological monitoring.

\section{A.3.1.2 Site Reconnaissance, April 1972}

In 1972, a site reconnaissance and survey was conducted with the objective of verifying reported observations that the muckpile was eroding away and its exact radiological condition was not known. A site visit was conducted in April 1972 primarily to sample the surface of the eroding muckpile. However, additional areas (decontamination area, clean scrap yard, CWD, shaft area) were also surveyed. One area in the "clean scrap yard" was found to have elevated radiological levels (45 mrad/hr) on pieces of fiberglass (REECo, 1973).

The 1972 reconnaissance concluded that a more extensive survey with additional sampling was needed at the Gnome-Coach Site (REECo, 1973). Between 1973 and 1977, additional surveys were 
made to reassess public safety and environmental conditions on and near the Gnome-Coach Site (DRI, 1988). These additional surveys led to the second cleanup effort conducted between 1977 and 1979.

\section{A.3.1.3 Second Decommissioning Effort, 1977 - 1979}

Between 1977 and 1979, DOE/NV implemented a D\&D operational plan for the Gnome-Coach Site. This plan was conducted in a phased approach (DOE/NV, 1978 and DOE/NV, 1981) and included the following:

\section{August 1977 - September 1978}

Phase I - Aerial and ground radiological surveys were conducted to establish radiological release criteria and an operational plan for D\&D activities was developed.

\section{March 1979 - September 1979}

Phase II - Existing monitoring wells were cleaned out and other miscellaneous preparations made for the anticipated D\&D activities.

Phase III - The operational plan was executed for the disposal of contaminated materials in accordance with the approved radiological release criteria. A final status survey and sampling for residual radioactive material was also conducted.

The radiological release guidelines used for the D\&D at the Gnome-Coach Site, as described in DOE/NV's operational plan (DOE/NV, 1979) for the 1977 through 1979 cleanup are as follows:

- Decontamination to levels below $2 \times 10^{-5} \mu \mathrm{Ci} / \mathrm{g}(20 \mathrm{pCi} / \mathrm{g})$ for beta-gamma emitters in soil, averaged over 0.25 ha $(0.62$ acre $)$

- $3 \times 10^{-2} \mu \mathrm{Ci} / \mathrm{mL}(30,000 \mathrm{pCi} / \mathrm{mL})$ of tritium in soil moisture

These guidelines are more conservative than those applied during initial cleanup in 1968-1969. Because the Phase I radiological survey results indicated tritium and Cs-137 as the indicator beta/gamma-emitters, the decontamination criteria were applied as if all contamination were Cs-137 and tritium (DOE/NV, 1981). 
The D\&D plan called for the contaminated materials to be disposed of into the Gnome cavity and drift and the Coach drift. Major site decontamination and restoration preparation activities included the rehabilitation and installation of a pump in Well USGS-1 for use as an operational water supply and the excavation of a water storage reservoir, cleanout and opening of the Gnome reentry holes SR-2A and LRL-7, establishment of a decontamination holding area and a clean holding area, fabrication and installation of a tritium effluent filter system at LRL-7, installation of a crushing plant on the north side of the salt muckpile, and the setup of slurry and mud tanks for the downhole disposal system operation (DOE/NV, 1981).

The D\&D system operation consisted of the disposal of contaminated soil and debris within the Gnome-Coach operational areas. Soil was removed from the larger contaminated areas by various mechanical methods. For small, well-defined surface areas, shovels were used to isolate and remove the contamination. In some cases, such as the CWD where contamination was disbursed throughout a large generalized area, the surface was scraped to a depth of 6 in. and/or trenches were dug when contamination was located at depth (DOE/NV, 1981). In areas where contamination was buried, a backhoe, front-end loader, or bulldozer was used. The removed soil and materials from these areas were loaded onto dump trucks, transported, and staged on the existing salt muckpile.

To ensure that a site was below the decontamination criteria levels, radiological surveys were conducted with a modified criteria for cleanup for surface variances of greater than $20 \mu \mathrm{R} / \mathrm{hr}$ above background (DOE/NV, 1981). Soil samples were collected and analyzed at an on-site mobile laboratory to verify the survey results. Based on the results of the analyses, the trenches would be backfilled, or excavation and scraping of the area would continue until the site was verified to be below the radiological release criteria.

The final phase of the D\&D operation consisted of the contaminated soil being taken from the staging areas and a combination of soil and salt would be loaded into a crusher unit and sent through a series of conveyor belts and shaker table units to sort out the larger debris (e.g., large pieces of wood, gloves, metal fragments) for later disposition. The pebble-sized soil and salt would again be fed into a final series of conveyor belts and two additional crusher units. The total tonnage was then weighed on the final conveyor belt, recorded, taken to a hopper, and deposited into the Gnome cavity by means of a water injection system. 
Over the duration of the D\&D operations, the cavity was filled to capacity. Approximately $35,750 \mathrm{y}^{3}$ of contaminated soil and salt were slurried into the Gnome cavity for disposal. The most conservative estimate of the total activity of Cs-137 deposited down the Gnome cavity was $1.06 \mathrm{Ci}$ (DOE/NV, 1981).

At the end of the crusher/slurry operations, contaminated soil, salt, and debris still remained. This excess contaminated material was packaged and shipped to the NTS for disposal as LLW. Historical records indicate 242 drums $(73,972$ pounds [lbs]) and 14 boxes $(50,200 \mathrm{lbs})$ were transported to the NTS for disposal. The radiological activity level of this material was 2.67 x $10^{2} \mathrm{Ci}$ (based on Cs-137). Excess nonradiological waste, scrap metal, and debris were also transported to the NTS for final disposition. Approximately $6,000 \mathrm{y}^{3}$ of clean salt from the salt muckpile remained after the disposal operations were completed. This clean salt was buried at the old laundry/lab area in a trench, covered with a thin layer of crushed concrete and vinyl, and filled with $6 \mathrm{ft}$ of clean soil. A more detailed account of the second major cleanup effort is contained in Gnome Site Decontamination and Decommissioning Project, Radiation Decontamination Clearance Report, March 28, 1979 -

September 23, 1979 (DOE/NV, 1981).

\section{A.3.2 Aerial Radiation Surveys (May 1972 and September 1979)}

An aerial radiological survey was conducted on May 13, 1972, after the 1968-1969 environmental restoration. A program known as the Aerial Radiological Measuring System (ARMS) was used to perform this aerial radiation survey of the Gnome-Coach Site and surrounding area. The objective of ARMS was to detect and document any anomalous gamma radiation levels in the environment from residual radioactive material following the environmental restoration activities conducted between 1968 and 1969.

The ARMS uses a high-sensitivity detection system which collected gamma-ray spectral and gross-count data. The data were computer-processed onto a four square-mile area map of the Gnome-Coach Site, showing gamma exposure rates three feet above the ground. The exposure rates measured within the survey regions were generally uniform and typical of rates resulting from natural background radiation in the United States ( 5 to $7 \mu \mathrm{R} / \mathrm{hr}$ ). Other than trace amounts of Cs-137 detected over the waste dump, no anomalies were detected that could be attributed to the Gnome test (EG\&G, 1973). 
A second aerial radiological survey was conducted on September 22 through 23, 1979, following cleanup efforts. The objective of this survey was to document the effectiveness of the cleanup effort and to provide overall certification that no major anomalous gamma radiation levels remained following the environmental restoration activities. The results were presented as isopleths showing the exposure rates from the man-made nuclide Cs-137. The survey indicated that above background levels of radioactive material exists in the vicinity of the venting fallout track, Gnome shaft, new laundry/lab area, salvage yard, and the CWD (Figure A.3-1) (DOE/NV, 1981).

\section{A.3.3 Ground Radiation Surveys (1968-1969, 1972, and 1977-1979)}

Ground radiation measurements were completed at the Gnome-Coach Site on three occasions. The first radiation survey was performed during from June 1968 through April 1969. The second survey as conducted in April, May, and October 1972. The third survey was conducted during Phase I and III of the 1977-1979 decommissioning.

The first radiation survey program was conducted in 1968 in the soil/salt muckpile. Seventy-nine holes were drilled into the muckpile, and the resulting debris was monitored and sampled. Representative cross-section samples were selected for laboratory analysis. The laboratory results indicated elevated levels of radiological contamination on the surface, and at certain depths within the muckpile, exceeding the criteria of $0.1 \mathrm{mR} / \mathrm{hr}$. The results of the sample analyses are summarized in On-Site Radiological Safety Report, Carlsbad Site Roll-Up Program (Tappan and Lorenz, 1969).

The second radiation survey was performed during the 1972 Site Reconnaissance using in situ instruments. Three surface locations on the muckpile were identified with readings above the $0.1 \mathrm{mR} / \mathrm{hr}$ 1968-1969 radiological release criteria. Other sites, including the decontamination site, clean scrap yard site, CWD site, and shaft were surveyed and showed readings above background but below the 1968-1969 radiological release criteria. These locations were found to be isolated areas of elevated radioactivity (REECo, 1973).

The third radiation survey was conducted in two phases during the second site decommissioning. During Phase I, radiation surveys were conducted to provide data to guide the design of the Phase II/III soil sampling. The objective of the Phase II/III survey was to confirm that the new radiological release criteria was met (i.e., $20 \mu \mathrm{R} / \mathrm{hr}$ above background) after the Phase III removal of 
contaminated materials. Background radiation used for this survey was $10 \mu \mathrm{R} / \mathrm{hr}$. None of the exposure rate measurements exceeded the 1968-1969 and the 1977-1979 radiological release criteria. The results for both of these surveys are summarized in Gnome Site Decontamination and Decommissioning - Phase I Radiological Survey and Operations Report, Carlsbad, New Mexico (DOE/NV, 1978), and Gnome Site Decontamination and Decommissioning Project, Radiation Decontamination Clearance Report, March 28, 1979 - September 23, 1979 (DOE/NV, 1981).

\section{A.3.4 Soil Sampling}

Soil sampling and analysis were performed by the AEC/DOE, and other outside agencies. The results for the outside agencies (EPA and EEG) are presented in Section A.4.0. The first three AEC/DOE soil sampling programs were performed in June 1968 through April 1969; April, May, and October in 1972; and between 1977 and 1979 during the second site decommissioning.

The first soil sampling program was conducted during the 1968-1969 initial cleanup (Tappan and Lorenz, 1969). The objective of this deactivation program was to remove and dispose of all surface contamination in excess of the established limit of $0.1 \mathrm{mR} / \mathrm{hr}$ (beta plus gamma), as measured by field instruments. All the operational areas within the Gnome Site were sampled before, during, and after the decontamination activities. The specific areas that were monitored and surveyed were the liquid waste tank, evaporation pond, miscellaneous storage areas and facilities, CWD, Coach drift and surface area, Gnome shaft and surface area, and the salt muckpile (Tappan and Lorenz, 1969). At the end of the cleanup operations, all of the operational areas underwent a detailed radiological survey. The survey revealed that radiological measurements were less than $0.1 \mathrm{mR} / \mathrm{hr}$ in all of the areas except the salt muckpile (Tappan and Lorenz, 1969).

The second soil sampling program was completed in stages over the months of April, May, and October in 1972 (REECo, 1973). The primary objective of this sampling effort was to better define the extent of contamination at the salt muckpile. Approximately 170 soil samples were collected on the muckpile from holes that were previously drilled during the 1968-1969 sampling program. In general, results from the samples collected showed that the predominant isotope was Cs-137. Strontium-90 analyses were conducted on some samples with the maximum result of $1 \mathrm{pCi} / \mathrm{g}$. The analytical results for the soil sampling programs are summarized in Carlsbad Reconnaissance 1972, Gnome Site (REECo, 1973). 
The third soil sampling program was conducted in two phases (Phase I and Phase II/III) between 1977 and 1979 during the second site decommissioning. The objective of the Phase I soil sampling program was to provide radiological data necessary to plan operations for the decontamination and decommissioning of the site in Phase II/III. The objective of the Phase II/III soil sampling program was to provide postdecontamination concentrations in soil for the predetermined radionuclide indicators, Cs-137 and tritium. Approximately 5,800 soil samples, including surface and shallow subsurface soil samples, were collected between the two phases of this operation at all of the operational areas impacted by radiological contamination (i.e., salvage yard, CWD, shaft, evaporation pond, and SGZ). The areal coverage of surface sampling was extensive across the Gnome-Coach Site (see Plate 1). Samples were analyzed at an on-site laboratory and a split of the samples was sent to the NTS for analysis.

\section{7-1979 Soil Sampling Results}

All soil analytical data was reviewed during this analysis to assess the Gnome-Coach Site. Phase I data is associated with the radiological conditions following the remediation conducted in 1968 and 1969. Phase II/III data was associated with the radiological conditions following the remediation conducted in 1977-1979. Phase II/III remediation and data collection focused on areas that were identified through Phase I as not having been adequately remediated in 1968-1969. Therefore, some results from Phase I were obtained before remediation occurred, and do not represent the radiological conditions after the Phase II/III remediation. To assess the current conditions at the site, a compilation of Phase I and Phase II/III data was organized by AOC. For example, if remediation occurred in an area, Phase I data may no longer be applicable and Phase II/III was used. In areas where remediation did not occur or was not required, Phase I or a combination of Phase I and II/III data was used. To avoid confusion, the data used at each area is stated with the understanding that other data may exist that is no longer applicable. Table A.3-1 summarizes the number of Cs-137 and tritium soil sample results above minimum detectable activities obtained during Phase I and II/III for each AOC at the Gnome Site.

During Phase I activities, operational areas having elevated surface measurements or potential for shallow subsurface contamination because of former site operations (i.e., CWD, shaft, salt muckpile, old laundry/lab) were characterized by griding an area, drilling at each location to a depth ranging 
Table A.3-1

Number of Sample Results for Each Area of Concern ${ }^{\mathrm{a}}$

\begin{tabular}{|c|c|c|c|c|}
\hline \multirow{2}{*}{ Generalized Area } & \multicolumn{2}{|c|}{ Cs-137 } & \multicolumn{2}{|c|}{ Tritium } \\
\hline & Phase I & Phase II/III & Phase I & Phase II/III \\
\hline Contaminated Waste Dump & 579 & 453 & 126 & 6 \\
\hline Salvage Yard & 527 & 51 & 5 & \\
\hline Road & 65 & 13 & & 2 \\
\hline Evaporation Pond and Waste Tank & 224 & 66 & 10 & 2 \\
\hline Salt Muckpile & 205 & 315 & 17 & 5 \\
\hline NFCS/Area 57 & 137 & 25 & 13 & \\
\hline Old Laundry/Lab & 130 & & 6 & \\
\hline Gnome SGZ & 404 & 88 & 2 & \\
\hline Decontamination Pad & 240 & 32 & 7 & \\
\hline Equipment Storage Yard & 104 & & 4 & \\
\hline New Laundry/Lab & 130 & 49 & 15 & \\
\hline Fallout Plume & 69 & 79 & 3 & 2 \\
\hline Gnome-Coach Shaft Area & 319 & 400 & & 2 \\
\hline General Site & 155 & 168 & 45 & \\
\hline General Site Background & 13 & & 10 & \\
\hline Waste Trench & & 4 & & \\
\hline Study 32 & & 35 & & \\
\hline Waterline & & 50 & & \\
\hline Nonoperational Areas & & 96 & & \\
\hline Well DD-1 & & 17 & & 3 \\
\hline Well SR-3A & & 6 & & \\
\hline Warehouse & & 17 & & \\
\hline Well LRL-7 & & 74 & & \\
\hline Crusher Plant & & 90 & & 1 \\
\hline Well USGS-8 & & 13 & & 9 \\
\hline
\end{tabular}

${ }^{a}$ The number of sample results are presented on this table. The historical data indicate that in some instances, if a Cs or tritium result was not detected it was not recorded. This means that there are more samples collected than there are reported results. 
from 1 to $20 \mathrm{ft}$, and collecting soil samples. Based on Phase I results, the shallow subsurface at the SGZ, old laundry/lab, shaft area, warehouse area, fallout track plume area, equipment storage area, Area 57, road between salvage yard and CWD, crusher plant area, LRL-7 area, LRL-8 area, and salvage yard were determined to be adequately characterized. Sufficient data exists to determine that either contamination was not encountered, detected, or if contamination was detected, appropriate remediation has been completed. During Phase I, Cs-137 leaching characteristics in soil were studied by collecting profile samples at 1-in. intervals in areas where no contaminated material had been buried (i.e., old laundry/lab, Area 57, and fallout area). This study demonstrated that surface contamination from Cs-137 was concentrated just below the surface to a maximum depth of $7 \mathrm{in}$. (DOE/NV, 1978).

Phase II/III data was biased, meaning that for areas that were not suspected of being contaminated above the 1977-1979 release criteria, there was limited Phase II/III sampling performed. During Phase II/III, soil samples were collected at various depths from the surface to $16 \mathrm{ft}$ at the CWD, SR-3A area (SGZ), evaporation pond/waste tank, salt muckpile, new laundry/lab area, shaft area, and USGS-8 area. Sample collection was biased and limited to areas identified with elevated measurements during Phase I. Samples were taken from drill cores or trenches and analyzed at an on-site laboratory. The CWD was the only AOC that required substantial cleanup and postdecontamination sampling for the shallow subsurface. Figure A.3-2 summarizes the results of the Cs-137 concentrations measured in a three-dimensional format for the CWD and displays the amount of characterization data available for this former operational area. Upon review of the historical data, areas that are still suspect and will require additional data collection include the decontamination pad, new laundry/lab area, USGS-4 and -8 drill pad area, and salt muckpile area.

Phase II/III shallow subsurface samples collected at the salt muckpile were above the 1979 release criteria. However, it is not clear if these samples were collected from atop the salt muckpile prior to removal or on the ground surface after removal. Because the values are above the release criteria, it is strongly suspected the samples were collected prior to removal. A confirmation in situ radiological survey has been proposed to confirm the salt muckpile remediation is complete.

As part of the historical data review, an evaluation was made of the Cs-137 and tritium results from the 1977-1979 sampling program because they represent the concentrations after the most recent site 
restoration. Only the Phase II/III data were utilized for the evaluation unless Phase I data determined an area was already below the release criteria without remediation or was remediated during Phase I, in which case the Phase I data were used. Although not verified during this evaluation, DOE/NV (1981) states that no areas exceeded the established release criteria of $20 \mathrm{pCi} / \mathrm{g}$ averaged over 0.25 hectare. Table A.3-2 summarizes the number of Cs-137 surface and shallow subsurface soil concentrations that exceeded $20 \mathrm{pCi} / \mathrm{g}$. The table shows that most AOCs had a small percentage of sample concentrations exceeding $20 \mathrm{pCi} / \mathrm{g}$; however, these values were not averaged over a 0.25 hectare as specified by the DOE 1979 release criteria for this review. All tritium concentration results were less than the 1979 DOE radiological release criteria. Figures A.3-3 through A.3-20 present surface sample results above the detection limit for Cs-137 for each AOC that were used for this evaluation. Plate 1 shows a more comprehensive view of the surface data points compiled across the site. Note that many of the Phase II/III samples were biased, meaning soil samples were collected: (1) where contamination was suspected and shown not to exist, (2) where removal actions had occurred, and/or (3) where the results were used to confirm the contamination was removed to below the established release criteria during this remedial action. This accounts for the clustering of the data and the large areas that were previously characterized and confirmed to not be contaminated, and thus not sampled as part of Phase II/III.

Table A.3-3 lists the minimum, maximum, average, and 95 percent Upper Confidence Level (UCL) for Cs-137 in surface soil samples and the minimum and maximum concentration for tritium in soil. Historical documents indicate that the maximum Cs-137 concentration of $28,000 \mathrm{pCi} / \mathrm{g}$ at the new laundry/lab area was removed by sampling (DOE/NV, 1981). Because of this statement, it is assumed that this concentration was not used in calculating if the new laundry/lab was below the release criteria. The maximum tritium concentration of $25,300 \mathrm{pCi} / \mathrm{mL}$ was measured at the CWD. Table A.3-4 gives the weighted average concentrations for AOCs with shallow subsurface sample data. The maximum and 95 percent UCL for surface soil, and the weighted average concentrations for shallow subsurface will be used as initial input values to calculate dose/risk in the preliminary radiological-screening evaluation presented in Appendix C.

To verify that Cs-137 was the primary isotope of concern at the Gnome-Coach Site, some randomly selected samples were sent to the analytical laboratory at the NTS for Sr-90 and Pu-239 analysis during the 1977-1979 sampling effort. The results for $18 \mathrm{Sr}-90$ and $8 \mathrm{Pu}-239$ analyses are 
Table A.3-2

Gnome-Coach Phase I, II, and III - Soil Sampling Results (1977-1979)

\begin{tabular}{|c|c|c|c|c|}
\hline Areas of Concern & $\begin{array}{c}\text { Total Samples } \\
\text { Collected and } \\
\text { Analyzed for Cs-137 } \\
\text { (most recent sampling } \\
\text { program) }\end{array}$ & $\begin{array}{c}\text { Total Samples } \\
\text { Cs-137 Concentrations } \\
\text { Greater Than or Equal } \\
\text { to DOE's } 20 \mathrm{pCi} / \mathrm{g} \\
\text { (DOE/NV, 1981) }\end{array}$ & $\begin{array}{c}\text { Total Samples } \\
\text { Collected and } \\
\text { Analyzed for Tritium } \\
\text { (most recent } \\
\text { sampling program) }\end{array}$ & $\begin{array}{c}\text { Total Samples } \\
\text { Tritium Concentrations } \\
\text { in Soil Moisture Greater } \\
\text { Than or Equal to DOE's } \\
30,000 \mathrm{pCi} / \mathrm{mL} \\
\text { (DOE/NV, 1981) }\end{array}$ \\
\hline $\begin{array}{l}\text { 1. Contaminated Waste } \\
\text { Dump }\end{array}$ & 453 (Phase II/III) & 48 & 6 (Phase II/III) & 0 \\
\hline 2. Salvage Yard & 51 (Phase II/III) & 4 & 5 (Phase I) & 0 \\
\hline 3. Warehouse Area & 17 (Phase II/III) & 2 & - & - \\
\hline $\begin{array}{l}\text { 4. Waste Tank - } \\
\text { Evaporation Pond }\end{array}$ & 69 (Phase II/III) & 2 & 2 (Phase II/III) & 0 \\
\hline 5. Gnome SGZ + DD-1 & 110 (Phase II/III) & 7 & 3 (Phase II/III) & 0 \\
\hline 6. Decontamination Pad & 32 (Phase II/III) & 1 & 7 (Phase I) & 0 \\
\hline $\begin{array}{l}\text { 7. Laundry/Lab Old and } \\
\text { Trench }\end{array}$ & 79 (Phase I \& II/III) & 9 & 6 (Phase I) & 0 \\
\hline 8. Laundry/Lab New & 49 (Phase II/III) & 5 & 15 (Phase I) & 0 \\
\hline 9. Salt Muckpile & 315 (Phase II/III) & 17 & 5 (Phase II/III) & 0 \\
\hline $\begin{array}{l}\text { 10. Gnome-Coach Shaft } \\
\text { Surface Area }\end{array}$ & 400 (Phase II/III) & 5 & 2 (Phase II/III) & 0 \\
\hline $\begin{array}{l}\text { 11. Fallout Track from } \\
\text { Venting }\end{array}$ & 79 (Phase II/III) & 13 & 2 (Phase II/III) & 0 \\
\hline $\begin{array}{l}\text { 12. Equipment Storage } \\
\text { Area }\end{array}$ & 61 (Phase I) & 0 & 4 (Phase I) & 0 \\
\hline 13. Area 57 (NFCS) ${ }^{a}$ & 120 (Phase I \& II/III) & 8 & 13 (Phase I) & 0 \\
\hline $\begin{array}{l}\text { 14. Road between the } \\
\text { Salvage Yard and the } \\
\text { CWD }\end{array}$ & 10 (Phase II/III) & 1 & 2 (Phase II/III) & 0 \\
\hline $\begin{array}{l}\text { 15. USGS-8 \& USGS-4 } \\
\text { Monitoring Wells }\end{array}$ & 10 (Phase II/III) & 1 & 9 (Phase II/III) & 0 \\
\hline 16. Crusher Plant & 161 (Phase II/III) & 0 & 1 (Phase II/III) & 0 \\
\hline 17. LRL-7 Drill Pad Area & 74 (Phase II/III) & 1 & - & - \\
\hline $\begin{array}{l}\text { 18. LRL-8 Drill Pad Area } \\
\text { (Study } 32 \text { ) }\end{array}$ & 35 (Phase II/III) & 0 & - & - \\
\hline TOTALS & 2,125 & 124 & 82 & 0 \\
\hline
\end{tabular}

${ }^{\text {a Area }} 57$ is same as "NFCS" data in DOE/NV, 1981

"'General Site" data in DOE/NV, 1981, used for Crusher Plant area as it is more representative of surface ground conditions.

"LRL-8 data is "Study 32" data in DOE/NV, 1981 
Table A.3-3

Gnome-Coach Phase I, II, and III - Surface ${ }^{a}$ Soil Analysis Results Statistics

\begin{tabular}{|c|c|c|c|c|c|c|}
\hline $\begin{array}{l}\text { Areas of } \\
\text { Concern }\end{array}$ & $\begin{array}{c}\text { Minimum } \\
\text { Cs-137 } \\
\text { Concentration } \\
\text { (pCi/g) }\end{array}$ & $\begin{array}{c}\text { Average } \\
\text { Cs-137 } \\
\text { Concentration } \\
(p \mathrm{Ci} / \mathrm{g})\end{array}$ & $\begin{array}{c}\text { Maximum } \\
\text { Cs-137 } \\
\text { Concentration } \\
(\mathrm{pCi} / \mathrm{g})\end{array}$ & $\begin{array}{c}\text { 95\% UCL } \\
\text { Cs-137 } \\
\text { Concentrations } \\
\text { (pCi/g) }\end{array}$ & $\begin{array}{c}\text { Minimum } \\
\text { Tritium } \\
\text { Concentration } \\
(p \mathrm{Ci} / \mathrm{mL})\end{array}$ & $\begin{array}{c}\text { Maximum } \\
\text { Tritium } \\
\text { Concentration } \\
(p \mathrm{Ci} / \mathrm{mL})\end{array}$ \\
\hline $\begin{array}{l}\text { 1. Contaminated } \\
\text { Waste Dump }\end{array}$ & 0.24 & 5.35 & 60 & 6.02 & 52 & 25,300 \\
\hline 2. Salvage Yard & 0.24 & 8.83 & 76 & 12.36 & 18 & 117 \\
\hline $\begin{array}{l}\text { 3. Warehouse } \\
\text { Area }\end{array}$ & 0.28 & 21.32 & 201 & 49.00 & - & - \\
\hline $\begin{array}{l}\text { 4. Waste Tank - } \\
\text { Evaporation } \\
\text { Pond }\end{array}$ & 0.66 & 5.24 & 38 & 6.78 & 21 & 28 \\
\hline $\begin{array}{l}\text { 5. Gnome SGZ \& } \\
\text { DD-1 }\end{array}$ & 0.26 & 4.21 & 39 & 5.36 & 531 & 2,090 \\
\hline $\begin{array}{l}\text { 6. Decontamination } \\
\text { Pad }\end{array}$ & 0.24 & 5.47 & 23 & 7.80 & 115 & 2360 \\
\hline 7. Laundry/Lab Old & 0.25 & 6.03 & 29 & 8.15 & 28.6 & 93.2 \\
\hline $\begin{array}{l}\text { 8. Laundry/Lab } \\
\text { New }\end{array}$ & 0.33 & 580.17 & 28,100 & $1,732.94$ & 1.84 & 473 \\
\hline 9. Salt Muckpile & 0.24 & 6.5 & 95.3 & 7.34 & 1 & 722 \\
\hline $\begin{array}{l}\text { 10. Gnome-Coach } \\
\text { Shaft Surface } \\
\text { Area }\end{array}$ & 0.21 & 6.36 & 465 & 8.72 & 132 & 1,160 \\
\hline $\begin{array}{l}\text { 11. Fallout Track } \\
\text { from Venting }\end{array}$ & 0.26 & 18.24 & 370 & 29.33 & 20 & 38 \\
\hline $\begin{array}{l}\text { 12. Equipment } \\
\text { Storage Area }\end{array}$ & 0.29 & 5.02 & 16 & 6.37 & 103 & 217 \\
\hline $\begin{array}{l}\text { 13. Area } 57 \mathrm{~b} \\
\text { (NFCS) }\end{array}$ & 1.49 & 4.78 & 14.6 & 6.1 & 2.2 & 213 \\
\hline $\begin{array}{l}\text { 14. Road between } \\
\text { the Salvage Yard } \\
\text { and the CWD }\end{array}$ & 1.25 & 10.24 & 52 & 21.17 & 45 & 117 \\
\hline $\begin{array}{l}\text { 15. USGS-8 \& } \\
\text { USGS-4 Drill } \\
\text { Pad Area }\end{array}$ & 0.26 & 5.22 & 34 & 13.6 & 178 & 23,100 \\
\hline 16. Crusher Plant ${ }^{\mathrm{c}}$ & 0.20 & 1.09 & 17.50 & 1.41 & 111 & 111 \\
\hline $\begin{array}{l}\text { 17. LRL-7 Drill Pad } \\
\text { Area }\end{array}$ & 0.17 & 1.95 & 67 & 3.77 & - & - \\
\hline $\begin{array}{l}\text { 18. LRL-8 Drill Pad } \\
\text { Area (Study } 32 \text { ) }\end{array}$ & 0.29 & 2.19 & 20 & 3.36 & - & - \\
\hline
\end{tabular}

${ }^{\mathrm{a}}$ Surface $=0$ to 2.0 in. bgs

${ }^{b}$ Area 57 data is same as "NFCS" data in DOE/NV, 1981

"General Site" data in DOE/NV, 1981, used for Crusher Plant area as it is more representative of surface ground conditions.

"LRL-8 data is same as "Study 32" data in DOE/NV, 1981 
Table A.3-4

Gnome-Coach Phase I, II, and III Shallow Subsurface Soil Analysis Results

\begin{tabular}{||l|c|c||}
\hline \multicolumn{1}{|c|}{$\begin{array}{c}\text { Sampling } \\
\text { Areas }\end{array}$} & $\begin{array}{c}\text { Range of Contaminant Depth } \\
\text { (ft) }\end{array}$ & $\begin{array}{c}\text { Volume Weighted Average } \\
\text { Cs-137 SubSurface Concentrations } \\
\text { (pCi/g) }\end{array}$ \\
\hline \hline $\begin{array}{l}\text { 1. Contaminated Waste } \\
\text { Dump }\end{array}$ & $0.166-16$ & 85.86 \\
\hline 2. Salvage Yard & $0.166-7$ & 6.66 \\
\hline $\begin{array}{l}\text { 3. Gnome SGZ } \\
\text { 4. Waste Tank - } \\
\text { Evaporation Pond }\end{array}$ & $0.166-6$ & 25.37 \\
\hline $\begin{array}{l}\text { 8. Laundry/Lab New } \\
\text { 9. Salt Muckpile }\end{array}$ & $0.166-10$ & 6.64 \\
\hline $\begin{array}{l}\text { 10.Gnome-Coach Shaft } \\
\text { Surface Area }\end{array}$ & $0.166-5$ & 38.69 \\
\hline $\begin{array}{l}\text { 15. USGS-8 \& USGS-4 } \\
\text { Monitoring Wells }\end{array}$ & $0.166-12$ & 223.54 \\
\hline
\end{tabular}

${ }^{\mathrm{a}}$ Maximum depth of contaminant detected at each area of concern

summarized in Table A.3-5. Both $\mathrm{Sr}-90$ and $\mathrm{Pu}-239$ were detected above minimum detectable concentrations. The laboratory results confirmed the assumption that Cs-137 is the predominant radiological COPC.

\section{A.3.5 Vegetation Sampling}

Two bioenvironmental sampling programs were conducted at the Gnome-Coach Site. In October 1972, a bioenvironmental sampling program was conducted by the EPA to document the radionuclide concentrations within plant and animal tissues (Smith and Giles, 1973). The second was conducted in May of 1978 by DOE/NV. The purpose of this sampling program was to document radionuclide concentrations of material that may enter into man's food chain. Two species of grass (i.e., black grama and dropseed grass) utilized by grazing animals, primarily cattle, were collected for analysis.

The first bioenvironmental sampling program collected grass samples from five locations on the Gnome-Coach Site (Figure A.3-21). All samples were analyzed for gamma emitters, strontium, and plutonium. The results for the analysis are presented on Table A.3-6. Detectable concentrations of 
Table A.3-5

Gnome-Coach Select Sample Locations for Cs-137, Sr-90, and Pu-239 Comparison

\begin{tabular}{|c|c|c|c|c|c|c|}
\hline $\begin{array}{c}\text { Library } \\
\text { No. }\end{array}$ & $\begin{array}{l}\text { Area of } \\
\text { Concern }\end{array}$ & Northing & Easting & $\begin{array}{l}\text { Cs-137 } \\
(\mathrm{pCi} / \mathrm{g})\end{array}$ & $\begin{array}{c}\text { Sr-90 } \\
(p C i / g)\end{array}$ & $\begin{array}{l}\text { Pu-239 } \\
(\mathrm{pCi} / \mathrm{g})\end{array}$ \\
\hline 33787 & CWD & 100725 & 101940 & 16.0 & 0.723 & 0.0149 \\
\hline 33793 & CWD & 100720 & 101960 & 22.3 & - & 0.0242 \\
\hline 33815 & CWD & 100700 & 101919 & 20.2 & 1.29 & $<0.0066$ \\
\hline 33855 & Road & 100920 & 101080 & 52.1 & - & $<0.0087$ \\
\hline 33879 & Crusher plant & 100520 & 100340 & 9.85 & 5.5 & $<.0058$ \\
\hline 33899 & Shaft & 100060 & 99960 & 10.9 & 0.332 & $<0.015$ \\
\hline 34099 & Crusher plant & 100520 & 100340 & 2.37 & 0.663 & $<0.0058$ \\
\hline 33933 & Shaft & 100040 & 100000 & 8.72 & 0.205 & $<0.0072$ \\
\hline 33592 & SR-3A (SGZ) & 100638 & 100762 & $<0.271$ & 0.489 & - \\
\hline 33620 & CWD & 100870 & 101880 & 37.1 & 7.56 & - \\
\hline 33610 & New laundry/lab & 100075 & 100165 & $<0.311$ & 0.337 & - \\
\hline 33638 & USGS-8 & 100400 & 97550 & $<0.215$ & 4.47 & - \\
\hline 33670 & CWD & 100780 & 101760 & 3.46 & 1.11 & - \\
\hline 33724 & CWD & 100720 & 101952 & 15.4 & 0.677 & - \\
\hline 33734 & CWD & 100720 & 101940 & 13.1 & 1.30 & - \\
\hline 33835 & CWD & 100752 & 101780 & $<0.261$ & 0.689 & - \\
\hline 34123 & Crusher plant & 100520 & 100340 & 11.3 & 0.678 & - \\
\hline 34611 & Salt muckpile & 100280 & 100265 & 95.3 & 0.487 & - \\
\hline 34875 & CWD & 100720 & 101910 & 22.9 & 0.959 & - \\
\hline 33602 & New laundry/lab & 100114 & 100191 & 111 & 3.42 & - \\
\hline
\end{tabular}

Zirconium-95 (Zr-95) and Ruthenium-103 (Ru-103) were found in the air-dried samples of black grama grass. Sand observed on the base of the plant stacks and worldwide fallout were stated as the most probable sources for this radioactivity. Gamma-emitting radionuclides were not detected.

The second set of bioenvironmental samples were analyzed for gamma emitters, strontium, and tritium. The results for the 23 vegetation samples are presented in Table A.3-7. Because of different laboratory techniques and lower detection limits, detectable concentrations of Cs-137, Sr-90, and tritium were found in these vegetation samples. Sand deposition on the plant together with 
Table A.3-6

First Historical Vegetation Sampling Results

\begin{tabular}{|c|c|c|l|}
\hline Station No. & $\begin{array}{c}\text { Zr-95 } \\
\mathbf{p C i} / \mathbf{g}\end{array}$ & $\begin{array}{c}\text { Ru-103 } \\
\mathbf{p C i} / \mathbf{g}\end{array}$ & \multicolumn{1}{|c|}{ Remarks } \\
\hline \hline 1 & 0.65 & --- & One of five samples contained detectable levels of Zr-95. \\
\hline 2 & 0.23 & --- & One of five samples contained detectable levels of Zr-95 and \\
& --- & 0.69 & one Ru-103. \\
\hline 3 & --- & 0.19 & Four of five samples contained detectable levels of Ru-103. \\
& --- & 0.40 & \\
\hline 4 & --- & 0.82 & Two of five samples contained detectable levels of Zr-95 and \\
& --- & 1.1 & two contained Ru-103. \\
\hline 5 & 0.83 & 0.32 & One of five samples contained detectable levels of Zr-95 and \\
& 0.51 & --- & one Ru-103. \\
\hline
\end{tabular}

*Table indicates values above the minimum limit of detection of counting systems used at the EPA National Environmental Research Center-Las Vegas.

Source: Smith and Giles, 1973

worldwide fallout from nuclear weapons tests were stated as the most probable source for this radioactivity (DOE/NV, 1978).

\section{A.3.6 Thermoluminescent Dosimeters (TLD)}

Because the primary pathway for exposure at the Gnome-Coach Site is external exposure, a review and summary of the TLD surveys is presented here for completeness. A TLD exposure survey was conducted in 1978 and 1979 at approximately 50 locations throughout the Gnome-Coach Site and surrounding area. Three sets of TLDs were posted starting from June 22, 1978, through September 18, 1979.

The first set of TLDs were posted from June 22, 1978 to August 23, 1978, and represented the radiation levels following the 1968-1969 major restoration effort. The second set of TLDs were posted from August 23, 1978 to April 12, 1979, to confirm the previous set of TLD radiation levels. The third set of TLDs were posted from April 12, 1979 to September 18, 1979, and represent the radiation levels during the cleanup activities performed in late March 1979 through September 23, 1979. 
Table A.3-7

Second Historical Vegetation Sampling Results

\begin{tabular}{|c|c|c|c|c|c|}
\hline $\begin{array}{l}\text { Generalized } \\
\text { Locations }\end{array}$ & Northing & Easting & Sr-90 ( $\mu \mathrm{Ci} / \mathrm{g})$ & $\begin{array}{c}\text { Tritium } \\
(\mu \mathrm{Ci} / \mathrm{mL})\end{array}$ & $\begin{array}{l}\text { Cs-137 } \\
(\mu \mathrm{Ci} / g)\end{array}$ \\
\hline Gnome-Coach Shaft & 459,342 & 643,653 & $1.48 \times 10-7$ & $8.09 \times 10-6$ & $4.05 \times 10-7$ \\
\hline Gnome-Coach Shaft & 459,342 & 643,973 & $3.57 \times 10-7$ & $1.43 \times 10-6$ & $2.00 \times 10-7$ \\
\hline Gnome-Coach Shaft & 459,362 & 643,913 & $1.05 \times 10-6$ & $2.28 \times 10-6$ & $1.15 \times 10-6$ \\
\hline Gnome-Coach Shaft & 459,462 & 643,613 & NA & $9.23 \times 10-7$ & NA \\
\hline Fallout Plume & 459,742 & 643,413 & $7.22 \times 10-8$ & $5.39 \times 10-6$ & $8.75 \times 10-8$ \\
\hline Salt Muckpile & 459,802 & 644,213 & $3.08 \times 10-7$ & $1.14 \times 10-6$ & NA \\
\hline Old Laundry/Lab & 459,942 & 643,893 & $4.45 \times 10-8$ & $6.66 \times 10-6$ & NA \\
\hline Evaporation Pond & 460,002 & 644,493 & $5.10 \times 10-7$ & $3.85 \times 10-4$ & $8.79 \times 10-7$ \\
\hline Evaporation Pond & 460,042 & 644,573 & $3.40 \times 10-7$ & $5.31 \times 10-6$ & $2.41 \times 10-7$ \\
\hline Evaporation Pond & 460,062 & 644,333 & $2.00 \times 10-7$ & $1.67 \times 10-6$ & NA \\
\hline $\begin{array}{l}\text { Contaminated } \\
\text { Waste Dump }\end{array}$ & 460,082 & 645,613 & $1.90 \times 10-7$ & $4.88 \times 10-6$ & NA \\
\hline $\begin{array}{l}\text { Contaminated } \\
\text { Waste Dump }\end{array}$ & 460,142 & 645,673 & $4.65 \times 10-7$ & $2.73 \times 10-6$ & NA \\
\hline Warehouse & 460,162 & 643,873 & $4.22 \times 10-8$ & $8.57 \times 10-7$ & NA \\
\hline Gnome SGZ & 460,162 & 645,013 & $1.72 \times 10-7$ & $4.68 \times 10-6$ & NA \\
\hline Warehouse & 460,222 & 644,173 & $2.18 \times 10-7$ & $4.48 \times 10-6$ & NA \\
\hline $\begin{array}{l}\text { Contaminated } \\
\text { Waste Dump }\end{array}$ & 460,222 & 645,513 & $5.81 \times 10-7$ & $1.04 \times 10-5$ & NA \\
\hline Gnome SGZ & 460,362 & 644,793 & $9.64 \times 10-8$ & $1.15 \times 10-6$ & NA \\
\hline Gnome SGZ & 460,482 & 644,813 & $7.53 \times 10-8$ & $1.49 \times 10-4$ & NA \\
\hline Gnome SGZ & 460,382 & 644,953 & $7.98 \times 10-8$ & $6.44 \times 10-6$ & NA \\
\hline Background & NA & NA & $1.11 \times 10-6$ & $<1.08 \times 10-6$ & NA \\
\hline Background & NA & NA & $3.89 \times 10-7$ & $9.36 \times 10-7$ & NA \\
\hline Background & NA & NA & $7.06 \times 10-7$ & $<8.93 \times 10-7$ & NA \\
\hline Background & NA & NA & $6.25 \times 10-8$ & $4.58 \times 10-6$ & NA \\
\hline
\end{tabular}

NA = Not analyzed for

Source: DOE/NV, 1978 
Results from the three sets of TLD data are presented in Table A.3-8. A comparison of the three sets of TLD results indicates a slight decrease in the average exposure rates between the pre- and final restoration periods, which may be attributed to the reduction in contaminated materials.

Table A.3-8

\section{TLD Monitoring Results} (Page 1 of 2)

\begin{tabular}{|c|c|c|c|c|c|}
\hline \multirow[b]{2}{*}{ Generalized Location } & \multirow[b]{2}{*}{ Northing } & \multirow[b]{2}{*}{ Easting } & \multicolumn{3}{|c|}{ Date of TLD Deployment } \\
\hline & & & $\begin{array}{c}\text { June } 22,1978 \text { to } \\
\text { August } 23,1978 \\
(\mu R / h r)\end{array}$ & $\begin{array}{c}\text { August 23, } 1978 \\
\text { to April 12, } 1979 \\
(\mu \mathrm{R} / \mathrm{hr})\end{array}$ & $\begin{array}{c}\text { April } 12,1979 \text { to } \\
\text { August } 18,1979 \\
(\mu R / h r)\end{array}$ \\
\hline Warehouse & 460,462 & 643,673 & 11.1 & 11.5 & 5.6 \\
\hline Fallout Plume & 459,962 & 643,113 & 8.4 & 10.7 & 6.9 \\
\hline Fallout Plume & 459,862 & 643,213 & 9.0 & 9.8 & 8.4 \\
\hline Fallout Plume & 459,762 & 643,313 & 9.6 & 11.7 & 8.5 \\
\hline Fallout Plume & 459,662 & 643,413 & 12.7 & 12.3 & 9.4 \\
\hline Fallout Plume & 459,562 & 643,513 & 9.0 & 8.3 & 6.4 \\
\hline Fallout Plume & 459,462 & 643,613 & 8.5 & 7.8 & 8.8 \\
\hline Salvage Yard & 460,662 & 644,913 & 7.5 & 7.9 & Lost \\
\hline Salvage Yard & 460,542 & 644,873 & 6.1 & 6.1 & Lost \\
\hline Salvage Yard & 460,462 & 644,713 & 7.5 & 7.6 & 6.7 \\
\hline Salvage Yard & 460,262 & 644,913 & 10.5 & 10.0 & 7.2 \\
\hline Salt Muckpile & 459,962 & 643,913 & 9.3 & 8.5 & Lost \\
\hline Salt Muckpile & 459,862 & 643,813 & 7.5 & 7.8 & Lost \\
\hline Salt Muckpile & 459,862 & 643,913 & 7.8 & 7.6 & Lost \\
\hline Salt Muckpile & 459,762 & 643,713 & 9.3 & 10.1 & Lost \\
\hline Salt Muckpile & 459,762 & 643,973 & 6.7 & 8.3 & 5.7 \\
\hline Salt Muckpile & 459,762 & 644,113 & 8.7 & Lost & Lost \\
\hline Old Laundry/Lab Facility & 460,262 & 643,913 & 8.2 & 7.8 & 5.5 \\
\hline Old Laundry/Lab Facility & 460,162 & 643,813 & 8.3 & 7.5 & 6.0 \\
\hline Old Laundry/Lab Facility & 460,162 & 643,913 & 7.3 & 7.8 & 6.6 \\
\hline Gnome SGZ & 460,162 & 644,413 & 7.2 & 8.1 & Lost \\
\hline Gnome SGZ & 460,062 & 644,413 & 9.8 & 8.9 & Lost \\
\hline Gnome SGZ & 460,062 & 644,613 & 8.5 & 7.7 & 7.1 \\
\hline Gnome SGZ & 459,862 & 644,613 & 8.6 & 8.2 & 5.8 \\
\hline Evaporation Pond & 460,262 & 644,213 & 7.7 & 8.0 & Lost \\
\hline Evaporation Pond & 460,162 & 644,113 & 9.6 & 10.3 & Lost \\
\hline Evaporation Pond & 460,162 & 644,213 & 8.0 & 7.6 & 6.4 \\
\hline Evaporation Pond & 460,162 & 644,313 & 7.3 & 8.5 & 8.0 \\
\hline
\end{tabular}


Table A.3-8

\section{TLD Monitoring Results}

(Page 2 of 2)

\begin{tabular}{|c|c|c|c|c|c|}
\hline \multirow[b]{2}{*}{ Generalized Location } & \multirow[b]{2}{*}{ Northing } & \multirow[b]{2}{*}{ Easting } & \multicolumn{3}{|c|}{ Date of TLD Deployment } \\
\hline & & & $\begin{array}{c}\text { June } 22,1978 \text { to } \\
\text { August } 23,1978 \\
(\mu R / h r)\end{array}$ & $\begin{array}{c}\text { August 23, } 1978 \\
\text { to April 12, } 1979 \\
(\mu R / h r)\end{array}$ & $\begin{array}{c}\text { April } 12,1979 \text { to } \\
\text { August } 18,1979 \\
(\mu R / h r)\end{array}$ \\
\hline Equipment Storage Yard & 459,562 & 644,013 & 8.2 & 8.0 & 5.9 \\
\hline Equipment Storage Yard & 459,468 & 643,901 & 8.4 & 10.8 & Lost \\
\hline Equipment Storage Yard & 459,462 & 643,913 & 7.7 & 7.5 & Lost \\
\hline Equipment Storage Yard & 459,362 & 643,913 & 11.3 & 10.8 & 6.1 \\
\hline Equipment Storage Yard & 459,362 & 644,013 & 9.8 & Lost & 6.7 \\
\hline Equipment Storage Yard & 459,262 & 643,813 & 8.4 & 8.3 & Lost \\
\hline Equipment Storage Yard & 459,262 & 644,013 & 9.0 & 11.6 & 8.8 \\
\hline Drum Storage Area & 459,062 & 643,613 & 8.1 & 7.8 & Lost \\
\hline Decontamination Pad & 459,922 & 644,193 & 8.7 & Lost & Lost \\
\hline Decontamination Pad & 459,922 & 644,313 & 8.3 & 7.8 & Lost \\
\hline Decontamination Pad & 459,862 & 644,413 & 8.1 & 7.4 & Lost \\
\hline Decontamination Pad & 459,762 & 644,313 & 8.1 & 8.8 & 7.2 \\
\hline Contaminated Waste Dump & 460,342 & 645,393 & 7.9 & 7.3 & 5.9 \\
\hline Contaminated Waste Dump & 460,162 & 645,213 & 8.3 & 8.3 & Lost \\
\hline Contaminated Waste Dump & 460,062 & 645,213 & 6.7 & 8.5 & Lost \\
\hline Contaminated Waste Dump & 460,022 & 645,393 & 9.9 & 10.1 & 7.8 \\
\hline Contaminated Waste Dump & 460,022 & 645,693 & 7.4 & 7.1 & Lost \\
\hline Gnome-Coach Shaft & 458,062 & 644,313 & 7.6 & 7.0 & Lost \\
\hline Background & 462,002 & 643,713 & 7.9 & Lost & Lost \\
\hline Background & 459,756 & 639,963 & 6.1 & 6.8 & Lost \\
\hline Background & 457,622 & 646,353 & 7.3 & 7.1 & 8.0 \\
\hline Background & 459,756 & 641,213 & 6.2 & 6.7 & Lost \\
\hline
\end{tabular}

Lost $=$ TLD not recovered after deployment

\section{A.3.7 Data Quality}

A mobile gamma spectroscopy system was the principal analytical measurement system used during the Gnome-Coach Site Phase I and II/III investigations. This system, which consisted of a Germanium-Lithium detector and associated single channel analyzer, was calibrated to measure Cs-137 in soil and water. Soil samples were counted for ten minutes and the minimum detectable 
concentrations was stated as $0.1 \mathrm{pCi} / \mathrm{g}$. Quality control at the mobile laboratory consisted of performing a daily background and radioactive source check. The daily background count was used to calculate the net counts on each sample. The ratio of the daily source count to the source count at calibration was used to adjust the Cs-137 efficiency.

Data summaries indicated that 207 of the 3,300 samples counted at the mobile laboratory during Phase I were sent to the analytical laboratory at the NTS. At the NTS laboratory, full gamma spectroscopy, tritium, and strontium analysis were performed. To evaluate the quality of the data, the ratio of Cs-137 concentrations measured at the mobile laboratory were compared to the Cs-137 concentration measured at the NTS laboratory. A ratio of 1.0 would indicate that the two laboratories reported the same Cs-137 concentration. Twenty-four samples had at least one result below the minimum detectable concentration and were not included in the ratio comparison. The remaining 183 sets of sample results had mobile laboratory to NTS laboratory ratios ranging from 0.35 to 2.81 . The median of the ratio was exactly 1.02 , with a standard deviation of 0.42 . A review of the ratio distribution showed that 40 percent of the paired observations were within 20 percent accuracy range and 75 percent were within 40 percent accuracy range. No duplicate or replicate sample results were available for measuring system precision (DOE/NV, 1978).

The basic mobile laboratory analytical measurement system used during Phase I was expanded during Phases II/III to also include tritium via distillation and liquid scintillation counter analysis, two multichannel analyzers and air filter analysis capabilities. As with Phase I, samples were sent to the NTS laboratory for gamma spectroscopy, tritium, and strontium analysis. This time, when any discrepancy between the Gnome mobile laboratory data and the NTS laboratory data were indicated, both systems were investigated and corrections to calibration or counting system made. Data generated during these periods of inconsistency were evaluated and either corrected or rejected. Upon reviewing the quality assurance programs, it is concluded that for Phase I and II/III sampling acceptable standard practices for the time were followed. 


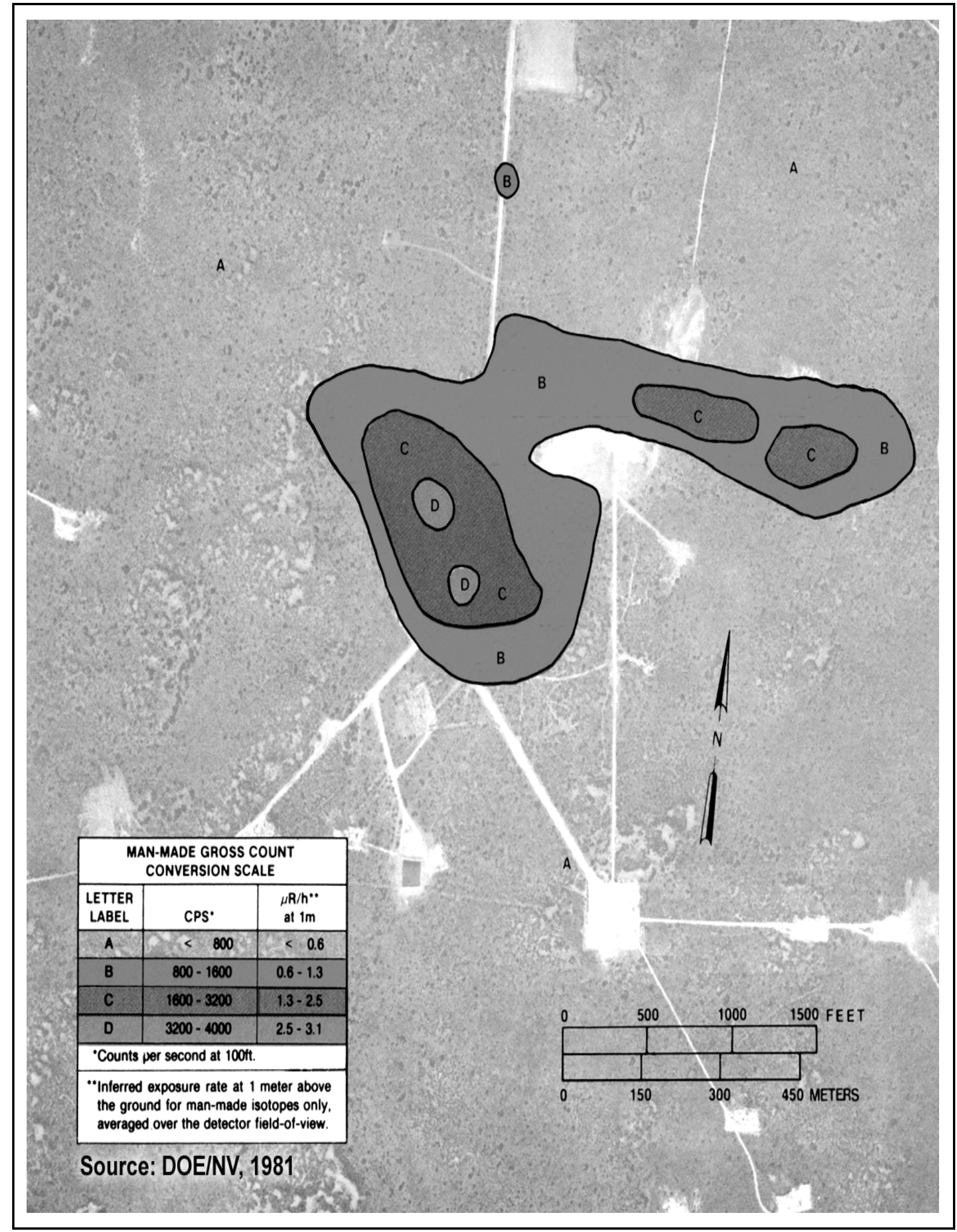

Figure A.3-1

Terrestrial Exposure Rate Levels: Man-Made Isopleths 


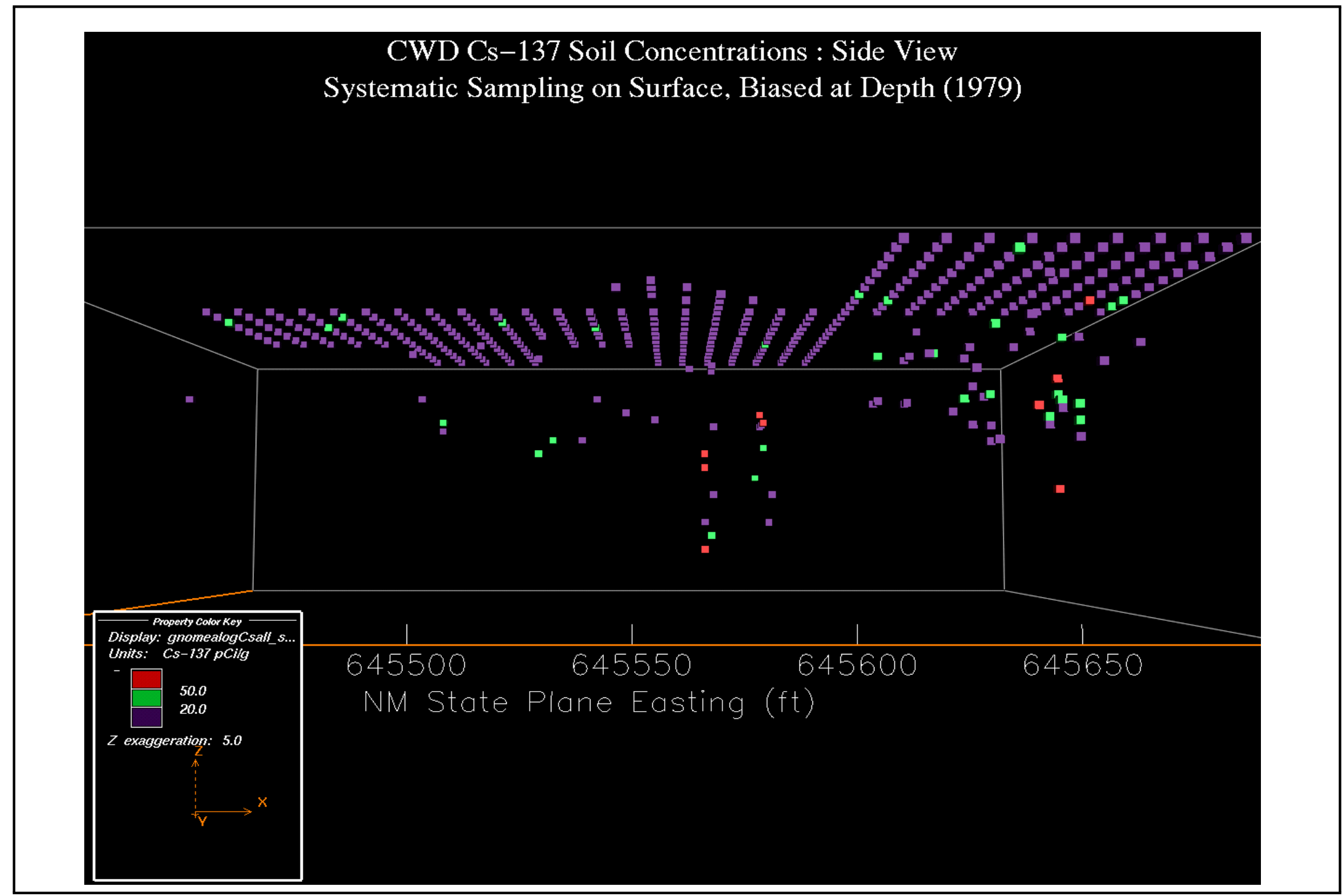

Figure A.3-2

CWD Cs-137 Soil Concentrations 


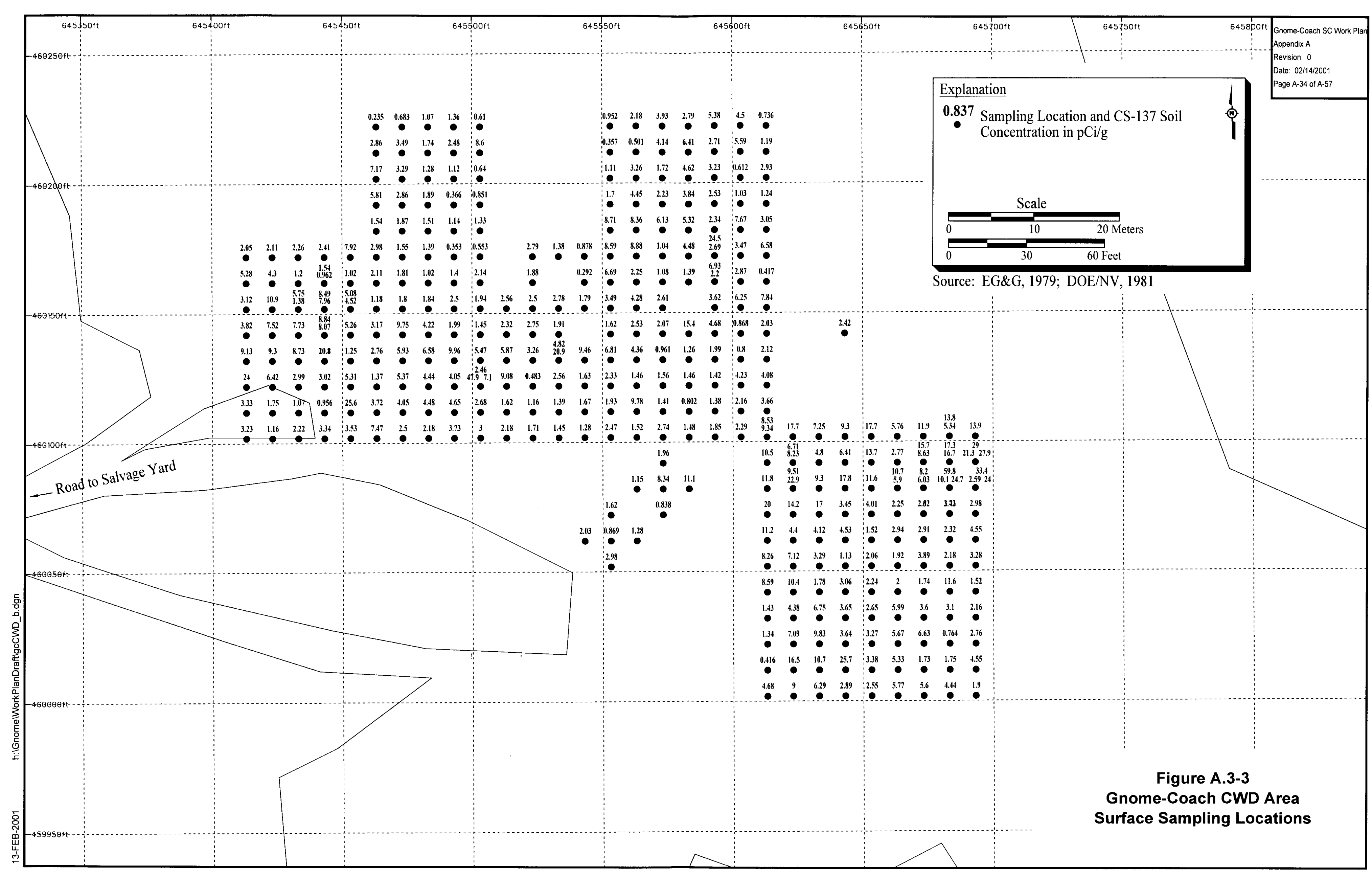




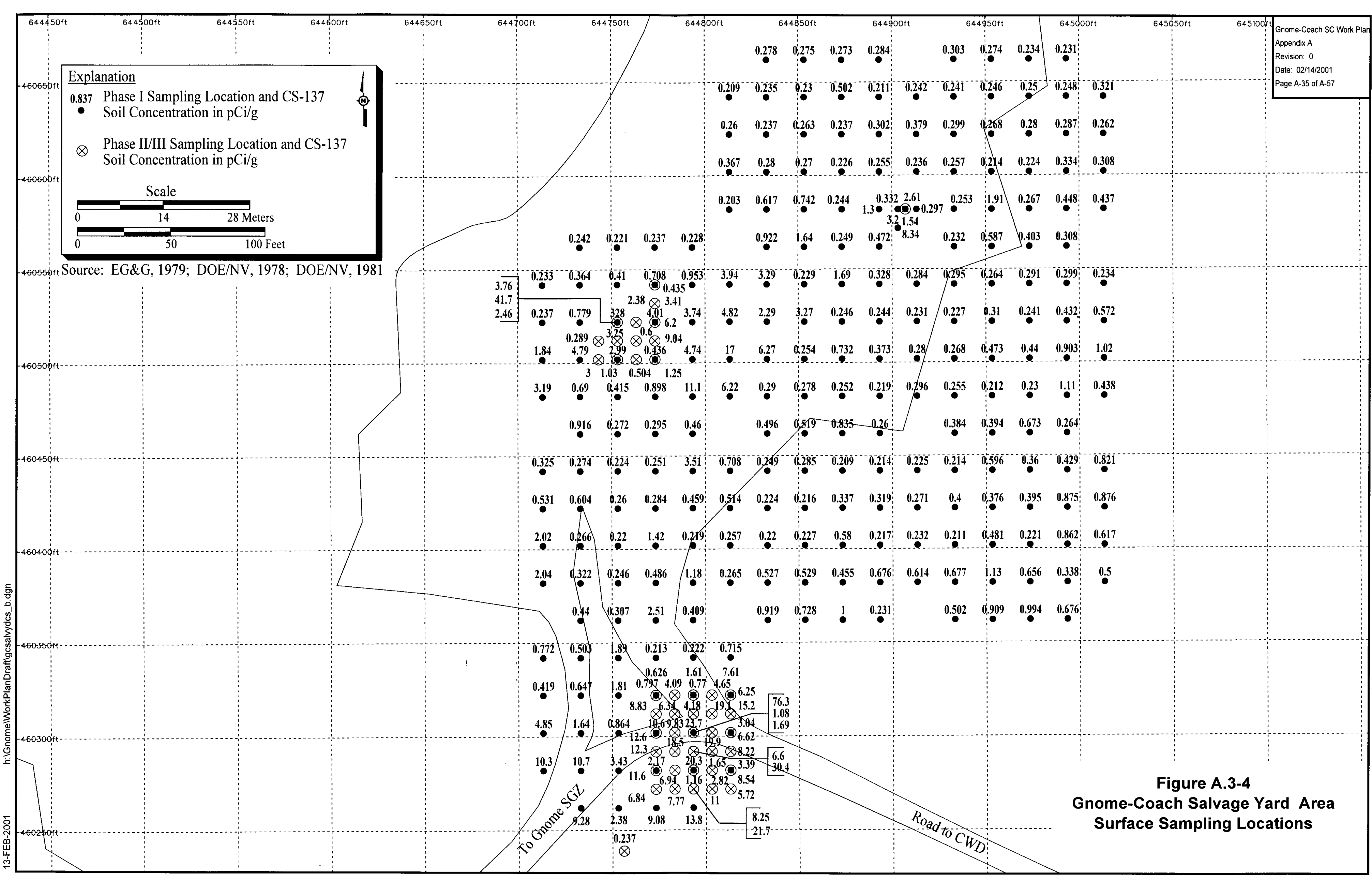




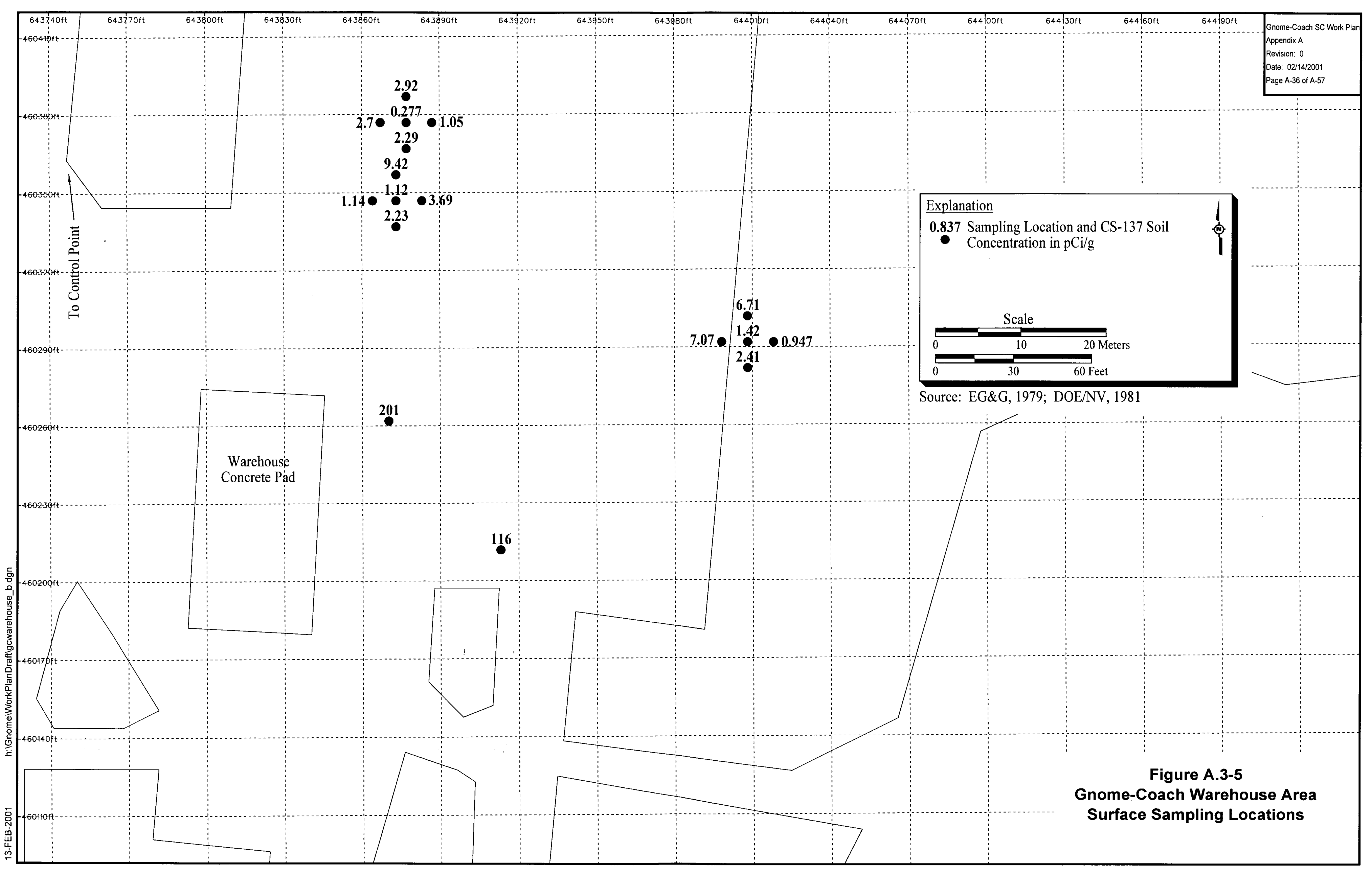




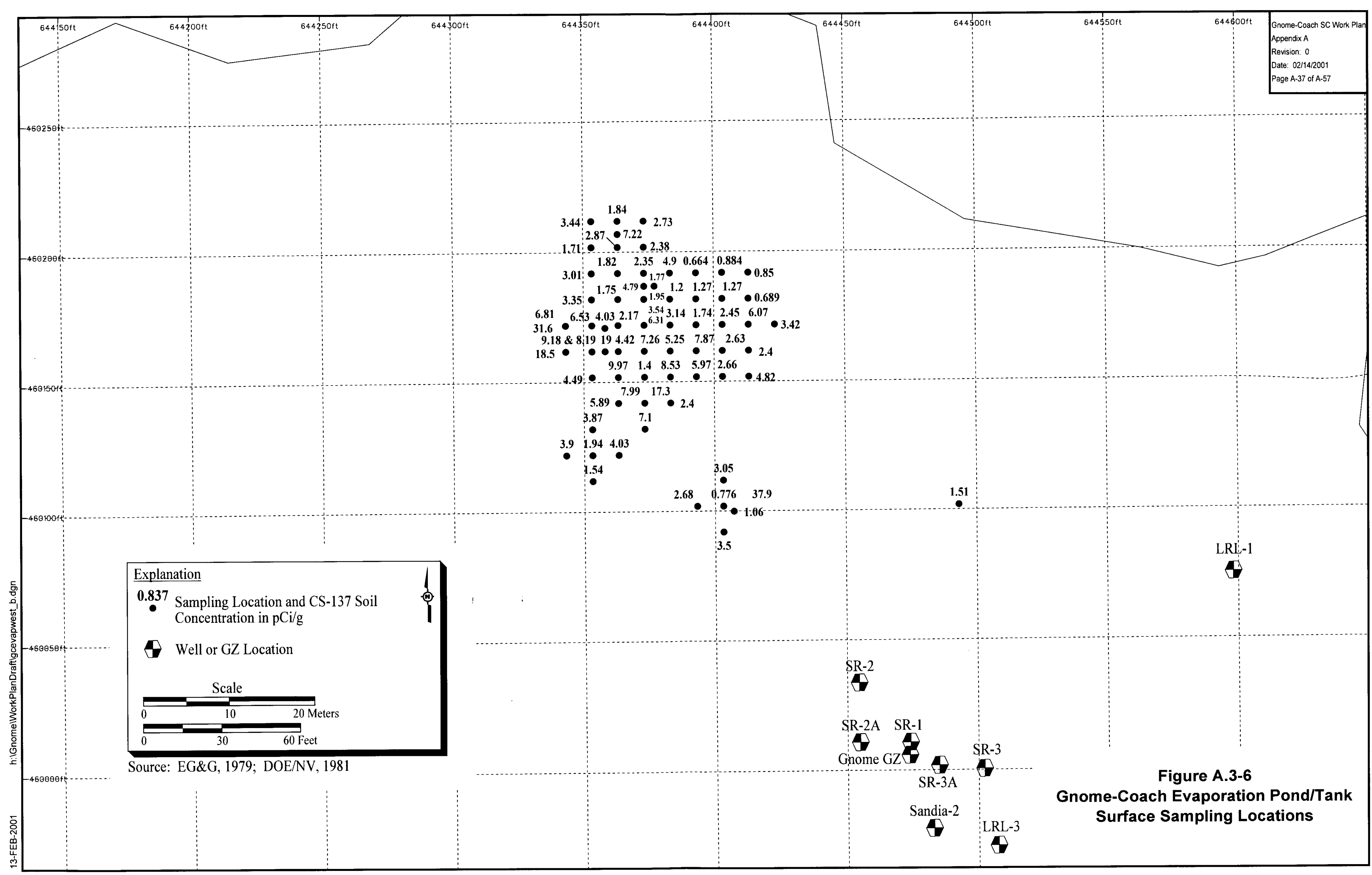




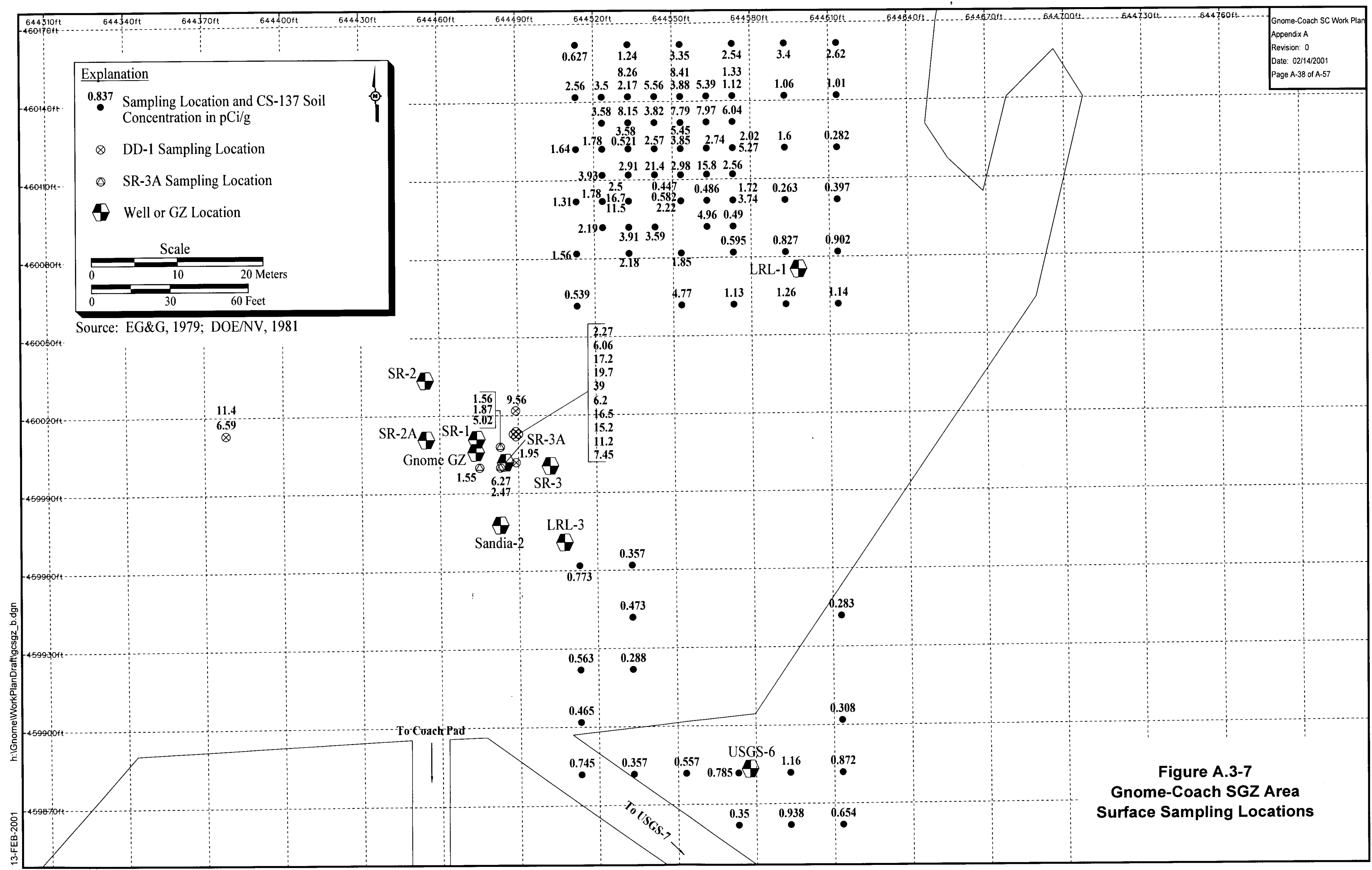




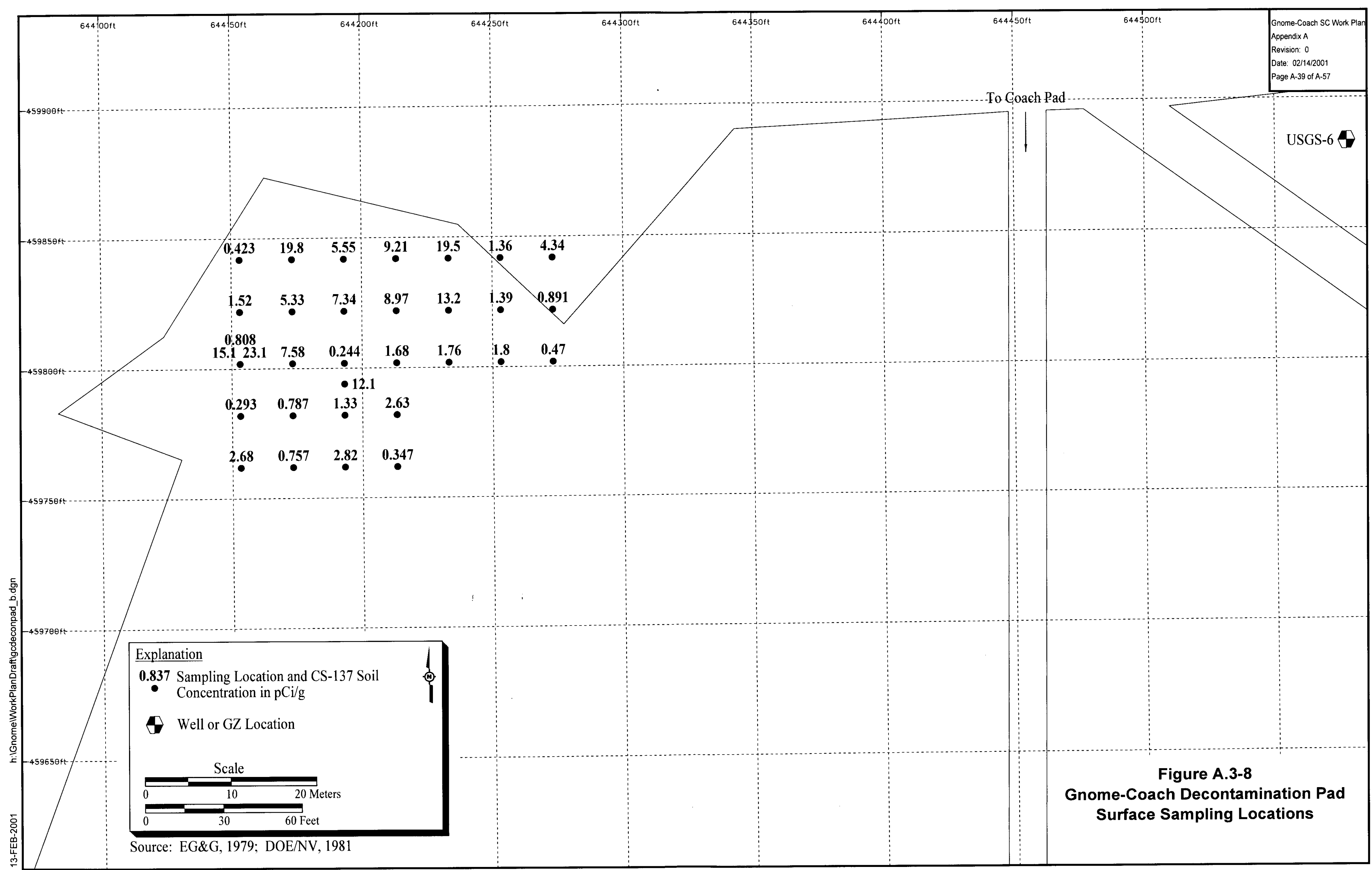




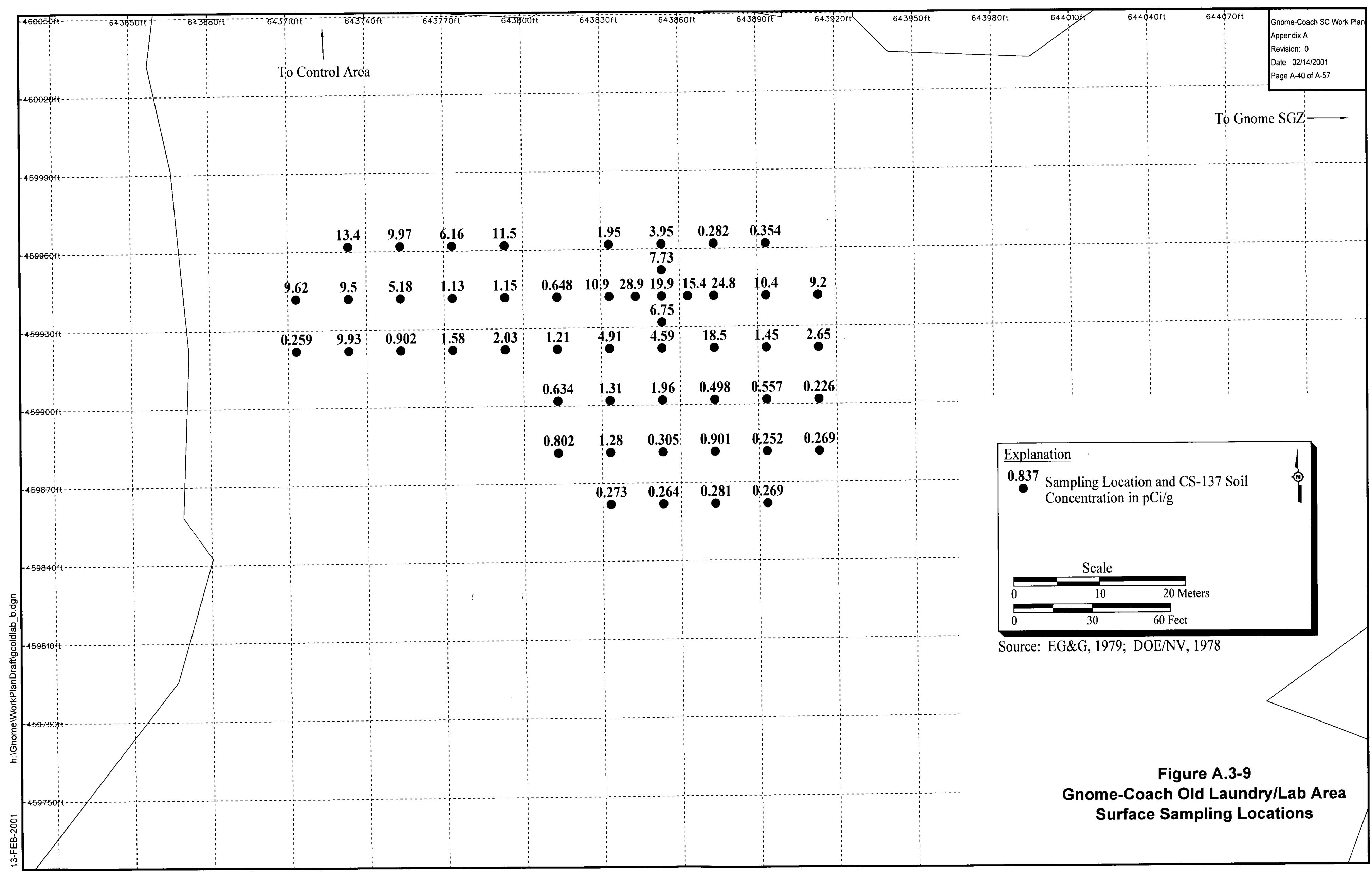




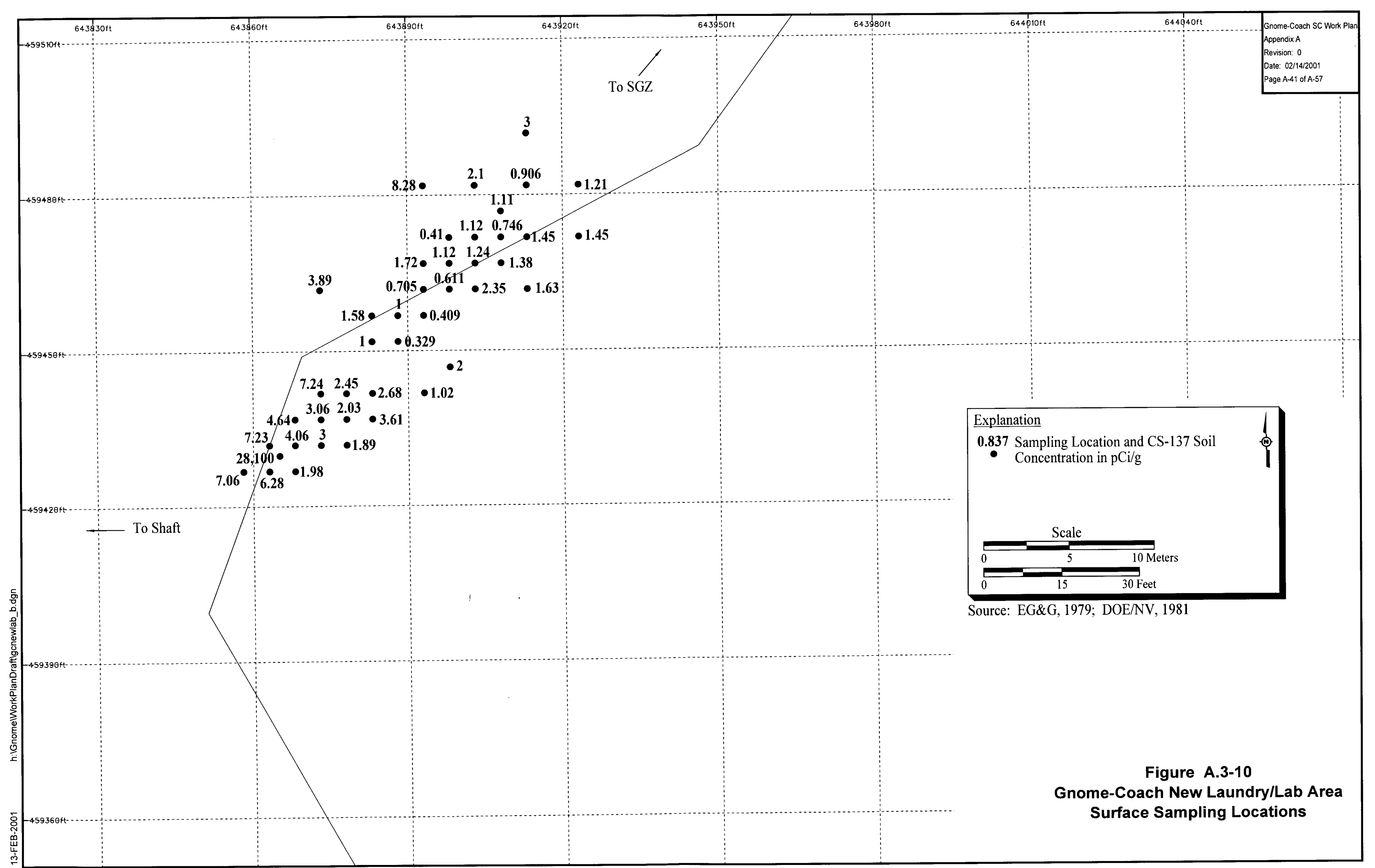




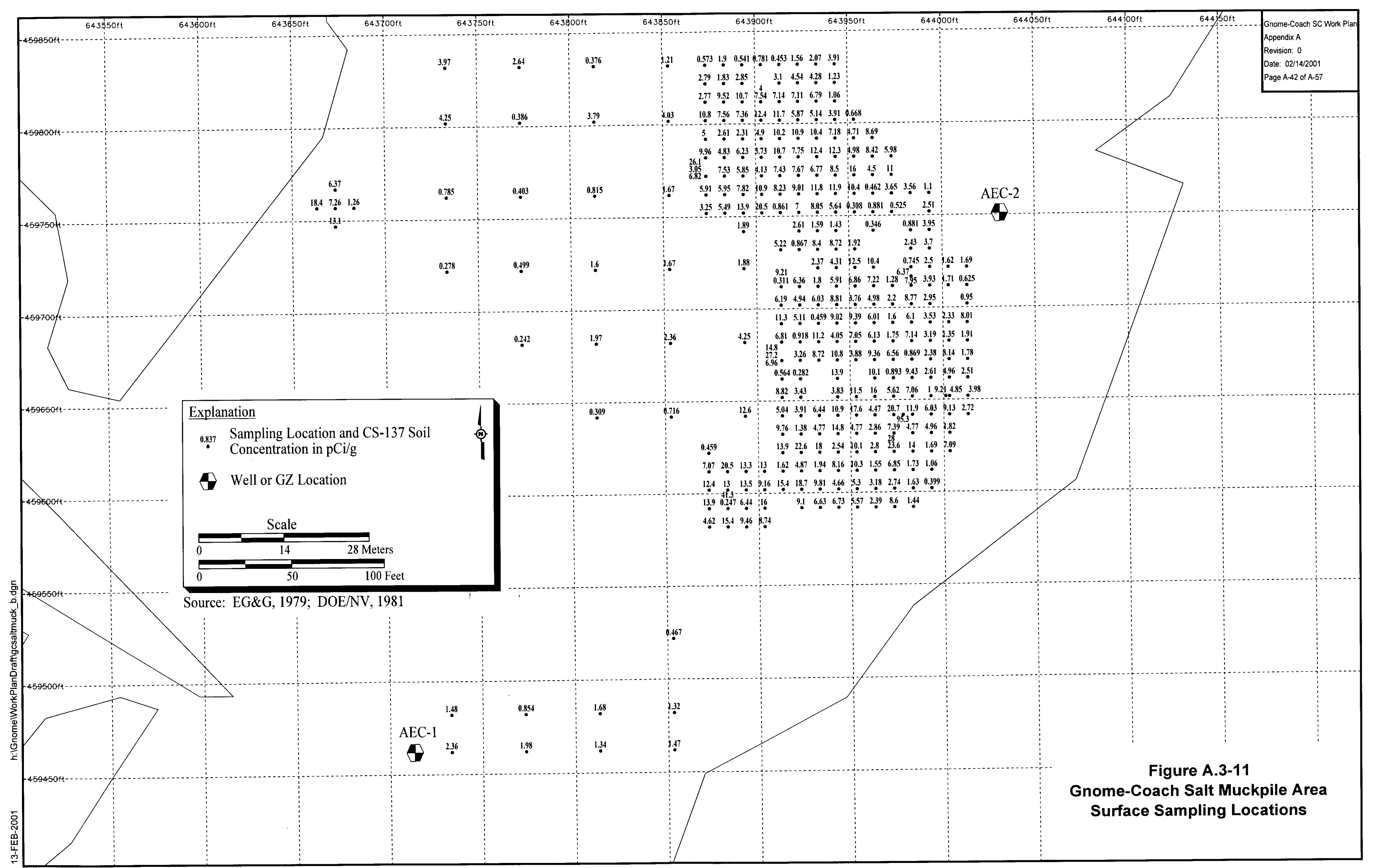




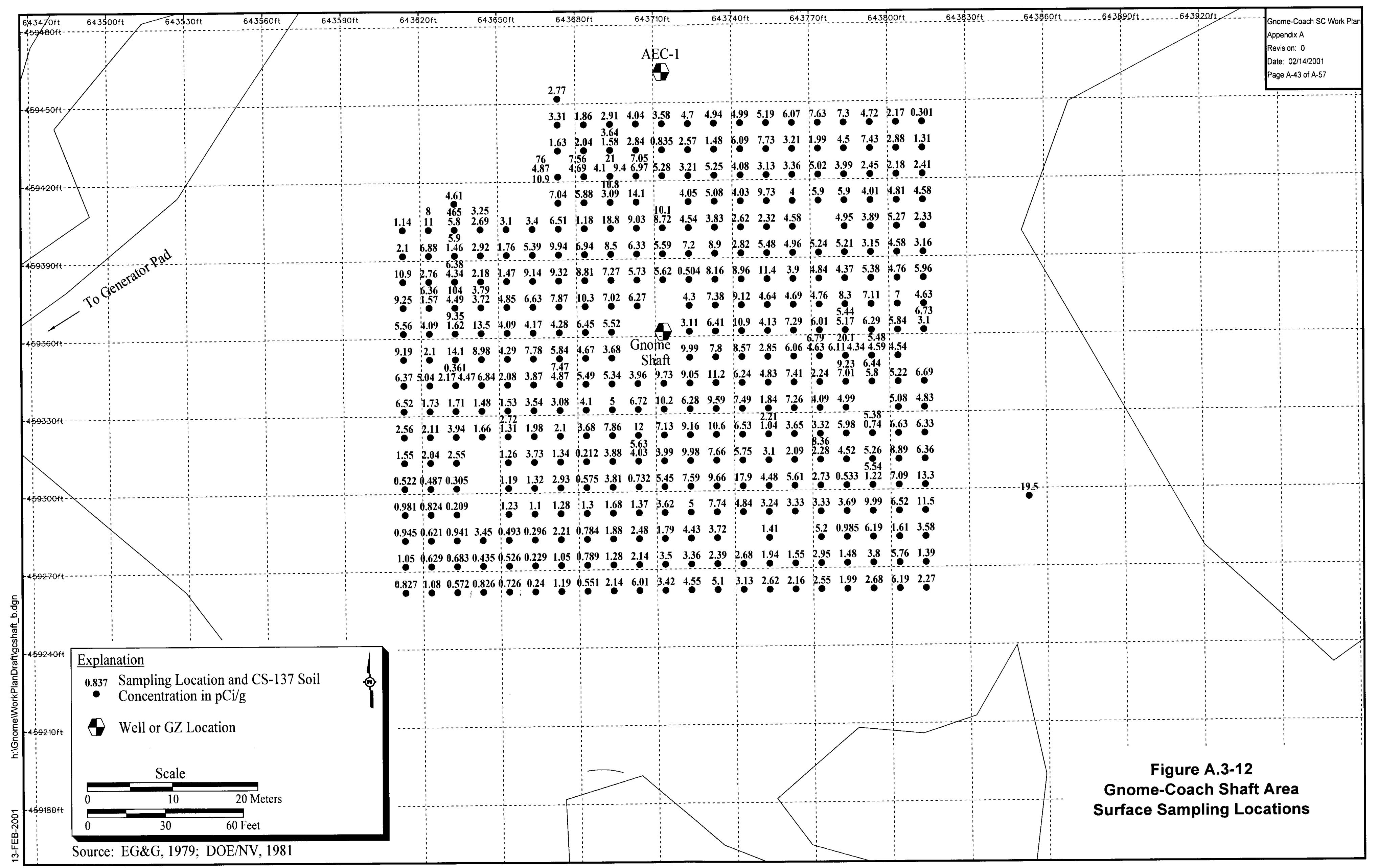




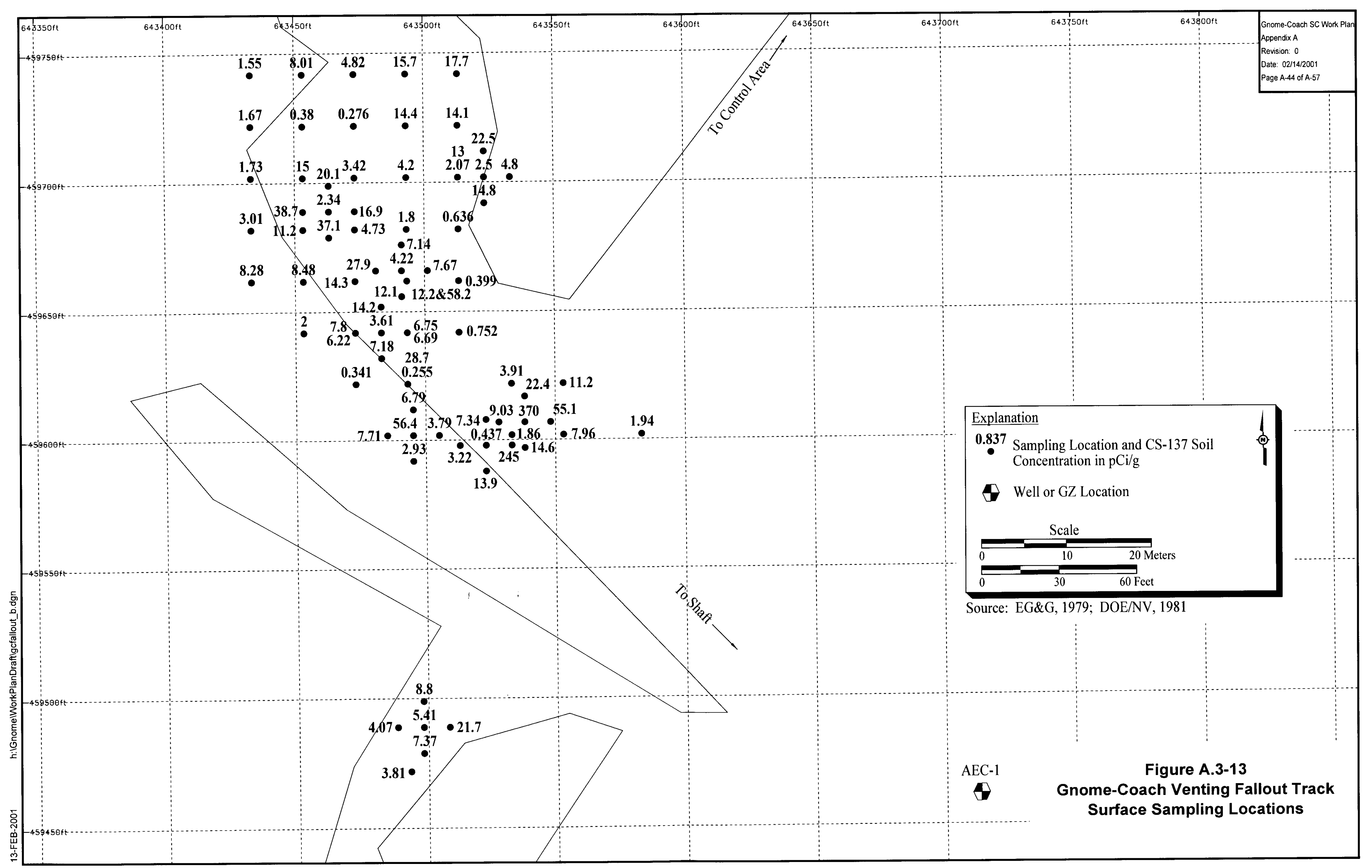




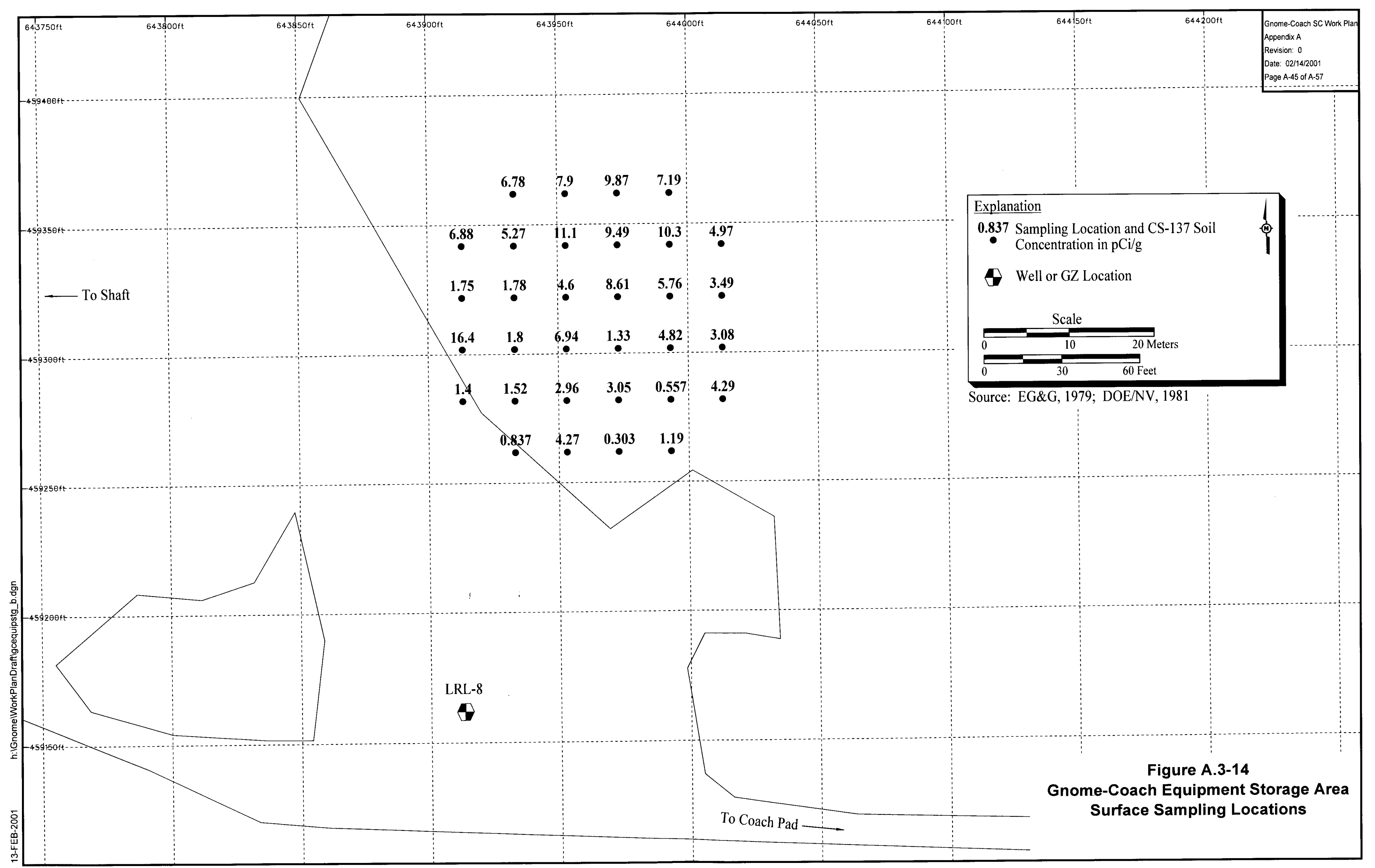




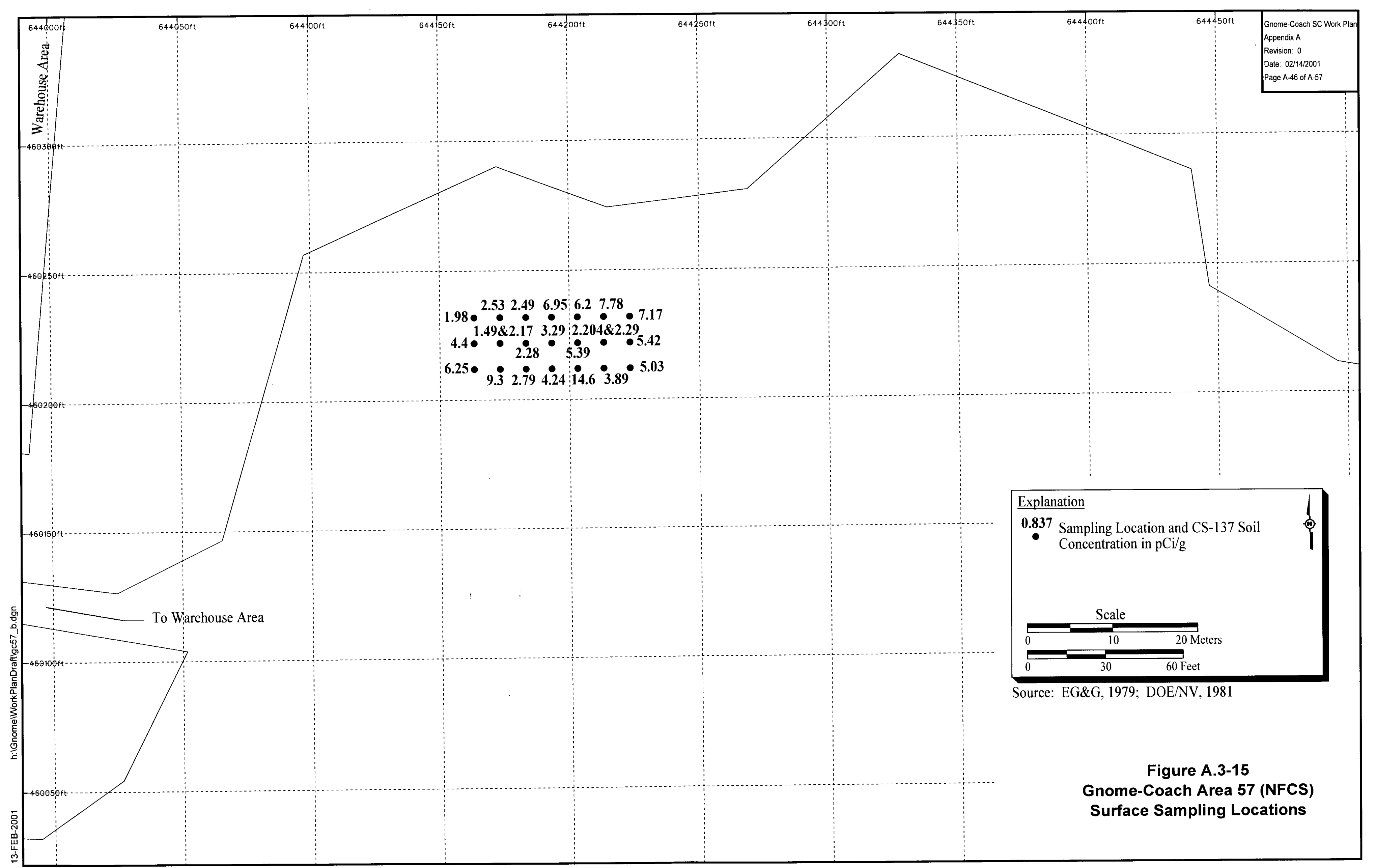




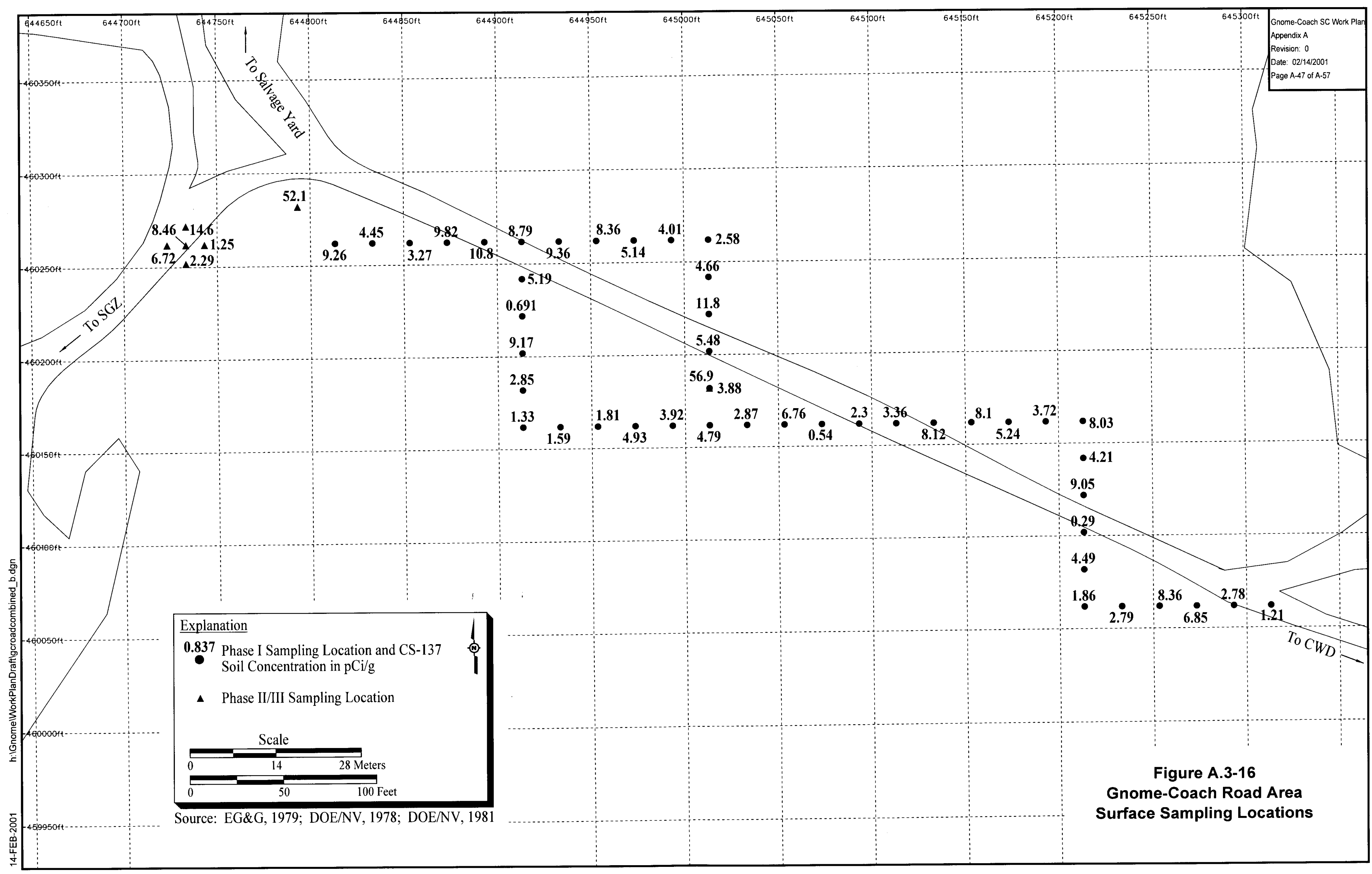




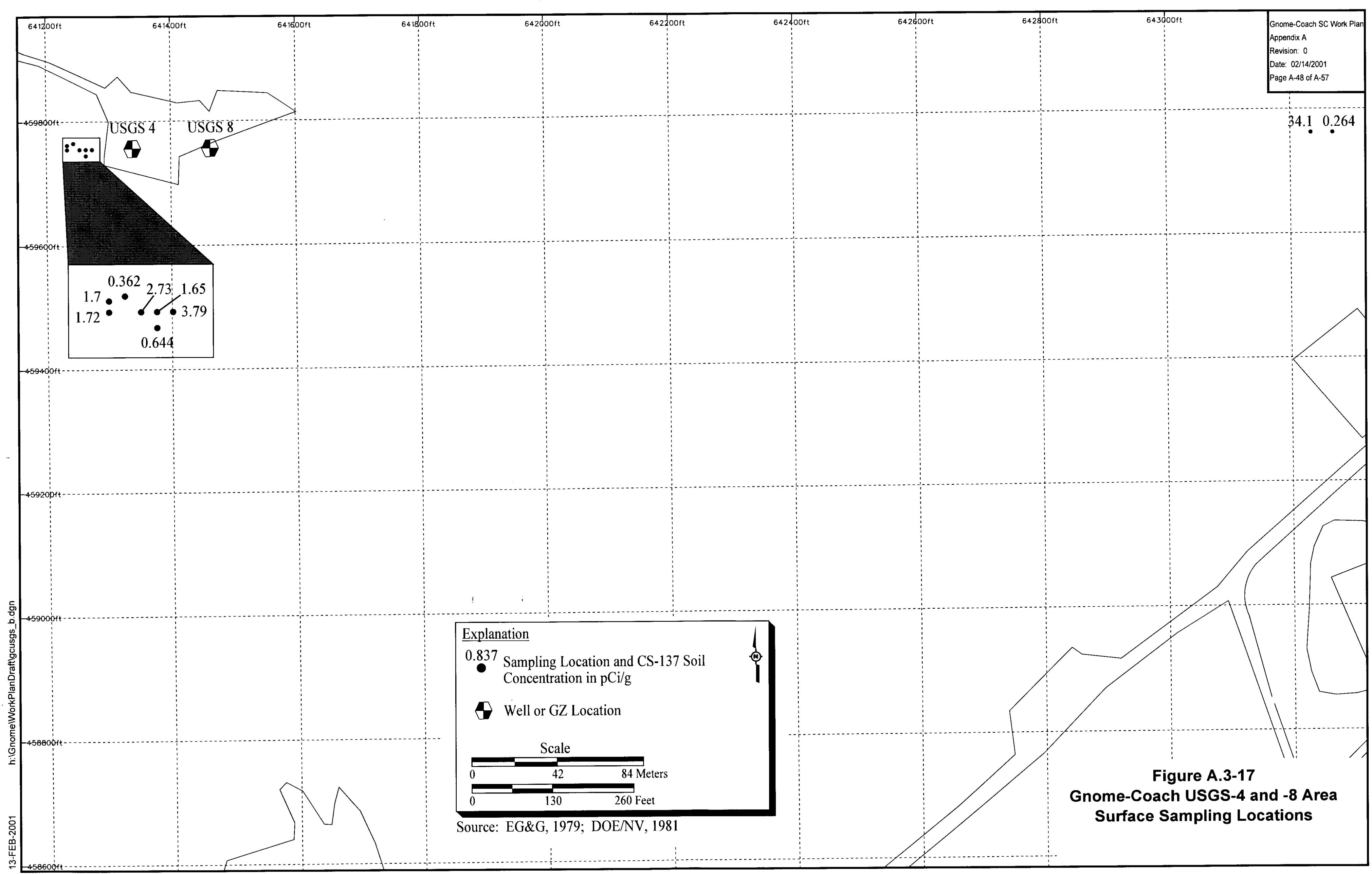




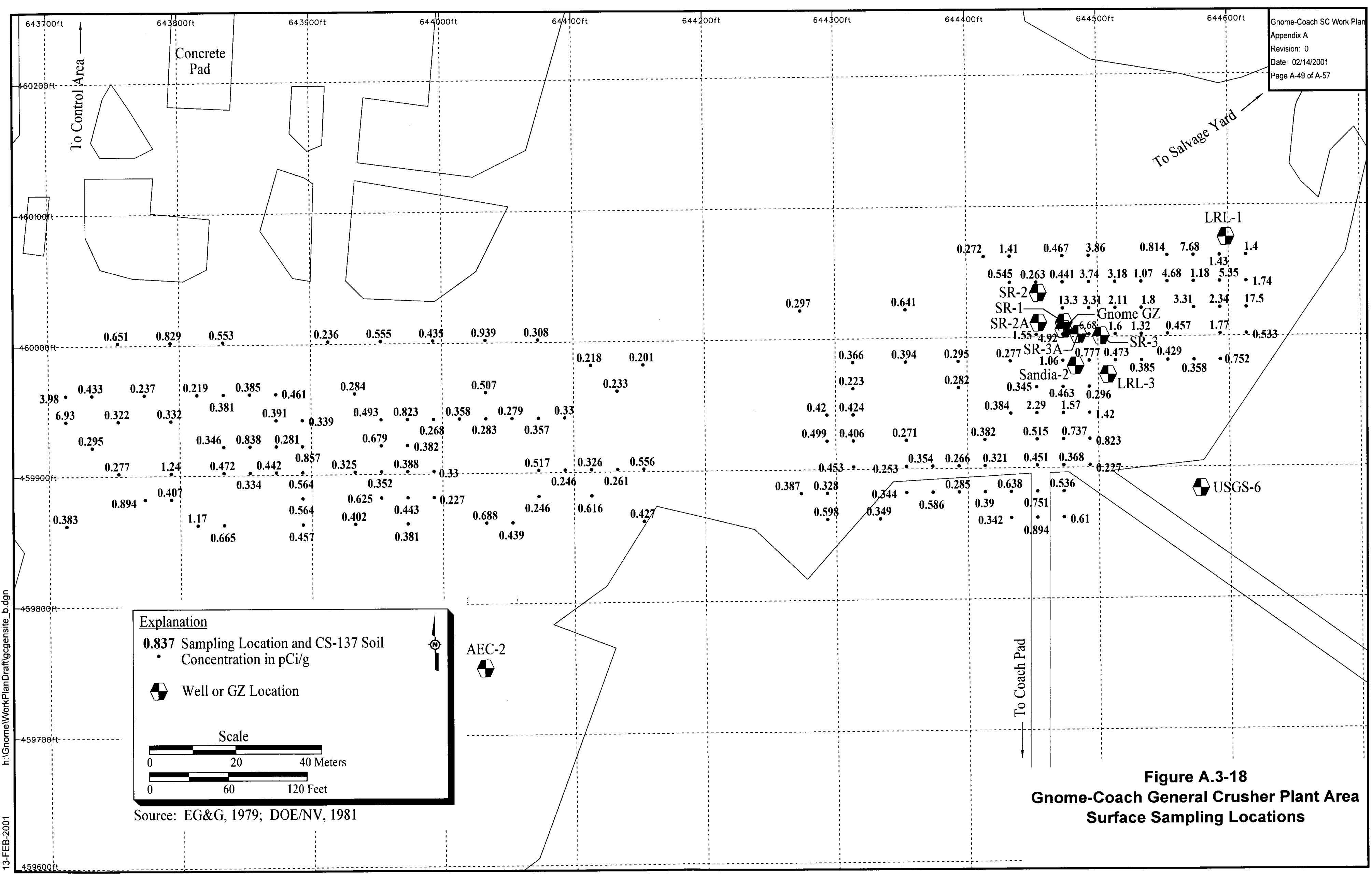




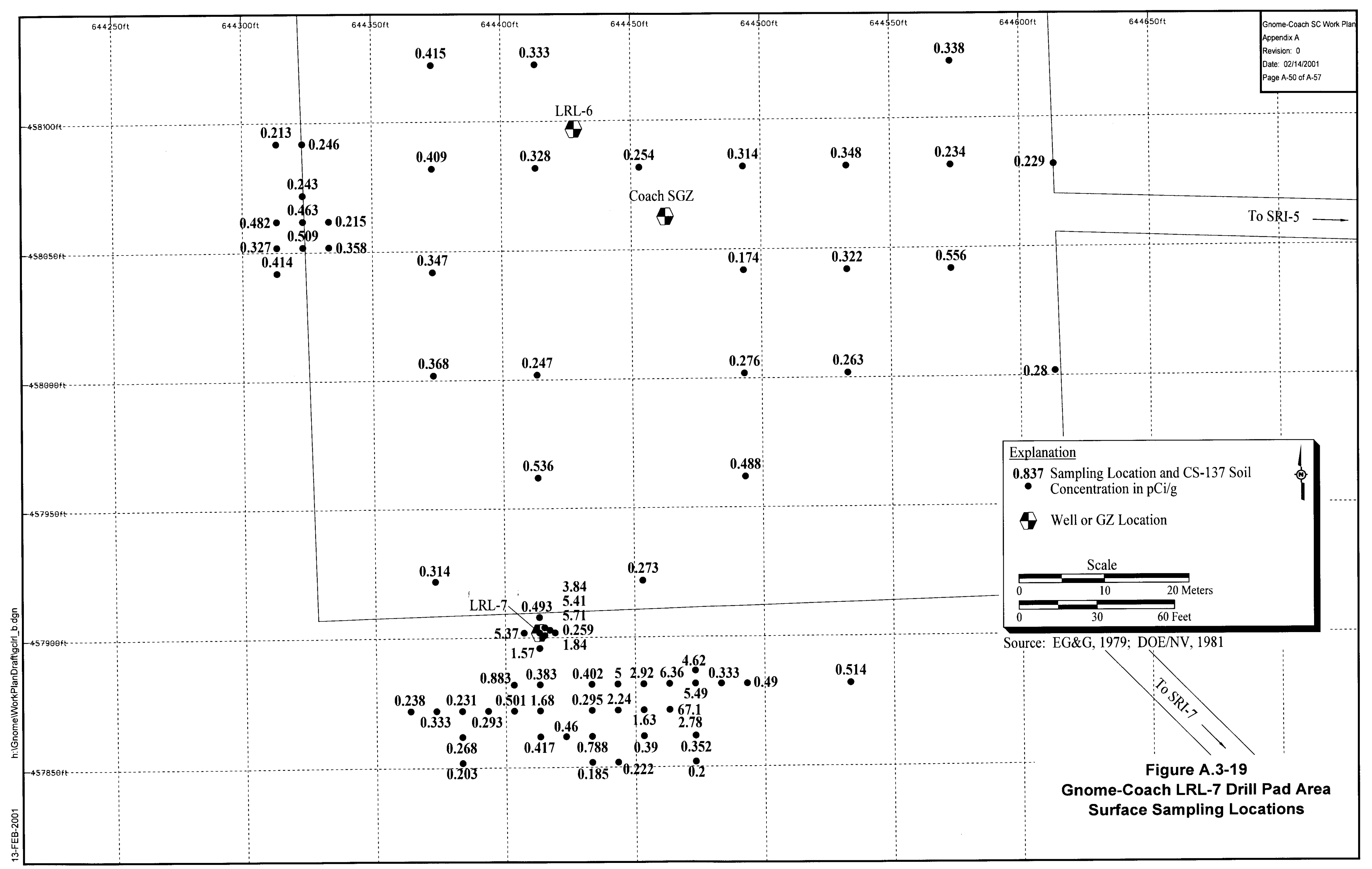




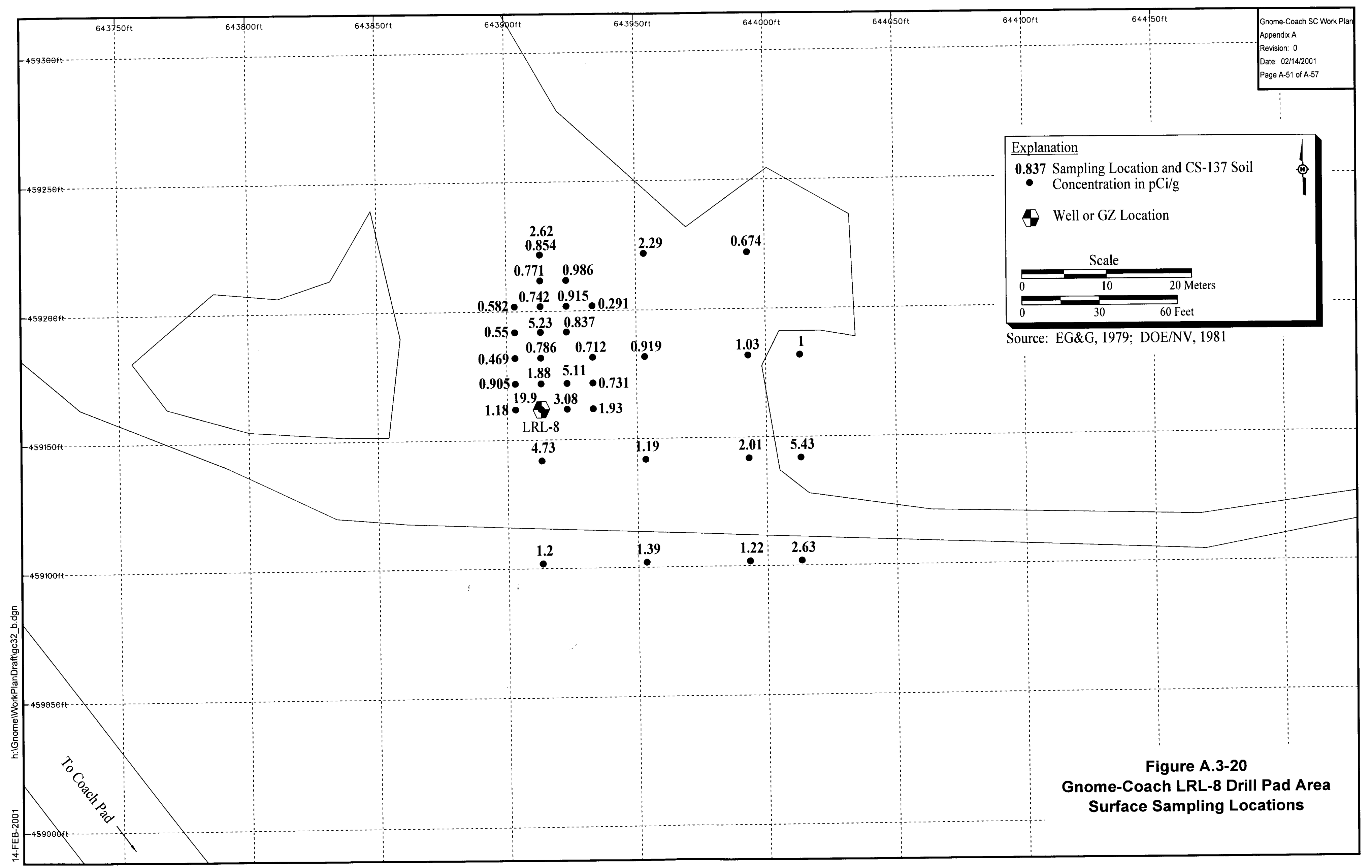




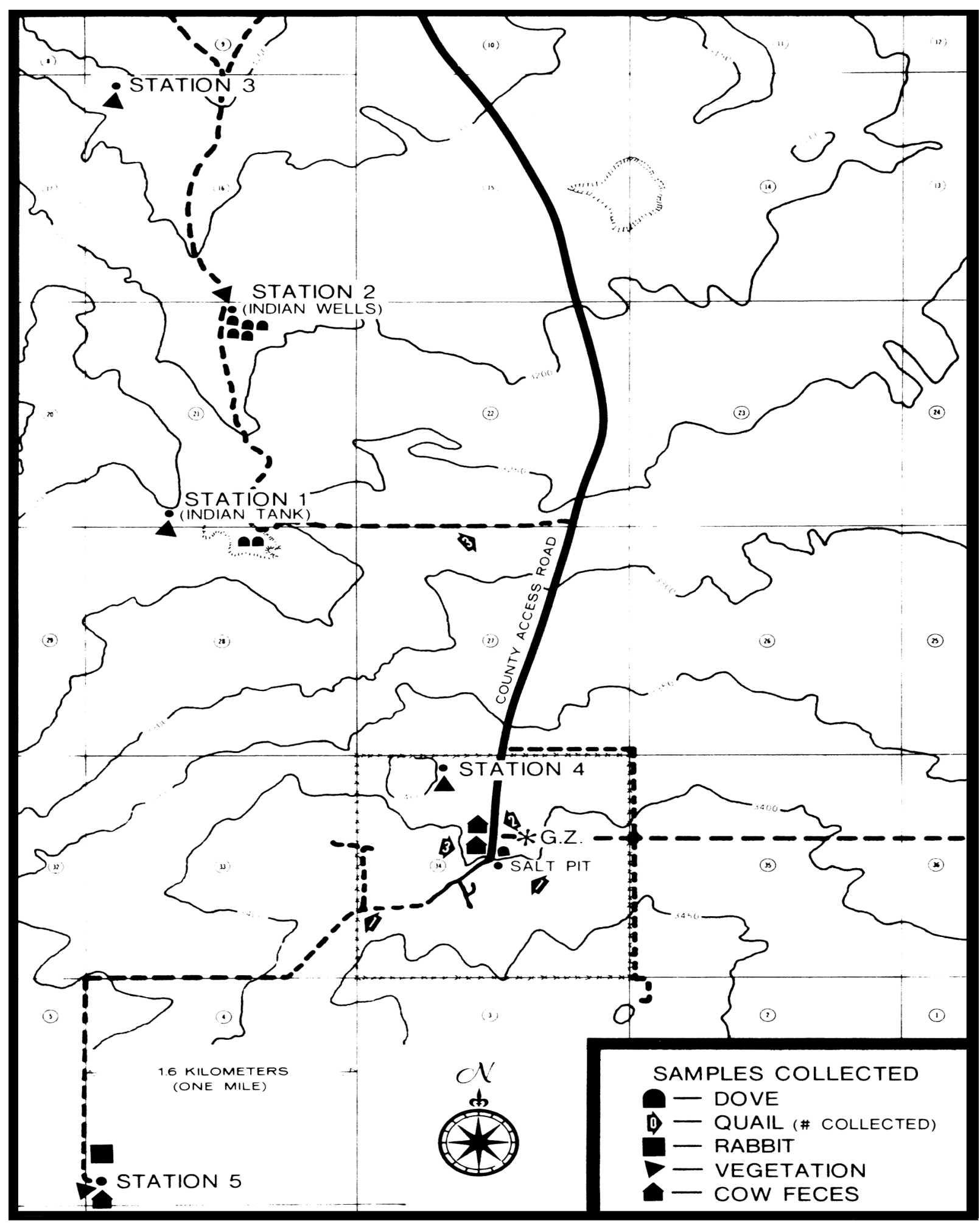

Source: Smith and Giles, 1973

Figure A.3-21

Vegetation Sampling Locations (1973) 


\section{A.4.0 Monitoring and Surveys for Post 1977-1979 Decommissioning (1980-2000)}

Survey and sampling programs were conducted by the EPA in 1994 (EPA, 1994) and the EEG in 1994 and 1995 (EEG, 1995) at the Gnome Site. These investigative programs identified areas that were above background radiological levels. The results for these two survey and sampling programs are described below.

\section{A.4.1 Environmental Protection Agency}

In June of 1992, the Gnome Site was selected by the EPA for a surface characterization study that would coincide with the EPA's annual LTHMP sampling activities. The study was conducted to assess the extent of activity remaining at the site and to provide data on the distribution of the contamination in the desert environment. Survey sites were selected based on previous operational areas and facilities such as waste disposal sites, building foundations, and around the shaft. The areas surveyed were also determined based on previously identified contaminated areas that had been cleaned up.

In situ field gamma-ray spectra (e.g., potassium-40, thorium-232, uranium-238, beryllium-7, Cs-137 and total gamma) measurements were collected at 22 locations utilizing two types of detectors. Twelve of the measurement locations were on site and 10 were off site. Soil core samples were collected at 11 locations with 2 on site and 9 off site. The areas with the highest in situ measurements were SGZ, shaft surface area, CWD, decontamination pad, wells USGS-4 and -8 as well as the venting plume fallout area. The highest exposure rate was $9.13 \mathrm{mR} / \mathrm{hr}$ located $490 \mathrm{ft}$ northwest of the shaft area, which is consistent with other surveys conducted at the Gnome-Coach Site. Ratios of Sr-90 to Cs-137 were calculated from soil samples collected near the Well DD-1 and Well USGS-8 and compared to ratios calculated from well water samples. These ratios demonstrate that spillage from well sampling was not the source of soil contamination near these wells. Additional details on the results of the surveys and sample analyses can be found in Residual Soil Radioactivity at the Gnome Test Site in Eddy County, New Mexico (EPA, 1994). 


\section{A.4.2 Environmental Evaluation Group}

The EEG conducted radiological surveys and sampling at the Gnome-Coach Site in 1995 at areas that were known to be contaminated based on previous radiological studies. The surveys and sampling were limited to the CWD site, the area surrounding the Gnome shaft, and the fallout plume area. The surveys were conducted using discrete radiation measurements collected at grid center intervals and a 100 percent walkover survey of the specified area with three radiation detection instruments. Both survey methods detected radioactivity above background within the locations surveyed (EEG, 1995). Areas with radioactivity above background were found along the Gnome fallout plume axis and at the CWD, predominately along the northern edge of the area surveyed (EEG, 1995).

Soil samples were taken from six of the highest soil radioactivity locations and sent for laboratory analyses. Two additional soil samples were collected at locations off the Gnome-Coach Site considered by EEG to be background. All of the samples were analyzed with gamma spectroscopy activities for Potassium-40 and Cs-137 were reported. The surface soil samples \#2 and \#3 were located approximately $130 \mathrm{ft}$ south and $230 \mathrm{ft}$ east of the main shaft, respectively. These sampling locations were selected based on in situ measurements. Sample \#2 had the maximum Cs-137 concentration of $83.40 \mathrm{pCi} / \mathrm{g}$ and Sample \#3 had $15.60 \mathrm{pCi} / \mathrm{g}$. The two background sample results were 0.64 and $0.07 \mathrm{pCi} / \mathrm{g}$.

Three out of the eight sample locations were analyzed for transuranics: $\mathrm{Pu}-239 / 240, \mathrm{Pu}-238$, and Am-241. Two soil samples had radioactivity concentrations above background. One of the above background soil samples was split into aliquots. Four of the aliquots were analyzed by an independent laboratory for radioactivity. Analysis results demonstrated that the radioactivity was heterogeneous (i.e., not uniformly distributed) in the soil matrix. A high transuranic result of $1,290 \mathrm{pCi} / \mathrm{g}(\mathrm{Pu}-239 / 240)$ was from one of these aliquot samples. However, only two sample locations were analyzed for this determination. Therefore, it should not be implied that there is significant plutonium contamination at the Gnome-Coach Site. 


\section{A.5.0 Conclusion}

Radiological surveys and soil sampling were conducted during and after the Gnome detonation, from December 1962 to January 1963, and during site decommissioning and restoration conducted in 1968 to 1969 , and from 1977 to 1979 . Radionuclides of concern detected at the site during and after site restoration include Cs-137, tritium, Sr-90, Pu-239/240, and Am-241. Cesium-137 was determined to be the primary contaminant of concern and was consistently used as the radionuclide indicator during site decommissioning and restoration.

After the 1979 site remedial action, Cs-137 was detected in soil above background but did not exceed the $1977-1979$ criteria of $20 \mathrm{pCi} / \mathrm{g}$ averaged over 0.25 hectare as reported in DOE/NV (1981). Tritium concentration results were all less than the $30,000 \mathrm{pCi} / \mathrm{mL}$ radiological release criteria. In situ radiological surveys completed after site decommissioning showed above background levels of Cs-137 in the vicinity of the shaft, old and new laundry/lab areas, evaporation pond, fallout track from shaft venting, and the CWD. Independent surveys and sampling conducted by EPA and EEG confirmed the same areas of elevated radiological contamination.

An assessment of the adequacy of the radiological sampling and monitoring was performed. The areal and vertical distribution of soil samples collected for the two phases of site characterization indicate that the number of soil samples collected in each of the areas of concern is adequate to characterize the site. The areal distribution of in situ radiological surveys also indicate that the identified areas of concern are adequately characterized. The quantity of data was evaluated and is adequate for site characterization purposes.

The results from this evaluation indicate that some areas of the site have Cs-137 soil concentration results that are of concern and require further investigation. Additional shallow subsurface data should be collected at the decontamination pad area, old laundry/lab area, new laundry/lab area and salt muckpile. In addition, a limited number of confirmatory measurements for Sr-90 should be made during the investigation to evaluate the relative leaching of Sr-90 compared to Cs-137, and to more accurately determine their relative ratios. A limited soil investigation should be made in the vicinity of the EEG (1995) detection of Pu-239/240 to confirm that this detection does not represent significant contamination. 


\section{A.6.0 References}

AEC, see U.S. Atomic Energy Commission.

Desert Research Institute. 1988. CERCLA Preliminary Assessment of DOE's Nevada Operations Office Nuclear Weapons Testing Areas. Las Vegas, NV.

DOE/NV, see U.S. Department of Energy, Nevada Operations Office.

DRI, see Desert Research Institute.

EEG, see Environmental Evaluation Group.

EG\&G. 1973. Radiological Survey of the Area Surrounding the Project Gnome Test Site Carlsbad, New Mexico, EGG-1183-1569. Las Vegas, NV.

EPA, see U.S. Environmental Protection Agency.

Environmental Evaluation Group. 1995. Radionuclide Baseline in Soil Near Project Gnome and The Waste Isolation Pilot Plant, DOE/AL/58309-58, EEG 58. Prepared by J.W. Kenney, P.S. Downes, D.H. Gray, and S.C. Ballard. Carlsbad, NM.

FR, see Federal Register.

Gardner, M.C., and J.J. Sigalove. 1970. Evaluation of the Project Gnome/Coach Site, Carlsbad, New Mexico for Disposition, Including Identification of Restrictions, Part I, NVO-1229-106, Part I. Palo Alto, CA: Teledyne Isotopes.

National Council on Radiation Protection and Measurements. 1993. Exposure of the U.S. Population from Diagnostic Medical Radiation, NCRP Report No. 100. Bethesda, MD.

NCRP, see National Council on Radiation Protection and Measurements.

NRC, see U.S. Nuclear Regulatory Commission.

REECo, see Reynolds Electrical \& Engineering Co., Inc.

Reynolds Electrical \& Engineering Co., Inc. 1973. Carlsbad Reconnaissance 1972, Gnome Site. Las Vegas, NV.

Smith, D.D., and K.R. Giles. 1973. Report of Bioenvironmental Sampling at the Gnome Site, Carlsbad, New Mexico-October 1972, NERC-LV-539-25. Prepared for the U.S. Atomic Energy Commission. Las Vegas, NV: U.S. Environmental Protection Agency. 
Tappan, J.T., and J.J. Lorenz. 1969. On-Site Radiological Safety Report, Carlsbad Site Roll-Up Program, NVO-410-2. Prepared for the U.S. Atomic Energy Commission. Mercury, NV: Reynolds Electrical \& Engineering Co., Inc.

U.S. Atomic Energy Commission. 1962a. Project Gnome - Final Report, On-Site Radiological Safety Report, PNE-133F. Prepared by Reynolds Electrical \& Engineering Co., Inc. Washington, DC.

U.S. Atomic Energy Commission. 1962b. Project Manager's Report Project Gnome, Plowshare Program. Washington, DC.

U.S. Atomic Energy Commission. 1965. Aeroradioactivity Survey and Geology of the Gnome (Carlsbad) Area, New Mexico and Texas (ARMS-1). Prepared by J.A. MacKallor. Washington, DC.

U.S. Department of Energy, Nevada Operations Office. 1978. Gnome Site Decontamination and Decommissioning - Phase I Radiological Survey and Operations Report, Carlsbad, New Mexico, NVO/0410-48, Vols. 1 and 2. Prepared by Reynolds Electrical \& Engineering Co., Inc. Las Vegas, NV.

U.S. Department of Energy, Nevada Operations Office. 1979. Project Gnome Decontamination and Decommissioning Plan, NVO 202. Las Vegas, NV.

U.S. Department of Energy, Nevada Operations Office. 1981. Gnome Site Decontamination and Decommissioning Project, Radiation Decontamination Clearance Report, March 28, 1979 September 23, 1979, DOE/NV/00410-59. Prepared by Reynolds Electrical \& Engineering Co., Inc. Las Vegas, NV.

U.S. Environmental Protection Agency. 1994. Residual Soil Radioactivity at the Gnome Test Site, Eddy County, New Mexico, EPA 600/R-94/117. Prepared by S.H. Faller. Las Vegas, NV. 


\section{Appendix B}

\section{New Mexico Quality Assurance Project Plan \\ (This quality assurance project plan is applicable to all U.S. Department of Energy, Nevada Operations Office sites in the State of New Mexico)}




\section{B.1.0 Introduction}

This QAPP is a planning document used for the Offsites Project New Mexico Sites by the DOE/NV Environmental Restoration Project (NV ERP). The NV ERP conducts environmental investigation and remediation activities at sites under the oversight of the DOE/NV. It is the policy of the NV ERP to conduct all environmental restoration activities in a manner that produces data of a known quality. Safety is integrated into management and work practices at all levels so that missions are accomplished while protecting the public, the worker, and the environment.

The information provided in this QAPP describes policies, organization, responsibilities, and objectives of the New Mexico Sites and is intended to provide a consistent framework for the collection, evaluation, analysis, and use of data. This QAPP provides for the evaluation of risks associated with the activities to be performed and uses the graded approach to determine the required level of quality assurance. This document supplements, and is to be used in conjunction with, project planning documents which will contain quality assurance (QA)/QC requirements appropriate for the site and activities being performed. Attachment 1 of this QAPP delineates the quality criteria that should be addressed in site-specific planning documents. In the event that project objectives or regulatory jurisdiction changes, this document will be reevaluated for adequacy.

The requirements of this QAPP are consistent with those provided in DOE Order 414.1A, Quality Assurance (DOE, 1999). The NV ERP activities shall also be in compliance with DOE Order 440.1A, Worker Protection Management for DOE Federal and Contractor Employees (DOE, 1998), and DOE Order 450.4, Safety Management System Policy (DOE, 1996b). Work at hazardous waste sites shall be conducted in accordance with the applicable sections of 29 Code of Federal Regulations (CFR) 1910.120, Hazardous Waste Operations and Emergency Response (CFR, 1998b), and in accordance with New Mexico Administrative Code regulations for the disposal of hazardous waste.

Work at the New Mexico Sites will be conducted in accordance with the applicable New Mexico Administrative Code regulations and New Mexico Statutes. Should radioactive waste be generated, it shall be handled and disposed of in accordance with 10 CFR Part 71, Subpart H, Packaging and Transportation of Radioactive Materials - Quality Assurance (CFR, 1998a), and NTSWAC 
(DOE/NV, 1999b). Sites that conduct activities or operations that involve radioactive and/or fissionable materials in such form and quantity that a nuclear hazard potentially exists shall also comply with the relevant parts of 10 CFR 830.120, Quality Assurance Requirements (CFR, 1996).

Figure B.1-1 delineates the hierarchy of documents for NV ERP activities.

\section{QAPP Organization}

The organization of this plan reflects the criteria of DOE Order 414.1A, Quality Assurance (DOE, 1999). The ten criteria therein covers three major areas: management, performance, and assessments. Management entails the planning and preparation required for the successful completion of the New Mexico Sites mission. Additionally, this section incorporates quality improvement processes to enable personnel to detect and prevent quality problems. The performance section establishes the requirements and procedures to be implemented to ensure that newly collected environmental data are valid, that uses of existing data are appropriate, and that methods of environmental modeling are reliable. Assessments provide a feedback loop to Offsites Project management whereby the feedback information can be used to evaluate and, if necessary, modify a system or process to ensure the quality of the product. 


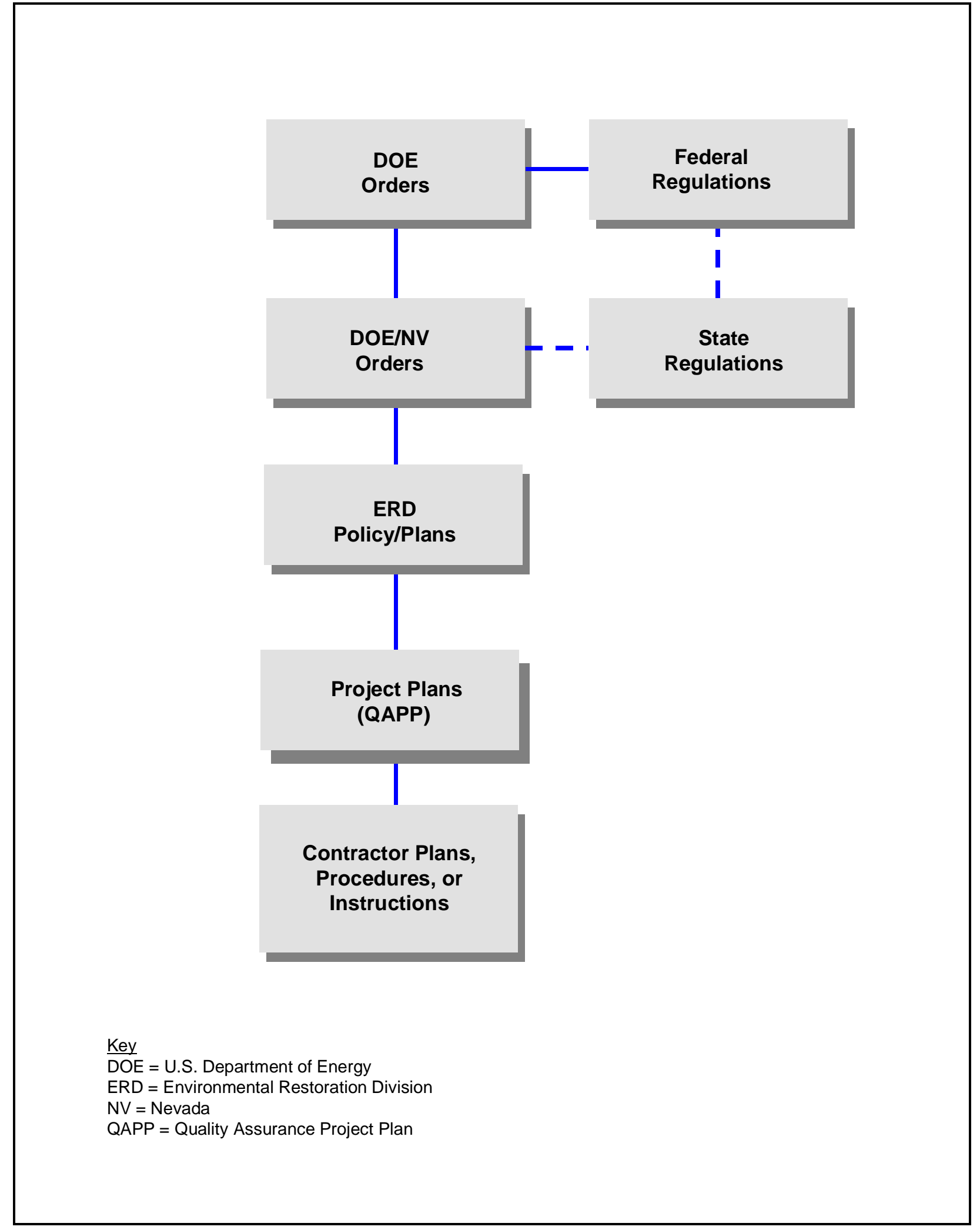

Figure B.1-1

Hierarchy of Documents 


\section{B.2.0 Criteria 1 - Quality Program}

The management systems for the New Mexico Sites encompass the planning and preparation necessary to ensure the successful completion of identified objectives. This QAPP has been prepared to provide the planning and control necessary for effective and efficient work processes. This document provides the overall QA Program requirements and the general quality practices to be applied to activities at the New Mexico Sites. Policy is established, roles and responsibilities are defined, lines of communication are identified, the needs and objectives of the Project are confirmed, and reviews are conducted to ensure (to the extent possible) that all necessary planning and preparation activities have taken place. Low-level radioactive and mixed waste managed under the NV ERP must also meet the requirements of the NTSWAC and the IT Corporation, Las Vegas (ITLV) waste certification program plan. The following sections describe the quality management systems to be employed for the effective management of the New Mexico Sites.

\section{B.2.1 Quality Management Policy}

It is the policy of the NV ERP to provide environmental management that incorporates applicable regulatory requirements. The Quality Management Program described in this document should be implemented for all New Mexico Sites environmental activities to ensure that work is performed in an efficient, controlled manner, and is appropriately documented. Project requirements should be applied on a graded approach, commensurate with the risk of failure of the items or processes and the potential harm those risks pose for human health and the environment. Activities shall conform with applicable federal, state, and local regulations, and contract requirements. Quality will be part of the normal course of work and incorporated from the earliest planning stages to completion of the work.

\section{B.2.2 Project Organization}

The DOE/NV Environmental Restoration Division (ERD) is responsible for the administration of the NV ERP. The NV ERP is a major project under the DOE Office of Environmental Management, Southwestern Area Programs. Personnel from the ERD are assigned project management and technical support responsibilities. All NV ERP Project Managers are responsible for achieving quality within the specific projects they manage. The DOE/NV ERD organization chart is provided in Figure B.2-1. 


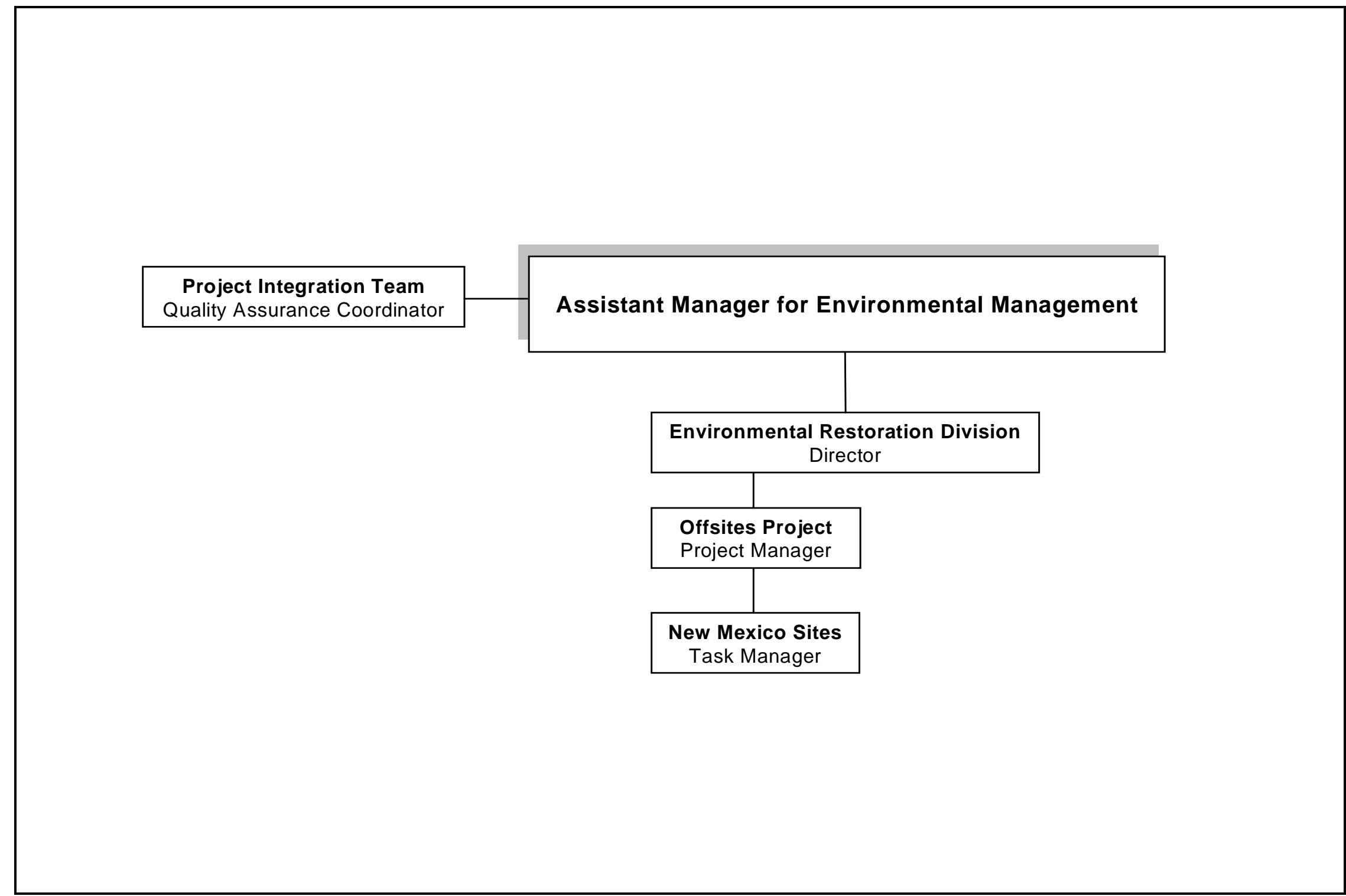

Figure B.2-1

DOE/NV ERD Organizational Chart 
Roles and responsibilities for NV ERP personnel and supporting contractors and organizations (referred to as Project participants) are described in the following sections.

\section{B.2.3 DOE/NV ERD Director}

The DOE/NV ERD Director has oversight and management responsibilities for all projects under the NV ERP and is responsible for the scope and implementation of the QA Program defined in this document. The Director is the senior management official responsible for ensuring that this QAPP is established, that quality requirements are implemented, and that opportunities for improvement are identified and incorporated.

\section{B.2.3.1 NV ERP Project Manager}

The NV ERP Project Manager reports directly to and is the prime point-of-contact with the DOE/NV ERD Director. The NV ERP Project Manager has day-to-day management responsibilities for technical, financial, and scheduling aspects of his/her assigned project and shall monitor contractor performance of project activities. At a minimum, the DOE/NV Project Manager is responsible for the following duties:

- Review, approve, and direct the implementation of NV ERP project-specific plans.

- Disseminate pertinent information from DOE/NV to NV ERP participants.

- Review and approve changes to NV ERP project-specific documents.

- Monitor the activities of participating organizations and provide direction and guidance for improvement.

- Verify Project participants are adequately executing the responsibilities as delineated in this section.

- Notify and apprise the DOE/NV ERD Director and DOE/NV ERP Quality Assurance Coordinator (QAC) of significant conditions adverse to quality.

- Act as the point-of-contact for state regulator for all aspects of the project. 


\section{B.2.3.1.1 NV ERP Task Manager}

The NV ERP Task Managers report directly to their respective NV ERP Project Managers. The Task Managers have day-to-day management responsibilities for technical and scheduling aspects of the assigned project task and shall monitor contractor performance of task activities. At a minimum, the Task Managers are responsible for the following duties:

- Ensure effective communication among contractors performing work for their assigned tasks.

- Participate in the organization and planning of activities.

- Perform periodic assessments (such as surveillances) of activities under their purview.

- Monitor the activities of participating organizations and provide direction and guidance for improvement.

- Notify the responsible NV ERP Project Manager and other involved personnel of significant conditions adverse to quality.

\section{B.2.3.1.2 NV ERP Quality Assurance Coordinator}

The NV ERP QAC has a direct line of communication with the DOE/NV ERD Director and the NV ERP Project Managers. The NV ERP QAC will provide the overall direction of the QA function. At a minimum, the NV ERP QAC shall have the following duties:

- Identify and respond to QA/QC needs of the NV ERP and provide QA/QC guidance or assistance to individual Project Managers and Task Managers.

- Verify that systems are in place to evaluate data against analytical quality criteria.

- Verify that appropriate corrective actions are taken for nonconforming conditions.

- Notify the DOE/NV ERD Director, the individual NV ERP Project Managers, and other involved personnel, of significant conditions adverse to quality or any adverse trends.

\section{B.2.3.2 New Mexico Sites Project Participants}

Project participants, such as supporting contractors and organizations, are responsible for developing the necessary procedures for their assigned scope of work and ensuring that work is performed in accordance with applicable federal, state, and local regulations, and approved NV ERP project plans 
and procedures consistent with individual contracts and agency agreements. To fulfill responsibilities specific to QA, participants shall, at a minimum, be responsible for the following:

- Report to the NV ERP Project Managers or NV ERP Task Managers concerning scope, schedules, costs, technical execution, and quality achievement of task order activities.

- Ensure the proper resources are provided for QA activities and that QA activities are integrated into project activities.

- Evaluate activities to ensure that planning document requirements are implemented.

- Implement applicable procedures and instructions that govern NV ERP activities.

- Verify that work is technically sound, of acceptable quality, and is consistent with project objectives.

- Ensure personnel are trained and qualified to achieve initial proficiency, maintain proficiency, and adapt to changes in technology, methods, or job responsibilities.

- Perform assessments, as applicable, to verify compliance with applicable requirements.

- Identify deficient areas and implement effective corrective action for quality problems.

- $\quad$ Notify the NV ERP Project Managers, the NV ERP Task Managers, and other involved personnel of significant conditions adverse to quality or any adverse trends.

- Verify that appropriate corrective actions are taken for nonconformances.

\section{B.2.3.3 Analytical Laboratories}

Analytical laboratories used to support the NV ERP are responsible for ensuring that samples are received, handled, stored, and analyzed according to the analytical laboratory's QA program and contract requirements. Analytical laboratories performing data analysis shall participate in Performance Evaluation Sample Programs appropriate for analyses performed and be subject to periodic audits. Subcontracted analytical services are subject to the same requirements. Verification of subcontractor conformance is the responsibility of the contracting organization. 


\section{B.2.4 Planning}

The NV ERP and participant personnel responsible for oversight of data collection operations should verify that the data-collection system design is defined, controlled, verified, and documented. All planning shall incorporate the principles of Integrated Safety Management to mitigate hazards to workers, the public, and the environment. A graded approach to data quality requirements shall be used to meet the sampling objectives and data needs of a given site and the dynamic nature of the program. Work assignments should be clearly communicated with lines of communication established among all participants. Organizations assigned lead responsibilities shall coordinate project planning with decision makers and participating organizations.

\section{B.2.4.1 Task Initiation}

A project kickoff meeting should be conducted at the beginning of each task. This meeting should brief key personnel assigned to the task on the purpose of the task, the expected outcome, the schedule for the task, and personnel responsibilities for completion of the effort. The responsible manager should monitor the planning process to ensure communication of status, to assess progress, and to implement any corrective action needed to achieve timely completion.

\section{B.2.4.2 Data Quality Objectives}

When appropriate, planning and scoping for environmental data/information needs will include the use of the DQO process to determine the type, quantity, and quality of the data to be collected and the appropriate use of such data. Participants in the DQO process for each operation should include representatives of all data users and decision makers involved with that operation. The DQO process provides a systematic procedure for defining the criteria that a data collection design should satisfy. The appropriate DOE/NV ERD personnel, NV ERP participants, and state regulators will jointly establish DQOs for each site, or group of similar sites, to allow the work to be planned in a manner that will ensure data will meet the needs of the end users. Representatives from these organizations should include data users and decision makers. 
The most current version of EPA QA/G-4, Guidance for the Data Quality Objectives Process (EPA, 1994a), or an equivalent approach that incorporates the applicable elements of QA/G-4, should be used to develop DQOs. The DQO process should:

- Clarify the study objective.

- Define the most appropriate type of data to collect.

- Determine the most appropriate conditions from which to collect the data.

- Specify tolerable limits on decision errors which will be used as the basis for establishing the quantity and quality of data needed to support the decision.

Results of the DQO process shall be documented and project participants shall use the DQOs to develop a scientific and resource-effective data collection design.

\section{B.2.5 Quality Indicators}

Data quality indicator goals are qualitative and quantitative statements that specify the data requirements for the project. Sample analytical data goals are based on the intended use of the data, current field procedures, instrumentation, and available resources. Quality indicator goals are established during the site-specific DQO process to properly support the overall project or sampling task objectives. An evaluation of the quality indicators shall be performed during the assessment of data to determine if the goals set during the DQO process have been accomplished. Indicators of data quality as they relate to data collection and laboratory analysis include precision, accuracy, representativeness, completeness, and comparability.

\section{B.2.5.1 Precision}

Precision measures the reproducibility of data under a given set of conditions. Specifically, precision is a quantitative measurement of the variability of a population of measurements compared to their average value. Precision for inorganic analyses shall be assessed by collecting, preparing, and analyzing duplicate field samples and by creating, preparing, and analyzing laboratory duplicates from one or more field samples. Precision for organic analyses shall be assessed by collecting, preparing, and analyzing matrix spike (MS) and matrix spike duplicate (MSD) samples. Precision will be reported as relative percent difference (RPD). The RPD is calculated as the difference 
between the measured concentrations of Sample 1 and Sample 2, divided by the average of the two concentrations, and multiplied by 100. If the RPD exceeds predetermined limits for a given parameter, the data shall be evaluated for usability based on the purpose for the data and reasons for the increased RPD. This evaluation must be documented.

\section{B.2.5.2 Accuracy}

Analytical accuracy is defined as the nearness of a measurement to the true or accepted reference value. It is the composite of the random and systematic components of the measurement system and measures bias in a measurement system. Accuracy measurements for spike samples and laboratory control samples shall be calculated as percent recovery, which is calculated by dividing the measured sample concentration by the true concentration and multiplying the quotient by 100 . The percent recovery shall be within the limits defined in site-specific plans. Values exceeding the acceptance criteria, established during the site-specific DQO process, must be evaluated for corrective actions.

Field accuracy is assessed by confirming that the documents of record track the sample from origin, through transfer of custody, to disposal. The goal of field accuracy is for all samples to be collected from the correct locations, at the correct time, placed in a correctly labeled container with the correct preservative, and sealed with custody tape to prevent tampering.

\section{B.2.5.3 Representativeness}

Representativeness expresses the degree to which sample data accurately and precisely represent a characteristic of a sample population, a parameter variation at a sampling point, a process condition, or an environmental condition (EPA, 1998). Representativeness depends on the proper design and execution of a sampling program and it will be achieved through careful selection of sampling intervals and locations as well as analytical parameters and the correct collection methods.

The number of samples collected must be sufficient to demonstrate that the data represent the population of interest to the statistical certainty required by the DQOs. Collection, storage, handling, and transport of samples should be performed in a manner that preserves the in situ characteristics of the samples and maintains the representativeness of the sample to the site. 


\section{B.2.5.4 Completeness}

Completeness is a measure of the amount of valid data obtained from a measurement system compared to the amount that was expected to be obtained under correct, normal conditions (EPA, 1998). Completeness is affected by unexpected conditions that may occur during the data collection process. The number of samples prescribed for an activity must be sufficient to meet data requirements identified in the DQO process and must consider typical loss of data caused by handling, shipping, and analytical processes.

\section{B.2.5.5 Comparability}

Comparability is a measure of the confidence with which one dataset or method can be compared with another (EPA, 1998). Comparability is achieved by using standard techniques and procedures (e.g., standard operating procedures) to collect and analyze representative samples and by reporting analytical results in appropriate units. Comparability is limited by the other quality indicators because only when precision and accuracy are known can datasets be compared with confidence.

\section{B.2.6 Reports to Management}

Contractor management and NV ERP Project Managers shall be made aware of project activities and shall participate in the development, review, and operation of these activities. Management shall be informed of quality-related activities through the receipt, review, and/or approval of:

- $\quad$ Project-specific plans and procedures

- Assessment reports

- Corrective action requests, corrective actions, and schedules

- Nonconformance reports (NCR)

Individuals identifying nonconforming conditions or deficiencies are responsible for documenting and reporting said conditions. All nonconformances and findings related to quality shall be corrected as required, documented, and properly reported. In addition, periodic assessment of QA/QC activities and data quality parameters shall be evaluated and reported to the participating project field and laboratory management. 


\section{B.2.7 Readiness Reviews}

Readiness reviews shall verify that all planning documents and processes are in place for the successful and efficient accomplishment of the mission. The readiness review includes verification that personnel are qualified and knowledgeable in the activities they are assigned to perform.

Readiness reviews shall be performed by participating organizations prior to the start of any major scheduled activity and prior to restarting work (following stop work orders) to verify and document that project planning and prerequisites have been satisfactorily completed. At a minimum, readiness reviews shall verify that the following issues have been addressed:

- The scope of work is compatible with project objectives.

- The planned work is appropriate to meet objectives.

- Work instructions have been reviewed for adequacy and appropriateness, formally approved, and issued to personnel who will be performing the work.

- Hazards have been identified, analyzed, categorized, and controls implemented.

- Proper resources (e.g., personnel, equipment, and materials) have been identified and are available.

- Assigned personnel have read the applicable work instructions and have been trained and qualified.

- Internal and external interfaces have been defined.

- Proper work authorizations and permits have been obtained.

- The calibration of all material and test equipment is current.

- A feedback mechanism has been established to facilitate process improvement. 


\section{B.3.0 Criteria 2 - Personnel Training and Qualifications}

The NV ERP and project participant management shall ensure that personnel are qualified and knowledgeable in the activities they perform. Training should emphasize correct performance of assigned work and provide an understanding of quality requirements. Personnel qualification and training records shall be maintained as quality documents in accordance with DOE Order 414.1A, Quality Assurance (DOE, 1999).

\section{B.3.1 Project Personnel}

Personnel shall be trained and qualified to perform the tasks to which they are assigned. Objective evidence of qualifications may include academic credentials, personal resumes, registrations and/or certifications, licenses, and training records. The qualifications of personnel shall be evaluated against assigned responsibilities, and any identified training needs must be addressed.

Training should be provided to achieve and maintain proficiency; adapt to changes in technology, methods, or job description; and allow for feedback and effectiveness of job performance. Training may take the form of orientation and/or indoctrination, formal classroom training, or on-the-job training. This training should include regulatory requirements, scopes of work, QA/QC requirements, and applicable work instructions.

Any required on-the-job training should be conducted and documented by personnel experienced in the task being performed in accordance with each organization's requirements. Any work performed by a trainee should be under the supervision of an experienced individual. Trainees should demonstrate capability prior to performing work independently.

\section{B.3.2 Subcontractor Personnel}

Subcontractor personnel shall be qualified and trained to perform the duties for which they were contracted. The contracting organization shall be responsible for verifying the qualifications of their subcontractors. 


\section{B.4.0 Criteria 3 - Quality Improvement}

An objective of the New Mexico Sites activities is to produce quality products and to continuously seek methods to improve both processes and products. Processes shall be established with the objective of preventing problems and improving quality. Peer reviews of various work products should be built into the work processes to ensure the quality of the products prior to release. All personnel are encouraged to identify and suggest improvements in all areas of work performed for the New Mexico Sites.

Management shall seek to cultivate an atmosphere which fosters the belief that improvement is always possible, and accountability and excellence must be established at all levels. It is equally important to identify and implement process improvements and efficiencies. Successful techniques should be evaluated to determine the potential for performance improvements in other areas or projects. The following sections identify processes that, at a minimum, shall be implemented.

\section{B.4.1 Internal Quality Control Checks}

Quality control checks shall be performed for data collected in the field and data obtained through on-site and/or off-site analysis. Information shall be reviewed by someone other than the originator to ensure correct collection, transcription, and manipulation. Transcribed data shall be verified to ensure the correctness of the transcription. Data that has been manipulated shall be checked to ensure the manipulation process was performed as the originator intended.

Proprietary computer applications used for the evaluation of historical data maintained or transferred via electronic media shall have QC checks performed that are appropriate to the application being used. These checks must be documented and maintained in accessible files.

Field sampling and laboratory analytical activities shall incorporate QC procedures. All field and laboratory operations and systems shall be evaluated for their potential to impact the quality of generated data. System quality controls that meet the requirements of this QAPP shall be established and documented through the use of approved procedures, plans, or instructions. 
The QC samples shall be incorporated into the analytical stream to assess the overall data quality produced by the program. The QC samples consist of field- and laboratory-generated samples which are used to evaluate sampling and analytical precision and accuracy as well as the levels of potential contamination introduced by the sampling and analytical effort. The following paragraphs describe the QC samples that will be generated.

\section{B.4.1.1 Field Quality Control}

The field data collection QC program is designed to provide confidence that data collected during field activities adequately represents the area of interest. For sampling activities, field QC samples provide a mechanism for assessing and documenting that the collection process meets the QA objectives of the project. The number and type of field QC samples required shall be determined during the planning process for each site. Field QC samples include, as applicable, trip blanks, equipment rinsate blanks, source blanks, field blanks, and field duplicates. Field QC samples shall be submitted to the laboratory in such a manner that the laboratory is not aware that the sample is for QC purposes. Collection and documentation of field QC samples shall be in accordance with approved procedures and site-specific plans. Other types of data collected, such as observational data and measurements, shall have the appropriate quality control checks applied to ensure the information collected is of a quality that meets the objectives of the activity.

\section{B.4.1.1.1 Equipment Rinsate Blank Samples}

An equipment rinsate blank is collected from the final rinse solution from the equipment decontamination process to determine the effectiveness of the decontamination process. The blanks shall be prepared by pouring deionized water through or over a sampling device after it has been decontaminated and prior to using the device for environmental sample collection. Care shall be taken to ensure that each part of the sample device which comes in contact with the sample is included in the rinse. If equipment rinsate blank analytical results indicate possible contamination of samples, environmental sample results shall be reviewed to determine whether qualifiers should be assigned to the data or whether the source should be resampled. Results of rinsate blank analyses shall be maintained with the corresponding sample analytical data in the laboratory records file and reported in the laboratory data package. One equipment rinsate blank sample shall be collected for each method of equipment decontamination employed. 


\section{B.4.1.1.2 Field Blank Samples}

Field blanks are collected and analyzed by the laboratory to determine if contamination in the air during sample collection and packaging may have contaminated the samples. The field blanks are prepared by pouring deionized water or solid material that is certified to be without the contaminants of concern into clean sample containers in the field near the sampling locations, or by exposing a clean swipe to the same ambient conditions as those present during sampling. Field blanks should be collected as closely in time and space to the environmental sample as possible. If field blank analytical results indicate possible contamination of associated samples, environmental sample results shall be reviewed to determine whether qualifiers should be assigned to the data or whether the source should be resampled. One field blank is collected for each 20 samples collected. Field blanks shall be analyzed for the same analytical suite as the samples being collected.

\section{B.4.1.1.3 Trip Blank Samples}

A trip blank is a 40-milliliter volatile organic analysis (VOA) container of organic-free water that is shipped to the field along with the other VOA sample containers. The blank is not opened, but is otherwise maintained, handled, stored, packaged, and shipped as if it were collected in the field. The purpose of the trip blank is to determine if contaminants have entered the sample through diffusion across the Teflon ${ }^{\mathrm{TM}}$-faced, silicone rubber septum of the sample vial during the performance of laboratory, field, or shipping procedures. The trip blank is only analyzed for volatile organic constituents. Trip blanks shall be submitted for analysis at a frequency of one sample per shipping container that contains field VOA samples. If trip blank analytical results indicate possible contamination, environmental sample results shall be reviewed to determine whether qualifiers should be assigned to the data.

Following the analyses, if the trip blanks indicate possible contamination of the samples, the appropriate project personnel shall be notified. Results of trip blank analyses shall be maintained with the corresponding sample analytical data in the laboratory records file and reported in the laboratory data package. 


\section{B.4.1.1.4 Duplicate Samples}

Field duplicates are QC samples that are collected as closely in time and space to the environmental sample as possible to assess sample variability and to measure sampling and analytical variability. Collection of the required number of duplicates shall be evenly distributed throughout the sampling activity. One duplicate shall be collected for each 20 samples collected. The field duplicates shall mirror the sampling and analytical profile of the original sample and be assigned a unique sample number. The duplicate sample number shall not indicate that it is a $\mathrm{QC}$ sample to minimize handling, analysis, and data-evaluation bias. Parameters to be analyzed shall be the same as those analyzed for the corresponding environmental samples. Sample management and documentation procedures for duplicates shall be the same as those used for environmental samples. When the RPD results between the environmental sample and its duplicate are outside control limits, environmental results will be reviewed to determine whether qualifiers should be assigned to the data.

\section{B.4.1.1.5 Source Blanks}

A minimum of one source blank shall be collected from each source of water used for project activities to include decontamination. Source blanks shall be analyzed for the same parameters as the original samples. Source blanks shall be collected as close to the source as practical, but may be collected from on-site storage containers.

\section{B.4.1.2 Analytical Laboratory Quality Control}

All on-site and off-site analytical laboratories performing analyses for the New Mexico Sites shall conduct their activities in accordance with a written and approved QA plan. Laboratory quality control (LQC) samples shall be analyzed using the same analytical procedures used to analyze environmental samples. Each analytical laboratory shall generate QC samples during each analytical run to assess and document accuracy and precision associated with each analytical measurement in accordance with the laboratory QA plan. All data from concurrently analyzed LQC samples and other quality controls which are used to demonstrate analytical control shall be included in the laboratory's analytical report. The requirements for the types and number of LQC samples will depend on the analytical procedure or method and the laboratory's QA objective for each test. 
Laboratory quality control samples include Laboratory Control Samples (LCS), method blanks, surrogate-spike, and MS/MSD samples.

\section{B.4.1.2.1 Laboratory Control Samples}

One LCS shall be prepared and analyzed with each batch of samples per matrix. The LCS shall be carried throughout the sample preparation and analysis procedures to assess laboratory accuracy and precision. The LCS shall be analyzed concurrently with each analytical batch for each analyte of interest and shall be prepared from standards independent of the calibration standard. Control limits for recovery shall be established, and recovery data shall be plotted on internal control charts. The LCS data outside these recovery limits shall be considered "out of control," and the laboratory shall initiate corrective action(s) that shall be performed in accordance with the laboratory's QA plan. Results of duplicate LCS analyses shall be reported as RPD and percent recovery and included with the associated analytical report. When LCS percent recovery is outside the control limits, environmental sample results will be reviewed to determine whether qualifiers should be assigned to the data.

\section{B.4.1.2.2 Method Blank Samples}

Method blanks shall be analyzed by the laboratory to check for instrument contamination and contamination and interference from reagents used in the analytical method. A method blank shall be concurrently prepared and analyzed for each analyte of interest for each analytical batch. Method blank data outside statistical control limits shall be considered "out of control," and corrective action(s) shall be performed in accordance with the laboratory's QA plan. Method blank data shall be reported in the same units as the corresponding environmental samples, and the results shall be included with each analytical report.

\section{B.4.1.2.3 Surrogate-Spike Samples}

Surrogate-spike sample analysis shall be performed for all samples analyzed by gas chromatography (GC), gas chromatography/mass spectrometry (GC/MS), and High Performance Liquid Chromatography (HPLC) to monitor laboratory performance and analytical procedures on a sample-by-sample basis. Surrogate standards are nontarget compounds added to GC, GC/MS, and HPLC standards, blanks, and samples prior to extraction or purging. Surrogate compounds are 
compounds that are not expected to be present in the associated environmental samples but behave similar to target compounds chromatographically. Surrogate compounds and concentrations added shall be those specified in the applicable analytical method. Recovery values for surrogate compounds shall be within the control limits specified by the laboratory and in accordance with assessment procedures in the laboratory's QA plan, or the analysis shall be repeated. Results of surrogate-spike sample analyses shall be reported as percent recovery. When surrogate percent recovery is outside the control limits, environmental sample results will be reviewed to determine whether qualifiers should be assigned to the data.

\section{B.4.1.2.4 Matrix-Spike/Matrix-Spike Duplicate Samples}

Project site-specific MS/MSD samples shall be analyzed by the laboratory to determine interferences of the sample matrix on the analytical methods and subsample variance of the laboratory data. A separate sample aliquot shall be spiked with the analytes of interest and analyzed with every 20 samples per matrix or, if fewer than 20 samples were collected, at least one of the samples shall be spiked. Results of the MS/MSD analyses shall be reported as percent recovery and RPD and included with the analytical report. Results that are outside the established recovery or reproducibility limits for the analytical method shall be considered "out of control," and the laboratory shall initiate corrective action(s) that shall be performed in accordance with the laboratory's QA plan. When the RPD results between the MS and MSD samples are outside control limits, environmental results will be reviewed to determine whether qualifiers should be assigned to the data. The MS/MSD samples shall not be collected for radiochemical analysis.

\section{B.4.1.2.5 Laboratory Duplicate Samples}

Two aliquots of the same sample per matrix shall be prepared and analyzed for inorganic analysis, and the duplicate results will be used to calculate the precision as defined by the RPD. If the precision value exceeds the control limit, the appropriate laboratory personnel will identify the root cause of the nonconformance and implement corrective actions. A laboratory duplicate analysis shall be performed with every 20 samples. When the RPD results between the environmental sample and its lab duplicate are outside control limits, environmental results will be reviewed to determine whether qualifiers should be assigned to the data. 


\section{B.4.1.3 On-Site Radiological Laboratory Quality Control}

On-site radiological laboratory analysis may be performed for direct counting of soils by gamma spectral analysis. Any on-site laboratory analysis shall be performed in accordance with written, approved work instructions by trained personnel using properly calibrated equipment. Gamma spectroscopy requires physical preparation of the sample and direct counting. QC checks required shall verify the accuracy and precision of the counting system. A NIST-traceable mixed gamma standard shall be used.

\section{B.4.1.3.1 Instrument Control Samples}

An instrument control sample shall be analyzed with each batch of samples. The control sample shall be carried through the analysis procedures to assess laboratory accuracy and precision. Control limits for recovery shall be established, and recovery data shall be plotted on internal control charts.

\section{B.4.1.3.2 Blank Samples}

Blanks shall be analyzed to check for instrument and container contamination. A method blank shall be concurrently prepared and analyzed for each analytical batch. A minimum of one method blank shall be analyzed with each 20 samples.

\section{B.4.1.3.3 Duplicate Samples}

Duplicate results will be obtained and used to calculate precision. One in 20 samples shall be counted twice to provide precision data.

\section{B.4.2 Data Precision, Accuracy, and Completeness}

Quality control sample results are used to evaluate laboratory and field precision and accuracy. Precision shall be determined by comparing the concentrations of the various constituents between duplicate analyses. Accuracy shall be determined by comparing analytical results with the known (true) value of a reference standard (i.e., a laboratory control sample). The analytical accuracy for the spiked samples must be within the accepted accuracy of the method of analysis for the analyte of interest. Sample results falling outside of acceptable ranges for precision and accuracy shall be brought to the attention of laboratory management for evaluation and corrective action(s), as needed. 
Completeness shall be determined by comparing the amount of valid data obtained from a measurement system to the amount that was expected to be obtained. Data precision, accuracy, and completeness requirements shall be dependant on the end use of the data and determined during the DQO process for each site.

Laboratory results shall be checked upon receipt. If there appears to be an error in the analysis, the laboratory shall be contacted immediately, and corrective action(s) must be taken. If investigation reveals that processes were not in control, corrective action(s) shall be taken, and the resulting data evaluated to determine any impacts.

\section{B.4.3 Corrective Action}

This section establishes the methods and responsibilities for identifying, reporting, controlling, and resolving conditions of nonconformance and conditions adverse to quality for activities performed in support of the New Mexico Sites work.

\section{B.4.3.1 Nonconformance}

A nonconformance is a deficiency in characteristic, documentation, or procedure that renders the quality of an item or activity as unacceptable, or indeterminate. The NV ERP policy encourages all personnel to identify and document nonconforming items and processes. It is also NV ERP policy to identify nonconformances in a manner that focuses on solutions and discourages fault-finding to encourage the open identification and resolution of problems. Individuals identifying nonconforming conditions or items are responsible for documenting and reporting the nonconformance. Responsible personnel should be notified at the time the nonconformance is identified so that, when possible, corrective measures may be taken immediately.

All NCRs shall be handled in accordance with each organization's internal processes. An NCR shall specify:

\section{- Originator}

- Date of the nonconformance

- NCR number (unique)

- Responsible organization

- Requirement(s) 
- Nature of the nonconformance

- Disposition

- Technical justification for disposition

When an NCR affects cost, schedule, scope, or is a H\&S issue, the applicable NV ERP Project Manager and the NV ERP QAC and Health and Safety Representatives must be notified.

\section{B.4.3.2 Cause Analysis}

A root cause is the most basic element that, if corrected, will prevent recurrence of the same (or similar) problem. Cause analysis should be used where the understanding of the basic underlying cause is important to the prevention of similar or related problems. The cause analysis should be used to gain an understanding of the deficiency, its causes, and the necessary corrective actions to prevent recurrence. The level of effort expended should be based on the possible negative consequences of a repeat occurrence of a problem. The term "root cause" is used generally and does not require the use of highly sophisticated methods such as is used for accidents.

\section{B.4.3.3 Trend Analysis}

Trend analyses should be performed on nonconforming conditions, deficiencies, root causes, and the results of improvement initiatives to identify any possible trends. Adverse trends shall be brought to the attention of the appropriate management. Positive trends, such as improved performance or cost savings resulting from enhancements or the application of new technology, should be shared to facilitate improvement in other areas or projects. As appropriate, information obtained from trend analyses should be included in a Lessons Learned system.

\section{B.4.3.4 Lessons Learned}

A Lessons Learned system has been established at DOE/NV as a focal point for reporting and retrieving important information concerning experiences gained through previous activities. Improvement can be fostered through incorporation of applicable Lessons Learned into work processes and project planning activities, including work plan development, budget development, and strategic planning. The Lessons Learned program should be used interactively with other management tools such as critiques, assessments, readiness reviews, and evaluations of field activities. 


\section{B.5.0 Criteria 4 - Documents and Records}

The New Mexico Sites shall have planning documents, as deemed necessary, for the work to be performed. Contractors may determine that additional procedures are necessary to further define the responsibilities and activities of specific scopes of work. Figure B.1-1 is a flowchart of the guidance documents.

\section{B.5.1 Documents and Records}

Systems and controls shall be implemented by project participants for identifying, preparing, reviewing, approving, revising, collecting, indexing, filing, storing, maintaining, retrieving, distributing, and disposing of pertinent quality documentation and records.

\section{B.5.1.1 Document Review and Control}

Plans and reports shall be reviewed for quality requirements, technical adequacy, completeness, and accuracy prior to their approval and issuance. The NV ERP documents shall be reviewed in accordance with the DOE/NV procedure AMEM-02-002, Document Review and Coordination (DOE/NV, 1999a).

A system or process for identifying documents that require control and controlling those documents shall be implemented to ensure that the latest revision of a document is used. The New Mexico Sites management is responsible for ensuring that personnel who perform work are in possession of the most current version of the documents applicable to the activities being conducted.

Revisions to controlled documents shall be approved by the same level of authority or organization as the original. Documents no longer in use should have their status clearly indicated, and record copies should be maintained in accordance with DOE Order 200.1, Information Management Program (DOE, 1996a).

\section{B.5.1.2 Change Control}

Changes or modifications to approved procedures or plans may be necessary to adjust an activity to actual field conditions or to revise programmatic methods of implementing project requirements. 
New Mexico Sites participants shall ensure that changes are properly identified, documented, approved, and controlled in accordance with the individual procedures of each participant organization. Verbal authorization of changes are permitted but must be documented and followed up with a written change notice in a timely manner. Changes shall be approved commensurate with the original document prior to implementation of the change. Changes to the SSHASP shall be in accordance with the participants applicable procedures. The DOE/NV Project Manager shall be notified of changes that impact the technical scope, cost, or schedule of the project.

\section{B.5.1.3 Records Maintenance}

Sufficient records of New Mexico Sites activities shall be prepared, reviewed, and maintained. Project records shall be maintained in accordance with DOE Order 200.1 (DOE, 1996a), Information Management Program. Contractors and other agency participants shall have a system in place for the storage and retrieval of quality records that is consistent with environmental regulations and DOE Order 200.1 (DOE, 1996a). 


\section{B.6.0 Criteria 5 - Work Processes}

The performance of activities shall be based upon the objectives of the project. Details of specific, environmental, data-collection activities will be discussed in the applicable site-specific planning documents. Appropriate technical methods or a scientific rationale shall be employed. Activities shall be performed in accordance with approved procedures and site-specific plans that comply with the applicable requirements of DOE Orders, procedures, and project planning documents. Upon request, contractors and participating organizations shall supply the DOE/NV with copies of applicable procedures. Deviations from the applicable approved project plans and procedures shall be approved and documented.

\section{B.6.1 Evaluation and Use of Existing and New Data}

Existing and new data shall be evaluated against current requirements for their intended use. This analysis consists of editing, screening, checking, auditing, verification, and review. Methods shall be in place for the control and transfer of data, control of interpretive work products, and the control of data within a database. The process should provide guidance for gathering, manipulating, and distributing data. The quality of existing data shall be determined, based on the traceability of data and the level of QA/QC applied to the data during initial collection, prior to inclusion into a central database. Reports or interpretative works shall indicate the quality of the data being used. Prior to use, newly acquired analytical data will be evaluated against predetermined objectives and criteria.

\section{B.6.2 Computer Hardware and Software}

Computer hardware/software configurations are defined as the combination of computer program software version, operating software version, and model of computer hardware. Computer software and hardware/software configurations used in the acquisition, modeling or storage of environmental data shall be installed, tested, used, maintained, controlled, and documented to meet the requirements of the user and/or data management criteria. Compatibility between software and hardware systems must be achieved for long-term retrievability. To the extent possible, contractor's and project participant's hardware and software should be compatible with that of the NV ERP. 


\section{B.6.2.1 Computer Systems}

Computer hardware/software configurations for the storage and manipulation of environmental data should be tested by knowledgeable individuals prior to actual use and the results documented and maintained. Changes to hardware/software configurations should be assessed to determine the impact of the change on the technical and quality objectives of the environmental program. If any of the components are changed or modified and a new configuration results, or if program requirements change so that the capability of the hardware/software configurations to meet the new requirements is uncertain, then the configuration should be retested and redocumented.

Computer hardware/software configurations integral to measurement and testing equipment (M\&TE) that are calibrated for specific uses do not require further testing unless the software uses change or the configuration is modified.

The physical media on which software is stored shall be controlled and protected so that software and data are physically retrievable and protected from loss or compromise by catastrophic events. Back-up copies shall be maintained so that a single event will not cause a significant loss of software or data.

\section{B.6.2.2 Software Design/Development}

Project participants involved in the development or use of major-use software for modeling or technical computations will develop and implement processes for the development, modification, verification/validation, and control of computer software codes. Code criteria should be clearly defined prior to development or purchase and should be consistent with applicable national standards. Software will be qualified for use, based on its ability to provide acceptable results for its intended application. The configuration of software should be controlled and documented so traceability is maintained through the developmental history. Documentation of the development or modification of software codes must include the appropriate peer reviews and verification/validation. 


\section{B.6.2.2.1 Code Evaluation}

Newly developed computer codes or modifications to existing software shall be reviewed and the reviews documented by individuals who are knowledgeable in the area of code development. Reviewers should consider the following aspects:

- Assumptions are reasonable and valid

- Correctness of the mathematical model

- Conformance of methods to accepted and published concepts (recognizing that alternative methods and interpretations other than those of the evaluators may be acceptable)

- Consistency of results with known data

- Reasonable and prudent use of data and analysis tools

- Appropriateness for intended purpose

\section{B.6.2.2.2 Code Verification/Validation}

Software should be qualified for use based on its ability to provide acceptable results for the intended application. Software verification and validation activities will include provisions for providing confidence that the software adequately and correctly performs all intended functions. The extent of verification/validation required shall depend on the complexity, risk, and uniqueness of the code. Computer software code modifications shall be verified and validated according to the same requirements as the original code. Verification of changes may be limited to the scope of the modification, if the rest of the code is not affected. Acquired technical software used without modification must have operational checks performed through test cases to verify that the software is functioning as intended.

Computer applications, project participants, used for the evaluation of historical data maintained or transferred via electronic media shall have QC checks performed as appropriate to the application being used. These checks must be documented and maintained in project files. 


\section{B.6.2.2.3 Software Documentation}

All developed or procured computer codes shall be uniquely identified. Computer software code documentation shall be maintained with associated calculations and reference material.

Documentation will consist of software design and reference material, verification/validation records, operational test records, and user-oriented information.

\section{B.6.2.3 Peer Review of Software and Code Applications}

The peer review is an assessment of the assumptions, calculations, extrapolations, alternate interpretations, methodology, acceptance criteria, and conclusions pertaining to interpretive work products generated through use of computer software. Peer reviews shall be performed and documented to ensure that interpretive work products are technically adequate, properly documented, and satisfy established technical and quality requirements. Peer reviewers shall possess the appropriate subject matter/technical expertise and not have participated in preparing the original work. All review comments and the attendant comment responses shall be recorded on review sheets and maintained in the project files. The acceptable level of accuracy of each interpretive work product should be established by project management.

\section{B.6.3 Field Investigation}

Field activities generally involve the collection of data for the purpose of decision making. Field data acquisition shall be accomplished through the use of approved plans, procedures and/or instructions, by qualified personnel, using appropriate tools and calibrated equipment. Additionally, all work shall be performed safely within the controls established to prevent/mitigate hazards. Details of specific environmental data collection activities shall be delineated in the associated project plans and instructions. Data acquisition methods for which a procedure does not exist (those that are unique, experimental, or under development) shall be detailed in the project-specific plans or instructions. 


\section{B.6.3.1 Sample Custody}

Chain of custody for each field sample collected must be documented to provide the traceability of possession from the time the samples are collected until disposal. A sample is considered to be in custody if it meets any of the following criteria:

- Is in a person's actual possession

- Is in a person's unobstructed view after being in the person's physical possession

- Is in a secured area to prevent tampering after having been in the person's physical possession

- Is in a designated secured area, restricted to authorized personnel only

Sampling events shall be monitored to ensure that custody procedures and records are being properly implemented. Without exception, sample custody shall be continuously maintained for all samples collected.

\section{B.6.3.1.1 Chain of Custody Form}

Each individual who possesses a sample is responsible for sample custody until the sample is relinquished to another individual or a secure storage area via the chain of custody form. Field teams shall initiate chain-of-custody forms for samples collected during field activities in accordance with written and approved procedures and/or instruction. Whenever samples are transferred to a new sample custodian, the new custodian shall sign his or her name, the company name, and note the time and date that the transfer occurred. There shall be no gaps on the record of custody. The chain of custody form shall accompany the samples during handling and shipment, and it shall chronicle the history of custody.

\section{B.6.3.1.2 Custody Seals}

To ensure that tampering is easily detectable, each sample container shall be individually sealed with a custody seal. The seal shall be placed over or around the lid of the sample container so that the container cannot be opened without breaking the seal. Each custody seal shall be initialed and dated by the sample custodian. 


\section{B.6.3.1.3 Sample Labels and Identification}

Sample labels shall contain the unique sample numbers and other sampling information. This information must be entered using indelible ink and the label securely affixed to the container. All information and data for a sample are keyed to each sample's unique number. The sample label shall contain the following required information:

- Project name

- Unique sample number

- Sampling date and time (military)

- Sample location and depth interval (if applicable)

- Sample medium

- Requested analyses

- Name of the individual collecting the sample

- Preservation or conditioning of the sample

Each sample number shall be indicated on both the container and field data/sample collection forms. For samples requiring multiple containers, the same sample identification numbers shall be required on each container. Labels that are not plastic coated and have the potential to smear or deteriorate shall be covered with clear tape.

\section{B.6.3.1.4 Sample Handling, Preservation, Packaging, and Shipping}

Proper sample handling is achieved by selecting the appropriate sample containers, preservation procedures, and holding times for specific analyses. Where applicable, sample containers shall be certified clean per EPA protocol and shall remain sealed until ready for use. Certificates of container cleanliness shall be maintained in the project files. A table of parameters and analytical methods is provided in Attachment 2.

Upon completion of sampling, labeling, and custody sealing, each sample shall be placed in a separate, sealable plastic bag; transferred to an appropriate shipping container cooled with ice to $4^{\circ} \mathrm{C}\left( \pm 2^{\circ} \mathrm{C}\right)$, if required; and protected from breakage by using shock-absorbent packing material. Approved procedures must comply with Title 49 CFR, Parts 170 to 180 (CFR, 1999), for the packaging, labeling/placarding, and shipping of samples. 


\section{B.6.3.1.5 Decontamination}

To prevent cross-contamination of samples, equipment coming in contact with samples shall be decontaminated prior to use, between sampling locations, and before leaving the site. Certification of cleanliness shall be obtained for disposable or precleaned sampling equipment, if they are not decontaminated by the sampling organization. Decontamination activities shall be performed and documented in accordance with the participating organization's approved written procedures.

Equipment rinsate blanks shall be submitted to the analytical laboratory to assess the effectiveness of the decontamination process. If the rinsate blank results indicate possible contamination, corrective actions shall be implemented to preclude recurrence. Sample results obtained using the suspect sampling equipment shall be reviewed to determine whether analytical qualifiers should be assigned to the data.

\section{B.6.3.1.6 Investigation-Derived Waste}

Investigation-derived waste (IDW) shall be containerized pending the results of waste characterization. To ensure compliance with DOE requirements and federal and state regulations, IDW shall be characterized and disposed of in accordance with approved plans.

\section{B.6.3.1.7 Field Documentation}

Field documentation should be of sufficient detail to facilitate the reconstruction of field activities. Field personnel shall document activities on a logbook or on the appropriate form as required by each contractor doing work for the New Mexico Sites. Documentation should be made in indelible ink and include all information applicable to the activity being performed.

Field-generated records shall be independently reviewed to verify they are complete and accurate. This review should be noted on the reviewed document with an initial and date. Records shall be preserved and maintained in accordance with Section B.5.1.3.

\section{B.6.3.1.8 Photographic Documentation}

With the approval of the DOE/NV Project Manager, photographs may be taken during the corrective action investigation and/or corrective action activities. Photographs shall be documented on a 
photographic log in accordance with contractor procedures. The photographs and negatives shall be processed and stored in accordance with DOE/NV security procedures and National Archives and Records Administration regulations.

\section{B.6.3.2 Identification and Control of Items}

The New Mexico Sites participants shall establish and document sufficient controls to ensure that quality-affecting items, such as equipment, components, and material can be readily identified. These controls shall be established to prevent incorrect use, to retain integrity of materials, and to preserve the desired operating characteristics of equipment. Controls shall be applied that are based on the risk to the project if control of the item is lost. Appropriate controls shall be applied prior to and subsequent to use. Specific requirements for preservation and packaging shall be identified in project documents.

Hazardous materials shall be properly controlled and transported in accordance with Title 49 CFR, Part 171-180, Transportation - Hazardous Materials Shipping Regulations (CFR, 1999).

\section{B.6.3.3 Calibration and Preventive Maintenance}

The M\&TE used at the New Mexico Sites shall be uniquely identified and controlled. A system of calibration and preventive maintenance shall be employed by project participants to ensure the proper operation of M\&TE. Reference standards of the correct type, range, and acceptable uncertainty shall be used for collecting data consistent with the project objectives.

\section{B.6.3.3.1 Calibration}

Approved procedures or the manufacturer's recommendations shall be used to calibrate M\&TE prior to use and at prescribed intervals thereafter. The frequency of calibrations (periodic or factory) shall be based on the manufacturer's recommendations, national standards of practice, equipment type and characteristics, and past experience. Operational, or in-house, calibrations and/or source-response checks shall be performed on the appropriate M\&TE prior to the start of work and at prescribed intervals to verify the equipment's continued accuracy and operational function. 
Equipment for which the periodic calibration period has expired, equipment that fails calibration, or equipment that becomes inoperable shall be tagged "out-of-service" and, when possible, segregated to prevent inadvertent use. Results of activities performed using equipment that is out of calibration shall be evaluated for adverse affects and the appropriate personnel notified.

Physical and chemical standards shall have certifications traceable to National Institute of Standards and Technology, EPA, or other nationally recognized agencies. Supporting documentation on all reference standards and equipment shall be maintained.

\section{B.6.3.3.2 Preventive Maintenance}

Preventive maintenance shall be performed to maintain performance and reliability, prevent equipment from failing during use, and to identify sources for repair replacement. Preventive maintenance programs shall include all sensitive equipment.

Field equipment preventive maintenance programs will provide the following, as applicable:

- A listing of the equipment included in the program

- The frequency of maintenance considering manufacturer's recommendations and/or previous experience with the equipment

- A list of spare parts to be maintained

- Activities to be performed in the event of equipment failure (i.e., spare parts maintained, backup instrumentation, or sources to repair or replace instrumentation)

\section{B.6.3.4 Laboratory Operation}

Laboratories performing analytical work for the New Mexico Sites must operate in accordance with an acceptable written QA program. Plans and procedures relevant to the New Mexico Sites work must be made available upon request. Deviations from approved procedures shall be documented.

All New Mexico Sites participants who subcontract analytical services must ensure quality of services through established procurement practices and oversight activities. Laboratories must participate in an Interlaboratory Performance Evaluation program appropriate to sample types and 
analyses. The laboratory must provide the results of these performance evaluation studies along with the laboratory's response to any deficiencies which were identified upon request.

\section{B.6.3.4.1 Preanalysis Storage}

Samples received at the analytical laboratory that have been entered into the sample tracking system shall be placed into a storage refrigerator or secure storage area until analyzed. The methods of storage are generally intended to:

- Retard biological action

- Retard hydrolysis of chemical compounds and complexes

- Reduce volatility of constituents

- Reduce adsorption effects

- Reduce light exposure

Preservation methods are generally limited to $\mathrm{pH}$ control, preservative addition, and refrigeration. Preanalysis sample storage procedures shall be documented and described in laboratory-specific procedures.

\section{B.6.3.4.2 Post-Analysis Storage}

The possibility of reanalysis requires that proper environmental control for post-analysis samples be provided. These controls shall be described in laboratory-specific procedures. The samples shall be properly disposed of by the laboratory unless other arrangements have been made to return them to the site. The laboratory must contact the participants designated personnel prior to disposal of samples.

\section{B.6.4 Analytical Data Usability}

Analytical data received for input into a project shall be assessed for acceptability against the requirements stipulated in the applicable project document. Personnel should verify that analytical data reports have been reviewed by appropriate individuals other than those generating the analytical data or the report, and that all forms of the report (printed or electronic) carry a notice of any limitations on the use of the data. 


\section{B.6.4.1 Data Management}

Analytical data shall be controlled and managed to guarantee data integrity throughout acquisition and development. Systems must be established for directing analytical data results into a controlled data management system. Requirements shall be established for identification, collection, selection, control, and transfer of analytical data both within and external to the NV ERP data management system. Analytical data that are submitted shall be qualified and traceable to original data records and procedures established for processing, storage, and control of data. Analytical data users are responsible for determining if the data are sufficient for their intended use.

Each participating organization responsible for generating environmental data for the New Mexico Sites shall have a management plan for handling data that describes the flow of data from its generation through its final use and storage. The Data Management Plan shall include or reference the specific procedures to be used for data verification and validation to ensure that all data used to support decisions made for the New Mexico Sites are of known and documented quality. Procedures shall be used to optimize the detection and correction of errors and prevent data loss during data reduction, reporting, and data entry into databases.

\section{B.6.4.2 Evaluation and Use of Data}

Participating organizations shall have a system in place for the control and transfer of data and interpretive work products to the NV ERP Common Data Repository, and provide guidance for gathering, manipulating, and distributing data. The quality of existing data shall be determined, based on the traceability of data and the level of QA/QC applied to the data during initial collection and current requirements for their intended use. This analysis consists of editing, screening, checking, auditing, verification, and review. Reports, models, or interpretative works shall indicate the quality of the data being used. Prior to use, newly acquired analytical data will be evaluated against predetermined objectives and criteria. Computer applications used for the evaluation of data maintained or transferred via electronic media shall have quality control checks performed as appropriate to the application being used. 


\section{B.6.4.3 Data Reduction, Verification, and Validation}

Computations performed on raw data are considered data reductions. Numerical reduction of field and analytical data shall be formally checked in accordance with approved procedures, and this checking must be performed prior to the presentation of results. If unchecked results are to be presented, transmittals or subsequent calculations based on these results must be marked "preliminary" until the results are checked and determined to be correct.

Verification is the process of checking and reviewing the data reduction process. Data verification is a systematic review of data by qualified individuals to check data reduction and ensure that data meet specified guidelines.

Validation of analytical data is a comprehensive verification which includes complete review of raw data. The site-specific DQO process shall establish what percentage of analytical data packages shall be validated. Qualifiers may be attached to the data to indicate the results of the verification process. These qualifiers may restrict or limit certain uses of the data.

\section{B.6.4.3.1 Data Completeness Review}

A completeness review should be conducted to ensure that field and laboratory data and documentation are present and complete. During this review, problems should be identified and documented. Information from this review should accompany the data. The review should include the verification that:

- Overall deliverable objectives are met.

- Laboratory documentation is complete and accurate.

- Significant problems are identified in laboratory documentation.

- Chain of custody documents are complete and contain required information.

- Analytical practices are consistent with chain of custody requirements.

- Analytical information presented is correct and complete.

- Analytical practices are within technical guidelines.

- All field forms are present and complete.

\section{B.6.4.3.2 Data Review and Summary}

Selected QC checks and procedures shall be evaluated for compliance or noncompliance with DQO standards. Deficiencies in the data package shall be communicated to the laboratory, and additions or 
corrections to the data package shall be controlled. Data review shall be conducted by personnel with training in, and a technical understanding of, laboratory methods and data quality. Data review shall include, but not be limited to, the examination of the following:

- Analytical requirements have been met.

- Critical items meet the project requirements.

- Analytical method QC compliance evaluated and applied to results/qualifiers.

- Sample data quality indicator goals are evaluated.

- Surrogate data quality indicators are evaluated.

- Laboratory QC sample data quality indicators are evaluated.

- Calibration information evaluated and applied to results/qualifiers.

- Internal standard evaluated and applied to results/qualifiers.

- Serial dilution effects evaluated.

- Holding time criteria has been met.

- Laboratory data qualifiers are correct and explained or a key is included.

- Compound analyte concentration is accurate.

- Sample collection and storage requirements are met.

\section{B.6.4.3.3 Data Validation}

Data validation encompasses a complete validation of the analytical results according to EPA functional guidelines or an equivalent industry-standard protocol. Data validation and review of Contract Laboratory Program (CLP) and CLP-like data packages shall be performed in accordance with the USEPA Contract Laboratory Program, National Functional Guidelines for Inorganic Data Review (EPA, 1994b) and Contract Laboratory Program, National Function Guidelines for Organic Data Review (EPA, 1999), or a national standard. This review is designed to be conducted by personnel with training in, and a technical understanding of, laboratory methods and data quality, and with the extensive experience required of professionally trained data validators. Calculations of results from raw data will be verified, and data validation qualifiers will be assigned. The results of this review and a summary of parameter detections shall be forwarded to the appropriate Project Manager.

Data validation shall include a check of the calculation of all QC sample results and a third party confirmation of a minimum of five percent, based on direction from the DOE/NV Radioactive Waste Acceptance Program, of the sample result calculations from characterization samples or samples intended to demonstrate that the contaminant(s) of concern have been isolated, stabilized, and/or 
removed. Data validation shall also include a check of all the functional guideline parameters included in lower-level reviews.

The percentage of data packages to be validated for the New Mexico Sites shall be dependent on the end use of the data, and established during the site-specific DQO process. Sample results selected for validation shall be determined by use of a random-number generator or may be selected by project management in cases where special criteria exist. The DOE/NV New Mexico Sites Task Manager shall maintain the option of having additional validation performed.

\section{B.6.4.4 Laboratory Data Reporting}

Analytical data reports must contain, at a minimum, the following information:

- Cover page with the reviewer's signature, data qualifiers, and a description of any technical difficulties encountered during the analyses

- Date the sample was received

- Date the sample was prepared

- Date the sample was analyzed

- Sample identification number

- Laboratory sample identification number

- Analytical method reference number

- Analytical results

- Tabulated QC sample results

- Instrument tuning and calibration results

- Final copy of the chain of custody form, with appropriate signatures

- Hard copy raw data of calibration, QC samples, and the analyses of field samples

Data packages shall be required for all analytical results unless sample results are excluded from data validation by DOE/NV project management. Validated data shall be reviewed to determine whether 
they meet the DQOs of the investigation. The data shall be reviewed to ensure that the required number of samples were collected, critical samples were collected and analyzed, and the results passed data-validation criteria. The data shall also be reviewed to determine whether detection limits were met. Data-reporting techniques shall be in accordance with the project data-reporting requirements; data-reporting procedures should be consistent with those found in the User's Guide to the Contract Laboratory Program (EPA, 2000).

\section{B.6.4.4.1 Data Reporting}

Data shall be reported in accordance with standardized formats. Electronic data transfers shall be delivered, along with the hard copy, on 3.5-inch diskettes or other methods agreed upon with the NV ERP Common Data Repository custodial organization. The laboratory data will not be loaded into the common data repositories for general use until it has been verified/validated. 


\section{B.7.0 Criteria 6 - Design}

Any quality-affecting items or processes designed in support of the New Mexico Sites shall be in accordance with a documented design control process and based on sound engineering and scientific principles using the appropriate standards. The acceptability and adequacy of the design product shall be verified or validated by a qualified individual(s) other than those who performed the original design. Verification and validation shall be completed prior to approval and implementation of the design. Design records shall include the design steps and sources of input that support the final output. The final design output shall be approved in accordance with the participants' internal procedures. Changes or modifications to the final design shall be subject to the same control measures and approvals as applied to the original design. 


\section{B.8.0 Criteria 7 - Procurement}

Procurement of items and services for the New Mexico Sites shall be consistent with standard commercial purchase order terms and conditions, and performed in cooperation with the DOE/NV Contracts Management Division. Project participants must have processes in place that meet the requirements of their contracts or agreements and applicable federal requirements.

\section{B.8.1 Procurement Control}

Items and services of a technical nature procured in support of the New Mexico Sites shall be of a quality that meets the requirements of the project. Project participants shall establish controls to ensure that, as a minimum, procured items and services meet specifications delineated in the procurement documents. Each participating organization shall have systems in place to track items and confirm the delivery of procured items and services as specified. Project participants shall have a program in place, invoking the appropriate quality requirements of the contractor's QA program and specifying any project requirements for the procurement of items and services.

Subcontractors procured for New Mexico Sites activities must be evaluated for prior experience, ability to perform specific tasks, and cost. The capabilities of subcontractor personnel shall be assessed by the procuring contractor to verify qualifications and determine the type and amount of training and supervision needed for environmental restoration activities.

\section{B.8.1.1 Procurement Documents}

Procurement documents for the New Mexico Sites shall define the scope of work for the item or service being procured and provide specifications, acceptance criteria, shipping and handling requirements, health and safety requirements, and any documentation required, as applicable. Technical specifications shall either be directly included in the procurement documents or included by reference to specific drawings, specifications, procedures, regulations, or codes that describe the items or services to be furnished. Procurement documents shall be reviewed for accuracy and completeness by qualified personnel prior to initial issue. Changes to a procurement document require the same level of review and approval as the original document. 


\section{B.8.1.2 Measurement and Testing Equipment}

Procurement documents shall also require that all purchased and rented M\&TE be calibrated to existing national standards prior to acceptance and that calibration documentation is provided. Calibration certification and instrument manufacturer's manuals should be available in project files for M\&TE. Schedules for recalibration shall be established and implemented for M\&TE requiring periodic calibration.

\section{B.8.1.3 Verification of Quality Conformance}

If applicable, procurement documents for New Mexico Sites-related items or services shall require access to the subcontractor's or vendor's facilities, including their subtier facilities, work areas, and records for assessments to verify acceptability. Upon delivery, procured items or services shall be inspected for conformance to procurement specifications and requirements prior to using items or placing them in service. Project personnel have the authority to stop work if significant quality problems are identified. Procured items should be evaluated for suspect/counterfeit parts. If there are indications that suppliers knowingly supplied substandard items or services, the DOE Office of Inspector General shall be notified. 


\section{B.9.0 Criteria 8 - Inspection and Acceptance Testing}

Inspections and acceptance testing shall be accomplished for specific items in accordance with approved inspection documents and test procedures that reflect acceptance and performance criteria. Individuals performing inspections and acceptance testing shall be independent of those who performed the work. Quality-affecting materials used during characterization, corrective action, or sampling activities shall be inspected upon receipt for adequacy. The M\&TE used in the performance of inspections or acceptance tests shall be calibrated and properly maintained. Any item or work determined to be defective shall be controlled to avoid inadvertent use. 


\section{B.10.0 Criteria 9 - Management Assessment}

Planned and periodic assessments shall be conducted and shall involve the participation of project management. The primary emphasis of management assessments is to evaluate the implementation of the integrated QA program and identify problems that hinder the achievement of objectives. Contractor management should conduct periodic assessments that focus on such issues as the:

- Adequacy of implementation of the integrated QA program, with particular emphasis on quality improvement

- Existence of any management biases or organizational barriers that impede the improvement process

- Adequacy of the appraised organization's structure, staffing, and physical facilities

- Existence of effective training programs

The results of the assessment shall be documented in a final report and issued to the appropriate personnel. Management has the primary responsibility to ensure the timely follow-up of corrective actions, including an evaluation of the effectiveness of management's actions. Results of the management assessment should be entered into a tracking system for the purposes of identifying trends and lessons learned. 


\section{B.11.0 Criteria 10 - Independent Assessments}

Independent management and technical assessments shall be performed to verify compliance with applicable quality requirements, DOE policies, and procedures. Assessments shall be conducted to measure item and service quality, the adequacy of work performance, and to promote improvement. The scheduling of the assessments and resource allocation for independent assessments should be based on the status, risk, and complexity of work being assessed.

The group performing the independent assessment shall be composed of individuals that are not directly involved in the work being assessed. Each group performing independent assessments shall have sufficient authority and freedom to carry out the activities necessary to effectively conduct the assessment. Assessments should focus on improving the quality of the processes that lead to the end product.

Results of each assessment should be tracked and resolved by responsible management with follow-up of deficient areas. Assessment responses should include: corrective action, identification of the root cause, actions to prevent recurrence, and actions for improvement. 


\section{B.12.0 References}

American Society of Quality Control. 1994. American National Standard Institute, Specifications and Guidelines for Quality Systems for Environmental Technology Programs, ANSI/ASQ E-4. Milwaukee, WI.

ASQC, see American Society of Quality Control.

CFR, see Code of Federal Regulations.

Code of Federal Regulations. 1996. Title 10, Part 830.120, "Quality Assurance Requirements." Washington, DC.

Code of Federal Regulations. 1998a. Title 10 Part 71, "Energy - Packaging and Transportation of Radioactive Material." Washington, DC.

Code of Federal Regulations. 1998b. Title 29 Part 1910.120, "Hazardous Waste Operations and Emergency Response." Washington, DC.

Code of Federal Regulations. 1999. Title 49, Parts 170 through 180, "Transportation - Hazardous Materials Shipping Regulations." Washington, DC.

DOE, see U.S. Department of Energy.

DOE/NV, see U.S. Department of Energy, Nevada Operations Office.

EPA, see U.S. Environmental Protection Agency.

U.S. Department of Energy. 1990. Requirements for Quality Control of Analytical Data. Washington, DC.

U.S. Department of Energy. 1996a. Information Management Program, DOE Order 200.1. Washington, DC.

U.S. Department of Energy. 1996b. Safety Management System Policy, DOE Order 450.4. Washington, DC.

U.S. Department of Energy. 1998. Worker Protection Management for DOE Federal and Contractor Employees, DOE Order 440.1A. Washington, DC.

U.S. Department of Energy. 1999. Quality Assurance, DOE Order 414.1A. Washington, DC. 
U.S. Department of Energy, Nevada Operations Office. 1993. DOE/NV Quality Glossary. Las Vegas, NV.

U.S. Department of Energy, Nevada Operations Office. 1999a. Document Review and Coordination, AMEM-02-002, Rev. 0. Contained in Policies, Plans, Procedures, and Guidance Manual. Las Vegas, NV: Office of the Assistant Manager for Environmental Management.

U.S. Department of Energy, Nevada Operations Office. 1999b. Nevada Test Site Waste Acceptance Criteria, NTSWAC, DOE/NV-325, Rev. 2. Las Vegas, NV.

U.S. Environmental Protection Agency. 1994a. Guidance for the Data Quality Objectives Process, EPA QA-G-4. Washington, DC.

U.S. Environmental Protection Agency. 1994b. USEPA Contract Laboratory Program National Functional Guidelines for Inorganic Data Review, EPA-540/R-94/013. Washington, DC.

U.S. Environmental Protection Agency. 1998. Guidance for Quality Assurance Project Plans, EPA QA-G-5, EPA/600/R-98/018. Washington, DC.

U.S. Environmental Protection Agency. 1999. USEPA Contract Laboratory Program National Functional Guidelines for Organic Data Review, EPA-540/R-99/008. Washington, DC.

U.S. Environmental Protection Agency. 2000. User's Guide to the Contract Laboratory Program, EPA 540-R-99-004. Washington, DC. 


\section{B.13.0 Glossary}

\section{Acceptance Criteria}

Specific characteristics of an item, process, or service defined in codes, standards, or other requirement documents. (DOE/NV, 1993)

\section{Accuracy}

A measure of the closeness of an individual measurement or the average of a number of measurements to the true value. Accuracy includes a combination of random error (precision) and systematic error (bias) components that are due to sampling and analytical operations; the EPA recommends using the terms "precision" and bias," rather than "accuracy," to convey the information usually associated with accuracy. (EPA, 1998)

\section{Activity}

An all-inclusive term describing a specific set of operations or related tasks to be performed, either serially or in parallel (e.g., research and development, field sampling, analytical operations, equipment fabrication), that in total result in a product or service. (ASQC, 1994)

\section{Assessment}

The evaluation process used to measure the performance or effectiveness of a system and its elements. Assessment is an all-inclusive term used to denote any of the following: audit, performance evaluation, management systems review, peer review, inspection, or surveillance. (ASQC, 1994)

\section{Audit (Quality)}

A systematic and independent examination to determine whether quality activities and related results comply with planned arrangements and whether these arrangements are implemented effectively and are suitable to achieve objectives. (ASQC, 1994)

\section{Bias}

The systematic or persistent distortion of a measurement process which causes errors in one direction (i.e., the expected sample measurement is different from the sample's true value). (ASQC, 1994) 


\section{Calibration}

Comparison of a measurement standard, instrument, or item with a standard or instrument of higher accuracy to detect and quantify inaccuracies and to report or eliminate those inaccuracies by adjustments. (ASQC, 1994)

\section{Certification}

The act of determining, verifying, and attesting in writing to the qualifications of personnel, processes, procedures, or items in accordance with acceptance criteria. (DOE/NV, 1993)

\section{Characteristic}

Any property or attribute of a datum, item, process, or service that is distinct, describable, and/or measurable. (ASQC, 1994)

\section{Comparability}

A measure of the confidence with which one data set can be compared to another. (ASQC, 1994)

\section{Completeness}

A measure of the amount of valid data obtained from a measurement system compared to the amount that was expected to be obtained under correct, normal conditions. (ASQC, 1994)

\section{Condition Adverse to Quality}

An all-inclusive term used in reference to any of the following: failures, malfunctions, deficiencies, defective items or nonconformance. (DOE/NV, 1993)

\section{Corrective Action}

An action taken to eliminate the causes of an existing nonconformance, deficiency, or other undesirable situation in order to prevent recurrence. (ASQC, 1994)

\section{Criteria}

Rules or tests against which the quality of performance can be measured. They are most effective when expressed quantitatively. Fundamental criteria are contained in policies and objectives, as well as codes, standards, regulations, and recognized professional practices that DOE and DOE contractors are required to observe. (DOE/NV, 1993) 


\section{Data Quality Objectives (DQOs)}

Qualitative and quantitative statements derived from the DQO process that clarify study technical and quality objectives, define the appropriate types of data, and specify tolerable levels of potential decision errors that will be used as the basis for establishing the quality and quantity of data needed to support decisions. (ASQC, 1994)

\section{Data Quality Objectives Process}

A systematic strategic planning tool based on the scientific method that identifies and defines the type, quality, and quantity of data needed to satisfy a specific use. The key elements of the process include:

- Concisely defining the problem

- Identifying the decision to be made

- Identifying the key inputs to the decision

- Defining the boundaries of the study

- Developing the decision rule

- Specifying tolerable limits on potential decision errors

- Selecting the most resource efficient data collection design

Data quality objectives are the qualitative and quantitative outputs from the DQO process. The DQO process was developed originally by the EPA, but has been adapted for use by other organizations to meet their specific planning requirements. (ASQC, 1994)

\section{Data Usability}

The process of ensuring or determining whether the quality of the data produced meets the intended use of the data. (ASQC, 1994)

\section{Deficiency}

An unauthorized deviation from acceptable procedures or practices, or a defect in an item.

(ASQC, 1994)

\section{Design}

Specifications, drawings, design criteria, and performance requirements. Also the result of deliberate planning, analysis, mathematical manipulations, and design processes. (ASQC, 1994) 


\section{Document}

Any written or pictorial information describing, defining, specifying, reporting, or certifying activities, requirements, procedures, or results. (ASQC, 1994)

\section{Environmental Data}

Any measurements or information that describe environmental processes or conditions, or the performance of environmental technology. (ASQC, 1994)

\section{Environmental Data Operations}

Work performed to obtain, use, or report information pertaining to environmental processes and conditions. (ASQC, 1994)

\section{Graded Approach}

The process of basing the level of application of managerial controls applied to an item or work according to the intended use of the results and the degree of confidence needed in the quality of the results. (See data quality objectives process.) (ASQC, 1994)

\section{Independent Assessment}

An assessment performed by a qualified individual, group, or organization that is not a part of the organization directly performing and accountable for the work being assessed. (ASQC, 1994)

\section{Inspection}

An activity such as measuring, examining, testing, or gauging one or more characteristics of an entity and comparing the results with specified requirements in order to establish whether conformance is achieved for each characteristic. (ASQC, 1994)

\section{Item}

An all-inclusive term used in place of any of the following: appurtenance, facility, sample, assembly, component, equipment, material, module, part, product, structure, subassembly, subsystem, system, unit, documented concepts, or data. (ASQC, 1994) 


\section{Management Assessment}

The determination of the appropriateness, thoroughness, and effectiveness of management processes. (DOE/NV, 1993)

\section{Measurement and Testing Equipment (M\&TE)}

Tools, gauges, instruments, sampling devices or systems used to calibrate, measure, test, or inspect in order to control or acquire data to verify conformance to specified requirements. (ASQC, 1994)

\section{Method}

A body of procedures and techniques for performing an activity (e.g., sampling, chemical analysis, quantification) systematically presented in the order in which they are to be executed. (ASQC, 1994)

\section{Nonconformance}

A deficiency in characteristic, documentation, or procedure that renders the quality of an item or activity unacceptable or indeterminate; nonfulfillment of a specified requirement. (ASQC, 1994)

\section{Precision}

A measure of mutual agreement among individual measurements of the same property, usually under prescribed similar conditions, expressed generally in terms of the standard deviations. (ASQC, 1994)

\section{Procedure}

A specified way to perform an activity. (ASQC, 1994)

\section{Process}

Any activity or group of activities that takes an input, adds value to it, and provides an output to a customer. The logical organization or people, materials, energy, equipment, and procedures into work activities designed to produce a specified end result (work product). (DOE/NV, 1993)

\section{Quality}

The totality of features and characteristics of a product or service that bear on its ability to meet the stated or implied needs and expectations of the user. (ASQC, 1994) 


\section{Quality Assurance (QA)}

An integrated system of management activities involving planning, implementation assessment, reporting, and quality improvement to ensure that a process, item, or service is of the type and quality needed and expected by the customer. (ASQC, 1994)

\section{Quality Assurance Program}

The overall program (management system) established to assign responsibilities and authorities, define policies and requirements for the performance and assessment of work. (DOE, 1999)

\section{Quality Control $(Q C)$}

The overall system of technical activities that measures the attributes and performance of a process, item, or service against defined standards to verify that they meet the stated requirements established by the customer; operational techniques and activities that are used to fulfill requirements for quality. (ASQC, 1994)

\section{Quality Improvement}

A management program for improving the quality of operations. Such management programs generally entail a formal mechanism for encouraging work recommendations with timely management evaluation and feedback or implementation. (ASQC, 1994)

\section{Quality Indicators}

Measurable attributes of the attainment of the necessary quality for a particular environmental decision. Indicators of quality include: precision, bias, completeness, representativeness, reproducibility, comparability, and statistical confidence. (ASQC, 1994)

\section{Quality System}

A structured and documented management system describing the policies, objectives, principles, organizational authority, responsibilities, accountability, and implementation plan of an organization for ensuring quality in its work processes, products (items), and services. The quality system provides the framework for planning, implementing, and assessing work performed by the organization and for carrying out required QA and QC. (ASQC, 1994) 


\section{Readiness Review}

A systematic, documented review of the readiness for startup or continued use of a facility, process, or activity. Readiness reviews are typically conducted before proceeding beyond project milestones and prior to institution of a major phase of work. (ASQC, 1994)

\section{Record}

A completed document that furnishes evidence relating to items or activities. (DOE/NV, 1993)

\section{Remediation}

The process of reducing the concentration of a contaminant (or contaminants) in air, water, or soil media to a level that poses an acceptable risk to human health. (ASQC, 1994)

\section{Representativeness}

A measure of the degree to which data accurately and precisely represent a characteristic of a population, parameter variations at a sampling point, a process condition, or an environmental condition. (ASQC, 1994)

\section{Risk}

A quantitative or qualitative expression of possible loss which considers both the probability that an event occurrence will cause harm or loss and the consequences of that event. (DOE/NV, 1993)

\section{Root Cause}

The most basic reason for conditions adverse to quality that, if corrected, will prevent occurrence or recurrence. (DOE/NV, 1993)

\section{Self Assessment}

Assessments of work conducted by individuals, groups, or organizations directly responsible for overseeing and/or performing the work. (ASQC, 1994)

\section{Service}

The result generated by activities at the interface between the supplier and the customer, and by supplier internal activities to meet customer needs. Such activities in environmental programs include design, inspection, laboratory and/or field analysis, repair, and installation. (ASQC, 1994) 


\section{Specification}

A document stating requirements and which refers to or includes drawings or other relevant documents. Specifications should indicate the means and the criteria for determining conformance. (ASQC, 1994)

\section{Standard Operating Procedure}

A written document that details the method for an operation, analysis, or action with thoroughly prescribed techniques and steps, and that is officially approved as the method for performing certain routine or repetitive tasks. (ASQC, 1994)

\section{Surveillance (Quality)}

Continual or frequent monitoring and verification of the status of an entity and the analysis of records to ensure that specified requirements are being fulfilled. (ASQC, 1994)

\section{Technical Review}

A documented critical review of work that has been performed within the state of the art. The review is accomplished by one or more qualified reviewers who are independent of those who performed the work, but are collectively equivalent in technical expertise to those who performed the original work. The review is an in-depth analysis and evaluation of documents, activities, material, data, or items that require technical verification or validation for applicability, correctness, adequacy, completeness, and assurance that established requirements are satisfied. (ASQC, 1994)

\section{Traceability}

The ability to trace the history, application, or location of an entity by means of recorded identifications. In a calibration sense, traceability relates measuring equipment to national or international standard, primary standards, basic physical constants or properties, or reference materials. In a data collection sense, it relates calculations and data generated throughout the project back to the requirements for quality for the project. (ASQC, 1994)

\section{Training}

The process of providing for and making available to an employee(s) and placing or enrolling an employee(s) in a planned, prepared, and coordinated program, course, curriculum, subject, system, or 
routine of instruction or education, in fiscal, administrative, management, individual development, or other fields which improve individual and organizational performance and assist in achieving the agency's mission and performance goals. (DOE/NV, 1993).

\section{Validation}

Confirmation by examination and provision of objective evidence that the particular requirements for a specific intended use are fulfilled. In design and development, validation concerns the process of examining a product or result to determine conformance to user needs. (ASQC, 1994)

\section{Verification}

Confirmation by examination and provision of objective evidence that specified requirements have been fulfilled. In design and development, verification concerns the process of examining a result of a given activity to determine conformance to the stated requirements for that activity. (ASQC, 1994) 


\section{Attachment 1}

\section{Quality Criteria for Site-Specific Documents}




\section{Site-Specific Quality Assurance Project Plans Requirements}

Site-specific planning documents must contain $\mathrm{QA} / \mathrm{QC}$ requirements appropriate for the site and activities being performed. This attachment delineates the quality criteria that should be included in either the site-specific planning document or addressed in an appendix to the appropriate document:

- Quality Objectives and Criteria for Measurement Data: Describe the project quality objectives and performance criteria.

- Special Training Requirements/Certification: Identify and describe any specialized training or certification requirements and discuss how such training will be provided and how the necessary skills will be assured and documented.

- Required Documentation and Records: Define the information that must be included in the data report package and the reporting format. Identify documents (e.g., interim progress reports, final reports) that will be produced. Specify the final disposition of records including retention period.

- Sampling Process Design: Describe any experimental design or data collection design for the project and classify all measurements as critical or non-critical.

- Sampling Methods Requirements: Describe specific performance requirements for the method. Address what to do when a failure in the sampling occurs, who is responsible for the corrective action, and how the effectiveness of the corrective action shall be determined and documented.

- Laboratory Requirements: Identify volume requirements, preservative requirements, and holding times.

- Analytical Methods Requirements: Identify the analytical methods, waste disposal requirements (if any), and specific performance requirements for the method.

- Quality Control Requirements: Identify required measurement QC check for both the field and laboratory. State the frequency of analysis for each type of QC check.

- Instrument/Equipment Testing, Inspection, and Maintenance Requirements: Describe how inspections and acceptance testing of environmental sampling and measurement systems and their components will be performed and documented. 
- Reports to Management: Identify the frequency and distribution of reports issued to inform management of the status of the project.

- Reconciliation with Data Quality Objectives: Describe how the results obtained from the project or task will be reconciled with the requirements defined by the data user or decision maker. 


\section{Attachment 2}

\section{Laboratory Chemical, Toxicity Characteristic Leaching Procedure, and Radiochemistry Analytical Requirements for New Mexico Sites}




\section{Laboratory Chemical, Toxicity Characteristic Leaching Procedure, and Radiochemistry Analytical Requirements for New Mexico Sites}

(Page 1 of 7 )

\begin{tabular}{|c|c|c|c|c|c|c|}
\hline $\begin{array}{l}\text { Parameter or } \\
\text { Analyte }\end{array}$ & $\begin{array}{l}\text { Medium or } \\
\text { Matrix }\end{array}$ & $\begin{array}{l}\text { Analytical } \\
\text { Method }\end{array}$ & $\begin{array}{c}\text { Minimum } \\
\text { Reporting Limit }\end{array}$ & $\begin{array}{l}\text { Regulatory } \\
\text { Limit }\end{array}$ & $\begin{array}{c}\text { Relative } \\
\text { Percent } \\
\text { Difference } \\
\text { (RPD) }^{\mathrm{a}} \\
\end{array}$ & $\begin{array}{c}\text { Percent } \\
\text { Recovery } \\
(\% R)^{\mathrm{b}}\end{array}$ \\
\hline \multicolumn{7}{|c|}{ ORGANICS } \\
\hline \multirow{2}{*}{$\begin{array}{l}\text { Total Volatile Organic } \\
\text { Compounds (VOCs) }\end{array}$} & Water & \multirow{2}{*}{$\begin{array}{l}8260 B^{c} \\
5030 B^{c}\end{array}$} & \multirow{2}{*}{$\begin{array}{l}\text { Analyte-specific } \\
\text { estimated } \\
\text { quantitation limits }^{d}\end{array}$} & \multirow{2}{*}{$\begin{array}{l}\text { Not Applicable } \\
\text { (NA) }\end{array}$} & $14^{\mathrm{e}}$ & $61-145^{e}$ \\
\hline & Soil & & & & $24^{e}$ & $59-172^{e}$ \\
\hline \multicolumn{7}{|l|}{$\begin{array}{c}\text { Toxicity } \\
\text { Characteristic } \\
\text { Leaching Procedure } \\
\text { (TCLP) VOCs }\end{array}$} \\
\hline Benzene & \multirow{10}{*}{ Aqueous } & \multirow{10}{*}{$1311 / 8260 \mathrm{~B}^{\mathrm{c}}$} & $0.050 \mathrm{mg} / \mathrm{L}^{\mathrm{d}}$ & $0.5 \mathrm{mg} / \mathrm{L}^{\mathrm{d}}$ & \multirow{10}{*}{$14^{e}$} & \multirow{10}{*}{$61-145^{e}$} \\
\hline $\begin{array}{c}\text { Carbon } \\
\text { Tetrachloride }\end{array}$ & & & $0.050 \mathrm{mg} / \mathrm{L}^{\mathrm{d}}$ & $0.5 \mathrm{mg} / \mathrm{L}^{\mathrm{d}}$ & & \\
\hline Chlorobenzene & & & $0.050 \mathrm{mg} / \mathrm{L}^{\mathrm{d}}$ & $100 \mathrm{mg} / \mathrm{L}^{\mathrm{d}}$ & & \\
\hline Chloroform & & & $0.050 \mathrm{mg} / \mathrm{L}^{\mathrm{d}}$ & $6 \mathrm{mg} / \mathrm{L}^{\mathrm{d}}$ & & \\
\hline 1,2-Dichloroethane & & & $0.050 \mathrm{mg} / \mathrm{L}^{\mathrm{d}}$ & $0.5 \mathrm{mg} / \mathrm{L}^{\mathrm{d}}$ & & \\
\hline 1,1-Dichloroethene & & & $0.050 \mathrm{mg} / \mathrm{L}^{\mathrm{d}}$ & $0.7 \mathrm{mg} / \mathrm{L}^{\mathrm{d}}$ & & \\
\hline Methyl Ethyl Ketone & & & $0.050 \mathrm{mg} / \mathrm{L}^{\mathrm{d}}$ & $200 \mathrm{mg} / \mathrm{L}^{\mathrm{d}}$ & & \\
\hline Tetrachloroethene & & & $0.050 \mathrm{mg} / \mathrm{L}^{\mathrm{d}}$ & $0.7 \mathrm{mg} / \mathrm{L}^{\mathrm{d}}$ & & \\
\hline Trichloroethene & & & $0.050 \mathrm{mg} / \mathrm{L}^{\mathrm{d}}$ & $0.5 \mathrm{mg} / \mathrm{L}^{\mathrm{d}}$ & & \\
\hline Vinyl Chloride & & & $0.050 \mathrm{mg} / \mathrm{L}^{\mathrm{d}}$ & $0.2 \mathrm{mg} / \mathrm{L}^{\mathrm{d}}$ & & \\
\hline \multirow{2}{*}{$\begin{array}{l}\text { Total Semivolatile } \\
\text { Organic Compounds } \\
\text { (SVOCs) }\end{array}$} & Water & \multirow{2}{*}{$8270 C^{c}$} & \multirow{2}{*}{$\begin{array}{l}\text { Analyte-specific } \\
\text { estimated } \\
\text { quantitation limits }^{d}\end{array}$} & \multirow{2}{*}{ NA } & $50^{\mathrm{e}}$ & $9-127^{e}$ \\
\hline & Soil & & & & $50^{\mathrm{e}}$ & $11-142^{\mathrm{e}}$ \\
\hline \multicolumn{7}{|l|}{ TCLP SVOCs } \\
\hline o-Cresol & \multirow{6}{*}{ Aqueous } & \multirow{6}{*}{$1311 / 8270 C^{c}$} & $0.10 \mathrm{mg} / \mathrm{L}^{\mathrm{d}}$ & $200 \mathrm{mg} / \mathrm{L}^{\mathrm{d}}$ & \multirow{6}{*}{$50^{\mathrm{e}}$} & \multirow{6}{*}{$9-127^{e}$} \\
\hline m-Cresol & & & $0.10 \mathrm{mg} / \mathrm{L}^{\mathrm{d}}$ & $200 \mathrm{mg} / \mathrm{L}^{\mathrm{d}}$ & & \\
\hline p-Cresol & & & $0.10 \mathrm{mg} / \mathrm{L}^{\mathrm{d}}$ & $200 \mathrm{mg} / \mathrm{L}^{\mathrm{d}}$ & & \\
\hline Cresol (total) & & & $0.30 \mathrm{mg} / \mathrm{L}^{\mathrm{d}}$ & $200 \mathrm{mg} / \mathrm{L}^{\mathrm{d}}$ & & \\
\hline $\begin{array}{l}\text { 1,4-Dichloro- } \\
\text { benzene }\end{array}$ & & & $0.10 \mathrm{mg} / \mathrm{L}^{\mathrm{d}}$ & $7.5 \mathrm{mg} / \mathrm{L}^{\mathrm{d}}$ & & \\
\hline 2,4-Dinitrotoluene & & & $0.10 \mathrm{mg} / \mathrm{L}^{\mathrm{d}}$ & $0.13 \mathrm{mg} / \mathrm{L}^{\mathrm{d}}$ & & \\
\hline
\end{tabular}




\section{Laboratory Chemical, Toxicity Characteristic Leaching Procedure, and Radiochemistry Analytical Requirements for New Mexico Sites}

(Page 2 of 7 )

\begin{tabular}{|c|c|c|c|c|c|c|}
\hline $\begin{array}{c}\text { Parameter or } \\
\text { Analyte }\end{array}$ & $\begin{array}{l}\text { Medium or } \\
\text { Matrix }\end{array}$ & $\begin{array}{l}\text { Analytical } \\
\text { Method }\end{array}$ & $\begin{array}{l}\text { Minimum } \\
\text { Reporting Limit }\end{array}$ & $\begin{array}{l}\text { Regulatory } \\
\text { Limit }\end{array}$ & $\begin{array}{l}\text { Relative } \\
\text { Percent } \\
\text { Difference } \\
\text { (RPD) }^{\mathrm{a}}\end{array}$ & $\begin{array}{l}\text { Percent } \\
\text { Recovery } \\
(\% \mathrm{R})^{\mathrm{b}}\end{array}$ \\
\hline $\begin{array}{l}\text { Hexachloro- } \\
\text { benzene }\end{array}$ & \multirow{8}{*}{ Aqueous } & \multirow{8}{*}{$1311 / 8270 C^{c}$} & $0.10 \mathrm{mg} / \mathrm{L}^{\mathrm{d}}$ & $0.13 \mathrm{mg} / \mathrm{L}^{\mathrm{d}}$ & \multirow{8}{*}{$50^{e}$} & \multirow{8}{*}{$9-127^{e}$} \\
\hline $\begin{array}{l}\text { Hexachloro- } \\
\text { butadiene }\end{array}$ & & & $0.10 \mathrm{mg} / \mathrm{L}^{\mathrm{d}}$ & $0.5 \mathrm{mg} / \mathrm{L}^{\mathrm{d}}$ & & \\
\hline $\begin{array}{l}\text { Hexachloro- } \\
\text { ethane }\end{array}$ & & & $0.10 \mathrm{mg} / \mathrm{L}^{\mathrm{d}}$ & $3 \mathrm{mg} / \mathrm{L}^{\mathrm{d}}$ & & \\
\hline Nitrobenzene & & & $0.10 \mathrm{mg} / \mathrm{L}^{\mathrm{d}}$ & $2 \mathrm{mg} / \mathrm{L}^{\mathrm{d}}$ & & \\
\hline $\begin{array}{l}\text { Pentachloro- } \\
\text { phenol }\end{array}$ & & & $0.50 \mathrm{mg} / \mathrm{L}^{\mathrm{d}}$ & $100 \mathrm{mg} / \mathrm{L}^{\mathrm{d}}$ & & \\
\hline Pyridine & & & $0.10 \mathrm{mg} / \mathrm{L}^{\mathrm{d}}$ & $5 \mathrm{mg} / \mathrm{L}^{\mathrm{d}}$ & & \\
\hline $\begin{array}{c}\text { 2,4,5-Trichloro- } \\
\text { phenol }\end{array}$ & & & $0.10 \mathrm{mg} / \mathrm{L}^{\mathrm{d}}$ & $400 \mathrm{mg} / \mathrm{L}^{\mathrm{d}}$ & & \\
\hline $\begin{array}{c}\text { 2,4,6-Trichloro- } \\
\text { phenol }\end{array}$ & & & $0.10 \mathrm{mg} / \mathrm{L}^{\mathrm{d}}$ & $2 \mathrm{mg} / \mathrm{L}^{\mathrm{d}}$ & & \\
\hline \multirow{2}{*}{$\begin{array}{c}\text { Total } \\
\text { Pesticides }\end{array}$} & Water & \multirow{2}{*}{$8081 A^{c}$} & \multirow{2}{*}{$\begin{array}{l}\text { Analyte-specific } \\
\qquad(\mathrm{CRQL})^{\mathrm{e}}\end{array}$} & \multirow{2}{*}{ NA } & $27^{\mathrm{e}}$ & $38-131^{e}$ \\
\hline & Soil & & & & $50^{\mathrm{e}}$ & $23-139^{e}$ \\
\hline \multicolumn{7}{|l|}{$\begin{array}{c}\text { TCLP } \\
\text { Pesticides }\end{array}$} \\
\hline Chlordane & \multirow{7}{*}{ Aqueous } & \multirow{7}{*}{$1311 / 8081 A^{c}$} & $0.0005 \mathrm{mg} / \mathrm{L}^{\mathrm{e}}$ & $0.03 \mathrm{mg} / \mathrm{L}^{\mathrm{d}}$ & \multirow{7}{*}{$27^{e}$} & \multirow{7}{*}{$38-131^{e}$} \\
\hline Endrin & & & $0.001 \mathrm{mg} / \mathrm{L}^{\mathrm{e}}$ & $0.02 \mathrm{mg} / \mathrm{L}^{\mathrm{d}}$ & & \\
\hline Heptachlor & & & $0.0005 \mathrm{mg} / \mathrm{L}^{\mathrm{e}}$ & $0.008 \mathrm{mg} / \mathrm{L}^{\mathrm{d}}$ & & \\
\hline $\begin{array}{l}\text { Heptachlor } \\
\text { Epoxide }\end{array}$ & & & $0.0005 \mathrm{mg} / \mathrm{L}^{\mathrm{e}}$ & $0.008 \mathrm{mg} / \mathrm{L}^{\mathrm{d}}$ & & \\
\hline $\begin{array}{c}\text { gamma-BHC } \\
\text { (Lindane) }\end{array}$ & & & $0.0005 \mathrm{mg} / \mathrm{L}^{\mathrm{e}}$ & $0.4 \mathrm{mg} / \mathrm{L}^{\mathrm{d}}$ & & \\
\hline Methoxychlor & & & $0.005 \mathrm{mg} / \mathrm{L}^{\mathrm{e}}$ & $10 \mathrm{mg} / \mathrm{L}^{\mathrm{d}}$ & & \\
\hline Toxaphene & & & $0.05 \mathrm{mg} / \mathrm{L}^{\mathrm{e}}$ & $0.5 \mathrm{mg} / \mathrm{L}^{\mathrm{d}}$ & & \\
\hline \multirow[b]{2}{*}{$\begin{array}{l}\text { Polychlorinated } \\
\text { Biphenyls (PCBs) }\end{array}$} & Water & \multirow[b]{2}{*}{$8082^{c}$} & \multirow{2}{*}{$\begin{array}{c}\text { Analyte-specific } \\
\text { contract required } \\
\text { quantitation limits } \\
(\mathrm{CRQL})^{\mathrm{e}}\end{array}$} & \multirow[b]{2}{*}{ NA } & \multirow[b]{2}{*}{ Lab-specific ${ }^{\dagger}$} & \multirow[b]{2}{*}{ Lab-specific $^{\dagger}$} \\
\hline & Soil & & & & & \\
\hline \multirow{2}{*}{$\begin{array}{l}\text { Total } \\
\text { Herbicides }\end{array}$} & Water & \multirow{2}{*}{$8151 A^{c}$} & $1.3 \mu \mathrm{g} / \mathrm{L}^{\mathrm{c}}$ & \multirow{2}{*}{ NA } & \multirow{2}{*}{ Lab-specific ${ }^{f}$} & \multirow{2}{*}{ Lab-specific $^{f}$} \\
\hline & Soil & & $66 \mu \mathrm{g} / \mathrm{kg}^{\mathrm{c}}$ & & & \\
\hline \multicolumn{7}{|l|}{$\begin{array}{c}\text { TCLP } \\
\text { Herbicides } \\
\end{array}$} \\
\hline $2,4-\mathrm{D}$ & \multirow{2}{*}{ Aqueous } & \multirow{2}{*}{$1311 / 8151 A^{c}$} & $0.002 \mathrm{mg} / \mathrm{L}^{\mathrm{d}}$ & $10 \mathrm{mg} / \mathrm{L}^{\mathrm{d}}$ & \multirow{2}{*}{ Lab-specific $^{f}$} & \multirow{2}{*}{ Lab-specific $^{f}$} \\
\hline $2,4,5-\mathrm{TP}$ & & & $0.00075 \mathrm{mg} / \mathrm{L}^{\mathrm{d}}$ & $1 \mathrm{mg} / \mathrm{L}^{\mathrm{d}}$ & & \\
\hline
\end{tabular}




\section{Laboratory Chemical, Toxicity Characteristic Leaching Procedure, and Radiochemistry Analytical Requirements for New Mexico Sites} (Page 3 of 7 )

\begin{tabular}{|c|c|c|c|c|c|c|}
\hline $\begin{array}{c}\text { Parameter or } \\
\text { Analyte }\end{array}$ & $\begin{array}{l}\text { Medium or } \\
\text { Matrix }\end{array}$ & $\begin{array}{l}\text { Analytical } \\
\text { Method }\end{array}$ & $\begin{array}{c}\text { Minimum } \\
\text { Reporting Limit }\end{array}$ & $\begin{array}{l}\text { Regulatory } \\
\text { Limit }\end{array}$ & $\begin{array}{c}\text { Relative } \\
\text { Percent } \\
\text { Difference } \\
\text { (RPD) }{ }^{\mathrm{a}}\end{array}$ & $\begin{array}{c}\text { Percent } \\
\text { Recovery } \\
(\% R)^{\mathrm{b}}\end{array}$ \\
\hline \multirow{4}{*}{$\begin{array}{c}\text { Total Petroleum } \\
\text { Hydrocarbons (TPH) }\end{array}$} & $\begin{array}{c}\text { Water } \\
\text { Gasoline }\end{array}$ & \multirow{4}{*}{ 8015B modified ${ }^{c}$} & $0.1 \mathrm{mg} / \mathrm{L}^{\mathrm{g}}$ & \multirow{4}{*}{ NA } & \multirow{4}{*}{ Lab-specific $^{f}$} & \multirow{4}{*}{ Lab-specific } \\
\hline & Soil Gasoline & & $0.5 \mathrm{mg} / \mathrm{kg}^{\mathrm{g}}$ & & & \\
\hline & Water Diesel & & $0.5 \mathrm{mg} / \mathrm{L}^{\mathrm{g}}$ & & & \\
\hline & Soil Diesel & & $25 \mathrm{mg} / \mathrm{kg}^{\mathrm{g}}$ & & & \\
\hline \multirow{2}{*}{ Explosives } & Water & \multirow{2}{*}{$8330^{c}$} & $14 \mu \mathrm{g} / \mathrm{L}^{\mathrm{c}}$ & \multirow{2}{*}{ NA } & \multirow{2}{*}{ Lab-specific $^{\dagger}$} & \multirow{2}{*}{ Lab-specific $^{\dagger}$} \\
\hline & Soil & & $2.2 \mathrm{mg} / \mathrm{kg}^{\mathrm{c}}$ & & & \\
\hline \multirow{2}{*}{$\begin{array}{c}\text { Polychlorinated } \\
\text { Dioxins and Furans }\end{array}$} & Water & \multirow{2}{*}{$8280 \mathrm{~A} / 8290^{c}$} & $0.05 \mu \mathrm{g} / \mathrm{L}^{\mathrm{c}}$ & \multirow{2}{*}{ NA } & \multirow{2}{*}{ Lab-specific $^{f}$} & \multirow{2}{*}{ Lab-specific } \\
\hline & Soil & & $5 \mu \mathrm{g} / \mathrm{kg}^{\mathrm{c}}$ & & & \\
\hline \multicolumn{7}{|c|}{ INORGANICS } \\
\hline \multicolumn{7}{|l|}{$\begin{array}{c}\text { Target Analyte List } \\
\text { Metals }\end{array}$} \\
\hline \multirow{2}{*}{ Aluminum } & Water & $6010 \mathrm{~B}^{\mathrm{c}}$ & $100 \mu \mathrm{g} / \mathrm{L}^{\mathrm{g}, \mathrm{h}}$ & \multirow{22}{*}{ NA } & \multirow{22}{*}{$20^{h}$} & \multirow{22}{*}{$75-125^{\mathrm{h}}$} \\
\hline & Soil & $6010 \mathrm{~B}^{\mathrm{c}}$ & $10 \mathrm{mg} / \mathrm{kg}^{\mathrm{g}, \mathrm{h}}$ & & & \\
\hline \multirow{2}{*}{ Antimony } & Water & $6010 B^{c}$ & $20 \mu \mathrm{g} / \mathrm{L}^{\mathrm{g}, \mathrm{h}}$ & & & \\
\hline & Soil & $6010 \mathrm{~B}^{\mathrm{c}}$ & $2 \mathrm{mg} / \mathrm{kg}^{\mathrm{g}, \mathrm{h}}$ & & & \\
\hline \multirow{2}{*}{ Arsenic } & Water & $6010 \mathrm{~B}^{\mathrm{c}}$ & $10 \mu \mathrm{g} / \mathrm{L}^{\mathrm{g}, \mathrm{h}}$ & & & \\
\hline & Soil & $6010 B^{c}$ & $1 \mathrm{mg} / \mathrm{kg}^{\mathrm{g}, \mathrm{h}}$ & & & \\
\hline \multirow{2}{*}{ Barium } & Water & $6010 B^{c}$ & $200 \mu \mathrm{g} / \mathrm{L}^{\mathrm{g}, \mathrm{h}}$ & & & \\
\hline & Soil & $6010 \mathrm{~B}^{\mathrm{c}}$ & $20 \mathrm{mg} / \mathrm{kg}^{\mathrm{g}, \mathrm{h}}$ & & & \\
\hline \multirow{2}{*}{ Beryllium } & Water & $6010 \mathrm{~B}^{\mathrm{c}}$ & $5 \mu \mathrm{g} / \mathrm{L}^{\mathrm{g}, \mathrm{h}}$ & & & \\
\hline & Soil & $6010 \mathrm{~B}^{\mathrm{c}}$ & $0.5 \mathrm{mg} / \mathrm{kg}^{\mathrm{g}, \mathrm{h}}$ & & & \\
\hline \multirow{2}{*}{ Boron } & Water & $6010 \mathrm{~B}^{\mathrm{c}}$ & $100 \mu \mathrm{g} / \mathrm{L}^{\mathrm{g}, \mathrm{h}}$ & & & \\
\hline & Soil & $6010 \mathrm{~B}^{\mathrm{c}}$ & $10 \mathrm{mg} / \mathrm{kg}^{\mathrm{g}, \mathrm{h}}$ & & & \\
\hline \multirow{2}{*}{ Cadmium } & Water & $6010 \mathrm{~B}^{\mathrm{c}}$ & $5 \mu \mathrm{g} / \mathrm{L}^{\mathrm{g}, \mathrm{h}}$ & & & \\
\hline & Soil & $6010 \mathrm{~B}^{\mathrm{c}}$ & $0.5 \mathrm{mg} / \mathrm{kg}^{\mathrm{g}, \mathrm{h}}$ & & & \\
\hline \multirow{2}{*}{ Calcium } & Water & $6010 \mathrm{~B}^{\mathrm{c}}$ & $1,000 \mu \mathrm{g} / \mathrm{L}^{\mathrm{g}, \mathrm{h}}$ & & & \\
\hline & Soil & $6010 B^{c}$ & $100 \mathrm{mg} / \mathrm{kg}^{\mathrm{g}, \mathrm{h}}$ & & & \\
\hline \multirow{2}{*}{ Chromium } & Water & $6010 B^{c}$ & $10 \mu \mathrm{g} / \mathrm{L}^{\mathrm{g}, \mathrm{h}}$ & & & \\
\hline & Soil & $6010 \mathrm{~B}^{\mathrm{c}}$ & $1 \mathrm{mg} / \mathrm{kg}^{\mathrm{g}, \mathrm{h}}$ & & & \\
\hline Copalt & Water & $6010 \mathrm{~B}^{\mathrm{c}}$ & $10 \mu \mathrm{g} / \mathrm{L}^{\mathrm{g}, \mathrm{h}}$ & & & \\
\hline Covalt & Soil & $6010 \mathrm{~B}^{\mathrm{c}}$ & $1 \mathrm{mg} / \mathrm{kg}^{\mathrm{g}, \mathrm{h}}$ & & & \\
\hline Conner & Water & $6010 B^{c}$ & $10 \mu \mathrm{g} / \mathrm{L}^{\mathrm{g}, \mathrm{h}}$ & & & \\
\hline 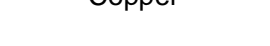 & Soil & $6010 \mathrm{~B}^{\mathrm{c}}$ & $1 \mathrm{mg} / \mathrm{kg}^{\mathrm{g}, \mathrm{h}}$ & & & \\
\hline
\end{tabular}




\section{Laboratory Chemical, Toxicity Characteristic Leaching Procedure, and Radiochemistry Analytical Requirements for New Mexico Sites}

(Page 4 of 7 )

\begin{tabular}{|c|c|c|c|c|c|c|}
\hline $\begin{array}{l}\text { Parameter or } \\
\text { Analyte }\end{array}$ & $\begin{array}{l}\text { Medium or } \\
\text { Matrix }\end{array}$ & $\begin{array}{l}\text { Analytical } \\
\text { Method }\end{array}$ & $\begin{array}{c}\text { Minimum } \\
\text { Reporting Limit }\end{array}$ & $\begin{array}{l}\text { Regulatory } \\
\text { Limit }\end{array}$ & $\begin{array}{c}\text { Relative } \\
\text { Percent } \\
\text { Difference } \\
\text { (RPD) }^{\mathrm{a}} \\
\end{array}$ & $\begin{array}{c}\text { Percent } \\
\text { Recovery } \\
(\% \mathbf{R})^{\mathrm{b}}\end{array}$ \\
\hline \multirow{2}{*}{ Iron } & Water & $6010 B^{c}$ & $100 \mu \mathrm{g} / \mathrm{L}^{\mathrm{g}, \mathrm{h}}$ & \multirow{34}{*}{ NA } & \multirow{34}{*}{$20^{h}$} & \multirow{34}{*}{$75-125^{\mathrm{h}}$} \\
\hline & Soil & $6010 B^{c}$ & $10 \mathrm{mg} / \mathrm{kg}^{\mathrm{g}, \mathrm{h}}$ & & & \\
\hline \multirow{2}{*}{ Lead } & Water & $6010 B^{c}$ & $3 \mu \mathrm{g} / \mathrm{L}^{\mathrm{g}, \mathrm{h}}$ & & & \\
\hline & Soil & $6010 \mathrm{~B}^{\mathrm{c}}$ & $0.3 \mathrm{mg} / \mathrm{kg}^{\mathrm{g}, \mathrm{h}}$ & & & \\
\hline \multirow{2}{*}{ Lithium } & Water & $6010 \mathrm{~B}^{\mathrm{c}}$ & $10 \mu \mathrm{g} / \mathrm{L}^{\mathrm{g}, \mathrm{h}}$ & & & \\
\hline & Soil & $6010 B^{c}$ & $1 \mathrm{mg} / \mathrm{kg}^{\mathrm{g}, \mathrm{h}}$ & & & \\
\hline \multirow{2}{*}{ Magnesium } & Water & $6010 B^{c}$ & $1,000 \mu \mathrm{g} / \mathrm{L}^{\mathrm{g}, \mathrm{h}}$ & & & \\
\hline & Soil & $6010 \mathrm{~B}^{\mathrm{c}}$ & 100 mg/kg ${ }^{g, h}$ & & & \\
\hline \multirow{2}{*}{ Manganese } & Water & $6010 B^{c}$ & $10 \mu \mathrm{g} / \mathrm{L}^{\mathrm{g}, \mathrm{h}}$ & & & \\
\hline & Soil & $6010 \mathrm{~B}^{\mathrm{c}}$ & $1 \mathrm{mg} / \mathrm{kg}^{\mathrm{g}, \mathrm{h}}$ & & & \\
\hline \multirow{2}{*}{ Mercury } & Water & $7470 A^{c}$ & $0.2 \mu \mathrm{g} / \mathrm{L}^{\mathrm{g}, \mathrm{h}}$ & & & \\
\hline & Soil & $7471 A^{c}$ & $0.1 \mathrm{mg} / \mathrm{kg}^{\mathrm{g}, \mathrm{h}}$ & & & \\
\hline \multirow{2}{*}{ Molybdenum } & Water & $6010 \mathrm{~B}^{\mathrm{c}}$ & $10 \mu \mathrm{g} / \mathrm{L}^{\mathrm{g}, \mathrm{h}}$ & & & \\
\hline & Soil & $6010 B^{c}$ & $1 \mathrm{mg} / \mathrm{kg}^{\mathrm{g}, \mathrm{h}}$ & & & \\
\hline \multirow{2}{*}{ Nickel } & Water & $6010 B^{c}$ & $20 \mu \mathrm{g} / \mathrm{L}^{\mathrm{g}, \mathrm{h}}$ & & & \\
\hline & Soil & $6010 B^{c}$ & $2 \mathrm{mg} / \mathrm{kg}^{\mathrm{g}, \mathrm{h}}$ & & & \\
\hline \multirow{2}{*}{ Phosphorus } & Water & $6010 B^{c}$ & $200 \mu \mathrm{g} / \mathrm{L}^{\mathrm{g}, \mathrm{h}}$ & & & \\
\hline & Soil & $6010 B^{c}$ & 20 mg/kg ${ }^{g, h}$ & & & \\
\hline \multirow{2}{*}{ Potassium } & Water & $6010 B^{c}$ & $1,000 \mu \mathrm{g} / \mathrm{L}^{\mathrm{g}, \mathrm{h}}$ & & & \\
\hline & Soil & $6010 B^{c}$ & $100 \mathrm{mg} / \mathrm{kg}^{\mathrm{g}, \mathrm{h}}$ & & & \\
\hline \multirow{2}{*}{ Selenium } & Water & $6010 \mathrm{~B}^{\mathrm{c}}$ & $5 \mu \mathrm{g} / \mathrm{L}^{\mathrm{g}, \mathrm{h}}$ & & & \\
\hline & Soil & $6010 \mathrm{~B}^{\mathrm{c}}$ & $0.5 \mathrm{mg} / \mathrm{kg}^{\mathrm{g}, \mathrm{h}}$ & & & \\
\hline \multirow{2}{*}{ Silica } & Water & $6010 \mathrm{~B}^{\mathrm{c}}$ & $50 \mu \mathrm{g} / \mathrm{L}^{\mathrm{g}, \mathrm{h}}$ & & & \\
\hline & Soil & $6010 B^{c}$ & $5 \mathrm{mg} / \mathrm{kg}^{\mathrm{g}, \mathrm{h}}$ & & & \\
\hline \multirow{2}{*}{ Silver } & Water & $6010 \mathrm{~B}^{\mathrm{c}}$ & $10 \mu \mathrm{g} / \mathrm{L}^{\mathrm{g}, \mathrm{h}}$ & & & \\
\hline & Soil & $6010 B^{c}$ & $1 \mathrm{mg} / \mathrm{kg}^{\mathrm{g}, \mathrm{h}}$ & & & \\
\hline \multirow{2}{*}{ Sodium } & Water & $6010 \mathrm{~B}^{\mathrm{c}}$ & $1,000 \mu \mathrm{g} / \mathrm{L}^{\mathrm{g}, \mathrm{h}}$ & & & \\
\hline & Soil & $6010 B^{c}$ & $100 \mathrm{mg} / \mathrm{kg}^{\mathrm{g}, \mathrm{h}}$ & & & \\
\hline \multirow{2}{*}{ Strontium } & Water & $6010 B^{c}$ & $50 \mu \mathrm{g} / \mathrm{L}^{\mathrm{g}, \mathrm{h}}$ & & & \\
\hline & Soil & $6010 B^{c}$ & $1 \mathrm{mg} / \mathrm{kg}^{\mathrm{g}, \mathrm{h}}$ & & & \\
\hline \multirow{2}{*}{ Thallium } & Water & $6010 B^{c}$ & $5 \mu \mathrm{g} / \mathrm{L}^{\mathrm{g}, \mathrm{h}}$ & & & \\
\hline & Soil & $6010 \mathrm{~B}^{\mathrm{c}}$ & $0.5 \mathrm{mg} / \mathrm{kg}^{\mathrm{g}, \mathrm{h}}$ & & & \\
\hline \multirow{2}{*}{ Tin } & Water & $6010 \mathrm{~B}^{\mathrm{c}}$ & $10 \mu \mathrm{g} / \mathrm{L}^{\mathrm{g}, \mathrm{h}}$ & & & \\
\hline & Soil & $6010 B^{c}$ & $2 \mathrm{mg} / \mathrm{kg}^{\mathrm{g}, \mathrm{h}}$ & & & \\
\hline
\end{tabular}




\section{Laboratory Chemical, Toxicity Characteristic Leaching Procedure, and Radiochemistry Analytical Requirements for New Mexico Sites}

(Page 5 of 7 )

\begin{tabular}{|c|c|c|c|c|c|c|}
\hline $\begin{array}{l}\text { Parameter or } \\
\text { Analyte }\end{array}$ & $\begin{array}{l}\text { Medium or } \\
\text { Matrix }\end{array}$ & $\begin{array}{l}\text { Analytical } \\
\text { Method }\end{array}$ & $\begin{array}{c}\text { Minimum } \\
\text { Reporting Limit }\end{array}$ & $\begin{array}{l}\text { Regulatory } \\
\text { Limit }\end{array}$ & $\begin{array}{c}\text { Relative } \\
\text { Percent } \\
\text { Difference } \\
\text { (RPD) }^{\mathrm{a}} \\
\end{array}$ & $\begin{array}{c}\text { Percent } \\
\text { Recovery } \\
(\% R)^{\mathrm{b}}\end{array}$ \\
\hline \multirow{2}{*}{ Titanium } & Water & $6010 \mathrm{~B}^{\mathrm{c}}$ & $20 \mu \mathrm{g} / \mathrm{L}^{\mathrm{g}, \mathrm{h}}$ & \multirow{8}{*}{ NA } & \multirow{8}{*}{$20^{\mathrm{h}}$} & \multirow{8}{*}{$75-125^{h}$} \\
\hline & Soil & $6010 \mathrm{~B}^{\mathrm{c}}$ & $1 \mathrm{mg} / \mathrm{kg}^{\mathrm{g}, \mathrm{h}}$ & & & \\
\hline \multirow{2}{*}{ Uranium } & Water & $6010 \mathrm{~B}^{\mathrm{c}}$ & $20 \mu \mathrm{g} / \mathrm{L}^{\mathrm{g}, \mathrm{h}}$ & & & \\
\hline & Soil & $6010 \mathrm{~B}^{\mathrm{c}}$ & $20 \mathrm{mg} / \mathrm{kg}^{\mathrm{g}, \mathrm{h}}$ & & & \\
\hline \multirow{2}{*}{ Vanadium } & Water & $6010 \mathrm{~B}^{\mathrm{c}}$ & $10 \mu \mathrm{g} / \mathrm{L}^{\mathrm{g}, \mathrm{h}}$ & & & \\
\hline & Soil & $6010 \mathrm{~B}^{\mathrm{c}}$ & $1 \mathrm{mg} / \mathrm{kg}^{\mathrm{g}, \mathrm{h}}$ & & & \\
\hline \multirow{2}{*}{ Zinc } & Water & $6010 \mathrm{~B}^{\mathrm{c}}$ & $20 \mu \mathrm{g} / \mathrm{L}^{\mathrm{g}, \mathrm{h}}$ & & & \\
\hline & Soil & $6010 \mathrm{~B}^{\mathrm{c}}$ & $2 \mathrm{mg} / \mathrm{kg}^{\mathrm{g}, \mathrm{h}}$ & & & \\
\hline \multicolumn{7}{|l|}{$\begin{array}{l}\text { TCLP RCRA } \\
\text { Metals }\end{array}$} \\
\hline Arsenic & \multirow{8}{*}{ Aqueous } & \multirow{8}{*}{$\begin{array}{l}1311 / 6010 B^{c} \\
1311 / 7470 A^{c}\end{array}$} & $0.10 \mathrm{mg} / \mathrm{L}^{\mathrm{g}, \mathrm{h}}$ & $5 \mathrm{mg} / \mathrm{L}^{\mathrm{d}}$ & \multirow{10}{*}{$20^{\mathrm{h}}$} & \multirow{10}{*}{$75-125^{h}$} \\
\hline Barium & & & $2 \mathrm{mg} / \mathrm{L}^{\mathrm{g}, \mathrm{h}}$ & $100 \mathrm{mg} / \mathrm{L}^{\mathrm{d}}$ & & \\
\hline Cadmium & & & $0.05 \mathrm{mg} / \mathrm{L}^{\mathrm{g}, \mathrm{h}}$ & $1 \mathrm{mg} / \mathrm{L}^{\mathrm{d}}$ & & \\
\hline Chromium & & & $0.10 \mathrm{mg} / \mathrm{L}^{\mathrm{g}, \mathrm{h}}$ & $5 \mathrm{mg} / \mathrm{L}^{\mathrm{d}}$ & & \\
\hline Lead & & & $0.03 \mathrm{mg} / \mathrm{L}^{\mathrm{g}, \mathrm{h}}$ & $5 \mathrm{mg} / \mathrm{L}^{\mathrm{d}}$ & & \\
\hline Mercury & & & $0.002 \mathrm{mg} / \mathrm{L}^{\mathrm{g}, \mathrm{h}}$ & $0.2 \mathrm{mg} / \mathrm{L}^{\mathrm{d}}$ & & \\
\hline Selenium & & & $0.05 \mathrm{mg} / \mathrm{L}^{\mathrm{g}, \mathrm{h}}$ & $1 \mathrm{mg} / \mathrm{L}^{\mathrm{d}}$ & & \\
\hline Silver & & & $0.10 \mathrm{mg} / \mathrm{L}^{\mathrm{g}, \mathrm{h}}$ & $5 \mathrm{mg} / \mathrm{L}^{\mathrm{d}}$ & & \\
\hline \multirow{2}{*}{ Cyanide } & Water & \multirow{2}{*}{$9010 \mathrm{~B}^{\mathrm{c}}$} & $0.01 \mathrm{mg} / \mathrm{L}^{\mathrm{h}}$ & \multirow{2}{*}{ NA } & & \\
\hline & Soil & & $1.0 \mathrm{mg} / \mathrm{kg}^{\mathrm{h}}$ & & & \\
\hline \multirow[b]{2}{*}{ Sulfide } & Water & \multirow[b]{2}{*}{$9030 \mathrm{~B} / 9034^{\mathrm{c}}$} & $0.4 \mathrm{mg} / \mathrm{L}^{\mathrm{c}}$ & \multirow[b]{2}{*}{ NA } & \multirow{4}{*}{ Lab-specific $^{f}$} & \multirow{4}{*}{ Lab-specific } \\
\hline & $\begin{array}{c}\text { Soil or } \\
\text { Sediment }\end{array}$ & & $10 \mathrm{mg} / \mathrm{kg}^{\mathrm{g}}$ & & & \\
\hline \multirow{2}{*}{$\mathrm{pH} /$ Corrosivity } & Water & $9040 B^{c}$ & \multirow{2}{*}{ NA } & $\mathrm{pH}>2^{\mathrm{i}}$ & & \\
\hline & Soil & $9045 C^{c}$ & & $\mathrm{pH}<12.5^{\mathrm{i}}$ & & \\
\hline \multirow[b]{2}{*}{ Ignitability } & Water & $1010^{c}$ & \multirow[b]{2}{*}{ NA } & $\begin{array}{c}\text { Flash Point } \\
<140^{\circ} F^{d}\end{array}$ & \multirow[b]{2}{*}{ NA } & \multirow[b]{2}{*}{ NA } \\
\hline & Soil & $1030^{c}$ & & $\begin{array}{c}\text { Burn Rate }^{c} \\
>2.2 \mathrm{~mm} / \mathrm{sec} \\
\text { nonmetals; } \\
>0.17 \mathrm{~mm} / \mathrm{sec} \\
\text { metals }\end{array}$ & & \\
\hline \multirow{2}{*}{$\begin{array}{l}\text { Total Dissolved } \\
\text { Solids }\end{array}$} & Water & 16019 & I ah-snecific & \multirow{4}{*}{ NA } & \multirow{2}{*}{ Lab-specific } & \multirow{2}{*}{$80-120$} \\
\hline & Soil & 100.1 & Lan-opecion & & & \\
\hline \multirow{2}{*}{ Bromide } & Water & EPA 300.0 & $100 \mu \mathrm{g} / \mathrm{L}^{\mathrm{g}}$ & & 15 & $85-115$ \\
\hline & Soil & EPA 300.0 & $2 \mathrm{mg} / \mathrm{kg}^{\mathrm{g}}$ & & T & שו \\
\hline
\end{tabular}




\section{Laboratory Chemical, Toxicity Characteristic Leaching Procedure, and Radiochemistry Analytical Requirements for New Mexico Sites}

(Page 6 of 7 )

\begin{tabular}{|c|c|c|c|c|c|c|}
\hline $\begin{array}{l}\text { Parameter or } \\
\text { Analyte }\end{array}$ & $\begin{array}{l}\text { Medium or } \\
\text { Matrix }\end{array}$ & $\begin{array}{l}\text { Analytical } \\
\text { Method }\end{array}$ & $\begin{array}{l}\text { Minimum } \\
\text { Reporting Limit }\end{array}$ & $\begin{array}{l}\text { Regulatory } \\
\text { Limit }\end{array}$ & $\begin{array}{c}\text { Relative } \\
\text { Percent } \\
\text { Difference } \\
\text { (RPD) }^{\mathrm{a}} \\
\end{array}$ & $\begin{array}{c}\text { Percent } \\
\text { Recovery } \\
(\% \mathrm{R})^{\mathrm{b}}\end{array}$ \\
\hline \multirow{2}{*}{ Chloride } & Water & EPA 300.0 & $200 \mu \mathrm{g} / \mathrm{L}^{\mathrm{g}}$ & \multirow{8}{*}{ NA } & \multirow{4}{*}{20} & \multirow{2}{*}{$75-115$} \\
\hline & Soil & EPA 300.0 & $2 \mathrm{mg} / \mathrm{kg}^{\mathrm{g}}$ & & & \\
\hline \multirow{2}{*}{ Fluoride } & Water & EPA 300.0 & $200 \mu \mathrm{g} / \mathrm{L}^{\mathrm{g}}$ & & & $80-120$ \\
\hline & Soil & EPA 300.0 & $2 \mathrm{mg} / \mathrm{kg}^{\mathrm{g}}$ & & & $00-1<0$ \\
\hline \multirow{2}{*}{ Nitrate as $\mathrm{NO}_{3}$} & Water & EPA 300.0 & $200 \mu \mathrm{g} / \mathrm{L}^{\mathrm{g}}$ & & \multirow{4}{*}{15} & \multirow{4}{*}{$85-115$} \\
\hline & Soil & EPA 300.0 & $2 \mathrm{mg} / \mathrm{kg}^{\mathrm{g}}$ & & & \\
\hline \multirow{2}{*}{ Sulfate } & Water & EPA 300.0 & $1,000 \mu \mathrm{g} / \mathrm{L}^{\mathrm{g}}$ & & & \\
\hline & Soil & EPA 300.0 & $2 \mathrm{mg} / \mathrm{kg}^{\mathrm{g}}$ & & & \\
\hline \multicolumn{7}{|c|}{ RADIOCHEMISTRY } \\
\hline \multirow{2}{*}{$\begin{array}{l}\text { Gamma-emitting } \\
\text { Radionuclides }\end{array}$} & Water & EPA $901.1^{k}$ & \multirow{2}{*}{ Isotope-specific ${ }^{\mathrm{m}}$} & \multirow{2}{*}{ NA } & 20 & \multirow{10}{*}{$\begin{array}{c}\text { Tracer Yield } \\
30-105 \\
\text { Laboratory } \\
\text { Control } \\
\text { Sample Yield } \\
80-120\end{array}$} \\
\hline & Soil/Biota & HASL 300' & & & 35 & \\
\hline \multirow{2}{*}{$\begin{array}{l}\text { Isotopic } \\
\text { Plutonium }\end{array}$} & Water & $\begin{array}{c}\text { HASL } 300^{\prime} \text { or } \\
\text { ASTM D3865-97 }^{\mathrm{n}}\end{array}$ & $0.1 \mathrm{pCi} / \mathrm{L}$ & \multirow{2}{*}{ NA } & 20 & \\
\hline & Soil/Biota & $\begin{array}{c}\text { HASL } 300^{\prime} \text { or } \\
\text { ASTM C1001-90 }\end{array}$ & $0.05 \mathrm{pCi} / \mathrm{g}$ & & 35 & \\
\hline \multirow{2}{*}{$\begin{array}{l}\text { Isotopic } \\
\text { Uranium }\end{array}$} & Water & HASL 300' & $0.1 \mathrm{pCi} / \mathrm{L}$ & \multirow{2}{*}{ NA } & 20 & \\
\hline & Soil/Biota & HASL $300^{1}$ & $0.05 \mathrm{pCi} / \mathrm{g}$ & & 35 & \\
\hline \multirow{2}{*}{ Strontium - $90^{\mathrm{j}}$} & Water & & $1 \mathrm{pCi} / \mathrm{L}$ & \multirow{2}{*}{ NA } & 20 & \\
\hline & Soil/Biota & ASTM D5811-95 & $0.5 \mathrm{pCi} / \mathrm{g}$ & & 35 & \\
\hline \multirow{2}{*}{ Americium-241 } & Water & ASTM D3972 & $0.1 \mathrm{pCi} / \mathrm{L}$ & \multirow{2}{*}{ NA } & 20 & \\
\hline & Soil/Biota & ASTM 90M & $0.05 \mathrm{pCi} / \mathrm{g}$ & & 35 & \\
\hline \multirow{2}{*}{ Gross Alpha } & Water & EPA $900.0^{k}$ & $4 \mathrm{pCi} / \mathrm{L}$ & \multirow{2}{*}{ NA } & 20 & \multirow{6}{*}{$\begin{array}{l}\text { Laboratory } \\
\text { Control } \\
\text { Sample Yield } \\
80-120\end{array}$} \\
\hline & Soil & Lab Specific $^{\circ}$ & $4 \mathrm{pCi} / \mathrm{g}$ & & 35 & \\
\hline \multirow{2}{*}{ Gross Beta } & Water & EPA $900.0^{k}$ & $4 \mathrm{pCi} / \mathrm{L}$ & \multirow{2}{*}{ NA } & 20 & \\
\hline & Soil & Lab Specific ${ }^{\circ}$ & $4 \mathrm{pCi} / \mathrm{g}$ & & 35 & \\
\hline \multirow{2}{*}{ Tritium } & Water & EPA $900.0^{k}$ & $400 \mathrm{pCi} / \mathrm{L}$ & \multirow{2}{*}{ NA } & 35 & \\
\hline & Soil & EERFH01 ${ }^{p}$ & $5 \mathrm{pCi} / \mathrm{g}$ & & 20 & \\
\hline \multirow{2}{*}{ Radium-226/228 } & Water & PAI SOP $712 / 746$ & $1 \mathrm{pCi} / \mathrm{L}$ & $3 \mathrm{pCi} / \mathrm{L}$ & 20 & $75-125$ \\
\hline & Soil & PAI SOP 739 & $0.5 \mathrm{pCi} / \mathrm{g}$ & $5 \mathrm{pCi} / \mathrm{g}$ & 30 & $85-115$ \\
\hline Carbon-14 & Water & Lab Specific $^{\circ}$ & $\begin{array}{l}1 \text { Percent Modern } \\
\text { Carbon }\end{array}$ & NA & $\begin{array}{c}\text { Modern } \\
\text { Carbon }{ }^{r}\end{array}$ & $\begin{array}{l}\text { Within } \\
1 \text { Percent } \\
\text { Modern } \\
\text { Carbon }\end{array}$ \\
\hline
\end{tabular}




\section{Laboratory Chemical, Toxicity Characteristic Leaching Procedure, and Radiochemistry Analytical Requirements for New Mexico Sites} (Page 7 of 7 )

\begin{tabular}{|c|c|c|c|c|c|c|}
\hline \multicolumn{7}{|c|}{ STABLE ISOTOPES } \\
\hline Carbon-13 & \multirow{3}{*}{ Water } & \multirow{3}{*}{ Lab Specific $^{\circ}$} & \multirow{3}{*}{$N A^{t}$} & \multirow{3}{*}{ NA } & & \multirow{2}{*}{$\begin{array}{c}\text { Within } 0.4 \text { per } \\
\text { mil of } \\
\text { Standard }^{\text {s }}\end{array}$} \\
\hline Oxygen-18 & & & & & $+/-0.2$ per mil ${ }^{1}$ & \\
\hline Deuterium & & & & & $+/-1$ per mil ${ }^{\mathrm{r}}$ & $\begin{array}{l}\text { Within } 2 \text { per mil } \\
\text { of Standard }\end{array}$ \\
\hline
\end{tabular}

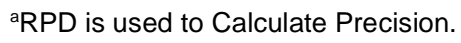

Precision is estimated from the relative percent difference of the concentrations measured for the matrix spike and matrix spike duplicate analyses of unspiked field samples, or field duplicates of unspiked samples. It is calculated by:

$R P D=100 \times\left\{\left(\left|C_{1}-C_{2}\right|\right) /\left[\left(C_{1}+C_{2}\right) / 2\right]\right\}$, where $C_{1}=$ Concentration of the analyte in the first sample aliquot, $C_{2}=$ Concentration of the analyte in the second sample aliquot.

b\% $R$ is used to Calculate Accuracy.

Accuracy is assessed from the recovery of analytes spiked into a blank or sample matrix of interest, or from the recovery of surrogate compounds spiked into each sample. The recovery of each spiked analyte is calculated by: $\% R=100 \times\left(C_{s}-C_{u} / C_{n}\right)$, where $\mathrm{C}_{\mathrm{s}}=$ Concentration of the analyte in the spiked sample, $\mathrm{C}_{\mathrm{u}}=$ Concentration of the analyte in the unspiked sample,

$\mathrm{C}_{\mathrm{n}}=$ Concentration increase that should result from spiking the sample

'U.S. Environmental Protection Agency's (EPAs) Test Methods for Evaluating Solid Waste, 3rd Edition, Parts 1-4, SW-846 (EPA, 1996)

'Estimated Quantitation Limit as given in SW-846 (EPA, 1996)

eEPA Contract Laboratory Program Statement of Work for Organic Analysis (EPA, 1988b; and 1991)

' In-House Generated RPD and \%R Performance Criteria

It is necessary for laboratories to develop in-house performance criteria and compare them to those in the methods. The laboratory begins by analyzing 15-20 samples of each matrix and calculating the mean \%R for each analyte. The standard deviation (SD) of each \%R is then calculated, and the warning and control limits for each analyte are established at \pm 2 SD and \pm 3 SD from the mean, respectively. If the warning limit is exceeded during the analysis of any sample delivery group (SDG), the laboratory institutes corrective action to bring the analytical system back into control. If the control limit is exceeded, the sample results for that SDG are considered unacceptable. These limits are reviewed after every 20-30 field samples of the same matrix and are updated at least semiannually. The laboratory tracks trends in both performance and control limits by the use of control charts. The laboratory's compliance with these requirements is confirmed as part of an annual laboratory audit. Similar procedures are followed in order to generate acceptance criteria for precision measurements.

${ }^{9}$ Minimum reporting level as directed to laboratory by contractor.

hEPA Contract Laboratory Program Statement of Work for Inorganic Analysis (EPA, 1988a; and 1994a)

'RCRA Regulations and Keyword Index, 1998 Edition

Isotopic minimum detectable concentrations are defined during the DQO process and specified in the CAIP, as applicable.

${ }^{\mathrm{k}}$ Prescribed Procedures for Measurements of Radioactivity in Drinking Water (EPA, 1980) or equivalent method

'Environmental Measurements Laboratory Procedures Manual (DOE, 1997) or equivalent method

mIsotope-Specific Minimum Reporting Limit to be specified in the work plan

${ }^{\mathrm{n}}$ American Society for Testing and Materials, or equivalent method.

'Laboratory-Specific Method, as preapproved by Analytical Services

PU.S. Environmental Protection Agency, Eastern Environmental Radiation Facility

${ }^{9}$ Standard Methods for the Examination of Water and Waste Water (APHA, 1995)

${ }^{\mathrm{r}}$ Measure of precision as directed to the laboratory by contractor.

${ }^{5}$ Measure of accuracy as directed to the laboratory by contractor.

${ }^{\mathrm{t}} \mathrm{A}$ ratio is reported; therefore, a minimum reporting limit is not applicable.

Definitions:

$\mu \mathrm{g} / \mathrm{kg}=$ Microgram(s) per kilogram $\mathrm{mg} / \mathrm{kg}=$ Milligram(s) per kilogram

$\mathrm{pCi} / \mathrm{L}=$ Picocurie(s) per liter $\mathrm{mg} / \mathrm{L}=$ Milligram(s) per liter $\mathrm{pCi} / \mathrm{g}=$ Picocurie(s) per gram $\mu \mathrm{g} / \mathrm{L}=$ Microgram(s) per liter 


\section{Table References}

APHA, see American Public Health Association.

American Public Health Association. 1995. Standard Methods for the Examination of Water and Waste Water, 19th Edition. Washington, DC.

RCRA Regulations and Keyword Index. 1998. ISSN 1074-1364. New York, NY: Elsevier Science, Inc.

U.S. Department of Energy. 1997. Environmental Measurements Laboratory Procedures Manual, HASL-300, 28th Edition, Vol. 1. New York, NY.

U.S. Environmental Protection Agency. 1980. Prescribed Procedures for Measurements of Radioactivity in Drinking Water, EPA-600/4-80-032. Washington, DC.

U.S. Environmental Protection Agency. 1988a. USEPA Contract Laboratory Program Statement of Work for Inorganic Analysis, SOW No. 788, EPA/540/R-94/093. Washington, DC.

U.S. Environmental Protection Agency. 1988b. USEPA Contract Laboratory Program Statement of Work for Organic Analysis, SOW No. 2/88, EPA/540/R-94/096. Washington, DC.

U.S. Environmental Protection Agency. 1991. USEPA Contract Laboratory Program Statement of Work for Organic Analysis, OLMO 1.8, EPA/540/R-94/078. Washington, DC.

U.S. Environmental Protection Agency. 1994a. USEPA Contract Laboratory Program Statement of Work for Inorganic Analysis, ILMO 3.0, EPA/540/R-94/076. Washington, DC.

U.S. Environmental Protection Agency. 1996. Test Methods for Evaluating Solid Waste, Physical/Chemical Methods, SW-846, $3^{\text {rd }}$ Edition, CD-ROM PB97-501928GEI. Washington, DC. 
Appendix C

\section{Radiological Screening Evaluation for the Gnome-Coach Site}




\section{C.1.0 Introduction}

This appendix provides an evaluation of the overall baseline human health effects of exposure to radionuclides of potential concern in surface and shallow subsurface soil at the Gnome-Coach Site, and summarizes the areas of potential concern for additional data collection. Groundwater at the Gnome-Coach Site is not potable for humans; therefore, was not evaluated in this assessment. This assessment focuses on the potential radionuclide dose at the surface, and justifies, if necessary, the need for additional radiological soil data collection. The input parameters and concentrations used in this evaluation are preliminary and may change in the final dose assessment following site characterization. In addition, the parameters may be refined based on collection of new data.

On December 10, 1961, the DOE detonated a 3-kiloton nuclear device approximately 25 miles southwest of Carlsbad, New Mexico. The Gnome test took place at a depth of 1,184 ft bgs in the bedded salts of the Salado Formation. Contamination occurred at the ground surface when venting from the shaft occurred a few minutes following the shot and continued for approximately 24 hours. In addition, several holes were drilled for reentry into the shot cavity that also resulted in surface contamination when radionuclides were entrained in the drilling fluids and soil borings and disposed of at the ground surface (Earman et al., 1996; Cooper and Glanzman, 1971; Gardner and Sigalove, 1970; USGS, 1962). Additionally, decontamination and decommissioning activities contributed to the surface contamination (Tappan and Lorenz, 1969; DOE/NV, 1978 and 1981).

The human health risk/dose assessment is an estimation of potential risk that may occur at the Gnome-Coach Site under current and future use conditions in order to determine the need for additional soil data collection. This dose assessment was performed in accordance with regulatory guidance using the Residual Radiation (RESRAD) computer code (Version 5.95) (ANL, 1993b). 


\section{C.2.0 Identification of Radionuclides of Potential Concern}

Five on-site surface radiological sampling and survey programs were conducted after the Gnome-Coach Site was deactivated in 1968. Two of the sampling programs were in conjunction with the major restoration efforts in 1968-1969 (Carlsbad Site Roll-Up Program [Tappan and Lorenz, 1969]) and 1977-1979 (Gnome Site D\&D Report-Phase I [DOE/NV, 1978] and Gnome Site D\&D Clearance Report [DOE/NV, 1981]). The third sampling program was conducted during the 1972 site reconnaissance survey (REECo, 1973). The fourth sampling/survey program was conducted in 1992 by the EPA for a surface characterization study (Residual Soil Radioactivity at the Gnome Site [EPA, 1994]). The fifth soil sample/survey program was conducted in 1994-1995 by the EEG for the purpose of obtaining information for a study on long-term trends in radionuclide transport in the area surrounding the WIPP (Radionuclide Baseline in Soil Near Project Gnome and the Waste Isolation Pilot Plant [EEG, 1995]). The results of the most recent and complete sampling programs are carried through this dose assessment. This includes the Phase I, II, and III radiation surveys of the 1979 restoration effort. All of the sampling and survey program results are summarized in detail in Appendix A of this Work Plan.

\section{C.2.1 Summary of Impacted Areas}

The Gnome-Coach Site has 18 potentially impacted areas from radiological contamination. A brief summary for each of these potentially impacted areas is presented below.

\section{Contaminated Waste Dump}

The CWD was used for the burial of radiologically contaminated soil and debris (e.g., metal, wood, salt muck, insulated wiring) generated from the Gnome mine-back operations. During the 1969 CWD cleanup, four burial pits were identified within the waste dump containing contaminated soil and debris measuring greater than $0.1 \mathrm{mR} / \mathrm{hr}$. This material was removed and disposed of in the shaft and Coach drift (Tappan and Lorenz, 1969). During the 1979 cleanup, additional contaminated soil and debris above the established 1979 cleanup levels was removed from the CWD and disposed of in the Gnome cavity (DOE/NV, 1981). 


\section{Salvage Yard}

The salvage yard was used to store salvaged material during Gnome-Coach Site operations and may potentially contain mud pits from well drilling. Metal scrap and debris were left in place after the 1968-1969 cleanup effort. Soil samples taken during the 1972 reconnaissance revealed gross gamma activity ranging from 4.5 to $46 \mathrm{pCi} / \mathrm{g}$. Scrap metal and burned debris were excavated and disposed of in the test cavity during the 1977-1979 cleanup effort. Only the burned debris were found to have elevated radiological levels during cleanup.

\section{Warehouse Area}

The warehouse was used to store hand tools and equipment, no other uses were identified. Radiologically contaminated material and concrete were removed from the warehouse during the 1968-1969 cleanup (Tappan and Lorenz, 1969). Buried scrap metal was uncovered during 1977-1979 cleanup and disposed of either in the Gnome cavity or shipped to the NTS.

\section{Waste Tank - Evaporation Pond}

The evaporation pond and liquid waste tank were utilized as part of the power measurement program at SGZ. During this program, contaminated liquid waste was generated and pumped from the cavity to the waste tank and evaporation pond. During 1968-1969 cleanup (Tappan and Lorenz, 1969), all the liquid waste from the tank and pond was pumped into the Gnome cavity. An additional $12 \mathrm{ft}$ of soil beneath the liner was contaminated and removed. This material was disposed of in the Gnome cavity.

\section{Gnome SGZ, SR-3A, and DD-1 Monitoring Well}

This AOC includes an area measuring 200 x $200 \mathrm{ft}$ and was used for posttest drilling operations of reentry Wells SR-2A and SR-3A (DOE/NV, 1978). This area may potentially contain mud pits from well drilling. Well DD-1 was also installed at this location in July of 1979 to provide access to the Gnome cavity for the disposal of the salt/soil slurry from decommissioning operations. Well DD-1 was not plugged after its use, but remained open for the LTHMP. Radiological contamination of the SGZ and Well DD-1 area occurred as a result of drill-back operations into the shot cavity and the 
slurry disposal operations. Sample results from SGZ, SR-3A, and DD-1 were combined for this summary because of the overlap in geographic location.

\section{Decontamination Pad}

A decontamination pad was used for the decontamination of equipment and facilities associated with Gnome-Coach Site during posttest activities (DOE/NV, 1978). Decontamination techniques included high-pressure detergent washing, vacuuming, and the use of solvents (AEC, 1962).

\section{Old Laundry/Laboratory}

Laundry decontamination and counting laboratory activities were performed at this facility during the drill-back activities. Sections of the area were contaminated by material spilled from trucks which hauled contaminated waste during the 1968-1969 cleanup. The area was subsequently cleaned up in 1979 (DOE/NV, 1978). At the end of 1977-1979 cleanup activities, about 6,000 $\mathrm{y}^{3}$ of uncontaminated salt was buried in a $380 \times 95 \times 12 \mathrm{ft}$ trench in this area and covered with crushed concrete and $6 \mathrm{ft}$ of clean soil.

\section{New Laundry/Laboratory}

This facility was built to provide a more centralized location for laundry and radiochemical laboratory activities. The principal radiological contamination of this facility was found in the subsurface at the sump area (DOE/NV, 1978). During the 1977-1979 cleanup, one trench was dug across the New Laundry/Lab sump area to determine the area encompassed by the sump (DOE/NV, 1978).

\section{Salt Muckpile}

Mine tailings from the construction of the Gnome drift and shaft were placed approximately $100 \mathrm{ft}$ north of the shaft. After the Gnome test, low-level radiologically contaminated salt from Gnome reentry operations was deposited on top, then clean salt from the Coach drift construction was placed over this (DOE/NV, 1978). The salt muckpile eventually encompassed an area of approximately 140,000 $\mathrm{ft}^{2}$. The muckpile was left in place following the 1969 cleanup. The radiologically 
contaminated salt muck was later removed during the 1979 cleanup by injection into the Gnome cavity or disposal as solid waste at the NTS (DOE/NV, 1981).

\section{Gnome-Coach Shaft Surface Area}

The ground area surrounding the shaft was used for posttest drilling operations and Project Coach construction. Radiological contamination of soil and equipment resulted from the venting episode following the Gnome detonation, posttest drill-back operations, and disposal of contaminated materials during cleanup efforts. Radiologically contaminated material and equipment were disposed of down the shaft. At the completion of disposal operations into the shaft, the concrete shaft collar was demolished with explosives to a depth of $5 \mathrm{ft}$ prior to setting a permanent concrete plug. The destruction of the collar deposited small contaminated concrete and soil particles on the surface; however, the material was excavated and disposed of in the shaft.

\section{Venting Fallout Track}

During the execution of Gnome in 1961, radioactive gas vented through the shaft and low-level fallout occurred in a northwest, downwind direction. The 1977 and 1979 aerial radiological surveys (DOE/NV, 1981) and 1994 EPA soil sample results (EPA, 1994) show the highest concentration of residual gamma contamination at a small area about $490 \mathrm{ft}$ northwest of the shaft. The EEG surveys (EEG, 1995) confirmed residual contamination in the same approximate area. The surface radiological contamination associated with the venting episode only extends a short distance from the shaft. However, small particles from demolishing the shaft collar during cleanup may also contribute to isolated contaminated locations.

\section{Equipment Storage Area}

This area was used as a holding area for tunneling equipment and may have been used as a sand-blasting area for the radiologically contaminated drill pipe (DOE/NV, 1978). The results of the DOE final status survey indicate that surface radiological contamination does not exist at this AOC. 


\section{Area 57}

This site became of interest during the 1977 Phase I investigation when surface radiation levels above background were measured. Contamination in this area was supposedly due to runoff from one of the contaminated areas closely associated with this area (DOE/NV, 1978). It is important to note that Area 57 is referred to as NFCS in the 1979 Phase II/III sampling program.

\section{Road Between the Salvage Yard and the CWD}

A dirt road approximately $700 \mathrm{ft}$ long existed in front of the Salvage Yard and the CWD. The road between these two areas of concern was contaminated during the mine-back operations when contaminated soil and debris was transported to and from the CWD and/or salvage yard from other areas of the site (DOE/NV, 1978).

\section{Crusher Plant}

A crushing and slurry facility (consisting of crushers, conveyor belts, and mixing tanks) was set up on the north side of the salt muckpile during the 1979 final phase of cleanup. The crusher reduced solids (salt muck and soil) to a size which could be mixed with gel-water to form a slurry that was subsequently pumped from mixing tanks into a disposal well.

\section{LRL-7 Drill Pad Area}

The LRL-7 hole was originally drilled as a cable hole into the Coach drift for the Project Coach experiment (DOE/NV, 1979). The hole was subsequently used to slurry contaminated salt/soil into the cavity during the 1969 cleanup (DOE/NV, 1979). Hole LRL-7 was redrilled and opened during the 1977-1979 cleanup effort. Reportedly a screen system was installed over a return pit and cement cuttings were collected and later injected into the cavity with the salt muck (DOE/NV, 1979). Hole LRL-7 was then configured to support the slurry operations in 1979 by hooking up a recirculating system to the Gnome cavity with a water line between the hole, SR-2A, and later DD-1 (DOE/NV, 1979 and 1981). The well was left open at the completion of cleanup efforts so that it could be used as part of the LTHMP. Sample results from the water line area have been included with LRL-7 sample data. 


\section{LRL-8 Drill Pad Area}

Hole LRL-8, located about $300 \mathrm{ft}$ southeast of the main shaft, was used for downhole disposal of contaminated slurried salt/soil during both cleanup efforts. Analytical results from the 1979 sampling programs under the heading "Study 32" have been identified as the area surrounding the LRL-8 hole, based on location coordinates. Hole LRL-8 was reported as being plugged and abandoned during the 1977-1979 cleanup operations (DOE/NV, 1979).

\section{Monitoring Wells USGS-4 and USGS-8 Surface Area}

In 1963, the USGS conducted a hydrologic tracer test in which Cs-137, tritium, I-131 and Sr-90 were injected into the Culebra aquifer at Well USGS-8 and pumped from Well USGS-4 (with subsequent reinjection in USGS-8). The soil surrounding the wells may have become contaminated during the reinjection phase of the tracer test. Both of these wells are sampled annually by EPA as part of the LTHMP.

\section{C.2.2 Analytical Data Used for Dose/Risk Calculations}

The analytical data for each of the potential impacted areas is summarized in Appendix A of the Gnome-Coach Work Plan. As summarized in Appendix A of the Gnome-Coach Work Plan, the primary radionuclide of concern is Cs-137. Both maximum (to characterize potential hot spots) and 95 percent UCL of the mean (to characterize an AOC as a whole) concentrations for each of the impacted areas will be evaluated in this dose assessment. These concentrations were used to obtain conservative values for dose/risk to the receptor. Although not used in this screening evaluation, a more representative dose may be obtained by using the mean concentration of each impacted area. Therefore, the use of the mean concentration will be evaluated at the completion of the site characterization and possibly revised in the final dose assessment. It is important to note that the concentrations measured at an AOC may change based on newly collected data and will be used in the final dose assessment following the characterization work.

If the 95 percent $\mathrm{UCL}$ of the mean concentration is greater than the maximum concentration of a given area, only the maximum concentration was evaluated in the dose assessment. Table C.2-1 summarizes the surface soil analytical data for each of the potentially impacted areas. Table C.2-2 provides the volume-weighted average concentrations for each of the potentially impacted areas that 
had shallow subsurface soil data analyzed. All of the sampling results presented in Table C.2-1 and Table C.2-2 were measured between 1977 and 1979. To account for radioactive decay in this evaluation, it was assumed that all of the sampling occurred in 1979. The radionuclide input concentrations were decay corrected to the present for the dose assessment.

Table C.2-1

\section{Gnome-Coach Phase I, II and III Surface Soil Analysis Results}

(Page 1 of 2)

\begin{tabular}{|c|c|c|c|c|c|c|}
\hline Sampling Areas & $\begin{array}{c}\text { Estimated Site } \\
\text { Areas }\left(m^{2}\right)\end{array}$ & $\begin{array}{l}\text { Approximate } \\
\text { Length of } \\
\text { Parallel } \\
(\mathrm{m})^{\mathrm{a}}\end{array}$ & $\begin{array}{c}95 \% \text { Upper } \\
\text { Confidence } \\
\text { Level (UCL) } \\
\text { Cs-137 Surface } \\
\text { Concentrations } \\
\text { (pCi/g) }\end{array}$ & $\begin{array}{c}\text { Maximum } \\
\text { Cs-137 Surface } \\
\text { Concentrations } \\
(\mathrm{pCi} / \mathrm{g})\end{array}$ & $\begin{array}{c}95 \% \text { Upper } \\
\text { Confidence } \\
\text { Level (UCL) } \\
\text { Tritium } \\
\text { Concentrations } \\
\text { (pCi/mL) }\end{array}$ & $\begin{array}{c}\text { Maximum } \\
\text { Tritium } \\
\text { Concentrations } \\
(\mathrm{pCi} / \mathrm{mL})\end{array}$ \\
\hline $\begin{array}{l}\text { 1.Contaminated } \\
\text { Waste Dump }\end{array}$ & 13,935 & 180 & 6.02 & 60 & $N A^{b}$ & 25,300 \\
\hline 2.Salvage Yard & 5,574 & 113 & 12.36 & 76.3 & NA & 117 \\
\hline $\begin{array}{c}\text { 3.Warehouse } \\
\text { Area }\end{array}$ & 5,574 & 113 & 49.00 & 201 & NA & NA \\
\hline $\begin{array}{l}\text { 4. Waste Tank - } \\
\text { Evaporation } \\
\text { Pond }\end{array}$ & 929 & 41 & 6.78 & 37.9 & NA & 28 \\
\hline $\begin{array}{c}\text { 5.Gnome SGZ + } \\
\text { DD-1 + SR-3A }\end{array}$ & 3,716 & 84 & 5.36 & 39 & NA & 2,090 \\
\hline $\begin{array}{c}6 . \\
\text { Decontamination } \\
\text { Pad }\end{array}$ & 929 & 41 & 7.80 & 23.10 & 1,530 & 2,360 \\
\hline $\begin{array}{l}\text { 7.Laundry/Lab } \\
\text { Old (Phase 1B) }\end{array}$ & 1,858 & 72 & 8.15 & 28.90 & NA & 93.2 \\
\hline $\begin{array}{c}\text { 8.Laundry/Lab } \\
\text { New }\end{array}$ & 520 & 30 & 1,733 & 28,100 & 205 & 473 \\
\hline 9.Salt Muckpile & 13,006 & 168 & 7.34 & 95.30 & NA & 722 \\
\hline $\begin{array}{c}10 . \\
\text { Gnome-Coach } \\
\text { Shaft Surface } \\
\text { Area }\end{array}$ & 5314 & 101 & 8.72 & 465 & NA & 1,160 \\
\hline $\begin{array}{l}\text { 11.Fallout Track } \\
\text { from Venting }\end{array}$ & 81,755 & 1,135 & 29.33 & 370 & NA & 38 \\
\hline $\begin{array}{c}\text { 12. Equipment } \\
\text { Storage Area } \\
\text { (Phase 1B) }\end{array}$ & 929 & 41 & 6.37 & 16.4 & NA & 217 \\
\hline $\begin{array}{l}\text { 13.Area } 57 \\
\text { (NFCS) }\end{array}$ & 111 & 18 & 6.1 & 14.60 & 138 & 213 \\
\hline $\begin{array}{l}\text { 14. Road } \\
\text { between the } \\
\text { Salvage Yard } \\
\text { and the CWD }\end{array}$ & 650 & $\begin{array}{l}213 \text { (assume } \\
\text { linear with } \\
\text { length of road) }\end{array}$ & 21.17 & 52.1 & NA & 117 \\
\hline
\end{tabular}


Table C.2-1

\section{Gnome-Coach Phase I, II and III Surface Soil Analysis Results} (Page 2 of 2)

\begin{tabular}{|c|c|c|c|c|c|c|}
\hline Sampling Areas & $\begin{array}{c}\text { Estimated Site } \\
\text { Areas }\left(\mathbf{m}^{2}\right)\end{array}$ & $\begin{array}{l}\text { Approximate } \\
\text { Length of } \\
\text { Parallel } \\
(\mathrm{m})^{\mathrm{a}}\end{array}$ & $\begin{array}{c}95 \% \text { Upper } \\
\text { Confidence } \\
\text { Level (UCL) } \\
\text { Cs-137 Surface } \\
\text { Concentrations } \\
\text { (pCi/g) }\end{array}$ & $\begin{array}{c}\text { Maximum } \\
\text { Cs-137 Surface } \\
\text { Concentrations } \\
\quad(p C i / g)\end{array}$ & $\begin{array}{c}95 \% \text { Upper } \\
\text { Confidence } \\
\text { Level (UCL) } \\
\text { Tritium } \\
\text { Concentrations } \\
\text { (pCi/mL) }\end{array}$ & $\begin{array}{c}\text { Maximum } \\
\text { Tritium } \\
\text { Concentrations } \\
(\mathrm{pCi} / \mathrm{mL})\end{array}$ \\
\hline $\begin{array}{c}\text { 15.USGS-8 \& } \\
\text { USGS-4 } \\
\text { Monitoring Wells }\end{array}$ & 1,858 & 72 & 13.59 & 34.1 & NA & 23,100 \\
\hline 16.Crusher Plant & 6,968 & 162 & 1.41 & 17.5 & NA & 111 \\
\hline $\begin{array}{l}\text { 17.LRL-7 Drill } \\
\text { Pad Areas }\end{array}$ & 8,361 & 131 & 3.77 & 67.1 & NA & NA \\
\hline $\begin{array}{c}\text { 18.LRL-8 Drill } \\
\text { Pad Areas }\end{array}$ & 1,329 & 60 & 3.36 & 20 & NA & NA \\
\hline
\end{tabular}

aLength of parallel is an input parameter that is area-specific and is provided here for convenience

${ }^{\mathrm{b}} \mathrm{NA}=$ Not applicable; calculated UCL greater than the maximum concentration due to the limited number of samples.

Table C.2-2

Gnome-Coach Phase I, II, and III Shallow Subsurface Soil Analysis Results

\begin{tabular}{|c|c|c|}
\hline $\begin{array}{c}\text { Gnome Sampling } \\
\text { Areas }\end{array}$ & $\begin{array}{c}\text { Range of Contaminant } \\
\text { Depth }^{\mathrm{a}} \text { (feet) }\end{array}$ & $\begin{array}{c}\text { Volume-Weighted Average } \\
\text { Cs-137 Subsurface Concentrations } \\
(\mathrm{pCi} / \mathrm{g})\end{array}$ \\
\hline $\begin{array}{l}\text { 1.Contaminated Waste } \\
\text { Dump }\end{array}$ & $0.166-16$ & 85.86 \\
\hline 2.Salvage Yard & $0.166-7$ & 6.66 \\
\hline 3.Gnome SGZ & $0.166-6$ & 25.37 \\
\hline $\begin{array}{l}\text { 4. Waste Tank - } \\
\text { Evaporation Pond }\end{array}$ & $0.166-10$ & 6.64 \\
\hline 8.Laundry/Lab New & $0.166-5$ & 38.69 \\
\hline 9.Salt Muckpile & $0.166-12$ & 223.54 \\
\hline $\begin{array}{l}\text { 10.Gnome-Coach } \\
\text { Shaft Surface Area }\end{array}$ & $0.166-6$ & 7.58 \\
\hline $\begin{array}{l}\text { 15.USGS-8 \& USGS-4 } \\
\text { Monitoring Wells }\end{array}$ & $0.166-2$ & 1.39 \\
\hline
\end{tabular}

${ }^{\mathrm{a}}$ Maximum depth of contaminant detected at each area of concern 


\section{C.3.0 Human Health Dose Assessment}

This human health assessment was performed in accordance with applicable state and federal guidance.

\section{C.3.1 Exposure Assessment}

This section identifies exposure pathways and quantifies radionuclide exposure. The purpose of this exposure assessment is to estimate the type and magnitude of exposure to humans based on existing and potential future land use. This information, in turn, will be used to refine the surface and shallow subsurface investigation strategy.

For each potentially complete exposure pathway identified in Section C.3.1.1, a reasonable maximum exposure (RME) scenario has been developed. The RME is the highest exposure that is reasonably expected to occur at a site (EPA, 1989). The intent of the RME, as defined by EPA, is to estimate a conservative exposure case (i.e., significantly exceeding the average case) that is still within the possible range of exposures. The RME is both protective and reasonable but is not the worst possible case (EPA, 1991a).

\section{C.3.1.1 Exposure Pathways}

For exposure and potential risks to occur, complete exposure pathways must exist. A complete pathway requires the following elements (EPA, 1989):

- A source and mechanism for release of contamination

- A transport or retention medium

- A point of potential human contact (exposure point)

- An exposure route at the exposure point

If any one of these elements is missing, the pathway is not considered complete. Following is a brief discussion of the exposure pathway elements.

Contamination sources and the transport/retention medium are the same as those addressed in Section C.2.0 of this appendix. However, at Gnome-Coach Site, the primary medium of concern is surface soil ( 0 to $1 \mathrm{ft}$ bgs) and shallow subsurface soil (1 to $20 \mathrm{ft}$ bgs). 
Exposure points are locations of human contact with contaminated media. Exposure points consider human activity patterns and the location of potentially exposed individuals relative to the location of contaminated media. Because the Gnome-Coach Site is in a remote area, the potential future land use for the site is recreational open space or trespasser. The current land use at the Gnome-Coach Site is ranching. Both the trespassing and ranching scenarios are examined in this assessment. To maintain the conservative methodology, the contact point for soil contamination, both surface and shallow subsurface, in all exposure scenarios is located at the contaminant source. In addition, the surface and shallow subsurface UCL and maximum concentrations at a given area of concern are carried through this dose assessment (i.e., surface and shallow subsurface soil are considered separate media). However, surface soil is considered the primary media of concern at the Gnome-Coach Site. Subsurface intrusion is restricted at the site and the shielding provided by the one foot of surface soil further limits the potential for subsurface exposure. Shallow subsurface soils are being evaluated in the screening evaluation to determine the potential need for additional data collection.

The following exposure routes were examined:

- Ingestion (soil and beef)

- Inhalation

- External exposure (includes dermal)

The potentially complete exposure pathways include exposure to surface and shallow subsurface soil. Figure 3-1 in the work plan illustrates the conceptual site model for the Gnome-Coach Site. Table C.3-1 lists the complete human exposure pathways for current and future land use. This table also indicates which pathways have been selected for risk characterization and presents the rationale for inclusion or exclusion of each pathway.

Since land use at the Gnome-Coach Site is expected to remain similar (i.e., no development is planned), future pathways will be similar to the current pathways listed above. Therefore, this risk assessment assumes that any restrictions currently in place will remain in place. Under these conditions, the current and future human health risks are identical (i.e., the pathways and receptors are the same). For the remainder of the document, these risks/doses will be linked to the same receptors with no further consideration of whether the exposure is current or future. 
Table C.3-1

Potentially Complete Human Exposure Pathways at Gnome-Coach Site

\begin{tabular}{|c|c|c|c|c|}
\hline $\begin{array}{l}\text { Environmental } \\
\text { Medium }\end{array}$ & Exposure Route & $\begin{array}{l}\text { Potentially Exposed } \\
\text { Population }\end{array}$ & $\begin{array}{l}\text { Pathway } \\
\text { Selected for } \\
\text { Evaluation }\end{array}$ & Reason for Selection or Exclusion \\
\hline Surface Soil & $\begin{array}{c}\text { Inhalation } \\
\text { Ingestion } \\
\text { External Exposure }\end{array}$ & $\begin{array}{l}\text { Residential } \\
\text { Occupational }\end{array}$ & No & $\begin{array}{c}\text { Gnome-Coach is in a remote area and the land use is } \\
\text { expected to remain similar in the future. }\end{array}$ \\
\hline Surface Soil & $\begin{array}{l}\text { Inhalation } \\
\text { Ingestion } \\
\text { External Exposure }\end{array}$ & $\begin{array}{l}\text { Trespasser } \\
\text { Rancher }\end{array}$ & Yes & $\begin{array}{l}\text { Potential intermittent recreational exposure is likely } \\
\text { under current and future conditions. Ranching occurs } \\
\text { at the Gnome-Coach Site. }\end{array}$ \\
\hline $\begin{array}{l}\text { Shallow Subsurface } \\
\text { Soil }\end{array}$ & $\begin{array}{l}\text { Inhalation } \\
\text { Ingestion } \\
\text { External Exposure }\end{array}$ & $\begin{array}{l}\text { Residential } \\
\text { Occupational }\end{array}$ & No & $\begin{array}{c}\text { Gnome-Coach is in a remote area and the land use is } \\
\text { expected to remain similar in the future. }\end{array}$ \\
\hline $\begin{array}{l}\text { Shallow Subsurface } \\
\text { Soil }\end{array}$ & $\begin{array}{l}\text { Inhalation } \\
\text { Ingestion } \\
\text { External Exposure }\end{array}$ & $\begin{array}{l}\text { Trespasser } \\
\text { Rancher }\end{array}$ & Yes & $\begin{array}{l}\text { Potential intermittent recreational exposure is likely } \\
\text { under current and future conditions. Ranching occurs } \\
\text { at the Gnome-Coach Site. }\end{array}$ \\
\hline Surface Soil & Ingestion of Meat & Rancher & Yes & $\begin{array}{l}\text { Ranching occurs at the Gnome-Coach Site. It is } \\
\text { assumed the ranchers ingest meat from onsite cattle. }\end{array}$ \\
\hline Surface Soil & Ingestion of Meat & $\begin{array}{l}\text { Residential } \\
\text { Occupational } \\
\text { Trespasser }\end{array}$ & No & $\begin{array}{c}\text { Gnome-Coach is in a remote area and the land use is } \\
\text { expected to remain similar in the future. }\end{array}$ \\
\hline Surface Water & $\begin{array}{l}\text { Inhalation } \\
\text { Ingestion } \\
\text { External Exposure }\end{array}$ & $\begin{array}{l}\text { Residential } \\
\text { Occupational } \\
\text { Trespasser } \\
\text { Rancher }\end{array}$ & No & $\begin{array}{l}\text { There are no permanent onsite surface water bodies } \\
\text { at the Gnome-Coach Site. }\end{array}$ \\
\hline Groundwater & $\begin{array}{l}\text { Inhalation } \\
\text { Ingestion } \\
\text { External Exposure }\end{array}$ & $\begin{array}{l}\text { Residential } \\
\text { Occupational } \\
\text { Trespasser } \\
\text { Rancher }\end{array}$ & No & Groundwater at the Gnome-Coach Site is nonpotable. \\
\hline
\end{tabular}




\section{C.3.1.1.1 Exposure Models}

The RESRAD computer code was developed at Argonne National Laboratory for the U.S. Department of Energy to calculate site-specific residual radioactive material guidelines as well as radiation dose and excess lifetime cancer risk to a chronically exposed on-site receptor (ANL, 1993b). A soil release guideline is defined as the radionuclide concentration in soil that is acceptable if the site is to be used without restrictions. Soil is defined as unconsolidated earth material at the surface and shallow subsurface, including rubble and debris that might be present. These guidelines are based on the following principles: (1) the annual radiation dose received by a member of the critical population group from the residual radioactive material, predicted by a realistic but reasonably conservative analysis and calculated as committed effective dose equivalent, should not exceed 25 mrem/yr (NRC, 1998); and (2) doses should be kept as-low-as-reasonably-achievable, a concept commonly known as ALARA (DOE/NV, 1997).

RESRAD uses a pathway analysis method in which the relation between radionuclide concentrations in soil and the dose to a member of a critical population group is expressed as a pathway sum, which is the sum of products of "pathway factors." Pathway factors correspond to pathway segments connecting compartments in the environment between which radionuclides can be transported or radiation emitted. Radiation doses, health risks, soil guidelines, and media concentrations are calculated over user-specified time intervals. The source is adjusted over time to account for radioactive decay and ingrowth, leaching, erosion, and mixing.

\section{C.3.1.1.2 Exposure Parameters}

Three types of parameters are used in exposure models to estimate potential dose:

- Radionuclide-related parameters (e.g., exposure point concentrations, dose conversion factors)

- Parameters that describe the exposed population (e.g., contact rate, exposure frequency, and duration)

- Site-specific parameters that are independent of the radionuclides and exposed receptors (e.g., climatology, geology) 
The exposed population, exposure-related parameters, and parameters are summarized in Table C.3-2. The exposure parameters were taken from the preliminary human health risk assessment (SNL, 1998), available site information, EPA guidance, industry standards, and best professional judgement using site-specific information where available. Upper-bound values are generally $90^{\text {th }}$ or $95^{\text {th }}$ percentile values, depending on the data available for each parameter. If no site-specific information was available, the RESRAD default was used as a reasonable upper bound estimate (ANL, 1993a). A combination of upper bound and average exposure parameters were used to estimate the RME for each scenario.

Table C.3-2 RESRAD Parameters for the Gnome-Coach Site (Page 1 of 4)

\begin{tabular}{|c|c|c|c|}
\hline Parameters & $\begin{array}{l}\text { Trespasser } \\
\text { Scenario }\end{array}$ & $\begin{array}{l}\text { Rancher } \\
\text { Scenario }\end{array}$ & Source of Parameter Data \\
\hline Area of contaminated zone $\left(\mathrm{m}^{2}\right)$ & Refer to Table C.2-1 & Refer to Table C.2-1 & Based on the site dimensions \\
\hline Initial input concentrations (pCi/g) & Refer to Table C.2-1 & Refer to Table C.2-1 & $\begin{array}{l}\text { Based on the on site measured radionuclide } \\
\text { concentrations }\end{array}$ \\
\hline Thickness of contaminated zone (m) & $\begin{array}{l}0.3 \mathrm{~m} \text { (surface) } \\
0.3 \text { to } 5 \mathrm{~m} \text { (shallow } \\
\text { subsurface) }\end{array}$ & $\begin{array}{l}0.3 \mathrm{~m} \text { (surface) } \\
0.3 \text { to } 5 \mathrm{~m} \text { (shallow } \\
\text { subsurface) }\end{array}$ & $\begin{array}{c}\text { Assumes } 1 \mathrm{ft} \text { depth of contamination for } \\
\text { surface soils }\end{array}$ \\
\hline Length parallel to aquifer flow (m) & Refer to Table $2-1$ & Refer to Table $2-1$ & Based on total site area \\
\hline Basic radiation dose limit (mrem/yr) & 25 & 25 & CFR, 2000 \\
\hline $\begin{array}{l}\text { Time since placement of radioactive } \\
\text { material }(\mathrm{yr})\end{array}$ & 0 & 0 & $\begin{array}{l}\text { Based on current radionuclide levels in soil } \\
\text { (decayed values) }\end{array}$ \\
\hline Cover depth (m) & $\begin{array}{l}0 \text { (surface soil) } \\
0.3 \mathrm{~m} \text { (shallow } \\
\text { subsurface) }\end{array}$ & $\begin{array}{l}0 \text { (surface soil) } \\
0.3 \mathrm{~m} \text { (shallow } \\
\text { subsurface) }\end{array}$ & Assumes no cover for surface contamination \\
\hline Density of cover material $\left(\mathrm{g} / \mathrm{cm}^{3}\right)$ & 2.0 & 2.0 & USDA, 1971 \\
\hline Cover depth erosion rate (m/yr) & $0.001 \mathrm{~m}$ & $0.001 \mathrm{~m}$ & RESRAD default \\
\hline Density of contaminated zone $\left(\mathrm{g} / \mathrm{cm}^{3}\right)$ & 2.0 & 2.0 & USDA, 1971 \\
\hline $\begin{array}{l}\text { Contaminated zone erosion rate } \\
\qquad(\mathrm{m} / \mathrm{yr})\end{array}$ & 0.001 & 0.001 & RESRAD default \\
\hline Contaminated zone total porosity & 0.4 & 0.4 & RESRAD default \\
\hline Contaminated zone effective porosity & 0.2 & 0.2 & RESRAD default \\
\hline $\begin{array}{l}\text { Contaminated zone hydraulic } \\
\text { conductivity (m/yr) }\end{array}$ & 10 & 10 & RESRAD default \\
\hline Contaminated zone $b$ parameter & 5.3 & 5.3 & RESRAD default \\
\hline Evapotranspiration coefficients & 0.99 & 0.99 & $\begin{array}{l}\text { Calculated value based on the regional climate } \\
\text { data }\end{array}$ \\
\hline Precipitation (m/yr) & 0.3 & 0.3 & DRI, 1988 \\
\hline Irrigation (m/yr) & 0 & 0 & No current on site irrigation \\
\hline
\end{tabular}


Table C.3-2

RESRAD Parameters for the Gnome-Coach Site

(Page 2 of 4 )

\begin{tabular}{|c|c|c|c|}
\hline Parameters & $\begin{array}{l}\text { Trespasser } \\
\text { Scenario }\end{array}$ & $\begin{array}{l}\text { Rancher } \\
\text { Scenario }\end{array}$ & Source of Parameter Data \\
\hline Irrigation mode & Overhead & Overhead & RESRAD default \\
\hline Runoff coefficient & 0.2 & 0.2 & RESRAD default \\
\hline $\begin{array}{c}\text { Watershed area from nearby stream } \\
\text { or pond }\end{array}$ & NA & NA & No groundwater consumption \\
\hline Accuracy for water/soil computations & NA & NA & No groundwater consumption \\
\hline Density of saturated zone $\left(\mathrm{g} / \mathrm{cm}^{3}\right)$ & NA & NA & No groundwater consumption \\
\hline Saturated zone total porosity & NA & NA & No groundwater consumption \\
\hline Saturated zone effective porosity & NA & NA & No groundwater consumption \\
\hline $\begin{array}{l}\text { Saturated zone hydraulic conductivity } \\
\qquad(\mathrm{m} / \mathrm{yr})\end{array}$ & NA & NA & No groundwater consumption \\
\hline Saturated zone hydraulic gradient & NA & NA & No groundwater consumption \\
\hline Saturated zone b parameter & NA & NA & No groundwater consumption \\
\hline Water table drop rate $(\mathrm{m} / \mathrm{yr})$ & NA & NA & No groundwater consumption \\
\hline $\begin{array}{l}\text { Well pump intake depth ( } \mathrm{m} \text { below } \\
\text { water table) }\end{array}$ & NA & NA & No groundwater consumption \\
\hline $\begin{array}{l}\text { Model: Nondispersion (ND) or } \\
\text { Mass-Balance (MB) }\end{array}$ & ND & ND & RESRAD default \\
\hline Well pumping rate $\left(\mathrm{m}^{3} / \mathrm{yr}\right)$ & NA & NA & No groundwater consumption \\
\hline $\begin{array}{l}\text { Number of Uncontaminated } \\
\text { unsaturated zone strata }\end{array}$ & NA & NA & No groundwater consumption \\
\hline Unsat. zone 1, thickness (m) & NA & NA & No groundwater consumption \\
\hline Unsat. zone 1 , soil density $\left(\mathrm{g} / \mathrm{cm}^{3}\right)$ & NA & NA & No groundwater consumption \\
\hline Unsat. zone 1 , total porosity & NA & NA & No groundwater consumption \\
\hline Unsat. zone 1 , effective porosity & NA & NA & No groundwater consumption \\
\hline $\begin{array}{l}\text { Unsat. zone } 1 \text {, soil-specific } b \\
\text { parameter }\end{array}$ & NA & NA & No groundwater consumption \\
\hline $\begin{array}{l}\text { Unsaturated zone } 1 \text {, hydraulic } \\
\text { conductivity }(\mathrm{m} / \mathrm{yr})\end{array}$ & NA & NA & No groundwater consumption \\
\hline $\begin{array}{l}\text { Exposure Frequency (d/yr) } \\
\text { (used as a calculation value) }\end{array}$ & $\begin{array}{l}4 \mathrm{~d} / \mathrm{yr} @ \\
24 \mathrm{hr} / \mathrm{d}\end{array}$ & $\begin{array}{c}6 \mathrm{~d} / \mathrm{yr} @ \\
8 \mathrm{hr} / \mathrm{d}\end{array}$ & $\begin{array}{l}\text { Personal communication with BLM } \\
\text { (Arnold, 2000) }\end{array}$ \\
\hline $\begin{array}{l}\text { Daily inhalation rate }\left(\mathrm{m}^{3} / \mathrm{d} \text { ) }\right. \\
\text { (used as a calculation value) }\end{array}$ & 14.56 & 9.84 & $\begin{array}{l}\text { Upper bound estimated based on the time } \\
\text { spent on site (Layton, 1993) }\end{array}$ \\
\hline Annual inhalation rate $\left(\mathrm{m}^{3} / \mathrm{y}\right)$ & 58.24 & 59.04 & $\begin{array}{c}\text { Calculated value based on the daily inhalation } \\
\text { rate and the exposure frequency }\end{array}$ \\
\hline Daily drinking rate $(\mathrm{L} / \mathrm{d})$ & NA & NA & No groundwater consumption \\
\hline Annual drinking rate (L/y) & NA & NA & No groundwater consumption \\
\hline Mass loading for inhalation $\left(\mathrm{g} / \mathrm{m}^{3}\right)$ & 0.00001 & 0.00001 & $\begin{array}{l}\text { Anspaugh, } 1974 \text { and a factor of } 1 \times 10^{-1} \text { to } \\
\text { account for arid environments }\end{array}$ \\
\hline
\end{tabular}


Table C.3-2

RESRAD Parameters for the Gnome-Coach Site

(Page 3 of 4 )

\begin{tabular}{|c|c|c|c|}
\hline Parameters & $\begin{array}{l}\text { Trespasser } \\
\text { Scenario }\end{array}$ & $\begin{array}{l}\text { Rancher } \\
\text { Scenario }\end{array}$ & Source of Parameter Data \\
\hline $\begin{array}{c}\text { Dilution length for airborne dust, } \\
\text { inhalation }(\mathrm{m})\end{array}$ & 3 & 3 & RESRAD default \\
\hline Exposure duration (yr) & 30 & 30 & EPA, 1991a \\
\hline Shielding factor, inhalation & 0.4 & 0.4 & RESRAD default \\
\hline Shielding factor, external gamma & 1.0 & 1.0 & Assumes shielding (worst case) \\
\hline $\begin{array}{l}\text { Fraction of time spent indoors (onsite } \\
\text { per year) }\end{array}$ & 0 & 0 & No time spent indoors \\
\hline $\begin{array}{c}\text { Fraction of time spent outdoors (on } \\
\text { site per year) }\end{array}$ & 0.011 & 0.0055 & Calculated from the exposure frequencies \\
\hline Shape factor, external gamma & 1.0 & 1.0 & RESRAD default \\
\hline $\begin{array}{l}\text { Fruits, vegetables and grain } \\
\text { consumption }(\mathrm{kg} / \mathrm{yr})\end{array}$ & NA & NA & NA \\
\hline Leafy vegetable consumption (kg/yr) & NA & NA & NA \\
\hline Meat consumption (kg/yr) & NA & 63.0 & $\begin{array}{l}\text { RESRAD default adjusted for home range } \\
\text { area }\end{array}$ \\
\hline Milk consumption (L/yr) & NA & NA & $\begin{array}{l}\text { Milk ingestion not considered; primarily beef } \\
\text { cattle }\end{array}$ \\
\hline Soil ingestion rate $(\mathrm{g} / \mathrm{yr})$ & 1.92 & 2.88 & $\begin{array}{c}\text { Based on } 480 \mathrm{mg} / \mathrm{day} \text { for the trespasser and } \\
\text { the rancher. EPA, } 1999 \mathrm{~b}\end{array}$ \\
\hline $\begin{array}{l}\text { Household water fraction } \\
\text { contaminated }\end{array}$ & NA & NA & No groundwater consumption \\
\hline Livestock water fraction contaminated & NA & NA & No groundwater consumption \\
\hline Irrigation water fraction contaminated & 0 & 0 & No on site irrigation water \\
\hline Contaminated fraction of plants & NA & NA & NA \\
\hline Contaminated fraction of meat & NA & 1.0 & Worst Case \\
\hline $\begin{array}{l}\text { Livestock fodder intake for meat } \\
\qquad(\mathrm{kg} / \mathrm{d})\end{array}$ & NA & 68 & RESRAD default \\
\hline Livestock water intake for meat $(\mathrm{L} / \mathrm{d})$ & NA & 50 & RESRAD default \\
\hline Livestock intake for soil $(\mathrm{kg} / \mathrm{d})$ & NA & 0.5 & RESRAD default \\
\hline $\begin{array}{l}\text { Mass loading for foliar deposition } \\
\qquad\left(\mathrm{g} / \mathrm{m}^{3}\right)\end{array}$ & NA & 0.00001 & $\begin{array}{l}\text { Anspaugh, } 1974 \text { and a factor of } 1 \times 10^{-1} \text { to } \\
\text { account for arid environments }\end{array}$ \\
\hline Depth of soil mixing layer $(\mathrm{m})$ & 0.3 & 0.3 & Based on depth of surface contamination \\
\hline Depth of roots $(\mathrm{m})$ & NA & 0.9 & RESRAD default \\
\hline $\begin{array}{l}\text { Household fractional usage from } \\
\text { groundwater }\end{array}$ & NA & NA & No groundwater consumption \\
\hline $\begin{array}{l}\text { Irrigation fractional usage from } \\
\text { groundwater }\end{array}$ & NA & NA & No groundwater consumption \\
\hline $\begin{array}{l}\text { Livestock fractional usage from } \\
\text { groundwater }\end{array}$ & NA & NA & No groundwater consumption \\
\hline
\end{tabular}


Table C.3-2

RESRAD Parameters for the Gnome-Coach Site

(Page 4 of 4 )

\begin{tabular}{|c|c|c|c|}
\hline Parameters & $\begin{array}{l}\text { Trespasser } \\
\text { Scenario }\end{array}$ & $\begin{array}{l}\text { Rancher } \\
\text { Scenario }\end{array}$ & Source of Parameter Data \\
\hline \multicolumn{4}{|c|}{ Storage times for contaminated foodstuffs } \\
\hline Fruits, non-leafy veg. \& grains (d) & NA & NA & NA \\
\hline Leafy vegetables (d) & NA & NA & NA \\
\hline Meat $(d)$ & NA & 20 & RESRAD default \\
\hline Milk (d) & NA & NA & NA \\
\hline Water well (d) & NA & NA & No groundwater consumption \\
\hline Water surface $(d)$ & NA & NA & NA \\
\hline Livestock fodder (d) & NA & 45 & RESRAD default \\
\hline \multicolumn{4}{|c|}{ Thickness of material (m) } \\
\hline in foundation & NA & NA & NA \\
\hline in contaminated zone soil & NA & NA & NA \\
\hline \multicolumn{4}{|c|}{ Density of material $(\mathrm{g} / \mathrm{cm})$} \\
\hline in the foundation & NA & NA & NA \\
\hline in the contaminated soil & NA & NA & NA \\
\hline \multicolumn{4}{|c|}{ Total porosity of material } \\
\hline in the foundation & NA & NA & NA \\
\hline in the contaminated soil & NA & NA & NA \\
\hline Volumetric water content & NA & NA & NA \\
\hline \multicolumn{4}{|c|}{ Diffusion coefficient for radon gas (m/sec) } \\
\hline in the foundation & NA & NA & NA \\
\hline in the contaminated soil & NA & NA & NA \\
\hline $\begin{array}{c}\text { Contamination zone radon diffusion } \\
\text { coefficient }\end{array}$ & NA & NA & NA \\
\hline Radon vertical dimension of mixing & NA & NA & NA \\
\hline Average annual wind speed (m/sec) & 3.5 & 3.5 & EEG, 1999 \\
\hline $\begin{array}{l}\text { Average building air exchange rate } \\
\qquad(1 / \mathrm{hr})\end{array}$ & NA & NA & NA \\
\hline Height of the building (room) (m) & NA & NA & A \\
\hline Building interior area factor & NA & NA & NA \\
\hline $\begin{array}{l}\text { Building depth below ground } \\
\text { surface }(m)\end{array}$ & NA & NA & NA \\
\hline Emanating power of Radon-222 gas & NA & NA & NA \\
\hline Emanating power of Radon-220 gas & NA & NA & NA \\
\hline
\end{tabular}

$\mathrm{NA}=$ Not applicable 


\section{C.3.2 Dose/Risk-Screening Evaluation}

This section provides an evaluation of the potential doses and risks associated with the exposure to Cs-137 and tritium at the Gnome-Coach Site. This assessment employs a health-protective bias that leads to the overestimation of potential dose. Individuals are exposed to an RME (see Section C.3.1) and exposure is evaluated (see Section C.3.1.1) to provide estimates of annual exposure. This dose/risk data generated for each area of concern will be compared to the dose/risk screening criteria. Areas of concern having dose/risks above the screening criteria will have additional soil data collected.

\section{C.3.2.1 Dose Screening Criteria}

This section summarizes the dose criteria guidelines from existing and proposed regulations and guidance. The dose criteria is used in the corrective action level evaluation by determining what level of residual concentrations of contaminants in the soil is acceptable and does not exceed established guidelines. The following is a brief summary of the applicable DOE and NRC regulations. Also included is a discussion of the As-Low-As-Reasonably-Achievable (ALARA) analysis as outlined in each of the regulations. The regulatory dose standards are summarized below:

- DOE Order 5400.5, Radiation Protection of the Public and the Environment (DOE, 1993)

- Title 10 of the Code of Federal Regulations (CFR), Part 20, Standards for Protection Against Radiation (CFR, 2000)

\section{DOE 5400.5}

The primary dose limits for members of the public from all U.S. Department of Energy activities, including remedial actions, are established in Chapters II and IV in DOE Order 5400.5 (DOE, 1993). Chapter II of DOE Order 5400.5 states, "the exposure of members of the public to radiation sources as a consequence of all routine DOE activities shall not cause, in a year, an effective dose equivalent greater then 100 mrem." The DOE Order 5400.5 is currently being revised, and the effective dose equivalent is being changed to 25 millirem per year (mrem/yr). It is anticipated DOE Order 5400.5 will be formerly revised in Fiscal Year 2001. 
The primary dose limit is expressed as a committed effective-dose equivalent, a term developed by the International Commission on Radiological Protection (ICRP) for their risk-based system, which requires the risk-weighted summation of doses to various tissues and organs of the body. The basic dose limit (100 mrem) is used in establishing guideline concentrations of residual radioactive material in the soil. This basic dose limit is an annual limit for members of the public who are assumed to participate in worst-case exposure scenarios (e.g., residential rancher and farmer). Other exposure scenarios could include an industrial worker and/or a recreational user. This regulation requires an environmental pathway analysis using approved models, such as RESRAD, to derive acceptable levels of radionuclides in soils from all exposure pathways. Radiation dose is assessed for these exposure scenarios every year during a 1,000-year time frame.

Chapter II of DOE Order 5400.5 requires that the ALARA process be adopted in planning, monitoring, cleanup, and control of residual radioactive material (DOE, 1993). DOE Order 5400.5 states "ALARA requires judgement with respect to what is reasonably achievable. Factors that relate to societal, technological, economic, and other policy considerations shall be evaluated to the extent practicable in making such judgements." These factors include:

- The maximum dose to members of the public

- The collective dose to the population

- Alternative processes

- Doses for each alternative process

- Costs for each technological alternative

- Differential doses from various pathways

The ALARA analysis may be quantitative (cost-benefit analysis) or qualitative. However, in either case, the bases for judgement should be clearly stated. The ALARA process for DOE Order 5400.5 is summarized in greater detail in Draft document, Applying the ALARA Process for Radiation Protection of the Public and Environmental Compliance with 10 CFR Part 834 and DOE 5400.5 ALARA Program Requirements - Volumes I and II (DOE, 1997).”

\section{CFR 20}

The NRC regulations establish standards for protection against ionizing radiation resulting from activities conducted under licenses issued by the NRC (CFR, 2000). Subpart D of 10 CFR 20 states that operations should be conducted so, "the total effective dose equivalent to individual members of 
the public from the licensed operation does not exceed 0.1 rem (100 mrem or 1 millisievert) in a year, exclusive of the dose contributions from background radiation, any medical administration the individual has received, voluntary participation in medical research programs, and the licensee's disposal of radioactive material into sanitary sewerage." Subpart E further states this criteria for license termination: "a site will be considered acceptable for unrestricted use if the residual radioactivity that is distinguishable from background radiation results in a total effective dose equivalent to an average member of the critical group that does not exceed $25 \mathrm{mrem} / \mathrm{yr}$, including that from groundwater sources of drinking water, and the residual radioactivity has been reduced to ALARA levels. Subpart E further states that if the land use was restricted the $25 \mathrm{mrem} / \mathrm{yr}$ limit would still apply. Therefore, an unrestricted exposure scenario would still have to be considered. The radiation dose (if the land restrictions fail) shall not exceed $100 \mathrm{mrem} / \mathrm{yr}$. Therefore, any individual will not receive more than the ICRP-recommended dose limit of $100 \mathrm{mrem} / \mathrm{yr}$ under any land-use scenarios.

Title 10 CFR 20 states that, to the extent practicable, procedures and engineering controls are based upon sound radiation protection principles to achieve ALARA occupational doses and doses to members of the public.

Based on the available information and regulations, a dose criteria of $25 \mathrm{mrem} / \mathrm{yr}$ is the only promulgated dose criteria and is considered protective to human health and will be used for comparison purposes at the Gnome-Coach Site.

\section{C.3.2.2 Risk-Screening Criteria}

The EPA classifies all radionuclides as Group A carcinogens. Ingestion and inhalation slope factors are central estimates in a linear model of the age-averaged, lifetime attributable radiation cancer incidence (fatal and nonfatal cancer) risk per unit of activity, inhaled or ingested, expressed as risk/pCi. External exposure slope factors are central estimates of lifetime-attributable radiation cancer incidence risk for each year of exposure to external radiation from photon-emitting radionuclides distributed uniformly in a thick layer of soil and are expressed as risk/yr per pCi/gram soil. When combined with site-specific media concentration data and appropriate exposure assumptions, slope factor can be used to estimate lifetime cancer risks to members of the general 
population due to radionuclide exposures. In most cases, cancer risks are limiting, exceeding both mutagenic and teratogenic risks.

In evaluating the calculated exposure from a potentially carcinogenic radionuclides, a reasonable level of risk must be selected. The EPA used an incremental lifetime cancer risk (ILCR) (also referred to as excess cancer risk) of one in one million $\left(1 \times 10^{-6}\right)$ as the lower bound of an acceptable range. The upper bound of an acceptable ILCR recommended by the EPA for drinking water is 1 in $10,000\left(1 \times 10^{-4}\right)(\mathrm{EPA}, 1999 \mathrm{a})$. In addition, the EPA specifies a risk range of $10^{-6}$ to $10^{-4}$ associated with the consideration and selection of remedial alternatives for contaminated media in the National Contingency Plan (NCP) (CFR, 1999).

Based on the regulatory precedents cited above, a reasonable and appropriate ILCR range would be from $10^{-6}$ to $10^{-4}$. As implemented under the NCP, pathway risks greater than $10^{-6}$ ILCR must receive risk management consideration (CFR, 1999). This quantitative risk screening is one of many factors that are considered in the decision-making process for the need for additional data collection. Therefore, there is no single risk value that defines "acceptable" and "unacceptable" risk. The purpose of this risk screening is to present qualitative estimates of potential risk; thus, all sites greater than the cumulative upper bound of $10^{-4}$ will be examined further for the need of additional data collection.

Cumulative site radionuclide ILCRs were developed for surface and shallow subsurface soils. However, the risks for the individual media were not combined. These cumulative ILCRs included all media and pathways that were appropriate to combine. Combined pathways occur when there is potential for an individual to be exposed to multiple pathways at the same given instant in time. Where the cumulative ILCR site risk to an individual based on the RME for both current and future land use is less than $10^{-4}$, action generally is not warranted unless there are adverse environmental impacts (EPA, 1991b).

\section{C.3.2.3 Results of the Human Health Dose/Risk-Screening Evaluation}

Based on the concentrations and input parameters summarized in the previous sections, the results for each potential receptor and general conclusions are as follows: 
- Confirmed that Cs-137 is the primary contributor to the calculated dose through external exposure. Tritium has a minimal contribution to the total dose.

- The input parameters that drive the external dose are time on site and Cs-137 concentrations.

- Trespasser in contact with surface soil (maximum concentrations) - The following site exceeded the dose criteria of $25 \mathrm{mrem} / \mathrm{yr}$ : new laundry/lab. The following sites exceed the upper bound cumulative ILCR of $10^{-4}$ : New laundry/lab, Gnome-Coach shaft surface area and the Fallout track from venting.

- Trespasser in contact with surface soil (UCL concentrations) - The only site to exceed the $25 \mathrm{mrem} / \mathrm{yr}$ dose criteria and the upper bound cumulative ILCR of $10^{-4}$ was the New laundry/lab.

- Rancher in contact with surface soil (maximum concentrations) - The only site to exceed the $25 \mathrm{mrem} / \mathrm{yr}$ dose criteria and the upper bound cumulative ILCR of $10^{-4}$ was the New laundry/lab.

- Rancher in contact with surface soil (UCL concentrations) - The only site to exceed the $25 \mathrm{mrem} / \mathrm{yr}$ dose criteria and the upper bound cumulative ILCR of $10^{-4}$ was the New laundry/lab.

- Trespasser and rancher in contact with shallow subsurface soil - None of the sites exceeded the $25 \mathrm{mrem} / \mathrm{yr}$ dose criteria and the upper bound cumulative ILCR of $10^{-4}$.

Historical data indicate areas which exceed the $25 \mathrm{mrem} / \mathrm{yr}$ dose criteria and the cumulative site ILCR of $10^{-4}$, and these may pose a potential risk to human health. To confirm concentrations of the historical data used, and reduce the uncertainty of the calculation results for a final dose/risk assessment, the New laundry/lab, Gnome-Coach shaft surface area, and the Fallout track from venting may require additional data collection. 


\section{C.4.0 References}

ANL, see Argonne National Laboratory.

Anspaugh, L. R., J.H. Shinn, and D.W. Wilson. 1974. "Evaluation of the Resuspension Pathway Toward Protective Guidelines for Soil Contamination with Radioactivity." In Proceedings Seminar on Radiological Safety Evaluation of Population Doses and Application of Radiological Safety Standards to Man and Environment, Portoraz, Yugoslavia, 20-24 May, 1974. p. 513. Vienna, Austria: International Atomic Energy Agency.

Arnold, D., SAIC. 2000. Personal communication to S. Daly (Bureau of Land Management), Carlsbad, New Mexico, regarding ranching habits at the Gnome-Coach Site, 31 August. Las Vegas, NV.

Argonne National Laboratory. 1993a. Data Collection Handbook to Support Modeling the Impacts of Radioactive Material in Soil, ANL/EAIS-8. Prepared by C. Yu, C. Loureiro, J.-J. Cheng, L.G. Jones, Y.Y. Wang, Y.P. Chia, and E. Faillace. Argonne, IL.

Argonne National Laboratory. 1993b. Manual for Implementing Residual Radioactive Material Guidelines Using RESRAD, Version 5.0, ANL/EAD/LD-2. Prepared by C. Yu, A.J. Zielen, J.-J. Cheng, Y.C. Yuan, L.G. Jones, D.J. LePoire, Y.Y. Wang, C.O. Loureiro, E.

Gnanapragasam, E. Faillace, A. Wallo III, W.A. Williams, and H. Peterson. Argonne, IL.

CFR, see Code of Federal Regulations.

Code of Federal Regulations. 1999. Title 40, Part 300, "National Oil and Hazardous Substances Pollution Contingency Plan.” Washington, DC: U.S. Government Printing Office.

Code of Federal Regulations. 2000. 10 CFR 20, "Standards for the Protection Against Radiation." Washington, DC: U.S. Government Printing Office.

Cooper, J.B., and V.M. Glanzman. 1971. Geohydrology of Project Gnome Site, Eddy County, New Mexico, USGS-PP-712-A. Denver, CO: U.S. Geological Survey.

Desert Research Institute. 1988. CERCLA Preliminary Assessment of DOE's Nevada Operations Office Nuclear Weapons Testing Areas. Las Vegas, NV.

DOE/NV see U.S. Department of Energy, Nevada Operations Office.

DRI, see Desert Research Institute. 
Earman, S., J. Chapman, K. Pohlmann, and R. Andricevic. 1996. Assessment of Hydrologic Transport of Radionuclides from the Gnome Underground Nuclear test Site, New Mexico, Publication No. 45142, DOE/NV/11508-11. Reno, NV: Desert Research Institute.

EEG, see Environmental Evaluation Group.

Environmental Evaluation Group. 1995. Radionuclide Baseline in Soil Near Project Gnome and The Waste Isolation Pilot Plant, DOE/AL/58309-58, EEG 58. Prepared by J.W. Kenney, P.S.

Downes, D.H. Gray, and S.C. Ballard. Carlsbad, NM.

Environmental Evaluation Group. 2000. Graphical Display of WIPP Meterological Data, Wind Speed and Direction Collected Through December 1999. Internet address http://www.rt66.com/ eeg/wipp_met_data.htm, 8 October.

EPA, see U.S. Environmental Protection Agency.

Gardner, M.C. and J.J. Sigalove. 1970. Evaluation of the Project Gnome/Coach Site, Carlsbad, New Mexico for Disposition, Including Identification of Restrictions, Part I, NVO-1229-106 Part I, 44p. Palo Alto, CA: Teledyne Isotopes.

Layton, D.W. 1993. "Metabolically Consistent Breathing Rates for Use in Dose Assessments." In Health Physics, Vol. 64(1): 23-36. Health Physics Society.

NRC, see U.S. Nuclear Regulatory Commission.

REECo, see Reynolds Electrical \& Engineering Co., Inc.

Reynolds Electrical \& Engineering Co., Inc. 1973. Carlsbad Reconnaissance 1972, Gnome Site. Las Vegas, NV.

SNL, see Sandia National Laboratories.

Sandia National Laboratories. 1998. A Preliminary Human Health Risk Assessment of the Gnome Site, New Mexico. Prepared for the U.S. Department of Energy, Nevada Operations Office by S. Conrad, M. Goodrich, and T. Feeney. Albuquerque, NM.

Tappan, J.T., and J.J. Lorenz. 1969. On-Site Radiological Safety Report, Carlsbad Site Roll-Up Program, NVO-410-2. Prepared for U.S. Atomic Energy Commission. Mercury, NV: Reynolds Electrical \& Engineering Co., Inc.

U.S. Atomic Energy Commission. 1962. Project Manager's Report, Project Gnome, Plowshare Program, NVO-1. Washington, DC.

U.S. Department of Agriculture, Soil Conservation Service. 1971. Soil Survey of Eddy Area, New Mexico. Washington, DC.: U.S. Government Printing Office. 
U.S. Department of Energy. 1993. Radiation Protection of the Public and the Environment, DOE Order 5400.5. Washington, DC: U.S. Government Printing Office.

U.S. Department of Energy. 1997. Applying the ALARA Process for Radiation Protection of the Public and Environmental compliance with 10 CFR 834 and DOE Order 5400.5, ALARA Program Requirements, Draft. Washington, DC: U.S. Government Printing Office.

U.S. Department of Energy, Nevada Operations Office. 1978. Gnome Site Decontamination and Decommissioning - Phase I Radiological Survey and Operations Report, Carlsbad, New Mexico, NVO/0410-48, Vols. 1 and 2. Prepared by Reynolds Electrical \& Engineering Co., Inc. Las Vegas, NV.

U.S. Department of Energy, Nevada Operations Office. 1979. Project Gnome Decontamination and Decommissioning Plan, NV-202. Las Vegas, NV.

U.S. Department of Energy, Nevada Operations Office. 1981. Gnome Site Decontamination and Decommissioning Project, Radiation Decontamination Clearance Report, March 28, 1979 September 23, 1979, DOE/NV/00410-59. Prepared by Reynolds Electrical \& Engineering Co., Inc. Las Vegas, NV.

U.S. Environmental Protection Agency (EPA). 1989. Risk Assessment Guidance for Superfund (RAGS), Vol. I, Human Health Evaluation Manual (Part A), EPA/540/1-89/002. Washington, D.C: Office of Emergency and Remedial Response.

U.S. Environmental Protection Agency. 1991a. Risk Assessment Guidance for Superfund, Vol. I, "Human Health Evaluation Manual, Supplemental Guidance: Standard Default Exposure Factors," OSWER Directive 9285.6-03. Washington, D.C: Office of Solid Waste and Emergency Response.

U.S. Environmental Protection Agency. 1991b. Role of the Baseline Risk Assessment in Superfund Remedy Selection Decisions, OSWER Directive 9355.0-30. Washington, D.C: Office of Solid Waste and Emergency Response.

U.S. Environmental Protection Agency. 1994. Residual Soil Radioactivity at the Gnome Test Site, Eddy County, New Mexico, EPA 600/R-94/117. Prepared by S.H. Faller. Las Vegas, NV.

U.S. Environmental Protection Agency. 1999a. "Current Drinking Water Standards: National Primary and Secondary Drinking Water Standards," on-line database, revised December, 1999. Washington, DC.

U.S. Environmental Protection Agency. 1999b. Exposure Factors Handbook, National Center for Environmental Assessment, CDROM. Washington, DC: Office of Research and Development.

U.S. Geological Survey. 1962. Hydrologic and Geologic Studies, Project Gnome Final Report, PNE-130F. Las Vegas, NV: U.S. Atomic Energy Commission Plowshare Program. 
Appendix D

Vegetation Sampling and Analysis Plan 


\section{D.1.0 Introduction}

This document is intended to supplement data collected as part of the Preliminary Human Health Dose/Risk Screening Evaluation of the Gnome-Coach Site, New Mexico. Previous studies of the area have emphasized measuring surface gamma radiation and radionuclide concentrations in soils and groundwater shortly after the Gnome event in 1961 and over several years of radiological monitoring and sampling at the Site. The first bioenvironmental sampling program was conducted by the EPA in October 1972 and a second bioenvironmental sampling program was conducted for DOE in 1978.

The current Human Health Dose/Risk Screening Evaluation effort has made a decision to emphasize Cs-137 and recognizes the need for additional vegetation sampling and analysis at the Gnome-Coach Site to (1) characterize levels of that radionuclide in important range grasses of the area and (2) provide crucial information for estimation of Cs-137 ingestion by range cattle as constituents of any pathway analysis to be conducted.

\section{D.1.1 Background}

Two sets of bioenvironmental sampling programs were conducted at the Gnome-Coach Site, the first by the EPA in October 1972 (Smith and Giles, 1973) and the second for DOE in May 1978 (DOE/NV, 1978). Review of the data on radionuclides in vegetation of the Gnome-Coach Site resulting from those two programs revealed a definite lack of data for Cs-137 in all areas. The EPA study provided no Cs-137 values in samples of two range grasses of interest collected in five areas located $0.27,1.2,1.9$, and 2.3 miles north-northwest and 1.4 miles southeast of the Gnome-Coach Site. The DOE data included 23 vegetation samples of grasses, forbs, and shrubs; however, only 6 of the 23 samples contained measurable Cs-137 concentrations and only two of those were grasses of importance to grazing livestock. Upon review of sampling procedures in these reports, it appears that the collection of biomass was not sufficient to allow detection above the MDA for Cs-137. It would be inappropriate to estimate Cs-137 intake by cattle as a vector of the radionuclide to human consumers from data of this nature. 


\section{D.1.2 Approach}

A focused and expedient vegetation sampling plan is proposed to provide necessary data on Cs-137 concentrations in range plants of the Gnome-Coach Site that are important forage for range cattle that graze the environs. An important condition of the study is to ensure that the sampling strategy provides analytical results which support the objectives of this investigation. Therefore, it is proposed to obtain adequate samples of important grass species of the area, with emphasis on black grama grass (Bouteloua eriopoda) and sand dropseed (Sporobolus cryptandrus) species. Additional forage species will be sampled if the key species are insufficient in biomass. Much of the site has been disturbed by past decommissioning and cleanup activities and is currently being grazed by cattle, all activities that will complicate the proposed vegetation sampling scheme; therefore, the Vegetation Sampling Plan is designed to have flexibility to adjust to on-site variables. This flexibility may include adjustments to species collection and sample locations based on field conditions.

\section{D.1.3 Objectives}

The objective of the field sampling plan is to collect and document radiological data concerning the possible presence and distribution of man-made radionuclides at the Gnome-Coach Site, especially Cs-137 in range forage grasses. This information will supplement past sampling efforts and provide defensible values for input to the range cattle parameters in the Human Health Risk Assessment.

Although the proposed vegetation sampling plan is limited in scope because of time and logistic constraints, it is designed to answer two basic questions: (1) what Cs-137 concentrations are currently found in range grasses of the Gnome-Coach Site and (2) how important are those levels of Cs-137 in the Human Risk Assessment? These questions will be investigated by using accepted sampling and analysis methods for the determination of the very low levels of Cs-137 expected to be found in the biota of the Gnome-Coach Site, particularly range forage grasses. 


\section{D.2.0 Field Sampling Plan}

\section{D.2.1 Scope}

This effort will be conducted in a survey (characterization) sampling mode. A general survey of the site will be initially made to select suitable sampling areas of the target range grass species, particularly black grama grass (Bouteloua eriopoda) and sand dropseed (Sporobolus cryptandrus), or a decision made for alternate species if the target species are not available in sufficient biomass for analytical purposes.

Tentative vegetation sampling locations are proposed as follows (see Figure D.2-1):

- Fallout plume area approximately 345 to $820 \mathrm{ft}$ northwest of the shaft, six sampling grids in a T-shape across the reported cloud vector

- Upwind vector approximately $985 \mathrm{ft}$ southeast of Gnome GZ, three sampling grids

- Control area approximately 490 to $655 \mathrm{ft}$ southwest of the Coach Site, three sampling grids

The first location is in the vicinity of maximum Cs-137 soil concentrations, historically measured in the downwind location of the fallout plume. Two upwind locations in the Gnome environs provide comparative values, including the control (background) location designated as an area located in relatively undisturbed habitat upwind of the Gnome-Coach Site and southwest of the Coach Exploratory Hole. The other upwind location will be based on the initial driveover radiological survey. Sampling target species in radiologically elevated areas will maximize the potential of detecting Cs-137, which is crucial in estimating Cs-137 ingestion by range cattle; therefore, the sampling locations listed above are tentative until field conditions can be assessed.

The proposed sampling locations have been made based on an aerial photographs dated 1979 and 1988 (EG\&G, 1979; 1988) and will be adjusted as necessary based on site conditions at the time of sampling. The major consideration in establishing the sampling areas will be the availability of sufficient biomass to provide at least three grass samples per location, plus 10 percent of total samples added for quality assurance and quality control considerations and distributed among duplicates, blanks, and blind samples. The EPA (Smith and Giles, 1973) reported obtaining samples of 100 to 200 grams (g) of (presumably wet) grass from approximately $390 \mathrm{ft}^{2}$, which were then compressed 


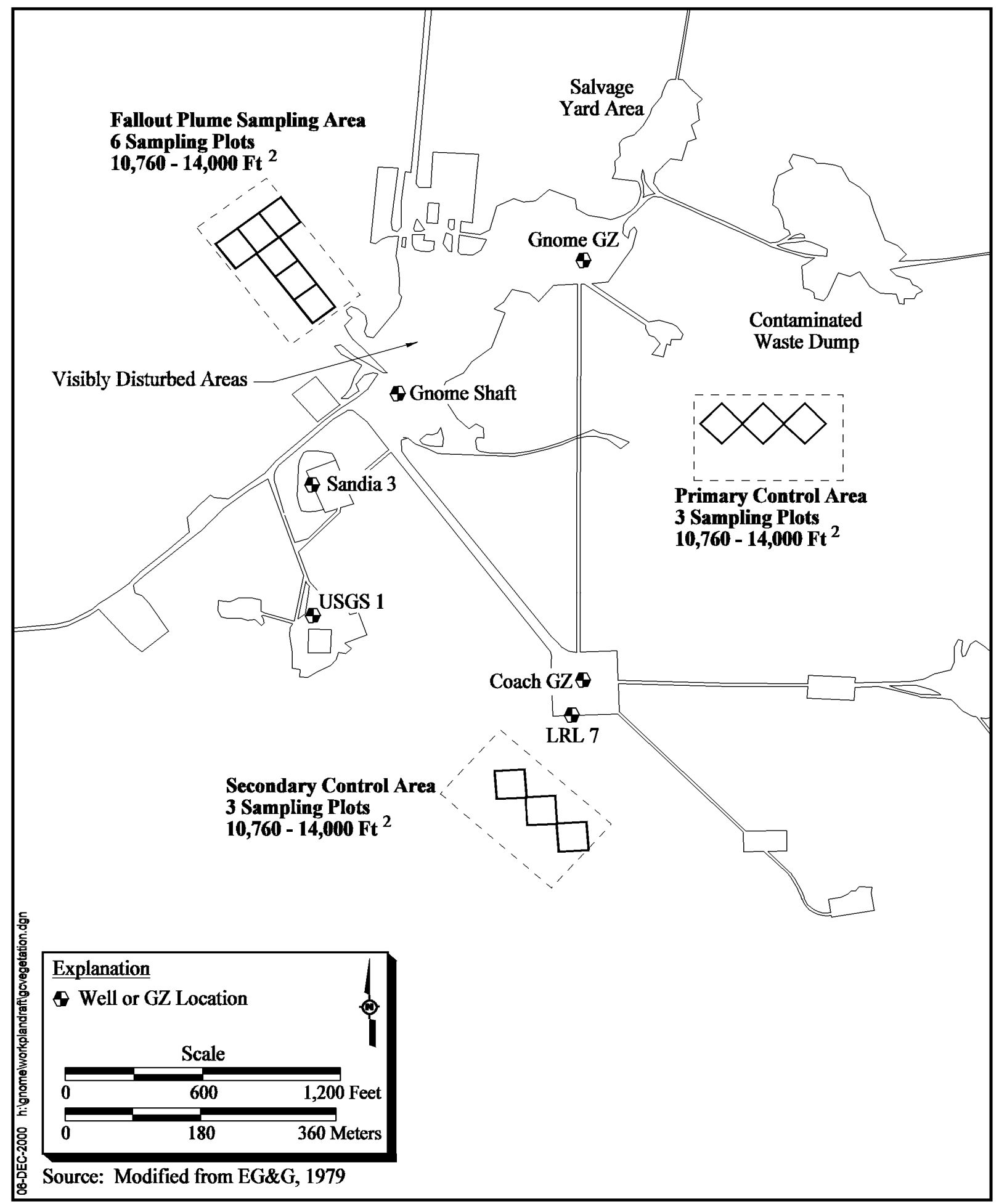

Figure D.2-1

Tentative Vegetation Sampling Areas and Plots at the Gnome-Coach Site 
into a $400 \mathrm{~mL}$ container for gamma analysis; none of the samples were above the MDA of Cs-137 and only Zr-95 and Ru-103 were reported as positive values. The DOE reported only two of four samples of Sporobolus contained above background concentrations of Cs-137 and with no indication of the area sampled or the weight (e.g., wet, dry, or ash) basis of the determination (DOE/NV, 1978).

The above results indicate that sampling areas must be considerably larger than the $390 \mathrm{ft}^{2}$ areas reported by EPA in order to obtain sufficient biomass to yield enough ashed sample for positive counting results in the nominal $0.01-0.1 \mathrm{pCi} \mathrm{Cs}-137 / \mathrm{g}$ ash detection range. Therefore, it is proposed to initially establish sampling plots of approximately 10,760 to $14,000 \mathrm{ft}^{2}$ from which to obtain 1,750-2,630 g of Bouteloua or Sporobolus, or about two kilograms of fresh (wet) grass, assuming a wet/ash weight ratio of 3.8 for Sporobolus and 5.7 for Bouteloua (Smith and Giles, 1973), and 40 percent reduction of count rate due to radiological decay over the past 22 years in order to obtain $>100 \mathrm{~g}$ of ash of those species for gamma analysis. Adjustment of these estimates may be made, as necessary, on the basis of container calibrations at the analytical laboratory.

\section{D.2.2 Sampling Rationale}

The number of samples to be collected and analyzed for Cs-137 is proposed to be (1) six in an area of about 330 by $655 \mathrm{ft}$ located in the fallout track that was reportedly traversed by the plume of contamination from the shaft; (2) three in a primary control area located in a southeasterly direction and approximately 655 to 1,640 ft from Gnome GZ; and (3) three in a secondary control area located southwesterly direction and approximately 395 to $985 \mathrm{ft}$ from the Coach Site. Driveover radiological survey results and ground reconnaissance prior to beginning the sampling will refine these proposed locations sited in areas of apparently little disturbance. Impacts of cattle grazing and site characteristics, such as rainfall history, on these selected areas can only be evaluated by much closer inspection and changes will be made, as necessary, to assure sampling sufficient biomass of the target species.

\section{D.2.3 Sampling Procedures}

Guidelines for the collection, handling, and documentation of samples collected under this field sampling plan are described in the following sections. 


\section{D.2.3.1 Sample Collection}

Samples will be collected in the following sequence to minimize the risk of cross-contamination between sites: (1) within the secondary control (SW) area; (2) within the primary control (SE) area; and (3) in the area traversed by the Gnome plume. This schedule will occur after the driveover radiological survey that will define AOCs (>25 mrem) for further consideration and necessary adjustments to the sampling regime will be made.

Emphasis will be placed on obtaining adequate biomass of the target species of range grasses, such as sand dropseed (Sporobolus cryptandrus), black grama (Boutelou eriopoda), and others by clipping individual plants about 2 in. above ground level, removing excess soil by shaking samples, and compositing individual plants in plastic bags until about $1.5 \mathrm{~kg}$ (Bouteloua)- $2.5 \mathrm{~kg}$ (Sporobulus) is obtained. If other grass species are to be collected instead of the above target species, the change will be noted in the field documentation.

\section{D.2.3.2 Sample Handling and Site Documentation}

Samples will be carefully labeled and sealed with custody tape, and all necessary field data and descriptions, including field wet weight, species sampled, and other data entered in the field documentation in accordance with the QAPP. Transfer and receipt of all samples will be documented and samples will be handled in strict conformance to chain-of-custody procedures at all times. Each sample will be assigned a unique sample control number and a corresponding label will be attached at the time of collection. Samples will be returned to an on-site sample preparation area for drying, ashing, and packaging for gamma analysis or shipped to an analytical laboratory if facilities are not available on-site.

Information about each sampling location and sampling point, including weather conditions, numbers and stand densities of vegetative types, date, time, and methods used to collect the samples will be recorded in field documentation and photographs will be taken at each sampling location for documentation. In addition, sampling locations will be identified with a stake marked with the sample designation for future reference. 
All samples will be returned to the field laboratory as convenient to the sampling activities, usually at the end of the day. Upon receipt at the field laboratory, samples will be logged in, chain of custody procedures completed, and secure storage of samples assured until further processing begins. 


\section{D.3.0 Field Laboratory Procedures}

\section{D.3.1 Sample Processing}

Vegetation samples received at the field laboratory will be receipted and custody transferred to the appropriate party. Samples will be weighed and transferred to an appropriate container, such as a tared aluminum baking tray, reweighed, and placed in a drying oven preset and operating at $100^{\circ} \mathrm{C}$ for at least 24 hours or until constant weight is achieved. Sample dry weight will be recorded in the laboratory documentation and the sample will be transferred to an airtight plastic bag marked with the sample identification number and sealed.

Dried samples will be securely stored until milled by a Wiley mill with a 2-mm screen, which will significantly reduce the volume of the sample prior to ashing for radionuclide analyses. Samples will be weighed prior to and after milling, and care taken to preserve sample identification at all stages of processing. Continuous records will be made in the laboratory documentation and custody will be maintained. Milling will also provide an opportunity to split homogeneous samples with other interested parties, if so indicated.

Milled samples will be placed in an appropriate tared aluminum baking tray or equivalent and ashed at $425-450^{\circ} \mathrm{C}$ in a muffle furnace for sufficient time to be completely ashed. The samples will then be reweighed and a suitable portion of the ash transferred to a tared counting container, sealed, and submitted for gamma spectrometric analysis. Excess sample ash will be archived in case of further analytical requirements.

\section{D.3.2 Radiochemical Analyses}

Gamma spectrometric analyses of the range grass samples should provide values within a 95 percent confidence interval, monitored through analyses of QC samples. Control limits for accuracy shall meet the requirements of the New Mexico QAPP (Appendix B). The HASL 300 analytical method (DOE, 1992) is the standard for this analysis and should have a minimum detection concentration of $0.04 \mathrm{pCi} / \mathrm{g}$ ash weight. A similar procedure is used by the EPA laboratory in Las Vegas (EPA, 1997c). Nominal detection limits for analyses are presented below (see Table D.3-1). Radioactive strontium analysis, alpha spectroscopy $\mathrm{Pu}-239 / 240$, and Am-241 determinations 
typically require sample ashing at high temperature $\left(500-650^{\circ} \mathrm{C}\right)$, splitting of the sample into two aliquots, and separate processing.

Table D.3-1

Nominal Detection Limits for Vegetation Samples

\begin{tabular}{|c|c|}
\hline Analysis & $\begin{array}{c}\text { Nominal Detection Limit } \\
\text { (pCi/g ash) }\end{array}$ \\
\hline \hline $\begin{array}{c}\text { Gamma Spectrometry (Cs-137) } \\
\text { Alpha Spectrometry (Pu-239/240 and } \\
\text { Am-241) }\end{array}$ & $0.01-0.1$ \\
\hline \begin{tabular}{c} 
Als \\
\hline
\end{tabular}
\end{tabular}




\section{D.4.0 Data Analysis}

Radioanalytical data will be presented as $\mathrm{pCi} / \mathrm{g}$ dry weight of vegetation for summarization and interpretation. 


\section{D.5.0 References}

EG\&G Energy Measurements. 1979. Photo Number 2988-228, 09 October. Nellis Air Force Base, NV: BN Remote Sensing Laboratory Photo Library.

EG\&G Energy Measurements. 1988. Photo Number 6014-08, 21 May. Nellis Air Force Base, NV: BN Remote Sensing Laboratory Photo Library.

Smith, D.D. and K.R. Giles. 1973. Report of Bioenvironmental Sampling at the Gnome Site, Carlsbad, New Mexico-October 1972, NERC-LV-539-25. Prepared for the U.S. Atomic Energy Commission. Las Vegas, NV: U.S. Environmental Protection Agency.

U.S. Department of Energy. 1992. Environmental Measurements Laboratory Procedures Manual, HASL-300, 27th Edition, Vol. 1. New York, NY.

U.S. Department of Energy, Nevada Operations Office. 1978. Gnome Site Decontamination and Decommissioning - Phase I Radiological Survey and Operations Report, Carlsbad, New Mexico, NVO/0410-48, Vols. 1 and 2. Prepared by Reynolds Electrical \& Engineering Co., Inc. Las Vegas, NV.

U.S. Environmental Protection Agency. 1997c. General Operation of Gamma-Ray Detector Systems, SOP No. NRA 2.17. Las Vegas, NV: Radiation and Indoor Environments National Laboratory. 


\section{Plate 1}

\section{Gnome-Coach Historical Soil Sample Locations (Phase I and/or Phase II/III)}




\section{Distribution}

\section{Copies}

Monica Sanchez

Environmental Restoration Division

DOE/Nevada Operations Office

P.O. Box 98518, M/S 505

Las Vegas, NV 89193-8518

Bill Wilborn

Environmental Restoration Division

DOE/Nevada Operations Office

P.O. Box 98518, M/S 505

Las Vegas, NV 89193-8518

Sabrina Lawrence

1 (Controlled)

Environmental Restoration Division

DOE/Nevada Operations Office

P.O. Box 98518, M/S 505

Las Vegas, NV 89193-8518

Jenny Chapman

Desert Research Institute

P.O. Box 19040, M/S 433

Las Vegas, NV 89132-0040

Dave Stahl

IT Corporation

P.O. Box 93838, M/S 439

Las Vegas, NV 89193

Dawn Arnold

SAIC

P.O. Box 93838, M/S 439

Las Vegas, NV 89193

James Bearzi

New Mexico Environment Department

1 (Controlled)

2 (Uncontrolled)

1 (Controlled)

4 (Uncontrolled)

1 (Controlled)

2 (Controlled)

Hazardous \& Radioactive Materials Bureau 2044-A Galisteo

P.O. Box 26110

Santa Fe, New Mexico 87502 
U.S. Department of Energy

Nevada Operations Office

Technical Information Resource Center

P.O. Box 98518, M/S 505

Las Vegas, NV 89193-8518

U.S. Department of Energy

Office of Scientific and Technical Information

P.O. Box 62

Oak Ridge, TN 37831-0062

U.S. Department of Energy

Nevada Operations Office

Public Reading Room

P.O. Box 98521

Las Vegas, NV 89193-8521

IT Corporation

Central Files

P.O. Box 93838, M/S 439

Las Vegas, NV 89193
1 (Uncontrolled)

1 (Electronic Copy)

1 (Uncontrolled)

1 (Controlled)

1 (Uncontrolled) 